\title{
Effects of a Mind-Consciousness-Thought (MCT) intervention on stress and well-being in freshman Nursing students
}

Judith A. Sedgeman

West Virginia University

Follow this and additional works at: https://researchrepository.wvu.edu/etd

\section{Recommended Citation}

Sedgeman, Judith A., "Effects of a Mind-Consciousness-Thought (MCT) intervention on stress and wellbeing in freshman Nursing students" (2008). Graduate Theses, Dissertations, and Problem Reports. 2848. https://researchrepository.wvu.edu/etd/2848

This Dissertation is protected by copyright and/or related rights. It has been brought to you by the The Research Repository @ WVU with permission from the rights-holder(s). You are free to use this Dissertation in any way that is permitted by the copyright and related rights legislation that applies to your use. For other uses you must obtain permission from the rights-holder(s) directly, unless additional rights are indicated by a Creative Commons license in the record and/ or on the work itself. This Dissertation has been accepted for inclusion in WVU Graduate Theses, Dissertations, and Problem Reports collection by an authorized administrator of The Research Repository @ WVU.

For more information, please contact researchrepository@mail.wvu.edu. 


\title{
EFFECTS OF A MIND-CONSCIOUSNESS-THOUGHT (MCT) INTERVENTION ON STRESS AND WELL-BEING IN FRESHMAN NURSING STUDENTS
}

\section{by}

\author{
Judith A. Sedgeman \\ Dissertation submitted to the College of Human Resources \& Education \\ at West Virginia University \\ in partial fulfillment of the requirements \\ for the degree of \\ Doctor of Education \\ in \\ Educational Psychology
}

\author{
Approved by: \\ Anne Nardi, PhD, Committee Chairperson \\ J. Keith Blevens, PhD \\ Daniel Hursh, PhD \\ Robert Pack, PhD \\ James Shumway, PhD \\ Richard Walls, PhD
}

Human Resources and Education

Morgantown, West Virginia

2008

Keywords: principles, mind, consciousness, thought, innate health, well-being, resiliency, stress, psychology, intuitive learning, nursing, health realization

Copyright 2008: Judith A. Sedgeman 


\title{
Abstract \\ EFFECTS OF A MIND-CONSCIOUSNESS-THOUGHT (MCT) INTERVENTION ON STRESS AND WELL-BEING IN FRESHMAN NURSING STUDENTS
}

\author{
Judith A. Sedgeman
}

\begin{abstract}
An emerging "health" paradigm, Mind-Consciousness-Thought (MCT), proposes that three universal Principles, Mind (life energy), Consciousness (the capacity to be aware of thinking as "reality"), and Thought (the ability to create thinking continually), explain how psychological experience is created from the inside-out, not created from the outside-in by events and circumstances. It proposes that life comes through us, not at us. It proposes that insight into the existence and operation of those principles reconnects people to their innate mental well-being, an always accessible source of balance, wisdom, and creativity (i.e., resiliency). It proposes that accessing mental well-being is incompatible with chronic stress, and that, once people realize the Principles that explain how the mind works, hope, optimism and resiliency incrementally increase in the face of changing life circumstances.
\end{abstract}

An on-line MCT educational module was created for freshman Nursing students, with pre- and post-tests to measure changes in their levels of stress and well-being. Pre- and post- tests were administered simultaneously to a control group without exposure to the module. MCT learning depends on reflection and insight. It was anticipated that the selfcontained "course within a course" would be sufficiently distinctive that students would appreciate and adapt to that learning style. In fact, although $70 \%$ of the 150 students who were assigned the module took the pre- and post-tests, there were fewer than four visits to 24 of the 48 content windows of the module and an average time spent of 47 seconds on all windows that were visited. Detailed tracking data show few, brief student visits to the critical parts of the learning module, with most visits, and the longest visits, to opening pages and the pre-post-questionnaires.

This research produced no measurable results. This is interpreted as being due to lack of meaningful participation in the intervention. It supports the assumption that MCT entails intuitive learning, ideally presented independent of traditional on-line courses that are set up for rote learning. MCT should be evaluated as a unique offering, which students enter with the understanding that the learning experience will be reflective and insight-based. Future research should focus on distinctive on-line presentations of MCT that invite intuitive learning. 


\section{Acknowledgements}

This dissertation represents the end of a nearly five-year journey on which I would never have embarked without the encouragement of my friend and colleague Dr. William Pettit. His good cheer and enthusiasm, coupled with his own lively curiosity and dedication to lifelong learning, sparked the inspiration for me to pursue the degree I had postponed for many years of my busy life. I have abiding gratitude for his consistent interest in my progress, his willingness to listen and respond to my questions and laugh at my stories, and his delight in each small success along the way. He was a constant supporter, right through the final weeks of polishing the dissertation when he took the time to do a thorough and thoughtful reading of the last draft and offered constructive suggestions that substantively improved the final product.

I owe much to my Committee Chair, Dr. Anne Nardi, who led by example throughout the process. Her infinite patience, her good will and helpfulness in the face of setbacks and wrong turns along the way, her non-judgmental, wise guidance are exemplary of an extraordinary educator dedicated to her students' success.

Dr. Richard Walls, whose energized and unforgettable courses launched me on this educational journey, brought great rigor to the structure, writing, and methodology of the dissertation. He never failed to offer encouragement and applause along the way, but his fine attention to detail and his careful review of the work set an admirable standard of excellence, challenging me throughout the process to keep working harder to improve the final product.

Dr. J. Keith Blevens, a highly respected teacher and innovator in Mind-ConsciousnessThought who was part of the original group of brave psychologists who brought this work to the world nearly 30 years ago, served throughout as a trusted, collegial advisor. I left every discussion with him inspired.

Drs. Jamie Shumway and Robert Pack, both admired colleagues of mine at the WVU Health Sciences Center, offered consistently sound and constructive guidance. Dr. Shumway's careful reading of the dissertation proposal and participation in the proposal defense considerably improved and simplified the plan. Dr. Pack had a knack for calling at the right moment to offer advice and reassurance to keep me on track. And last, but not at all least of the members of my committee, I appreciate Dr. Daniel Hursh. His gentle optimism and dedication to getting to the most meaningful questions brought a vision for research in my field alive for me.

I must also mention two faculty members not on my committee who truly helped me with an understanding of research methods and interpretation, and unselfishly gave of their time whenever I sought help. Dr. Sebastian Diaz, who is one of the best teachers I have ever known, and Dr. Reagan Curtis, who participated with me in a preliminary research project as he guided me through an independent study, and who showed me the basics of analysis through SPSS, were both wonderful mentors and friends. 
When the original research plan for this study got derailed, two members of the WVU School of Nursing faculty stepped in to support my research plans and offer their students as participants. I thank Nan Leslie, PhD, RNC, CRNP and Susan McCrone, PhD, RN, representing the Health Promotions/Risk Reduction department in the School of Nursing, for their interest in, and enthusiasm for, research generally, their dedication to quality education for their students, and their warm and open collegiality in supporting others in research and educational innovation. Also, I thank Amy Sparks, MSN, RN, CFNP, for inviting me into the Nursing 110 class.

I am grateful to Dr. Robert M. D'Alessandri, former Vice President of Health Sciences at West Virginia University, whose vision for bringing Mind-Consciousness-Thought into an academic setting first allowed me access to the opportunities I have enjoyed for a decade to learn more about my own work as I learned better how to explain it to others and place it in the context of the mental health field.

I am thankful to my many teachers, friends and colleagues around the world, too many to name individually, whose dedication to the Principles and faith in the innate health of all people have carried this work across the U.S. and to the far corners of the globe. Their sincere gratitude for its presence at West Virginia University, indicated by their enthusiastic interaction with the West Virginia Initiative for Innate Health over the years, has been the wind beneath our wings. They nurtured my dedication to developing courses and research to support the burgeoning understanding of this work.

I am profoundly grateful to my daughter, Sarah Quesen, whose own love of learning and willingness to take on daunting challenges just for the joy of expanding her horizons, is awesome and uplifting. While I was beginning this educational adventure, Sarah conquered Statistics, which she now teaches, and she modeled hope and courage by both deed and example. She helped me a lot with statistics, too.

I thank my many friends and colleagues at WVU who were consistently supportive, and put up with my absences from meetings and my focus on my studies and dissertation with good will and great humor. And I especially thank the Chair of my Department, Community Medicine, Dr. Alan Ducatman, who offered continual encouragement, and my friends, Dr. Gerry Dino and Dr. Kimberly Horn, who were cheerleading on the sidelines throughout the process. I thank Dr. Aina Puce, who encouraged me at the outset, helped me sharpen my focus, and was the first person to celebrate with me when I completed the dissertation. I owe particular thanks, also, to Dr. Rashida Khakoo, who has been an inspiring example of service and lifelong learning, and who has given me many opportunities to present and test my work in MCT in service to faculty development.

I thank Sydney Banks, the philosopher whose profound moment of enlightenment brought Mind-Consciousness-Thought into clarity and whose persistent teaching and guidance has inspired thousands of people to pursue the dream of mental well-being beyond what is considered possible today. Mr. Banks has been a great teacher, and a staunch supporter of my dream to complete this dissertation and contribute to the developing understanding of the paradigm shift represented by MCT. 
And I lovingly thank my grandson, Anthony, who kept me laughing as he cheered me on. For example, as I sat one day at the computer puzzling over data, he tiptoed into the room and said, "Excuse me, Grammy, I have a question that's really bothering me. Will I still have to be in school when I'm as old as you?"

Judith A. Sedgeman

February, 2008 


\section{TABLE OF CONTENTS}

Chapter One- Introduction..............................................

Stress Research................................................. 4

Resiliency Research.......................................... 6

Mind-Consciousness-Thought......................................... 7

Outside-In - Inside-Out Views................................... 10

MCT Model....................................................... 15

Purpose of Study .................................................. 17

Chapter Tw0 - Literature Review and Background........................ 19

Positive Psychology ............................................. 20

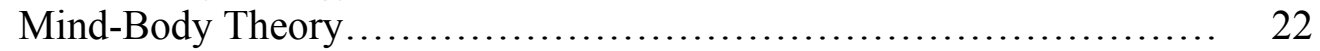

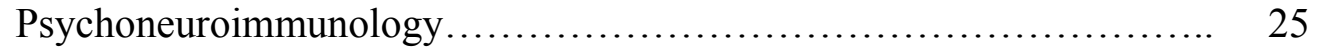

Assumptions of Stress Research.................................. 26

Assumptions of Resiliency Research............................... 33

Stress Research in Nursing..................................... 35

Leading Edge Resiliency Research................................ 38

MCT Background ................................................ 40

Context of MCT Philosophy ..................................... 44

MCT-Based Practice............................................. 50

MCT-Based Education............................................ 52

The Value of MCT-Based Learning............................. 57

Early Principle-Based Systems Change............................... 59

MCT in Education............................................... 63

MCT at West Virginia University.................................. 66

Morgantown High School Program.................................. $\quad 70$

Research Questions.............................................. 75

Chapter Threg-Method.................................................. 77

Participants......................................................... 77

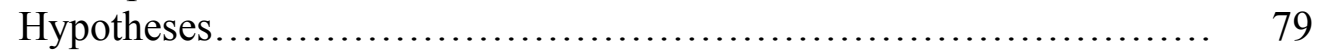

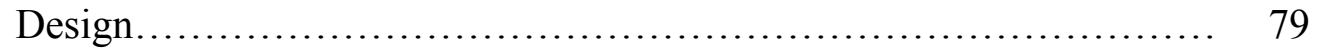

Materials............................................................ 86

Data Maintenance ............................................................. 87

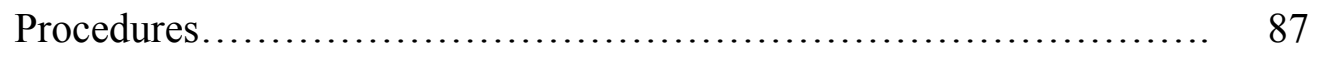

Analysis....................................................... 93

Chapter Four- Evaluation......................................... 96

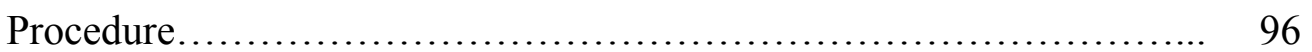

Sorting the Data.............................................. 102

Review of Usage Information................................... 105

Data Analysis............................................... 110

Correlation of PATCS and SF-36................................ 114 
Lurking Variables.............................................. 117

Conclusions................................................... 118

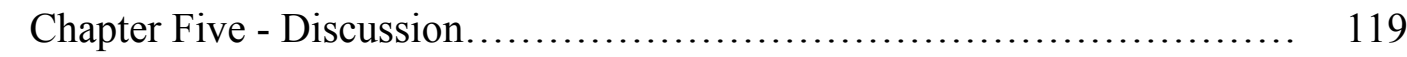

Preliminary Planning ........................................... 120

Preliminary Mistakes.......................................... 122

Implementation of the Module.................................... 124

Control Group....................................................... 127

Value of the Module............................................ 130

Future Research............................................... 136

Further Nursing Research....................................... 140

Other Educational Research Implications.......................... 142

Longitudinal Study Proposal...................................... 143

Conclusion........................................................ 144

References. ..................................................... 151

Appendix A ........................................................... 161

Substance Abuse and Mental Health Services Administration Report

Appendix B. ...................................................... 166

Data from National Pilot Study in Instrument Validation Project

Appendix C. ............................................................ 169

Grand Rounds PowerPoint Presentation

Appendix D. .............................................................. 185

SF-36 Questionnaire

Appendix E. . ......................................................... 191

SBI Questionnaire

Appendix F......................................................... 195

Morgantown High School Report

Appendix G. ....................................................... 202

Pettit Attachment to Thought Content Scale (PATCS)

Appendix H. .................................................... 204

Nursing 110 - Fall, 2007 Lecture PowerPoints

Appendix I.................................................... $\quad 224$

Nursing 110 - Spring, 2007 Lecture PowerPoints

Appendix J. . .......................................................... 236

Course Evaluation

Appendix K. ..................................................... 238

Permission to use SF-36 on-line

Appendix L. ...................................................... $\quad 240$

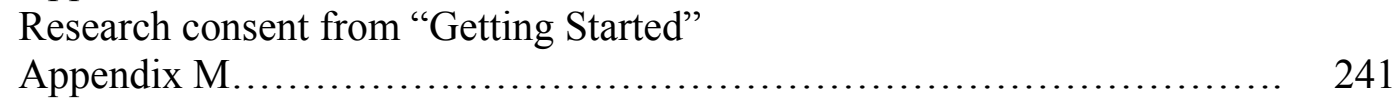

Demographic Information

Appendix N. ........................................................ 242 
Course Module cover and topic headings

Appendix O.

E-mails to Control Group

Appendix P.

Control Group Simple Forms

Appendix Q.

Four Questions for Nursing 110 Class

Appendix R.

Power Analysis

Author Biography...

\section{LIST OF FIGURES}

Figure 1 ....

Pre- post- and six-month follow-up: validation study part one

Figure 2....

Pre- post- and six month follow up: validation study part two

Figure 3 .....

Results, by subject, for general severity index of the BSI - HIV study

Figure 4 .

Categorization of student comments - Morgantown High School study

Figure 5 .

Correlation of BSI and PATCS scores - HIV project

Figure 6.

Research Plan

Figure 7.

Logic Model for On-line Module

Figure 8 .

PATCS-SF-36 Treatment Group Means

Figure 9 ....

PATCS-SF-36 Control Group Means

Figure 10 ....

Screen Shot-Study Information

\section{LIST OF TABLES}

Table 1

Results of the Modello and Homestead Gardens Housing Project

Table 2.

Statistics - Student Survey from MHS Project

Table 3

MHS Teacher and School-Wide measures before and after program implementation

Table 4 


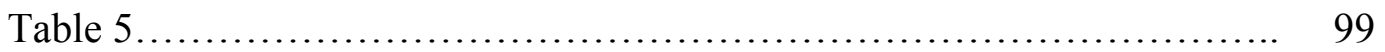

Response rates and matched responses

Table 6.

101

Planned and actual research procedures

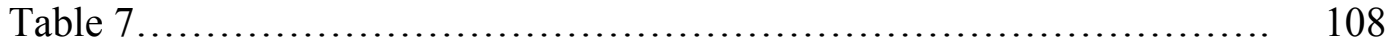

Tracking Data for each element of Module

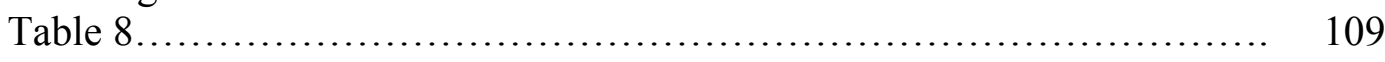

Minimum, maximum, mean time per visit to module pages

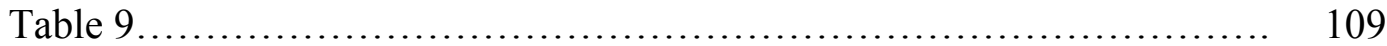

Minimum, maximum, mean time per visit to module pages without outlier

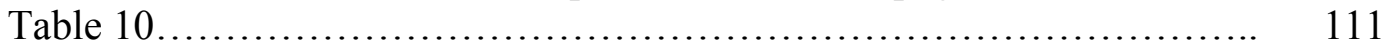

Power Analysis sample sizes (G-power)

Table 11

111

Distribution of responses

Table 12

112

PATCS and SF-36 mean scores

Table 13

113

Non-parametric tests

Table 14.

117

Pearson correlation, PATCS and SF-36

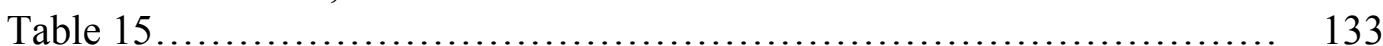

Average visits and time per visit, module content pages 
Chapter One

Introduction

"The mind is its own place, and in itself can make a heaven of hell and a hell of heaven."

John Milton

Is there a way to break the cycle of chronic stress and set people free from a state of mind that keeps them from optimal health, achievement and enjoyment of life? Or is the best we can offer people the prevailing view that they must learn and practice coping skills continually to fend off the inevitable stress that is a byproduct of life?

The discovery of principles that elicit an understanding of how the mind works to create thought and bring it to life as experience, which is the foundation upon which the Mind-Consciousness-Thought (MCT) approach is built, awakens people to the internal resiliency that provides them a natural immunity to stress. This approach boldly asserts that coping mechanisms we have come to depend on will become obsolete as people increasingly come to realize how to access their natural resiliency, regardless of circumstances (Sedgeman, 2005). That assertion has not yet been tested scientifically.

The principles on which MCT is based represent a "scientific revolution," as defined by Thomas Kuhn (1962), in the way mental health and mental health promotion is perceived and practiced. Yet it must be recognized, as described by Kuhn (1962), that the logic the principles propose (which might be called an "insideout" view of the creation of experience) represents a set of unique assumptions, just as the logic of the prevailing alternative view (which might be called an "outside-in" 
view of the creation of experience) represents its own unique assumptions. As Kuhn describes it:

Like the choice between competing political institutions, that between competing paradigms proves to be a choice between incompatible modes of community life. Because it has that character, the choice is not and cannot be determined merely by the evaluative procedures characteristic of normal science, for these depend in part upon a particular paradigm, and that paradigm is at issue. When paradigms enter, as they must, into a debate about paradigm choice, their role is necessarily circular. Each group uses its own paradigm to argue in that paradigm's defence [sic]. (p. 94)

Although there is a 30-year history of successful outcomes from providers across the United States and Canada using MCT-based approaches ${ }^{1}$ (Banerjee, Howard, Mansheim, \& Beattie, 2007; Bond, 2007; Borg, 1997; Marshall, 2004; Mills, 1995, 2005; Mills \& Mills, 2003; Mills \& Spittle, 2001; J. Pransky, 2003; Roy, 2007; Suarez, Mills, \& Stewart, 1987), most of the results are qualitative, anecdotal or afterthe-fact. The Mind-Consciousness-Thought approach is part of an emergent, healthbased prevention, education, and therapy paradigm. Built on the universal source of, and qualities of, healthy psychological functioning, this model has attracted many hundreds of practitioners around the world.

\footnotetext{
${ }^{1}$ The work can be found in the literature under "Innate Health," "Health Realization," "Psychology of Mind," and in various lists of "Strength-based" approaches. Many practitioners have used a variety of designations for the approach, but the common denominator that identifies them as principle-based is their core presentation of the Three Principles of Mind, Consciousness and Thought.
} 
MCT is emerging from what Kuhn (1962) calls the "pre-paradigmatic" stage to be recognized as a competing, new paradigm. From this point, it must enter into normal science, into the research process.

The common underpinning for all work in this inside-out paradigm is bringing people to their own understanding of three Principles: Mind, the formless energy behind all life; Thought, the ability to create forms or ideas from that formless energy; and Consciousness, the ability to be aware of life and experience thought as reality. Practitioners have called this work by many different names over the past several decades, but, regardless of the professional nomenclature, this paradigm is always and only identified by the three Principles at the heart of its teaching, and by its focus on pointing people to their own awareness of the Principles at work behind their perception of moment-to-moment experience.

The Principles represent the paradigm shift away from the enormous array of mental health techniques that address "factors" external to human beings that are said to create people's thoughts, feelings and behavior, and that are said to "cause" a vast array of symptoms and diagnoses. The Principles point towards a different paradigm: the realization that the ability to form thought and experience one's changing thinking as reality is the only factor that creates all of the infinite expressions of thoughts, feelings and behavior. An external circumstance "unthought" is not experienced; external events do not form thought, but rather thoughts in formation create our perceptions and experience of external events, moment-to-moment.

Program evaluations and well-designed research are called for to allow this new paradigm to be accepted into the mainstream and presented as an academic 
discipline that can support the increasing acceptability and demand for the approach (Lewis, 2003; SAMHSA, 2003; Sedgeman, 2005). It must be remembered, in Kuhn's words (1962), that:

Without commitment to a paradigm, there could be no normal science. Furthermore, that commitment must extend to areas and to degrees of precision for which there is no full precedent. If it did not, the paradigm could provide no puzzles that had not already been solved. (p. 100)

As the principle-based MCT models enter science, they do so not as an evolution from what has gone before, but as a revolution in how the mental health and prevention fields explain human experience and behavior, and facilitate change. The assumptions of the prevailing outside-in paradigm are quite clear; this paper will show that the assumptions of the principle-based inside-out paradigm are completely different from them.

\section{Stress Research}

Significant scientific evidence has emerged in the last decade demonstrating the deleterious effects of chronic stress on long-term health as well as on satisfaction and engagement with work and life across the entire life-span (Charney, 2004; Esch, Stefano, Fricchione, \& Benson, 2002b; Sapolsky, 2004b; Stefano, Benson, Fricchione, \& Esch, 2005; Stefano, Fricchione, Slingsby, \& Benson, 2001; VanItallie, 2002). It is important to distinguish chronic stress, the long-term, consistent experience of a state of stress, from acute stress, which is the immediate response of 
the mind and body to a challenge that must be met, a temporary state that ends with a return to balance, or homeostasis, when the challenge passes (Cannon, 1939; Sapolsky, 2004b; Selye, 1950).

It has long been known that human beings are designed to experience acute stress and recover. But a state of chronic stress leaves the body in a consistent condition of psychological and chemical "readiness" that is a departure from a healthful, dynamic and balanced state. As Sapolsky (2004) describes it:

If you repeatedly turn on the stress response, or if you cannot turn off the stress response at the end of a stressful event, the stress response can eventually become damaging. A large percentage of what we think of when we talk about stress-related diseases are disorders of excessive stress-responses. (p. 16)

Acute stress is part of the regular cycle of life and does no harm. Chronic stress, however, has increasingly come under scientific and medical scrutiny as an underlying cause and "trigger" of many "stress-related" chronic disease states (Charney, 2004; Niess, Monnikes, Dignass, Klapp, \& Arck, 2002; Sapolsky, 2004a). As researchers look more deeply into the phenomenon of stress, they increasingly document the ways in which the use of our minds affects our experience of living in our bodies. Indeed, regardless of the paradigm from which it is viewed, stress is now understood to be a psychological event that impacts the totality of the human experience, psychologically, physiologically and spiritually. 


\section{Resiliency Research}

During the past 30 years, as chronic stress was increasingly understood as a danger to human well-being, a research initiative was developing to study resiliency as a means to counter chronic stress. Resiliency is, literally, the capacity to bounce back. Masten (2001) defines it as "a class of phenomena characterized by good outcomes in spite of serious threats to adaptation or development” (p. 228). At this point in the research, the question of whether resiliency is a natural human resource that is accessed without effort (Banks, 2001; Kelley, 2004; Marshall, 2004; J. Pransky, 2003; Sedgeman, 2005) or a learned ability that must be taught, acquired, nurtured and practiced (Benson, 1982; Frederickson, 2001; Richardson \& Waite, 2002; Seligman \& Csikszentmihalyi, 2000; Stefano et al., 2005) is unresolved in the scientific community. But there is general agreement that resiliency is a universal human capacity, and that it provides the route to respite from chronic stress.

The call for a new positive psychology by Dr. Martin Seligman (Seligman \& Csikszentmihalyi, 2000), then president of the American Psychological Association, stimulated a surge of interest in researching resiliency as a health-enhancing and lifeenhancing human quality that might provide an answer to escalating stress (Frederickson, 2003). Resiliency is increasingly being seen as a prevention strategy, rather than a coping strategy (Kelley, 2004; Sedgeman, 2005).

Because the qualities inherent in a resilient outlook are also qualities that are necessary to succeed in school and in the maturation process, and because an understanding of the nature of resiliency leads people to a buoyant outlook in the face of all life challenges, it makes sense to focus resiliency efforts and research on young 
people (Benard \& Marshall, 1997a; Marshall, 2004). If awakening resiliency proves to be an effective prevention strategy, then reaching young adults will significantly improve the quality of their lives and those of generations to come.

Research is needed into the means of presenting this new paradigm, which is not "learned," as information, but rather "realized" through insight, what is called "intuitive" learning. And research is needed into the efficacy of such presentations.

\section{Mind-Consciousness-Thought}

Principle-based approaches such as MCT, which have accumulated a substantial body of qualitative evidence for effectiveness in building and sustaining resiliency, offer a new way to look at resiliency.

Often associated in the literature with "strength-based" approaches (Lewis, 2003; Wartel, 2003), this work is founded in three Principles, Mind, Consciousness and Thought (Banks, 1998) that describe why all people have innate health, a core resiliency that might be called the psychological immune system.

The principle-based MCT psychoeducational model has been used with troubled school students in California, Hawaii, Oregon, Minnesota, Vermont, Wisconsin, Florida and Iowa, as well as in Canada and Great Britain (Marshall, 2004; Mills \& Mills, 2003; Mills \& Spittle, 2001; J. Pransky, 2003; Shuford, Gaughen, \& Kiaka, 2000; Stewart, 1993). Although few peer-reviewed studies have been published, trained facilitators and practitioners, as well as school administrators and teachers, have reported significant improvements and a high level of satisfaction with 
the programs (Kelley \& Stack, 2000; Marshall, 2004; J. Pransky, 1998, 2003; Shuford et al., 2000).

The successes of using the Principles of Mind, Consciousness and Thought to awaken people to their innate health, and the future potential for this work, have received national recognition (Mills \& Mills, 2003). The Substance Abuse and Mental Health Services Association (SAMHSA) evaluated MCT-based work submitted as "Health Realization" in 2003 for consideration as a best practice. SAMHSA's review (Appendix A) was positive, and strongly suggested the urgency of continuing to develop good research into the work that shows considerable promise. The reviewer comments (SAMHSA, 2003) found that:

The first strength of this model is that it is a part of a complete and well-designed theory. A second strength of the Health Realization model is that several positive findings have been reported for interventions that use it, and these findings have been obtained in interventions involving different types of participants (e.g., residents of a housing development, teachers, inmates, students, etc.) In addition, the model enhances community partnerships and provides an appealing array of skill-building, mentoring, parent support, counseling and service activities that encourage participation and retention, and promote high expectations/achievements. (p. 2)

The report went on to say that despite the strengths cited, the model has three major weaknesses: 
The most serious weakness is that most of the studies lack comparison groups. ... Another weakness of this research is that the majority of the interventions involve small sample sizes. ... A third weakness of the ... research is that some of the studies do not use standardized measures for assessment. (p. 2)

In 1998, the Robert C. Byrd Health Sciences Center at West Virginia University committed to providing a home for the development of the principle-based Mind-Consciousness-Thought approach as an academic model that could be researched and taught to graduate students in public health and the health sciences. An initial national instrument validation study, conducted between 1999 and 2001, produced pilot data of sufficient interest (Appendix B) to point to a need for further study. The pilot study included almost 700 participants in several sites across the U.S. All received the same four-day seminar. Study results indicated significant improvement in the sense of well-being of participants in pre- and post-tests administered immediately before and after the program. Participants' well-being appeared to continue to improve over time without further intervention, since the sixmonth follow-up showed further positive change, although a significant attrition in respondents should be noted.

Those results, which were incidental to an instrument validation study, have not been published but were presented and discussed at Grand Rounds lectures at the WVU School of Medicine during 2002 in the departments of Medicine, Community Medicine, and Behavioral Medicine and Psychiatry. The full presentation made for those Grand Rounds is in Appendix C. 
Outside-In - Inside-Out Views

Many people have difficulty understanding why the MCT approach is truly a departure from the prevailing views in the movement toward positive psychology. Kelley describes the contrast between an inside-out and an outside-in view of life stress (Kelley, 2004).

When viewed through the logic of the three Principles ... a

fundamentally different view emerges of virtually all contemporary models of positive psychology. The main reason for this fact is that each positive model is based on the same faulty assumptions - that the absence of psychological well-being in adolescents is due to certain missing external factors. Thus, each positive model proposes the need to put some missing item(s) back into youth from the outside in. Even the pioneering models of positive psychology are grounded in this missing external factor perspective. (p. 263)

Sydney Banks, the philosopher and author whose insights first inspired the development of so much work based on the three Principles he discovered, explains it this way (Banks, 1998): “The answer people seek lies not in their separate beliefs, but in the realization that Thought is the common denominator in all psychological and spiritual understanding” (p. 63).

Banks defines thought not as content, but as "the creative agent we use to direct us through life" (p. 47). He explains the role of thought this way: "Thought is not reality; yet it is through Thought that our realities are created. It is what we as 
humans put into our thoughts that dictates what we think of life" (p. 49). In other words, an MCT approach explains that we are the thinkers of our thoughts, the creators of our perceptions of experience. When we look out into the world, we are making up what we make of it; the world is not forcing us to make up one thing or another.

Recognizing this as a prevention strategy is, in the words of nationally recognized author and prevention specialist Jack Pransky (2003):

...a humbling thought for those of us who, like myself, have worked for so many years to prevent the behavior problems that plague this society. Everything we have tried in the name of prevention has been with the best of intent. Many of our efforts have been effective ... I am suggesting that if we move directly to the point where true change occurs, we can be even far more effective than we are now. What we have missed, in my view, is this: We have forgotten, or ignored, or not realized where behavior comes from. All behavior arises from Thought. No matter what wonderful things we do in the name of prevention or health promotion, unless people's thinking changes, their behavior will not change. Our behavior always follows our thinking. This is an irrefutable fact one only has to reflect on to see its truth. (p. 14) MCT work, it must be emphasized, does not downplay or diminish the fact that people are faced with daunting and horrible circumstances. As Sedgeman (2005) 
explains in an article about the power of recognizing one's innate health through understanding the Principles:

Innate Health does not question the existence of external life circumstances that affect people - physical discomfort or limitations, the upheavals of war and weather, unforeseen tragedies, etc. It explains that there is an internal mediating factor between such external factors and each individual's experience of them; the factors do not have the power to determine a person's reaction to them, the person has the power to determine how the factors will affect him or her. (p. 50)

The prevailing views, regardless of their optimism and enthusiasm for people's strengths, make the assumption that stress is a "real" and unremitting factor, a condition to which people must find an appropriate response, and that stressful thoughts are "real" and must be dealt with in order for people to recover. (Csikszentmihalyi, 1990; Frederickson, 2001; Richardson \& Waite, 2002; Stefano et al., 2005).

In a book in which much of their most recent psychoneurological research on stress is compiled, for example, the authors Stefano et al (2005) open with their definition of stress:

Today, stress is a generic term that is defined as the effects of psychosocial and environmental factors on physical or mental well-being. We live in a modern world with fast-paced technological advancements, strengthening forces of globalization, 
and swelling amounts of information to digest. As we become busier and are bombarded by more stimuli each day, we find ourselves in increasingly stressful situations. (p. 7)

In contrast, models based on the three Principles, in the words of William F. Pettit, M.D., a long-time practitioner of MCT therapy, would define stress as a “physiological, psychological, spiritual experience of the 'dance' of negative/insecure thoughts through our limbic system and senses.” (W. F. Pettit, 2007) From an understanding of the Principles, one recognizes that stress is created from the insideout, a byproduct of the dynamic process of thought brought to life by consciousness. Such teaching focuses on recognition of the understanding that people think, rather than on analysis of the contents of what they think (G. Pransky, Mills, Sedgeman, \& Blevens, 1995; Sedgeman, 2005; Wartel, 2003). Since all thoughts are ephemeral and illusory, stressful thinking, like any other thinking, will pass more readily if the thinker understands how thought works. With that understanding, people come to see the feeling state of stress, i.e. a stressful state of mind, as a warning signal to leave upsetting thinking alone, rather than ruminating on it. They can allow their minds to quiet, and naturally return to a positive feeling state and a healthful process of thinking. Once their minds quiet, they regain access to clarity and common sense, the wellsprings of their ability to respond constructively and creatively to life events.

Principle-based approaches such as MCT see a quiet mind and a positive feeling state as the natural default setting for human beings. They represent that human psychology is no different from human physiology; the whole human is a selfcorrecting entity. Thus "natural" healthful functioning is the state to which people's 
minds return readily when they do not hang onto and ruminate over the content of any thinking (Banks, 1989a, 1989b, 1998, 2001; Mills, 1995; Mills \& Spittle, 2001; G. Pransky, 1998), just as "natural" breathing is restored when a runner who is out of breath stops running and allows the natural rhythm of breathing to return.

From the vantage point of a quiet mind and a positive feeling, people are able to address even the most daunting life circumstances with insight and common sense, and find creative solutions to life challenges. People are able to see the content of their thinking as variable, and recognize that things that appear unmanageable or insoluble in one state of mind appear manageable and soluble in another, even if the circumstances have not changed. Spittle (2005) describes it this way:

We are always thinking, but there is a different quality of thought when we are not erecting barriers to our innate wisdom. Insightful thoughts fill the space left by all the negative, worrisome thoughts we used to entertain so much. These new thoughts are calming, inspiring, exhilarating, and exceedingly helpful. These thoughts guide us to a better life. (p. 18)

As Banks (1998) explains:

Let your negative thoughts go. They are nothing more than passing thoughts. You are then on your way to finding the peace of mind you seek, having healthier feelings for yourself and for others. This is simple logic. (p. 108) 


\section{MCT Model}

The Mind-Consciousness-Thought psychoeducational model is used in both individual teaching, therapy and coaching, and in large groups. It is often delivered as a series of interactive group sessions led by a facilitator trained and experienced in the Principles. Since 2002, through the efforts of Sedgeman at WVU, there has been an effort to offer this model in a variety of on-line formats to make it more accessible to a broader range of students and professionals world-wide. There are two MCT based graduate level courses offered as electives on-line in the Public Health program at $\mathrm{WVU}^{2}$; there is a 2.5-unit continuing education course offered globally on-line through WVU Extended Learning ${ }^{3}$; there is an on-line module provided to Engineering students through a self-directed learning site called "Intensive Counselor" that is run by the College of Engineering and Mineral Resources. The online offerings have all been well-received by students based on student evaluations and commentaries, but they have not been formally researched.

A body of research is developing, also, that suggests that on-line mental health services, particularly those that are informational or educational in nature, are as effective as, and are more appealing to, users than individual or group interventions (Ybarra \& Eaton, 2005).

Whether offered in classroom settings or on-line, the MCT courses are grounded in the Principles of Mind, Consciousness and Thought, which describe the fact that all human beings share a common, inborn capacity to create their moment-

\footnotetext{
${ }^{2}$ PUBH 580, Prevention through Resiliency and PUBH 680, Health-Based Leadership

${ }^{3}$ The Natural Remedy for Stress and Burnout
} 
to-moment reality (Banks, 1989a, 1989b, 1998, 2001; Mills \& Spittle, 2001;

Sedgeman, 1997). All people use the formless energy of life itself (Mind) to generate ideas within their own minds (Thought) and become aware of those ideas and experience them as reality (Consciousness) (Banks, 1998).

The model awakens people's understanding of the thought process, i.e., that they think and how they create, hold, and use their thinking (G. Pransky et al., 1995). With that understanding, people recognize how their personal thinking creates their experience of reality, moment-to-moment. They can see how their feeling state is a barometer of the changing quality of their thinking, and they can recognize whether they are feeling secure and thinking clearly and insightfully, or feeling insecure and thinking in a way that creates and sustains stress and tension (J. Pransky, 2003). Participants gain insight into how to change their minds when they understand that they are the thinkers of their own thoughts and the architects of their own reality (Banks, 1998).

Resiliency is identified by the qualities enumerated by Seligman (Seligman \& Csikszentmihalyi, 2000): happiness, subjective well-being, optimism, faith, selfdetermination, wisdom, excellence and creativity. Those qualities are the desired result of all efforts to bring out the best in people. The question all the principle-based approaches pose is whether those qualities are inherent and always available, as much a part of the essence of being human as the breath of life that sustains us or the DNA that defines us, or whether, as the prevailing views of resiliency suggest, those qualities are attainable and renewable, as much within the grasp of human beings as flowers in the garden or books on the shelf. 


\section{Purpose of Study}

The purpose of this study was to conduct a collaborative program evaluation of an on-line course module, Ex-Stress Yourself, to introduce freshman nursing students to the Principles of Mind, Consciousness and Thought through the MCT psychoeducational model. The study population was drawn from the approximately 150 students enrolled in Nursing 110 on the Morgantown campus of the WVU School of Nursing. The MCT model was presented through Ex-Stress Yourself, an on-line module incorporated into the course, introduced by an in-class lecture explaining the research procedure and explaining to students how to access the module on-line, regardless of whether they enrolled in the research.

WVU Freshmen identified as pre-nursing but not yet enrolled in Nursing 110 served as a control group. These students were not exposed to the Ex-Stress Yourself intervention, but took the same tests at the same intervals. They were contacted through an e-mail delivered to their student e-mail addresses by the campus Web Administration office. The success of the program was to be tracked through repeated measures psychological testing, through on-line evaluations from participants, and through planned on-line forum discussions near the end of the Fall, 2007, semester during which the program is being researched.

Evaluations included pre- and post-testing of all program participants, using the SF(Short Form)-36 (Appendix D) (Ware, Kosinski, \& Gandek, 2005), as well as planned on-line focus group interviews with students. It was expected that the MCT exposure would provide sustained improvement in their overall sense of well-being. It 
was expected that the control group of students who took the evaluations without receiving the course module would show little or no change in pre- and post-testing.

Nursing students were chosen for this study because the Nursing program has a deep commitment to the well-being of students and recognizes that stress and anxiety are factors that can seriously impact both their performance and their wellbeing. There is a strong body of literature supporting the prevalence of stress in nursing students worldwide (Elliott, 2002; Maville, Kranz, \& Tucker, 2004; Shipton, 2002).

A pilot study conducted with freshman engineering students (Sedgeman, 2006) revealed that those professional students, who, like nursing students, are faced with the need to learn a large amount of technical information in a highly competitive learning environment, were all aware of the detrimental effects of stress and were all generally inclined to want to sidestep stress rather than cope with it. Like nursing students, they are exposed to a lot of information about coping mechanisms, an afterthe-fact means of addressing stress. What they were looking for was best summed up by one who said, "But if you can see it coming, you can stop it. Then, you know, you can see what you have to do" (p. 14). That is a call for wisdom, insight and clarity, for stress-prevention, rather than stress amelioration. This project was an effort to evaluate how well that call can be answered by an understanding of the Principles of Mind, Consciousness and Thought delivered as an on-line course module embedded within a traditional survey course. 


\section{Chapter Two \\ Literature Review and Background \\ "Reality is merely an illusion, albeit a very persistent one."}

Albert Einstein

Chronic stress is debilitating. It erodes the human potential, weakens the human immune system and withers psychological strengths such as self-esteem, enthusiasm and hopefulness (Charney, 2004; Sapolsky, 2004b; VanItallie, 2002).

The state of chronic stress underlies many disease states that diminish quality of life and reduce life expectancy (Sapolsky; VanItallie). In addition, the state of chronic stress is a major contributor to the inflation of national health care costs (Goetzel, Anderson, Whitmer, Ozminkowski, Dunn, \& Wasserman, 1998). There is nothing positive about chronic stress.

Evidence is coalescing around the idea that the ultimate answer to chronic stress may not lie in addressing external stressors, but in exploring and enhancing internal human capacities for resiliency. The intent to develop means to comprehend, build and buttress human resiliency is predominant in both behavioral (Csikszentmihalyi, 1990; Frederickson, 2001, 2003; Richardson \& Waite, 2002; Seligman \& Csikszentmihalyi, 2000) and biological investigations (Benson, 1982; Benson, Beary, \& Carol, 1974; Benson \& Goodale, 1981; Benson, Klemchuk, \& Graham, 1974; Benson, Kotch, \& Crassweller, 1977; Esch, Stefano, Fricchione, \& Benson, 2002a; Esch et al., 2002b; Kiecolt-Glaser \& Glaser, 1992; Pert, 1997; Stefano et al., 2005; Stefano, Murga, Benson, Zhu, Bilfinger, \& Magazine, 2001). 
Csikszentmihalyi's (1990) seminal work, Flow: The Psychology of Optimal Experience was a turning point, a new way for cognitive/behavioral theorists to look at the role of thought. Until that publication, the field primarily focused on the means to deal with negative thoughts; Csikszentmihalyi proposed that it is as effective to train people into positive thinking that is expressive, creative and uplifting as it is to train them to fight or reframe their negative thinking. Twenty-five years of research had convinced him that people achieve happiness by "achieving control over the contents of our consciousness" (p. 2). His work since then focused on the methods or techniques by which such control could be achieved.

\section{Positive Psychology}

Seligman and Csikszentmihalyi (2000) jointly launched the Positive Psychology movement with their call for a new strengths-focused psychology, in an edition of The American Psychologist entirely devoted to positive topics. After years of researching and treating pathology, they argued that it was time for the entire field of psychology to turn to researching human strengths, to train the spotlight on what causes and supports resiliency and optimism in people. In their presentation of this new view of psychology (2000), they wrote:

Psychology is not just a branch of medicine concerned with illness or health; it is much larger. It is about work, education, insight, love, growth and play. And in this quest for what is best, positive psychology does not rely on wishful thinking, faith, self-deception, fads or hand-waving: it tries to adapt what is best in the scientific 
method to the unique problems that human behavior presents to those who wish to understand it in all its complexity. (p.7)

Representative of research generated by the positive psychology movement is work being done at the Positive Emotion and Psychophysiology Laboratory, directed by Barbara Frederickson at the University of Michigan. Frederickson has demonstrated that positive emotions are a critical element for happiness and wellbeing. Frederickson's (2003) "broaden and build theory" describes how "experiencing a positive emotion leads to states of mind and to modes of behavior that indirectly prepare an individual for later hard times ... the positive emotions broaden an individual's momentary mind-set and by doing so help to build enduring personal resources" (p. 332).

Frederickson continues to research many techniques, such as humor, or cultivating gratitude, that appear to create the positive emotions that she believes broaden thinking. Frederickson's assumption is that positive emotions can be elicited by doing certain things, and that positive emotions cause positive thoughts and thus create positive actions and behaviors. Frederickson posits:

Because the positive emotions broaden people's thought-andaction repertoires, they may also loosen the hold that negative emotions gain on both mind and body, dismantle preparation for specific action and undo the physiological effects of negative emotions. (p. 334) 


\section{Mind-Body Theory}

Parallel to the increasing focus on positivity and resilience in psychology, there has been a movement to study the physiological consequences of chronic stress and the restorative and healing powers of resiliency and quietude. Representative of this research is Herbert Benson, a cardiologist who is the Director of the Mind-Body Institute at Harvard University Medical School. Benson spent years studying the physiology of transcendental meditators and Buddhist monks, discovering that individuals who entered a profoundly quiet state of mind simultaneously experienced protective and restorative physical benefits (Benson, 1997; Benson, Beary et al., 1974; Benson, Lehmann, Malhotra, Goldman, Hopkins, \& Epstein, 1982).

In the mid-1970's, Benson (1982) was the first Western scientist to receive permission to study a remote and small sect of monks who practice an advanced $g$ Tum-mo Yoga procedure in which, in the dead of winter, in unheated caves high in the windswept mountains of Tibet, they wrap their naked bodies in cold, wet sheets. As they sit on rock ledges in meditation, they warm and dry the sheets with their own body heat. They repeat this process again and again during several days of meditation. Benson filmed, as well as published, his research with this group, in which he and his team constantly monitored the monks' body temperatures, which remained normal and were unaffected by the cold. The medical expectation was that the combination of external sub-freezing temperatures and the cold wet sheets would result in hypothermia and death. But the monks experienced no ill effects. This research set Benson on a career-long search to better understand the relationship 
between sustaining mental quietude and sustaining healthful physiological and psychological states, regardless of external factors.

Benson $(1974,1975)$ developed a technique known as "the relaxation response," a Westernized version of a Buddhist meditation technique, to assist people into a state of quietude. Over time, bench researchers subsequently joined in evaluating the effects of that technique on body systems (Esch, Fricchione, \& Stefano, 2003; Esch et al., 2002a, 2002b).

In an introductory article (1974), Benson et al. posited that:

If the relaxation response proves to be of value in medicine, there exist many religious, secular or "therapeutic" techniques which elicit it. ... Belief in the technique in question may well be a very important factor in the elicitation of the relaxation response. Future studies should establish the most efficient method for a given individual. (p. 45)

In a conference presentation (2002), Benson reported that out of a quiet mind arise physiological states that "represent innate evolutionarily-preserved healing capacities that are activated by human intellectual processes that overcome worrisome and stressful thoughts through the repetitions of the relaxation response and through the actions of belief in the placebo effect."

In the years between 1974 and the present, Benson and his colleagues both generated and stimulated an enormous amount of research into the effects of practicing techniques to quiet the mind. Although they consistently conclude that a quiet mind is achievable as a result of many different practices, they do not consider 
whether such a state of mind can occur naturally, without the use of techniques, the assumption underlying all principle-based practices (Sedgeman, 2005). Such an assumption would be foreign to their paradigm.

The work of researchers affiliated with Dr. George Stefano, Director of the Neurosciences Institute at the State University of New York at Old Westbury, for example, showed that the movement from stress to quietude actually has an immediate molecular chemical effect within the cells of the body. Their initial research pinpointed nitric oxide (NO) a critical component of the immune system. They observed rapid, almost immediate, changes in NO concentration in response to increasing and decreasing stressful cognitions as people practiced the relaxation response. In one study (Stefano, Fricchione et al., 2001), they observed that the changes in NO were so rapid that they "may really represent the manifestation of a proactive mind-body link that evokes an innate protective response (p. 2).” In addition, they have researched natural morphine production within the body, noting that it, too, responds dramatically to immediate changes in stress (Fricchione, Mendoza, \& Stefano, 1994; Stefano, Cadet, Fimiani, \& Magazine, 2001). Their work suggests questions about the actual mechanisms at the origin of the process (Stefano, Fricchione et al., 2001):

...in order for cognitive ability to develop and succeed, however, there must first be a unifying consciousness to control or regulate the many individual neural processes that potentially summate a decision-making process. ...That is, the brain represents only neural tissues organized into various neural patterns that can work 
together or separately. Without a unifying component being able to cope with a focus, the significance and uniqueness of this coping strategy would be lost. ... Moreover, a unified entity, a 'mind', would only be involved with experience-related phenomena (both exteroceptive and interoceptive) since this is the realm in which coping strategies are designed. (p. 46)

In other words, a fundamental unanswered question remains: Does chemistry change thought or does thought change chemistry?

Psychoneuroimmunology

The scientific shift over the past 30 or more years towards recognizing the experience of chronic stress itself as an underlying contributor to many disease states and towards seeing the human capacity for resilience as a systemic healing mechanism led to an explosive development of psychoneuroimmunology, which is essentially the investigation of the biochemistry of a psychological immune system that addresses chronic stress (Lutgendorf \& Costanzo, 2003). In a comprehensive review of psychosomatic medicine and the evolution of psychoneuroimmunology, Kiecolt-Glaser et al (2002) concluded:

The evidence for a relationship between psychopathological symptoms and disorders and immunological alterations seems convincing. Furthermore, negative affect, a characteristic of most of the psychopathology spectrum, has been conceptualized as a key 
pathway for other psychological modifiers of immune function ... particularly interpersonal relationships and personality. (p. 17)

Research has established the positive physiological and psychological effects of resilience, as well as the extensive negative physiological and psychological effects of chronic stress (Frederickson, 2003; Karlamangla, Singer, McEwen, Rowe, \& Seeman, 2002; Pressman \& Cohen, 2005; Sapolsky, 2004b; Stefano et al., 2005). The persistent assumption that both stress and resilience are consequences of factors outside of the control of the individual, however, has kept research attention on the relation between stressors and the individuals who are subject to them, or on external factors that promote resilience. As a result, studies consistently focus on how best to protect people from stressors or equip them to respond resiliently to stressors as successfully as possible. Stress management has become a multi-billion-dollar industry, pursued by popular figures such as John Kabat-Zinn (1990), the author of Full Catastrophe Living, as well as dedicated scientists, such as Barbara Frederickson, George Stefano and Herbert Benson.

\section{Assumptions of Stress Research}

The outside-in assumptions that govern the prevailing understanding of stress date back to the first research in the subject conducted by Walter Cannon at the turn of the $20^{\text {th }}$ century. Cannon borrowed the term "stress" from the field of engineering. Cannon used it to describe pressure or challenges presented to an organism. Although the term did not come into popular parlance until it was widely disseminated in the mid-1950's by Hans Selye, the very decision to use such a term set the assumption in 
place that what was being studied was analogous to the "stress" of weight or wind or other forces on metals.

The mechanisms of acute stress are readily apparent, and have been since they were first described by Cannon (1939), who discovered the "fight or flight" mechanism. He was the first to describe the immediate changes in the sensory nervous system that occur after encounters with stressors, such as increased heart rate, rushing of the blood to the primary organs, a burst of adrenalin. Cannon's research (performed on rats) described the effects of acute stress, that is, a sudden and temporary response of the body to an external challenge.

The mechanisms of chronic stress are more complex and less clear, although current research is beginning to bring them into focus. Hans Selye (1950) described three stages of stress in what he called the general adaptation syndrome. The first two stages, "alarm" and "resistance" are similar to Cannon's fight or flight: the body is aroused and biochemical signals are sent throughout the system to prepare for a response in the "alarm" stage, and then the organism does battle against the stressor in the "resistance" stage.

Selye described the third stage as "exhaustion," which came to be linked in people's minds with chronic stress and still remains a powerful metaphor for the feeling of chronic stress. However, Selye assumed incorrectly that prolonged stress “depletes" the body's resources. That proved to be an inaccurate scientific description of the effect of the state of stress unrelieved over time, which has been shown instead to redirect the body's resources and thus leave the person vulnerable to disease (Charney, 2004; McEwen, 2000; Sapolsky, 2004b; Sapolsky, Krey, \& McEwen, 
1986). As Sapolsky points out, chronic stress does not actually deplete hormonal resources, but rather keeps the body in a constant, unrelieved state of hormonal imbalance, which creates what researchers describe as a "hormonal milieu" (VanItallie, 2002) that fosters disease states.

Sapolsky explains the effect of stress on hormones this way in his book Why Zebras Don't Get Ulcers (2004):

It is very rare, however, that any of the crucial hormones are actually depleted during even the most sustained of stressors. The army does not run out of bullets. Instead, the body spends so much on the defense budget that it neglects education and health care and social services.... It is not so much that the stress-response runs out, but rather, with sufficient activation, that the stress response can become more damaging than the stressor itself, especially when the stress is purely psychological. This is a critical concept, because it underlies the emergence of much stress-related disease. (p. 13)

Cannon (1939) and Selye (1950), both using animal studies, firmly established the scientific basis for the current study of stress. Their work focused on physiologic responses of laboratory rats to stressful external pressures, such as heat and cold, prolonged restraint of their legs, and surgical procedures performed without anesthesia. Most of the current investigations of chronic stress are still governed by their original, unchallenged assumptions. Stress continues to be studied as an inevitable result of pressures beyond the control of those experiencing the stress. 
Once ideas about psychological stress in human beings were extrapolated from the study of physiological stress responses in laboratory rats, studies of human stress by Richard Rahe and others (Rahe \& Arthur, 1978; Rahe, Biersner, Ryman, \& Arthur, 1972; Rahe, Mahan, \& Arthur, 1970; Rahe, Veach, Tolles, \& Murakami, 2000) established the prevailing view that there are distinct, measureable life stressors that cause stress. They even assumed that those life stressors can be ranked according to their level of influence on the degree of stress people experience.

The early work of Rahe and Holmes has evolved into a comprehensive inventory called the Stress and Coping Inventory (SCI) (Rahe et al., 2000), which measures four categories of stress and four categories of coping (p. 200). In the validation study for this instrument, the authors describe how they have continued to refine the list of external factors that induce stress and require coping mechanisms:

The new events add specificity to many of the original events. For example, "Change in Responsibilities at work from the SRE (Schedule of Recent Events) is, in the RLCQ (Recent Life Changes Questionnaire), followed by two options: 'Increased Responsibilities' and 'Decreased Responsibilities.' ... Further, the SRE inquired about death of a spouse and death of a close relative. The RLCQ retains the death of a spouse question but replaces the second question with 'Death of a child', 'Death of a parent', and Death of a sibling'. (p. 200) Psychologists now refer to "toxic" circumstances, relationships, emotions and events when describing stress-related syndromes. Stress- 
coping presentations address "noxious" events or "insults" to the psyche. Psychiatrists document "allostatic load" (McEwen, 2000; Ray, 2004), the "deleterious effects on psychological and physiological function when the acute stress response is not terminated" (W. F. Pettit, 2007). McEwen, who introduced the term "allostatic load" to medical literature (McEwen, 2002), refers to it as "the price the tissue or organ pays for an overactive or inefficiently managed allostatic response.” Therefore, allostatic load refers to the "cost of adaptation." (p. 921)

As Ray describes it (2004):

Stress/allostatic load is experienced when there is an inadequate match between an individual's coping skills and the environmental demands that the individual believes these skills must confront. It is important to note that it is not the coping skills that individuals have or do not have that are important. What counts are the coping skills that individuals believe they have or do not have. (p. 32)

The power of the prevailing outside-in paradigm to limit consideration of a new paradigm, even as more and more researchers look more deeply at the role of beliefs (a form of thought) in people's coping abilities, is evidenced also in a work by Marilyn Bowman (1997) questioning the universal diagnostic assumption that traumatic events "cause" post-traumatic stress syndrome (PTSD) in all people exposed to them. Bowman questions whether the event or the person has more power in determining distress: 
Whenever data are collected that include individual qualities (preand post-event) as well as event characteristics so these can be directly compared, individual qualities are more powerful in accounting for distress. Most people do not respond to even highly toxic events with persistent diagnosable mental disorders such as PTSD, and those who do respond with reports of serious deterioration in personal functioning and distress represent a small minority. The evidence shows that these people have a combination of individual factors that contribute significantly to their distress. These factors include cognitive competence, previous history of acts and experiences, and long-standing personality traits of emotionality and attraction to risk, as well as beliefs about the self, the world, sources of danger, and the appropriateness of emotional displays. (pp. 88-89)

Even as she questions why the "event-focused model is so persistent" (p. 136), however, she then concludes with an outside-in view of how therapeutic interactions need to be structured to account for individual differences and build strengths.

In the prevailing outside-in paradigm, it is assumed that some degree of stress is inevitable for all people, given the life demands and challenges everyone must face. It is assumed that "relief" from stress is a desirable, if temporary, departure from that normal expectation, and that people's ability to get that relief depends on their belief system or their access to coping skills or some combination of the two. Even though there is an increasing mention of people's "beliefs" (see Ray above) as a critical 
element in their coping capacity, the field does not address where those beliefs come from, how they change, and how people access them when they are facing stressors.

In studies of the role of optimism in healing, for example, Salovey et al. (2000) observed that "people's behavioral practices are a primary determinant of their physical health, and change in human behavior is likely the most efficient way to reduce disease morbidity and premature mortality (p. 113)." These authors studied the role of emotions in behavioral change, and showed that "people's mood states can influence people's beliefs regarding their ability to carry out health-promoting behaviors (p. 113), but their analysis of the change process started from the outside to look inward. "People's behavior may be motivated by the desire to improve their mood, but the processes by which the behavior alters mood is unclear (p. 116)." These authors call for further research "to tease apart the relative influences of physiological changes associated with the behavior and cognitive expectancies regarding the influence of behavior on emotional experience.” (p. 116) Techniques and methods that provide a respite from stress are therefore seen as the appropriate focus of stress remediation. The premise is that people who practice such techniques or methods must respond to a relentlessly stress-inducing milieu, but are better equipped to withstand and recover from stress (Antoni, 2003; Ashby, Isen, \& Turken, 1999; Benson, Greenwood, \& Klemchuk, 1975; Greenwood \& Benson, 1977; Lutgendorf \& Costanzo, 2003; Richardson \& Waite, 2002; Salovey et al., 2000; Sapolsky et al., 1986; Taylor, Kemeny, Reed, Bower, \& Grunewald, 2000). What most techniques have in common is that they provide coping mechanisms or strategies to provide more or less effective ways for people to adapt to 
inevitably stressful life circumstances. By inference, stress is presented as both real and constant in the human experience, a force that cannot be eliminated or defeated, only controlled or held at bay.

\section{Assumptions of Resiliency Research}

Resiliency is at the opposite end of the spectrum of human experiences from stress (Charney, 2004; Frederickson, 2003; Richardson \& Waite, 2002). Many means to facilitate resiliency in people to inhibit the experience of chronic stress are currently being proposed and evaluated (Fergus \& Zimmerman, 2004; Nilya, Crocker, \& Bartmess, 2004; Tebes, Irish, Puglisi, \& Perkins, 2004; Tugad, Frederickson, \& Barrett, 2004; Waite \& Richardson, 2004). Resiliency approaches are a step towards the notion that there are inherent human strengths that can be tapped into in the face of stressors, so they take the notion of "coping" to a new level: finding one's own strength in the face of adversity, rather than attempting to modify one's behaviors in the face of adversity.

Richardson and Waite (2002) offer a theoretical overview of resiliency theory that describes three "waves" of resiliency investigations. The first wave was based on the premise that people have "selective strengths or assets to help them survive adversity" (p. 65), but did not resolve the question of whether those strengths were learned or part of one's nature. The second wave was an effort to determine how resilient qualities are acquired or triggered through a process of "disruption and reintegration" (p. 66), suggesting that individuals encounter disruptions and then make conscious choices as to outcomes from those disruptions. This did not resolve 
the question of why some people seemed more able than others to "reintegrate" - that is, to come to peace with the "disruptions" and move beyond them. The third wave is the search for "What and where is the energy source or motivation to reintegrate resiliency" (p. 66)? The questions remain unanswered: Where does resiliency arise? How does it come alive?

Richardson (2002) describes resiliency as "a self-righting force within everyone that drives him/her to pursue self-actualization, altruism, wisdom and harmony with a spiritual source of strength" (p. 313). In their metatheory of resiliency, Richardson and Waite (2002) arrive at two postulates to support that definition. The first is that "a source for actuating resiliency comes from one's ecosystem" (p. 67), which suggests that people find strength from within their own belief system and experience as they need it. The second is that "Resilience is a capacity within every soul," which on its face suggests that they are offering the Mind-Consciousness-Thought idea that resilience is innate to all people, but which by their definition means that the brain can be taught to access energy from "the interdependence of all systems of human existence, both personally and as a community" (p. 68). So they are suggesting that all people have the ability to draw from profound external sources to generate resiliency, still an outside-in model.

Masten (2001), one of the most prominent resiliency theorists, suggests that resiliency is "ordinary magic" and observes that:

Ironically, expectations that special qualities were required to overcome adversity may have been influenced by prevailing deficit models of psychopathology that the early resilience investigators 
set out to overturn. In other words, expecting extraordinary

qualities in resilient individuals implied that ordinary adpative resources and systems were not enough. (p. 234)

At present, most resiliency studies still operate from the assumption that resiliency is a positive and constructive response to external stressors, which must be mediated. For example, Showron, Wester and Azen (2004) suggest that college students who have learned how to "differentiate" the self are better able to come to terms with the inevitable stressors and anxieties of college life. Conrad (2002) studied college students' responses to starting web-based classes to evaluate how such classes produced fear and anxiety and how they could be designed to lessen that effect.

Richardson and Waite (2002) have developed a training to develop resiliencyaccess skills in people which, while it is focused on deeper dimensions of experience, is based on learning and practicing skills and techniques. Even those who believe that people are "hard-wired" for resiliency, such as Henderson (2003), assume that there must be certain conditions met, or environments created, for that resiliency to emerge.

\section{Stress Research in Nursing}

The attempt to segregate and quantify external stressors and to study the methodology of coping is quite evident in research on nurses and nursing students. Studies from around the world report and define the circumstances that subjects indicate cause them the most stress and describe the coping mechanisms that help them allay that stress (Jones \& Johnston, 1997, 2000; Shipton, 2002). 
Although there is widespread agreement that stress is a significant problem for nursing students and nurses, there is disagreement among researchers as to what the primary sources of stress are. For example, a 2001 study of 561 nursing students in Taiwan reported "lack of professional knowledge and skills as well as the actual experience of caregiving" as the primary sources of stress (Sheu, Lin, \& Hwang, 2002, p. 171), acknowledging that the findings of this study are inconsistent with a number of other published studies, each suggesting altogether different sources of stress.

Not surprisingly, the literature from around the world is also filled with studies of instruments under development or qualitative methods to measure and catalogue stress and stressors more effectively (Admi, 1997a; Gigliotti, 2001; Hosoda, 2006; Maville et al., 2004; Timmins \& Kaliszer, 2002). Once again, there is no clear agreement on the best way to ascertain stress levels because there is no clear agreement on what, exactly, should be measured.

A number of studies address the development or efficacy of coping skills or interventions, regardless of the source or nature of the stressors (Admi, 1997b; Sharif \& Armitage, 2004; Shipton, 2002; Tully, 2004; Yonge, Myrick, \& Haase, 2002). These studies, too, have not resolved into any consistently recommended methodologies but still represent a field in search of answers. The idea of teaching resiliency as a means of stress prevention is not addressed at all in the current nursing literature.

A review of 24 doctoral dissertations focused on stress in nurses and nursing students since 1990 also reveals virtually no research into the idea of eliciting 
resiliency in preventing or ameliorating stress, although two studies approached the idea of "hardiness" as a factor in the ability of nurses to develop effective coping mechanisms against external stressors (Cox, 1995; Johnson-Holloway, 2001). The majority of the research projects focused on external factors that subjects perceived as causing them stress in the study and practice of nursing.

Thirteen of the dissertation studies measured or described stressors and the experience of stress (Bachman, 1998; Carr, 1989; Hesselberg, 2000; Hight, 1996; Huerta, 1990; Jennette, 1995; Johnson-Holloway, 2001; Keatley, 1998; Lamb, 1998; Reynolds, 1996; Rusin, 1990; Thurn, 1993). The common findings across the studies are that nursing students generally perceive themselves as highly stressed by a variety of personal, educational and professional factors, and generally are more stressed than other student populations. For example, in a study typical of the majority, Huerta (1990, pp. 1-2) found that financial problems, support system conflicts, relationship changes, academic fears, and personal and family illness were all cited by students experiencing stress. In addition, she found that the academic environment exacerbated those stresses by "infringing on personal time, causing illness, and producing clinical, academic and financial pressure."

Six doctoral dissertations since 1990 looked at and catalogued coping mechanisms adopted by nurses and nursing students (Cook, 1997; Cox, 1995; Kuhrik, 1996; Lomuti, 1995; Walton, 2002; Woodiel, 1997), most finding that results from the adoption of coping mechanisms were minimal or ambiguous. Four doctoral dissertations looked at interventions or educational strategies for nursing students to assist them to overcome stress (Backer, 1989; Davis-LaGrow, 1993; Marker, 2001; 
Morgan, 2001), with none indicating that any strategy was highly successful. Only one, Nikou (1998), looked specifically at "hardiness" as a predictor and found that, using Kobasa's (Duquette, Kerouac, Sandhu, Saulnier, \& Lachance, 1997) hardiness model to measure resiliency, high levels of hardiness did predict decreased stress and increased involvement in health-promoting behaviors in undergraduate nursing students.

Thus, although the literature reflects confusion about what causes stress or how stress should best be addressed, it is quite clear that stress is a significant factor in the lives of nurses and nursing students and there is a strong need for innovation in approaches to it. No MCT programs have been evaluated with Nursing students.

\section{Leading Edge Resiliency Research}

There are very few researchers looking at resiliency as a non-linear phenomenon, approaching it from a different paradigm. One of them, Blackerby (1998), attempted to apply Chaos Theory to psychological models. Her work is unique to her field, and although published, appears to have attracted little notice. Blackerby observes at the outset:

Physics and psychology are related at the confluence of the observed with the observer, formalized by Heisenberg in the uncertainty principle elaborated in 1958. Arguably, when people study nature, nature is studying itself because people are a part of nature. (p. 4) 
She follows Kuhn's (1962) argument, suggesting that the field of psychology is in a "pre-paradigmatic vortex," which will result in a change in metaphysical assumptions. She proposes a new non-linear model for understanding human behavior:

The type of model development suggested here will require significant theory-driven shifts from psychology's current linear, static perspective to a dynamic, nonlinear one. Such a theoretical shift will first require firm metaphysical foundations from the assumptions of the models. (p. 104)

She argues that behaviorism "fails theoretically because it neither incorporates nor integrates facts well-known in physics, its parenting science ... The closed system that behaviorists favor is one of reciprocal determinism between people and environment, where human beings have a status analogous to heating systems with furnaces and thermostats." (p. 127).

While she develops an argument founded in mathematics and physics, she is bound by the prevailing paradigm, even as she argues against it, and ultimately concludes:

Most current psychological models fail to address the metaphysical conditions inherent in the human system, thus bringing deep errors to psychological practice and empirical research. Psychologists are urged to examine their assumptions about the nature of human beings painstakingly. (p. 139) 
But how would they undertake to do that, to "study the human system as indivisible, in metaphysical terms" (p. 135) without a different paradigm? In an outside-in paradigm, there must always be a duality, a separation between the human and the human's context and a cause-and-effect, linear relationship between them. In the inside-out system described by Mind-Consciousness-Thought, there is no duality. Rather, the appearance of duality is an illusion of personal thinking. In the words of Sydney Banks (Banks, 1998):

When people search for truth, they often look in two directions - at the form and at the formless creating the idea of a duality in life. (p. 67)

Banks is proposing that the paradigm itself, the way people are accustomed to using their own thinking, is creating the "illusion" of duality, even though "all life is divine energy, whether in form or formless." (p. 70)

\section{MCT Background}

Since the late 1970 's, a completely different way of understanding and addressing stress and resiliency has been quietly spreading through the helping professions. The work is based on the assumptions that (1) all people have, inborn, an innate wellspring of psychological well-being from which to draw, their "innate health," and (2) all people can realize that and live from a healthy, wise, balanced state of mind, regardless of the "stressors" and external circumstances encountered over time (Howard \& Mansheim, 2005; Lewis, 2003; Mills, 2005; G. Pransky et al., 1995; J. Pransky, 2003; Sedgeman, 2005; Sedgeman \& Sarwari, 2006 ). In the inside- 
out paradigm based on the Principles of Mind, Consciousness and Thought, all people are capable of accessing a state of mental well-being, i.e., peace of mind, regardless of their diagnoses. People can lose access to that state of mental well-being by the innocent misuse of thought, so that they appear, to themselves and others, to be irremediably psychologically impaired. But all people have, within them, the capacity to regain mental well-being.

This is expressed from the perspective of an indivdual who "saw" the principles in action in a statement sent to Dr. William Pettit in 2008 by Molly Raudenbush, RN, who is, as of this writing, a Registered Nurse working at the hospital affiliated with WVU Medical school, and who is also pursuing a Master's Degree in nursing. She describes her experience as a patient who had been told she would never be able to return to work or to school to finish her Nursing degree, whose life dramatically changed after MCT therapy:

Learning the Principles of Mind, Thought and Consciousness has given me freedom from depression, panic attacks, bipolar disorder. My life changed in one moment, by one thought that I was not a sick person. An understanding of the three Principles restored my mental well-being and has allowed me to live my life with a beautiful feeling. I was once deemed hopeless, I'd never get better. I am grateful that I more than "got better." Today, I live a blessed life. 
The evolution of Mind-Consciousness-Thought and other work for which the foundation is the three Principles has occurred incrementally, through the random experience of practitioners who were personally touched by the underlying logic of it. Each in their own field, they started to develop a wide variety of practical ways to share that logic with clients in many diverse settings, including substance abuse programs, jails, schools, business organizations, health care institutions, underprivileged communities, youth development programs, homeless shelters, nonprofit agencies, families, clinical therapy and personal coaching.

The diversity of practitioners and applications has been a source of confusion for those looking to evaluate it. What is it? What population is it trying to reach? For whom is it most helpful? Why are there so many people doing so many different things with so little published information to show for it? Is it even possible that one approach can cross so many populations? How do you "do" it?

A review of the literature describing many people's work to bring the three Principles to light (Mills \& Mills, 2003) is a trip through philosophy (Banks, 1998), philosophical fiction (Banks, 1989a, 1989b, 2001, 2004), non-fiction (Gunn \& Gullickson, 2005; Mills, 1995; Mills \& Spittle, 2001; G. Pransky, 1998; J. Pransky, 1998; Spittle, 2005; Stewart, 1993; Suarez et al., 1987), anecdotal reports (Marshall, 1998; Mills, 1991; Mills, Dunham, \& Albert, 1998), case studies, personal testimonies, conference presentations (Howard \& Mansheim, 2005; Marshall, 1998; Mills, 2005; Sedgeman, 1996, 1997; Shuford et al., 2000), unpublished dissertations (Bond, 2007; Borg, 1997; J. Pransky, 1999; Roy, 2007) compilations of post-test data with no matching pre-test data, bulletins, magazine and newspaper articles, web-sites, 
self-help books (Bailey, 1999; Carlson \& Bailey, 1997; Flood, 1999; J. Pransky, 2001; Spittle, 2005), self-published books (Karn, 1998; Kausen, 2003; S. Pettit, 1987), practitioner handbooks (Benard \& Marshall, 1997b; J. Pransky \& Carpenos, 2000), video and audiotapes, book chapters (Lewis, 2003; Marshall, 2004), textbooks (G. Pransky, 1998; J. Pransky, 2003). Only a handful of peer-reviewed journal articles (Banerjee et al., 2007; Kelley, 2004; Kelley \& Stack, 2000; G. Pransky et al., 1995; Sedgeman, 2005; J. Sedgeman \& A. Sarwari, 2006) have been published. The references cited here are not exhaustive, but representative.

The theoretical model, however, as SAMHSA reviewers noted (2003), "is part of a complete and well-designed theory." All the literature generated by these practitioners is consistent with that theory, which is fundamentally articulated in the discoveries and works of Sydney Banks, whose insights into principles that explain the nature and role of thought are the springboard for all the work being done under the various professional descriptors that its practitioners have chosen. The essence of this understanding is expressed in Banks' philosophical book, The Missing Link (1998):

All human psyches are rooted in universal truth and no person's psyche is better than any other's. Only to the degree of the individual's psychological and spiritual understanding does it appear to vary. (p. 7)

The literature about principle-based work portrays a significant and critically important phase of a major breakthrough in its gestation period. Dedicated practitioners from many fields of the helping professions are committed to nurturing 
it and seeing it grow, but it has not yet been delivered, whole, to the fields it proposes to change as a fully examined, vital, operational approach. Sedgeman (2005), in an article about the "Mind-Consciousness-Thought" principle-based model used at West Virginia University, describes it this way:

[MCT] sees the research demonstrating that quietude fosters psychological and physiological benefits that can ameliorate, or even reverse, the effects of chronic stress as evidence for the pressing need to investigate its effects. MCT is a new prevention strategy in mental health which may hold promise for a significant reduction in the problem of chronic stress. (p. 51)

\section{Context of MCT Philosophy}

It is tempting to place the Principles in a linear sequence of thought linked to developing ideas in philosophy, theology, physics, psychology and psychiatry. Compelling presentations of such sequential arguments have been generated ( $\mathrm{J}$. Pransky, 1999), and they are illuminating and deserve respectful scrutiny. Yet an equally, if not more, compelling argument must be considered that if, indeed, all inside-out approaches are founded in principles, then by the very definition of principles (Banks, 1998; Sedgeman, 1997), its fundamental philosophical groundwork is not "new," did not emerge logically from a historical development of ideas in other fields, and cannot be linked directly to trends of thought.

Such an argument would say, instead, that MCT is a based on a discovery of something that has always been true, and, once realized, it can be identified 
historically in the expressions of many deep, insightful thinkers in many fields over the course of human history. Banks (1998) describes principles as "universal constants that can never change and never be separated" (p. 22). That places the Principles of Mind, Consciousness and Thought in the context of other discoveries of universal laws, such as gravity, or thermodynamics - logical universal operating principles always at work, regardless of whether they are known or unknown to humankind (Sedgeman, 1997).

The common ground for these two arguments might be found in the notion of universal wisdom, described this way by Banks (1998):

Spiritual Wisdom lies within the consciousness of all living creatures. It is formless. The second it is revealed to a human soul, it has taken on a form that can only represent its true nature. ( $p$.

Thus, the expression of the Principles might have taken infinite forms through the thinking of many wise people over time, and it can be found throughout all of human expression, in every field of human endeavor.

What is unique about Banks' discovery at this time in the history of human thought is that it represents a coherent expression of these Principles in the context of human well-being at a time when the whole scientific world is searching for a unifying principle. The linear thinking that has dominated scientific thought since the $17^{\text {th }}$ century is being called into question by the deeper logic of quantum physics. Perhaps the most articulate spokesman for that search, physicist Stephen Hawking, put it this way (Hawking, 1996): 
However, if we do discover a complete theory, it should in time be understandable in broad principle by everyone, not just a few scientists. Then we shall all, philosophers, scientists, and just ordinary people, be able to take part in the discussion of the question of why it is that we and the universe exist. If we find the answer to that, it would be the ultimate triumph of human reasonfor then we would know the mind of God. (p. 233)

As physics has increasingly probed what has come to be identified under the general rubric of "chaos theory," other disciplines have begun to wonder about the implications it holds. For example, Blackerby (1998) writes:

Psychological models must follow and be consistent with the nature of the human system. Psychology today tacitly portrays human beings as closed, linear systems. In reality, the human psychological system exhibits neither closed nor simply linear phenomena, and consequently must have more authentic theoretical modeling than it has been given thus far. (p. 84) The physicist David Bohm (1999), proposed in his book Wholeness and the Implicate Order:

The new form of insight can perhaps best be called Undivided Wholeness in Flowing Movement. This view implies that flow is, in some sense, prior to that of the 'things' that can be seen to form and dissolve in this flow. One can perhaps illustrate what is meant here by considering the 'stream of consciousness'. This flux of 
awareness is not precisely definable, and yet it is evidently prior to the definable forms of thoughts and ideas which can be seen to form and dissolve in the flux, like ripples, waves and vortices in a flowing stream. As happens with such patterns of movement in a stream, some thoughts recur and persist in a more or less stable way, while others are evanescent. (p. 11)

Bohm's brilliant work attempts to reconcile the forms of life with the formless, piling metaphor upon metaphor to suggest the timeless oneness of life, which takes on the appearance of a duality of form and formless only as we attempt to grasp it, understand it and describe it in words.

Sedgeman (2005) refers to "experience inchoate" (p. 49) in describing the energetic movement from formlessness to form. In the formless, there are no distinctions; it is a unified state. Only when the formless flows into form do we create the illusory manifestation of duality, an apparent separation between what is formless and what is form and an apparent separation of the infinite possibilities of formcreation. Yet it is like pure light breaking into a rainbow as it passes through a crystal; it is the same light in a different expression.

The search for the unity that transcends duality is described also in The Missing Link by Banks (1998) this way:

The world in the form of nature is a reflection of the human mind, which creates an illusionary gap between the spiritual and the physical. This gap, in turn, creates the duality of life. Trapped in this duality, our minds become full of disillusionment and lostness. 
As the human mind ascends in divine consciousness, the gap

between subject and object begins to vanish and the oneness of life

emerges. There is one Universal Mind, common to all, and

wherever you are, it is with you, always. There is no end or

limitation, nor are there boundaries, to the human mind. (pp. 34-

While it may seem arcane to talk about formlessness and form in the context of psychological functioning, the "moment of truth" that sets people free from living at the mercy of self-created stress and negativity, regardless of the words they use to describe it, is the moment of insight into the understanding that we create our ideas from nothing, and ideas continue to flow constantly through our minds as we do so because we are part of the life force described by the new physics, the constant interplay between energy and matter. The Principles are always at work, recognized or not.

As a sidebar, it might be mentioned that Sydney Banks has been invited to visit with a number of prominent physicists who are intrigued by the Principles as he discusses them in greater and greater depth, since it is becoming clear that energy itself is not formless; that formlessness, the ultimate unifying principle, is before all the known world. Bohm approaches that idea with the statement:

...it may be said that space, which has so much energy, is full rather than empty. The two opposing notions of space as empty and space as full have indeed continually alternated with each 
other in the development of philosophical and physical ideas. ( $p$ 190)

Bohm calls the formlessness before form "holomovement", which he says "includes the principle of life" (p. 195). Banks calls it the "formlessness before the formation of time space and matter." Facilitators of MCT approaches use whatever metaphors come to mind to point clients towards it. It becomes increasingly easy to accept the Principles as universal truth as people from all walks of life, and all levels of education, and all cultures, and all ages "see" for themselves, and recognize themselves as the thinkers of their thoughts, creating their moment-to-moment experience of their own personal reality.

In the words of Beverly Wilson (Kennedy, 2000), a former heroin addict, a former street person, who spent years in the drug culture and had her children taken from her more than once by social service agencies, who wound up in a Principlebased program in Santa Clara County, California: "I realized that I'm making this up. I was terrorizing myself with my own thinking. Now that's powerful!"

Since she started having insights into her own innate health more than 10 years ago, Ms. Wilson has earned a Master's Degree in International Relations and works as a teacher for others learning the principle-based approach (described there as Health Realization) in Santa Clara County, as well as a mentor for many clients. She also serves as a consultant to the human resources departments of several large corporations. 


\section{MCT-Based Practice}

Although Sydney Banks first recognized and described the three Principles in operation more than 30 years ago, Principle-based practice is in its academic infancy. Nonetheless, there is a rich vein of work product to be mined and examined (Mills \& Mills, 2003), and there is an across-the-board willingness of practitioners to open their work to scrutiny, to collaborate and cooperate with researchers, to share in developing a more rigorously defined body of knowledge.

At this point, there is a widely agreed-upon, fundamental method of evoking the understanding. Although there are individual differences among MCT-based practitioners, all of them base the work they do with whatever client group they work with on the three Principles of Mind, Consciousness and Thought and on the assumption that every person has innate mental well-being. All of them operate under the assumption that the helping professional's work is to elicit the innate mental wellbeing in clients, to point the way for people to find their own insights and access peace of mind and mental well-being themselves (Kelley, 2004; Sedgeman, 2005). It is a psychoeducational model, no matter the setting, the means of delivering the message, or the client base.

Most importantly, all MCT practitioners operate from recognition that the "health of the helper" is the bedrock of the work, the recognition that it is impossible to share what you do not have. So these practitioners are all individuals who realized innate health first for themselves and find themselves on a continual journey of insight and understanding. They rely on their own resiliency. They "know" whereof they speak because they are always looking to move increasingly more deeply into 
the quality of mental life they describe as a possibility to their clients. They have personal experience of the psychological, physiological and spiritual benefits of realizing the Principles in operation. They have seen their own moments of upset decrease consistently in frequency, intensity and duration. When questions arise about the replicability of MCT work, the first answer always is, "As you increasingly see the Principles at work behind life and discover the health within yourself, you will see from your own insights how best to share that direction with others."

The common sense recognition that the power of teaching is best measured by the depth of understanding of the teacher is expressed by Banks (1998) this way:

There are so many teachers in the world and so many theories about life. When selecting a teacher, ask yourself ... Is my teacher a well-balanced person? Is he or she happy? Does my teacher reflect and demonstrate the quality of life I desire? If the answer to any of these questions is no, move on in your journey. Otherwise you may become one of the blind, led by the blind. (p. 89) The primary "manual" for delivering MCT programs is the lively, present-in-themoment, innate wisdom of the facilitator or practitioner. Without access to that wisdom, any books or practice guides describing the approach are useless because the teaching becomes intellectualized. Without the "health of the helper," interactions are bereft of the feeling of health, and the hopefulness of the certainty that all people share the same source of mental well-being -- what psychologist Howard calls a "partnership of health" (Howard \& Mansheim, 2005) that brings innate health to life. 
Although there is a loosely-knit collaborative group of practitioners who were among the first to see the difference and the promise in this approach (Mills \& Spittle, 2001), the rapid increase in interest in the Principles has resulted in a geometric increase in practitioners who sometimes stumble into each other at conferences, or learn about each other through colleagues or clients, but who have no organized connectivity. There is no journal dedicated to the Principles; there is a Foundation that maintains an informational web-site, (http://threeprinciples.org/), but it is entirely dependent upon incoming information from people who know that it exists.

The primary academic locations for the work, as this is written in 2008, are the well-established National Resilience Resource Center at the University of Minnesota and the West Virginia Initiative for Innate Health at West Virginia University. There are principle-based practitioners with faculty appointments at other universities, including Portland State, San Jose State, Wayne State University, the University of Hawaii, the University of Vermont, Nova University, West Georgia University. As a new generation of students is exposed to the work, however, they are beginning to exert pressure to get the inside-out paradigm represented by the three Principles established in curricula and provide programs of study so they can make it their professional focus.

\section{MCT-Based Education}

Much of what has been written specifically about teaching based on the Principles of Mind, Consciousness and Thought has been written by this author (Sedgeman, 1996, 1997), who has taken the inspiration for principle-based teaching directly from 
being a student of Sydney Banks (Banks, 1989a, 1989b, 1998). MCT-based teaching elicits insights from the learner so that people see for themselves and are able to express their learning in their own words. The fundamental premise of MCT-based teaching and learning is expressed by Sydney Banks in The Missing Link:

It is one thing to listen to the words of the wise and quite another to be a follower. Any good teacher will tell you never to be a follower. A wise teacher will draw out your innate knowledge. Followers fail. They readily adopt another's beliefs and cease to think for themselves. (pp. 93-94)

The essence of MCT-based teaching is to invite people to see information as material to be illuminated by their own intuition and common sense. It requests people to ask deeper questions and seek their own wisdom, and not to embrace ideas that don't make sense to them in their own minds. It calls upon people to reflect on, rather than only to process, knowledge. It points people to the realization of their own creativity and the possibility of original thought.

MCT-based teaching is derived from the idea that there are two ways in which people use their minds. One is personal and rational, meaning that we use our minds to access and process already-known information (Sedgeman, 1996, 1997). In the context of teaching and learning, that means thinking about ideas that have been presented to us, or that we already know. As long as the learners' minds are focused on comparing and fitting such information into the existing framework of their knowledge, asking if things are alike or different, useful or not useful, interesting or 
boring, easy or hard, there is learning going on, but it stops at the boundaries of the already known. That is, we can only compare and contrast known information with other known information. We can only judge the relativity of one thing to another between one thing we know and another thing we know. And we can only think about these questions by processing thoughts until we reach a conclusion. All rational, evaluative thinking involves doing something (whether constructive or nonconstructive) within the confines of already-thought thoughts.

MCT-based teachers would be the first to say there is real value in such thinking; the preservation of knowledge and the academic process depend on it, and it is a valid, cumulative learning strategy (Sedgeman, 1996). It is about sorting, cataloguing, judging and processing information. It is the "librarian" in our heads. But it has a significant limitation. Although it may lead the learner to information the learner had not yet known, it will not lead the learner to his/her own ideas that have never been known before, to unique insights, to understanding that originates within the learner and thus "belongs" to the learner and informs his/her life. It may lead the learner to use his/her mind effectively and strategically, but it will not help the learner to understand and appreciate the uses and power of the mind to generate unique ideas, to express creativity, or to realize things for him- or herself.

Understanding the Principles opens access to a second, impersonal and intuitive dimension of thought. The Principles describe what happens before there is any thought content, which is why it is "impersonal." The Principles operate before the formation of personal thought, and describe the formless energy that creates the formation of thought. Understanding how thought works, the Principles in action, 
allows learners to be comfortable not knowing while reflecting, in certainty that one can see beyond one's knowledge, beyond prevailing ideas and systems of thought, and draw from wisdom beyond the intellect to experience transformative insights, new thoughts. The Principles describe how people think and see things for themselves, and they explain the source of original ideas, insights. They point to deeper learning in which the student is consistently engaged in the "Aha!" moments that make learning satisfying and sustained.

To give an example, imagine a student assigned to study inventors and inventions. If the student studied only with the librarian in his head, he would gather data about people identified as important inventors and search through it for interesting ways of making connections, seeing similarities and differences. At the end, he would know more than he knew when he started about inventors and invention. He would definitely have learned something more meaningful and interesting than what he previously knew. He could probably answer many questions. But there are certain types of questions that such pursuit would still leave unanswered:

1. What explains the origin of ideas that have never been conceived before?

2. Why do some people find original ideas and find ways to articulate them, while others do not, even though they may search for them?

3. What is the difference between those ideas and the culture-specific ideas that surround them and how do inventors use what they know without being limited by it? 
4. What is the qualitative difference in the thought processes of people we call "inventors" and people we do not?

5. What is the universal common denominator by which people seem to "recognize" the insight that translates into an invention?

The answer to such questions will never be found by looking harder at the material gathered by the inner librarian. And the questions are bigger than inventors; they are questions about the nature of life as thinking human beings that make such people possible. Principle-based educators place high value on such questions because they cross the bridge between intellectual knowledge and profound understanding of life, wisdom.

Dialogue based on the Principles of Mind, Consciousness and Thought is concerned with these deeper types of questions. The Principles explain the nature and origin of thought, both original thought and the capacity to re-think thoughts. The Principles explain how and why people can change their minds. The Principles explain how and why people become "believers" and how and why people break free from closely held beliefs. They explain how and why all people, at any time, are able to access original thought, to think and see for themselves. With the Principles as a foundation for learning, people are free to see knowledge for what it is and to know that they can continue to discover more.

In the words of Sydney Banks:

To seek truth from the form alone is only half the truth; it traps you in a cosmic lie ... One is a learned intellectual process. The other is a realization 
of knowledge from within the depths of our own consciousness. (pp. 14-15)

\section{The Value of MCT-Based Learning}

Principles are at work universally whether their power or influence are discovered and understood or not. Whether they are discovered or not dramatically affects the quality of life within whatever realm the discovered principles describe. The discovery of gravity as a principle that explained the relationship of objects, for example, made possible scientific advances in architecture, aerospace technology, astronomy, and physics. But objects remained in exactly the same relationship to each other as they had always been before anyone understood the principle of gravity. The fact of understanding did not change or affect the operations of the principle of gravity in any way; the understanding only changed and affected the creative capacity of those who understood the principle of gravity.

The early Greeks and Arabs, for example, had a sophisticated understanding of the principles of mathematics. That understanding was virtually hidden from the European continent and the knowledge base of most people there during the Middle Ages, but that understanding still existed in parts of Asia. Regardless of who understood the principles, the principles continued to govern the lives of all people equally. Those who understood them flourished in their understanding and made use of it to further civilization. Those who did not understand them invented myths, alchemy and magic to explain the inexplicable, and lived in greater fear and uncertainty. The same principles operated the same way both for those who 
understood and flourished in creativity, and for those who did not understand and survived in uncertainty. The principles of mathematics governed their purview and generated a predictable universe, whether people recognized them or not. But those who did not recognize them were lost in their own theories and stories about why things happened as they did; those who did recognize them understood their world better.

The very ability people have to doubt, to argue, to deny and to distrust is both proof of the Principles of Mind, Consciousness and Thought in action and evidence that people's personal thinking can drown out their intuitive connection to insight. The very power of the principle of Thought, the capacity to live from original thought, is the very same power that allows us to be held in place by thoughts we continually process, blocking the natural flow of thought. That is because every thought that we bring to mind appears to us as our reality in the moment. There is no limit to how many times we can continually bring the same thought to mind and call it our life, oblivious to the possibilities in the unknown because we are innocently living in the self-created prison of the known. Principle-based educators would say it is not necessary to judge or tinker with the prison. It is our gift to come to the realization that it is a prison, and to know where the key is if we want to escape. Sydney Banks (1998) describes it this way:

Among the greatest gifts given to us are the powers of free thought and free will, which give us the stamp of individuality, enabling us to see life as we wish. These same gifts can also be the 
greatest weaknesses of humanity. We often lack

the strength to change our minds, so we get

stuck in the negative thoughts and behaviors of the past.

(p. 50)

What is profound about the Principles of Mind, Consciousness and Thought is the enormous learning and healing implications of the unleashed power of thought within people who recognize and appreciate that power. Traditional educators tend to place faith in the rational uses of the mind and tend to discount the intuitive uses of the mind; principle-based educators seek to restore the balance between the two. As described by Sydney Banks (Banks, 1998):

The Universal Mind, or the impersonal mind, is constant and unchangeable. The personal mind is in a perpetual state of change. All humans have the inner ability to synchronize their personal mind with their impersonal mind to bring harmony to their lives. (p. 31)

\section{Early Principle-Based Systems Change}

The first recognized attempt at systems change, or impacting an entire community, through Principle-based education occurred in 1987 in a housing project in Dade County, Florida, called Modello (J. Pransky, 1998). Living conditions had become so bad in this project that it was no longer possible for the county and state to deliver services to residents. The State Attorney for Florida threatened to sue Dade 
County to improve conditions at this project. Dr. Roger Mills, one of the first practitioners in the development of principle-based psychology, began a program of parent education classes, and trained a handful of social workers to bring this understanding to the residents (Mills, Bradford, \& Garcia, 1989).

This work is documented in the book Modello: A Story of Hope for the Inner City and Beyond by Jack Pransky (1998). Dr. Pransky, a well-known prevention specialist, was originally quite skeptical of stories he heard about what happened in Modello, so he undertook to interview residents, providers, county officials, police, teachers - everyone he could find who had been involved in the project during the interventions. In his book, he recounts their stories almost entirely in their own words. His skepticism dissolved into a commitment to dedicate the rest of his career to disseminating the significance of the three Principles in the prevention of mental illness and social dysfunction.

In his words, as he introduces his book:

This is a book about hope, about the triumph of the human spirit, about how all people have something inside them so powerful, so beautiful, so resilient that once tapped even some of the most terrible living conditions can be overcome ... most all who knew would agree that in the Modello and Homestead Gardens housing projects violence, delinquency, child abuse and neglect, alcohol and drug abuse, truancy, teenage pregnancy, and welfare dependency decreased markedly. Many residents improved their education and secured jobs. (p. 13) 
At the time the Modello project was undertaken, Dr. Mills and his colleagues were working on a modest budget. They had no access to research support or researchers. Nonetheless, the story of Modello and the appearances of the residents whose lives were changed at national psychology and social work conferences as well as on national television, helped to launch a community change process in many other places across the U.S. and beyond (Mills \& Spittle, 2001). It provided the impetus for one of the largest efforts in the world to use the Principles to transform lives, in Santa Clara County, CA, where the county has created a training division to provide principle-based training to hundreds of human services workers and counselors who offer outreach to thousands of clients.

An example of the influence of the Modello residents can be found in a dissertation study by Jack Pransky (1999), for which he conducted phenomenological research on a series of trainings for violence prevention in Bemidji, Minnesota. In 1997, he invited one of the former Modello residents, Cynthia Stennis, to co-lead one of the trainings. She, and others from that project, have become national trainers and continue to touch lives, more than a decade after their lives were first touched. They have become mentors as well as exemplars of what Pransky (1999) explains is the impact of an understanding of the Principles, in work that was then called Health Realization:

Through Health Realization, then, people change because they have new thoughts — often in the form of new insights — that alter the way they experience life. Life never again looks as it did, therefore they cannot go on as they have. This change occurs from the realization of 
their power within to create the internal life they then experience.

From this new understanding, they view their relationship to their problems and problematic behaviors in new and healthier ways. (pp.

Mills (2003) documents what can be known about Modello and other related projects on a web-site maintained by the U.S. Department of Health \& Human Services. His own, unpublished, data are shown in Table 1. These data have been widely disseminated as other such programs have been undertaken in many other communities, and have never been questioned by authorities who were involved in the project. Nonetheless, they have neither been tested nor replicated at this point.

\section{Table 1}

Results of the Health Realization Project in Modello and Homestead Gardens

Risk Factors

Households selling or using drugs

Overall crime rate

Teen pregnancy

School dropout rates

Child abuse and neglect

Households on public assistance

School absenteeism/truancy

Parent unemployment rate
Before

$65 \%$

Endemic

$50+\%$

$60 \%$

Endemic

$85 \%$

$65 \%$

$85 \%$
After

$20 \%$

$70-80 \%$ decrease

$10 \%$

$10 \%$

$70 \%+$ decrease

$35 \%$

Negligible

$35 \%$ 


\section{MCT in Education}

Most of the academic faculty involved with MCT-based work are educators or practitioners whose focus has been bringing this work to life in school or university settings or into the counseling profession.

Marshall (2004) describes how and why the MCT-based approach can be effective in school settings. She suggests that "resilience is an inside-out process - an existential process of every child and youth 'being and becoming.' This involves learning how the protective mechanism of healthy psychological functioning occurs (p.66)." Marshall, whose work at the National Resilience Resource Center (NRRC) at the University of Minnesota has paved the way for many people who want to use the

Principles to affect educational programs and systems, reports on the outcomes of two principle-based interventions in school systems in St. Cloud, Minnesota and Menomonie, Wisconsin, where this model was used.

Marshall's goal is to affect as many parts of one system as possible to bring about a critical mass of new understanding that results in systems change, rather than to accept opportunities as they arise to work with small groups in a variety of systems, which is the way many principle-based practitioners have gone about their work. As a result, the NRRC's work has been notable for its impact.

In St. Cloud, for example, Marshall and others worked over several years in a District-wide Student Assistance Team training which, by 2003, had reached 2,500 people from all the agencies and non-profits serving children, youth and families. In Menomonie, a rural location, more than 350 persons were involved in the trainings. 
Programs were evaluated by means of questionnaires, structured interviews, focus groups and school district records. In St. Cloud, a survey at North Middle School revealed the following (2004):

- $13 \%$ increase in students who say students are generally respectful to each other;

- $21 \%$ increase in students who say students are generally respectful to adults;

- $\quad 9 \%$ increase in students who say the school is a friendly place;

- $10 \%$ increase in students who say adults in this school are helpful.

- $21 \%$ increase in faculty believing there is good communication;

- $27 \%$ increase in faculty believing they can participate in school-level decisions;

- $19 \%$ increase in faculty believing North is a good place to work;

- $24 \%$ increase in faculty believing students of different races get along well;

- $34 \%$ increase in faculty believing students respect each other;

- $44 \%$ increase in faculty believing students respect adults;

- $40 \%$ increase in faculty believing positive interactions among students have increased;

- $33.9 \%$ increase in faculty believing positive student-to-adult interactions increased. (p. 74)

The framework for the NRRC's program, devised by Benard and Marshall (1997b), arose from their realization that "the foundation for systems-change tapping resilience rests first on leaders' belief about human functioning and the natural 
capacity for resilience" (2004, p. 67). Their intervention began with in-depth discussion with school leaders to allow them to question their prevailing beliefs and develop their understanding that:

... this innate capacity for resilience, when realized and tapped with effective evidence-based strategies, restores hope for healthy human development and societal progress across the board, including prevention of substance abuse and related high-risk behaviors, improved performance, relationships, and mental health. (2004, p. 68)

As a result of focus group interviews following the interventions in Menomonie, Marshall found that, "As understanding is deepened and the circle of trained persons grows, systems begin to shift toward common sense, health and well-being - natural systemic resilience” (2004, p. 79). Marshall concludes:

There is a simpler way for organizations to be and it begins with the inside-out process of resilience-based systems change called Resilience/Health Realization. Protective factors - caring, encouraging high expectations, and meaningful opportunities for participation - are extended naturally as the health of the helper blossoms. Improved school climate and student outcomes are inevitable by-products. What was difficult and overwhelming becomes effortless and gratifying. (2004, p. 79) 


\section{Mind-Consciousness-Thought at West Virginia University}

An effort to develop a research questionnaire that specifically measures the changes expected from MCT interventions was begun in 1998. This effort is ongoing, and the instrument under development (the SBI-64) has undergone numerous

modifications. The reliability study is complete, but the instrument validity and a scoring mechanism are not yet established. Although there are many well-established scales to evaluate mental well-being, the inside-out paradigm demands a different kind of question. Most well-being scales look at outcomes, or at thoughts, feelings and behaviors, as though they were "real." A strong measure to evaluate a principlebased program would have to inquire about whether the respondents understand the relationship between their experience and the use of their own thinking explained by the Principles. In other words, a typical likert-scale question in an outside-in questionnaire might be: "In the last week, to what extent have you felt downhearted and depressed such that nothing could cheer you up?" That question, in a study designed specifically to evaluate the MCT approach, might be asked this way: "In the last week, to what extent have you taken discouraging or depressing thoughts so seriously that you could not allow them to pass?"

Incidental to the original study of the questionnaire in development, however, data emerged that were of interest to the group working on the instrument. It appeared that participants who were pre-tested before MCT workshops, post-tested immediately following the workshops, and then post-tested again six months later, sustained the changes that were shown in the first post-test on the factors that were emerging from the questionnaire (Appendix E). For example, as a result of a Principle 
Component Analysis on the data, four statements explained almost half of the variance on the first set of items on the questionnaire, which addressed experiences people perceive as limitations to their success and clarity. Those were:

- I worry.

- I get stressed out.

- I've got a lot on my mind.

- I feel the way I do because of the stuff that happens.

For each of these statements, there was a positive change pre- and post- the intervention, and at the six-month follow up, that change was sustained, or even slightly improved (Figure 1).
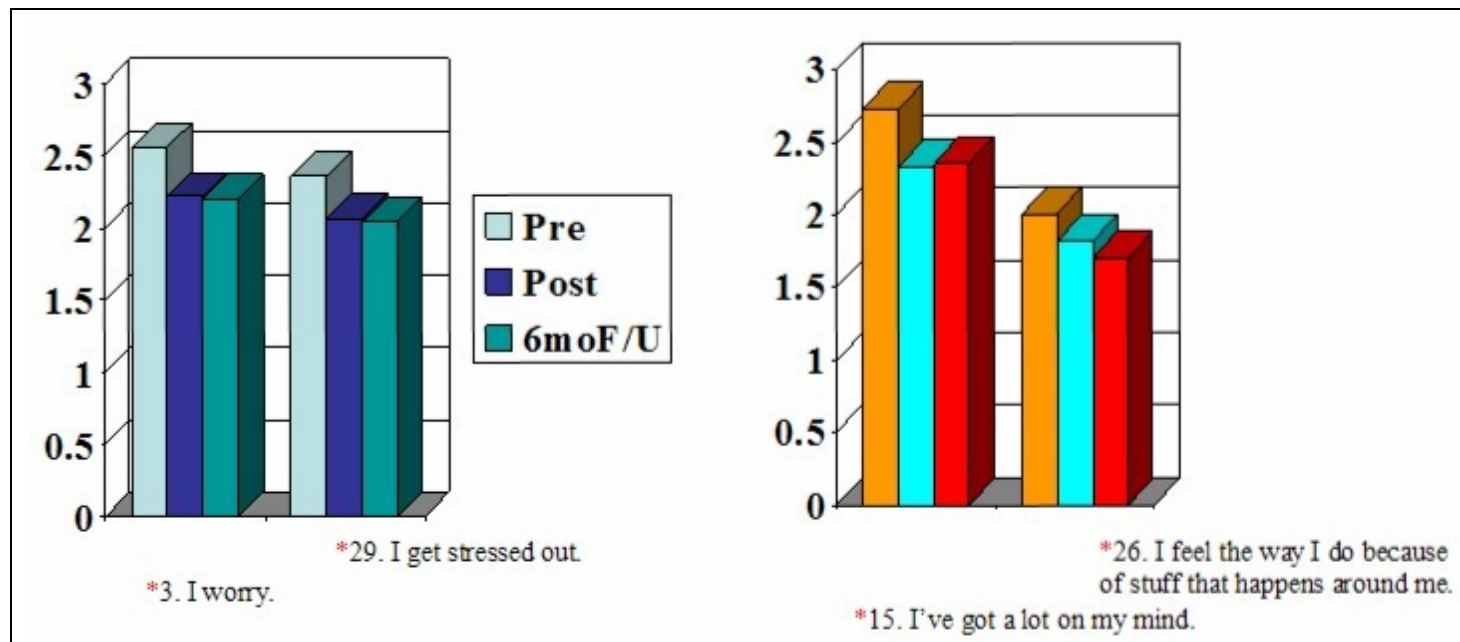

Figure 1. Pre- post- and six-month follow up results for the most significant questions on the first half of the SBI-64: The X-axis= time; the $\mathrm{Y}$-axis = the mean likert scale responses for the three sets of questionnaires. These results were an incidental part of a validation study. Although statistically significant $(p<0.05)$, the data may be skewed by the fact that there were far fewer respondents for the six-month follow-up. Respondents could have self-selected for reasons that would influence the results. 
On the second set of items, which address people's understanding of their own state of mind and resiliency, four statements explained more than $40 \%$ of the variance. They were:

- When I can't figure something out, I get frustrated.

- When I fail at something, I start to doubt myself.

- When I'm down, I don't take my thinking seriously.

- When I'm upset, I calm down before acting.

Significant positive change was observed for these factors $(\mathrm{p}<0.05)$ between the preand post and between the pre- and 6-month follow-up results (Figure 2).

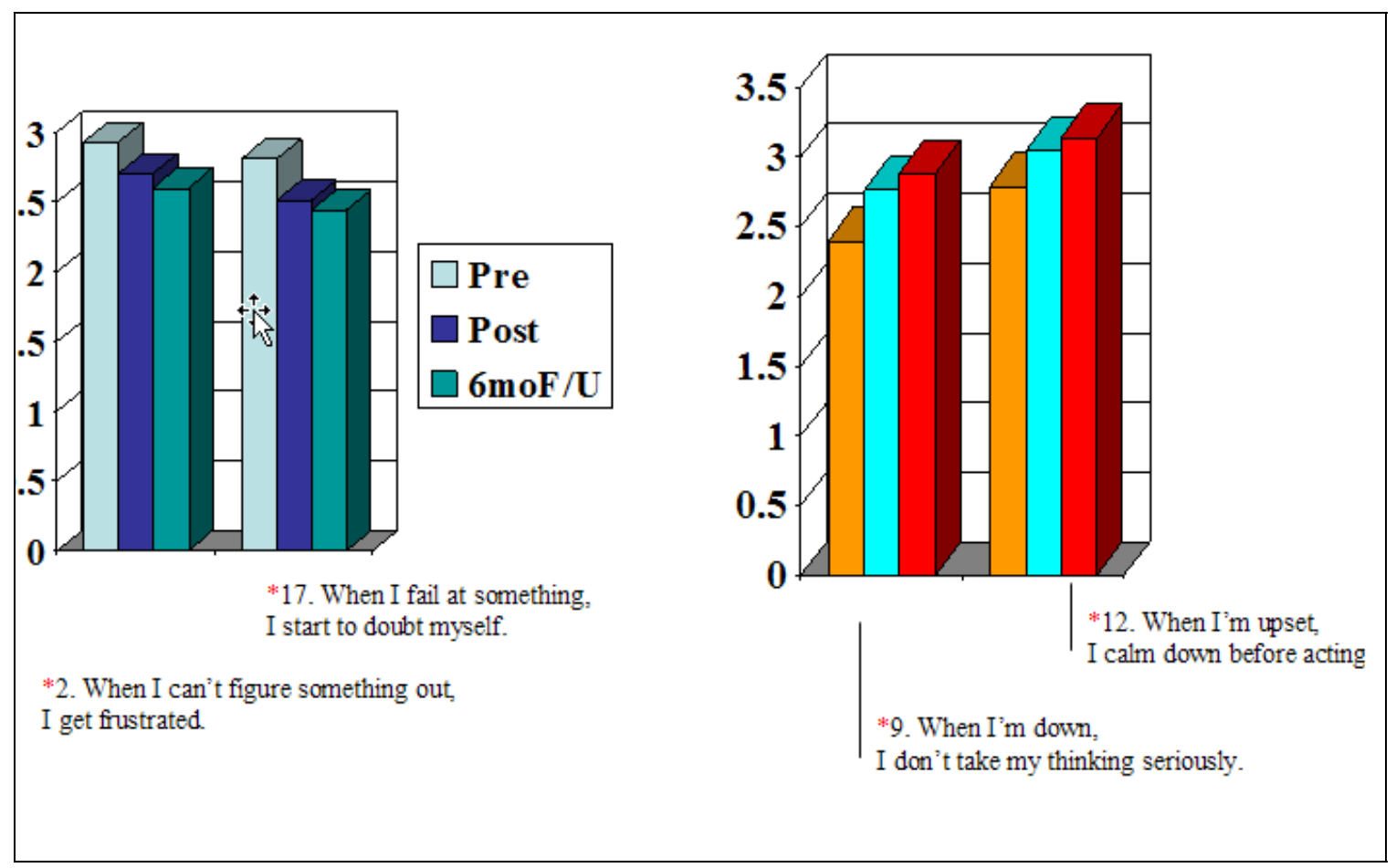

Figure 2. These graphs show pre- post- and six-month follow-up on the questions that explained more than $40 \%$ of the variance on the second part of the SBI -64 . The $\mathrm{X}$-axis indicates time; the $\mathrm{Y}$-axis indicates the mean likert scale (1-4) response for each of the three sets of questionnaires. 
While the data shown in Figures 1 and 2 were not the point of the research, which is an instrument validation study, these results generated curiosity that led to the desire to conduct further studies with already-validated instruments to evaluate the effect of MCT interventions.

In 2005, a study was undertaken with HIV-positive patients in the Positive Health Clinic at West Virginia University Medical School, using the Brief Symptom Inventory (Derogatis \& Spencer, 1982) to evaluate change (Sedgeman \& Sarwari, 2006). The same pattern of improvement appeared in this study (Figure 3), with much more reliable data gathering:

Three of the participants pre-tested in the non-patient normal range on the BSI, according to the BSI normative data, but even within that range, all three showed improvement from the intervention. The other four participants pre-tested in the mid-range, classified by the BSI as "psychiatric outpatient." All of those showed improvement from the intervention that was sustained at the time of the second posttest. Although two of those four showed a variation between the gains indicated immediately after the seminar and the gains one month later, two others showed continuing improvement and substantial gains between the post-seminar result and the follow-up test. One of those actually scored slightly higher on the BSI immediately after the seminar, but improved subsequent to the seminar. (p. 398). A poster presentation of this study was presented at the Annual Neurosciences Meeting sponsored by The Neurosciences Institute of WVU At Nemocolin Woodlands, Pennsylvania, in November, 2007. 
This study also incorporated a new instrument in development at West Virginia University, the Pettit Attachment to Thought Content Scale (PATCS), which is currently being tested. Results on the PATCS correlated well with the BSI results, but were not published because the instrument is not yet validated.

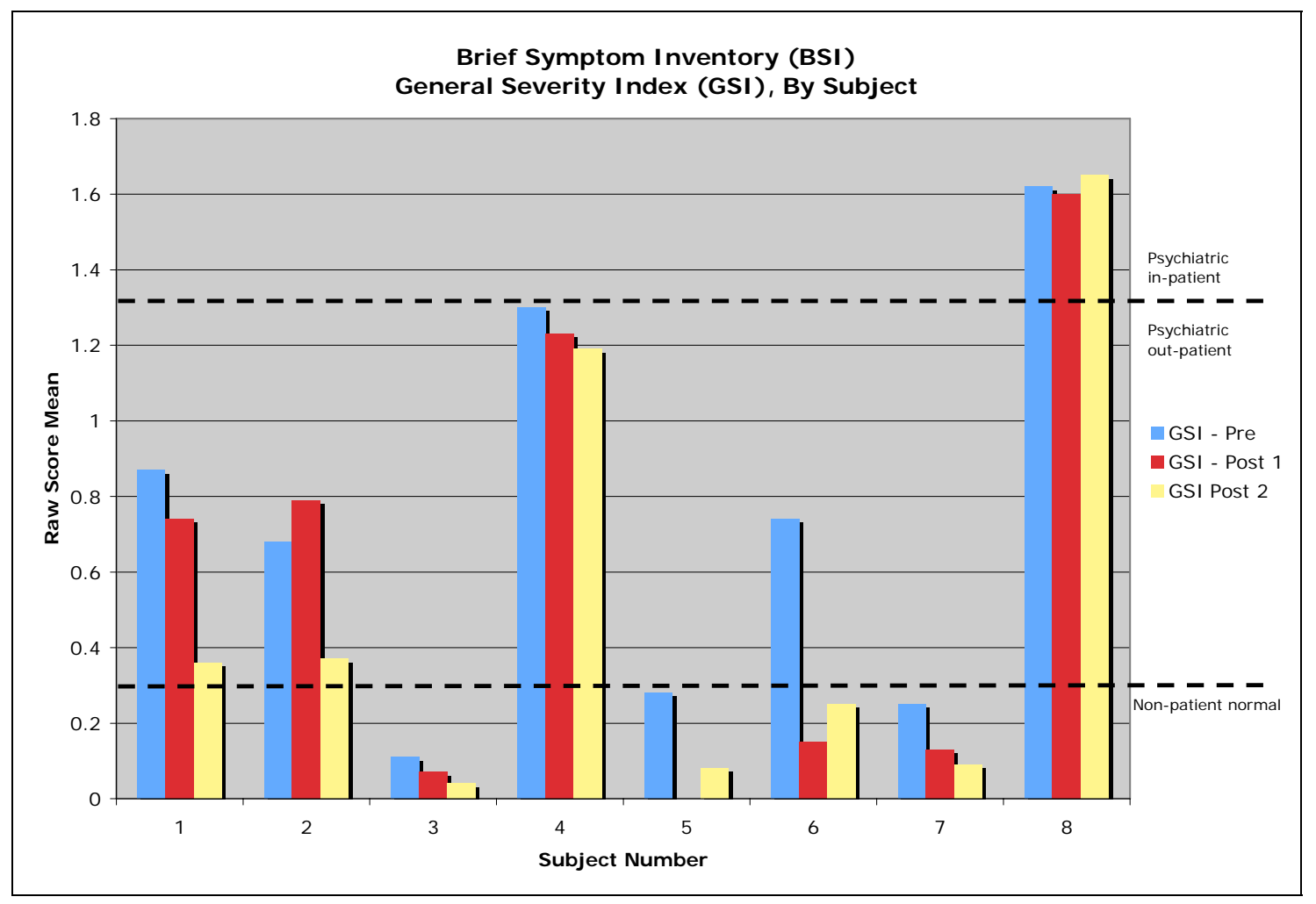

Figure 3. Results, by subject, for the General Severity Index (the summary index that represents the level of distress of the participant) of the Brief Symptom Inventory for the HIV study. Only the one subject who tested initially as a psychiatric in-patient showed no change from the MCT intervention.

\section{Morgantown High School Program}

A program evaluation of 90 -minute MCT seminars offered to all the students at Morgantown High School in Morgantown, WV, in Spring, 2006, indicates that, 
even under difficult learning conditions, the majority of students respond favorably to the message of MCT (Figure 4). The seminars were set up during 90-minute study hall periods, for as few as 80 to as many as 120 mixed $9^{\text {th }}$ through $12^{\text {th }}$ graders each time (12 seminars in all). Students were sent to one insufficiently large room which was stuffy and uncomfortable. Because of the room configuration, it was impossible to incorporate small group discussions or activities of any sort into the seminars. Once seated, students did not have room to move. And most of the students were not made aware, in advance, that they would lose their study hall time. PowerPoint equipment was available but did not always function well and not all the students could see the PowerPoints or the blackboard from the sides of the room.

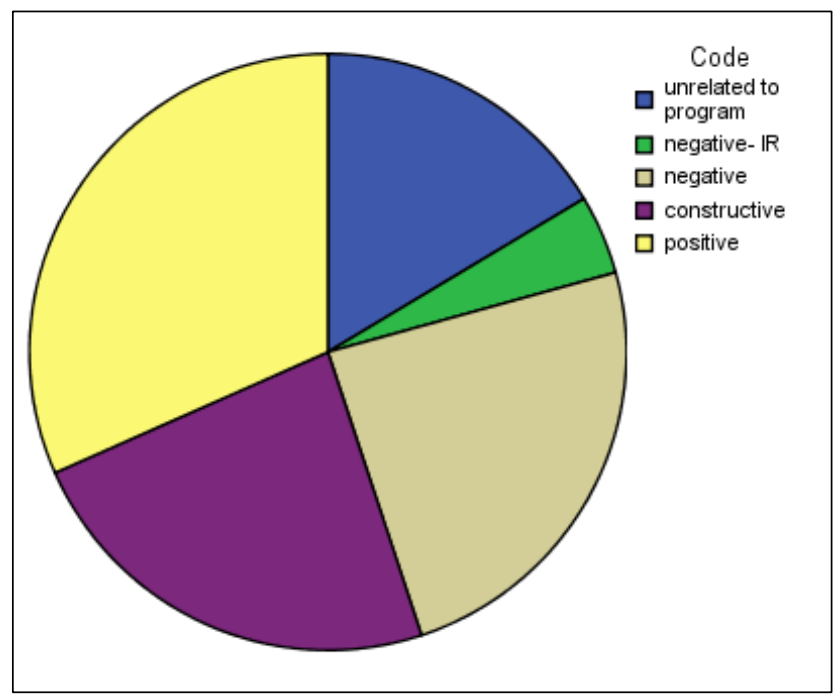

Figure 4. Categorization of student comments on questionnaires after each seminar at Morgantown High School ( $n=806)$. For more detailed explanation, see Appendix F). Note that positive and constructive responses represent the majority of responses. "Unrelated to program" refers to comments, such as "Save the whales!" that bore no relationship to the program. Not all students made comments on their questionnaires. 
One of the surprising outcomes of the seminar is that only a small fraction of students wrote negative comments about the circumstances of the seminar (labeled Negative IR - green slice - in Figure 4). Another surprising outcome was the response students gave to the statement on the questionnaire: "The presenter showed respect for students," where the average was 4.2 out of a possible 5 (Table 2). This is not as much a statement about the person presenting the seminar as it is about the milieu in which MCT is presented; the assumption is "no one is damaged goods" and "everyone has innate health in them." A number of students commented that this was a novel and welcome idea.

An interim report describing only the student and teacher surveys (Appendix F) was presented to school officials. A majority of students offered unconditionally positive, or positive-constructive comments on their program evaluation forms $(n=806)$ which led to a decision to follow up with one of the most frequent constructive recommendations from students, that the MCT model be taught to peer counselors at the school because students are more likely to benefit from it when it is presented by their peers in the context of teen-age life. In 2006-07, MCT was shared in-depth with the high school's peer counselors, so that the peer counselors would be able to train future peers and intervene from this perspective consistently. 
Table 2

Results of Student Evaluations

$\begin{array}{lrrrrrr} & & \text { Question 1 } & \text { Question 2 } & \text { Question 3 } & \text { Question 4 } & \text { Question 5 } \\ \text { N } & \text { Valid } & 785 & 790 & 789 & 789 & 787 \\ & \text { Missing } & 22 & 17 & 18 & 18 & 20 \\ \text { Mean } & 2.539 & 2.844 & 4.224 & 2.887 & 2.591 \\ \text { Median } & 2.000 & 3.000 & 5.000 & 3.000 & 2.000 \\ \text { Std. Deviation } & 1.1152 & 1.1645 & 1.0973 & 1.1720 & 1.3146 \\ \text { Minimum } & 1.0 & 1.0 & 1.0 & 1.0 & 1.0 \\ \text { Maximum } & 5.0 & 5.0 & 5.0 & 5.0 & 5.0\end{array}$

The full questionnaire can be seen in Appendix F. Question 1 was "The program held my attention and made sense to me. Question 2 was "The examples and stories helped me get the point. Question 3 was "The presenter showed respect for students." Question 4 was "This program helped me understand why people get upset and how people calm down." Question 5 was "I think programs on this topic should be presented to students every year." The likert scale went from 1-not at all to 5completely. Not all students answered all questions; not all students made comments.

The student questionnaire will be improved if it is used again: Question 1 was ambiguous, since it linked two ideas which may not, in the students' minds, have been linked. And question 5 was unclear, since some students interpreted it to mean that they would receive the same program each year through all four years of high school and some interpreted it to mean what was intended, that every Morgantown High School student would be exposed to this program.

Evaluation would have been improved, as well, if students were asked to give their grade level. It appeared to the presenter that $9^{\text {th }}$ and $10^{\text {th }}$ graders were less responsive to the program than $11^{\text {th }}$ and $12^{\text {th }}$ graders.

Teachers were asked just prior to and 5 weeks after the program concluded how often they observed students fighting/engaging in hostile or dangerous conduct and how often they observed students in emotional reactions. They were also asked a 
series of 3 Likert-type items (internal consistency $\alpha=.57$ ) regarding the level of stress present in their school (e.g., "How would you rate your stress level when you are dealing with upset students?"). School-wide attendance and referral rates were collected for time periods covering 53 school days prior to and following delivery of the program. Means (standard deviations) indicate small non-significant decreases in each of these teacher and school-wide measures (See Table 3).

Table 3

Teacher and School-Wide Measures Before and After Program Implementation

Item/Scale

About how many times in the past 5 weeks have you observed students fighting or engaged in conduct that you consider hostile or dangerous?

About how many times in the past 5-weeks have you observed students in emotional reactions?

On a scale of 1 to 5,1 being never stressed at all and 5 being stressed most of the time, how would you rate the stress level among your students?

On the same scale, how would you rate your stress level when you are dealing with upset students?

On a scale of 1 to 5,1 being never and 5 being most of the time, how often do you observe that students have the ability to calm down and regulate their own behavior?

Percentage (across 53 school days) of students absent

Number of Disciplinary Referrals during 53 school day period

\section{Pre Post}

$2.49(4.6) \quad 2.14(2.3)$

$6.18(6.7) \quad 5.23(5.8)$

$3.29(0.6) \quad 3.26(0.6)$

$3.14(0.7) \quad 2.94(0.9)$

$2.83(0.6) \quad 2.74(0.8)$

7.44(1.7) 7.16(1.6)

$200 \quad 102$

NOTE: Numbers in parentheses are standard deviations. 
These data were presented in a poster presentation to the Hawaii International Conference on Education in January, 2008. by Dr. Reagan Curtis, who was the Principal Investigator for the study. The data do not allow the conclusion that the program impacted these variables, but they do give reason for optimism. Each student participated in a single workshop in less than optimal teaching/learning conditions and yet there was a consistent break across multiple measures indicating change occurring concurrent with the time at which these workshops occurred.

Developing and presenting this program provided invaluable learning in preparation for developing programs for Nursing freshmen.

\section{Research Questions}

This study proposed to address stress in nursing students from the unique inside-out perspective of MCT, raising the question of whether the MCT understanding offered on-line within the structure of an established curriculum will reduce students' experiences of stress and anxiety and enhance their natural sense of well-being. A pilot study to ascertain the likelihood that students would elect to participate in an on-line intervention was conducted in 2006 with students in the College of Engineering at WVU; the pilot was not replicated with nursing students.

An on-line MCT module embedded in a freshman nursing course was studied. The research questions were:

1. A. Does the MCT intervention offered on-line change the general level of well-being of participants as measured by the SF-36 administered pre- and post- the intervention? 
B. Does the control group show no change in general level of well-being over the same testing period?

2. Do changes in well-being as measured by the SF-36 Mental Health Scale following the MCT intervention correlate with changes in the PATCS?

3. What is revealed about lurking variables from the Focus Group interviews and evaluation comments that may account for data and evaluations? 


\section{Chapter Three}

Method

"What is our life but an endless flight of winged facts or events? In splendid variety these changes come, all putting questions to the human spirit."

Ralph Waldo Emerson

\section{Participants}

Participants for this study were drawn from the freshman class at the West Virginia University School of Nursing. Criteria for participation in the study were that participants must be registered students in the pre-nursing program on the WVU Morgantown campus and must be 18 years old or older.

The study was conducted with freshman students in Nursing 110, for whom the Ex-Stress module was integrated into their course and was the required unit of study on the subject of stress. Participation in research of the module was completely voluntary and a decision not to participate would not affect their grade or class standing, although 15 extra credit points were awarded to those who completed the research questionnaires. There were 150 students enrolled in Nursing 110 in Fall, 2007; it was anticipated that as many as 100 of them would choose to be in the research cadre. The Nursing 110 students received a 45-minute face-to-face lecture to introduce the module and explain the navigation of the on-line activities before the module opened to them (Appendix H, p. 204) Students in Nursing 110 who were $<18$ years old were advised to opt out of the research because of the inclusion criteria for the study. Demographic data were checked when study data were entered to be sure 
that no participants under 18 were included and all participants who were not 18 years old when the study started were eliminated from the study.

A second group, the control group, was drawn from pre-nursing students on the Morgantown campus identified as pre-nursing but not yet enrolled in Nursing 110, which is offered in both the Fall and Spring semesters to accommodate the large number of interested students. These participants were administered the pre- and posttests on-line on the same schedule as the Nursing 110 students on the Morgantown campus, but received no intervention. Freshman students who agreed to participate in the research as the control group were not exposed to the module from the web-site during the fall semester; it would be part of their course work in the spring semester, when they take Nursing 110. The e-mail link to the control group surveys was sent to nearly 200 students. The assumption was that, if the study results were positive, the fact that the module is built into Nursing 110 in the Spring semester would address the intent-to-treat issue.

All students in the control group who met the research inclusion criteria and submitted the full series of questionnaires received a $\$ 15$ Morgantown Mall gift certificate. Students in the treatment group who elected to participate in the research and complete the series of questionnaires received 15 bonus (extra-credit) points for their course. It should be noted that all students in Nursing 110 were exposed to the Module, since it was a study unit in their course, and all students were expected to discuss it in discussion groups and questions from it were included in their regular examinations. The Ex-Stress Yourself module was assigned as a unit within the course; therefore, participation in it was not presented as optional to the students. 
Only participation in the research, i.e., answering the pre- post- and post-post questionnaires, was optional.

\section{Hypotheses}

There were three main hypotheses for this study:

1. Students who complete the on-line module Ex-Stress Yourself, will experience increased levels of well-being and less stress as measured by the SF-36 (Appendix D) and the PATCS (Appendix G).

2. The control group will show no significant change in well-being and stress as measured by the SF-36 and the PATCS between pre- and post-tests.

3. Results for the PATCS will correlate with results for the SF-36.

\section{Design}

The study is a mixed methods study. One arm of the study is a collaborative program evaluation, with the lecturer and course coordinator for Nursing 110, the Chairperson for Health Promotion/Risk Reduction in the WVU School of Nursing, and the researcher acting as an evaluation team (Patton, 1997), involved in planning, conducting, and analyzing the evaluation. The qualitative pilot study with engineering freshmen conducted in Spring 2006 (Sedgeman, 2006), coupled with in-depth discussions with senior nursing faculty and a trial lecture with Nursing 110 students (Appendix I) in April, 2007, served as the initial needs assessment.

Evaluation design took place between January and July, 2007. Because the preand post-testing, including the qualitative research component, took place on-line, the 
design phase included meetings with several representatives of the Office of Information Technology (OIT) at West Virginia University, and the assignment of an OIT technical advisor to assist with development and testing of the on-line research process. The research phase began in August, 2007, and was completed by midDecember, 2007.

The collaborative evaluation was to be based on an evaluation questionnaire (Appendix J) embedded in the VISTA 4 Learning Management System, known as eCampus at WVU, and administered on-line to students who accessed Ex-Stress Yourself. In addition, at least two and up to five focus group interviews were to be conducted with students who volunteered for them within a few weeks after the final post-tests. The focus group interviews were to take place in on-line chat rooms, discussion boards, or Horizon Wimba Live Classrooms. The students would have signed up for the focus groups on an electronic calendar that would allow them to select dates and times and automatically limit each group to seven members. Focus groups were to be conducted by the seminar presenter, and electronic records preserved.

The second arm of the study was a non-experimental repeated measures design using the SF-36 Health Survey (Appendix D) and the Pettit Attachment to Thought Content Scale (PATCS) (Appendix G). These tests would be administered to participants pre-, post- and six weeks post- the Ex-Stress Yourself intervention.

The SF-36 is well-validated and used nationally and internationally with both lay groups and patient groups (Ware et al., 2005). The QualMetrics Corporation, which 
distributes the test instrument, gave permission for the test to be incorporated in the on-line assessment tool within the eCampus course (Appendix K).

The PATCS is an instrument in development by the West Virginia Initiative for Mind-Consciousness-Thought. The PATCS is not validated. It has been used with the Brief Symptom Inventory (BSI) (Derogatis \& Melisaratos, 1983) in a study of the effect of an Mind-Consciousness-Thought Seminar on HIV positive patients (Sedgeman \& Sarwari, 2006), as well as other programs at WVU and elsewhere. Although data from the PATCS have not been published, they did correlate relatively well $(r=.78)$ with the BSI (see Figure 5) in the HIV study, despite the small number of participants and the inclusion of one outlier. The Brief Symptom Inventory was not used in this research because the publisher would not grant permission for it to be administered on-line.

Correlation data are available to show relationships between the SF-36 and many other measures of mental and physical well-being, but the SF-36 has not been correlated with the BSI. The SF-36 does correlate well with other highly regarded global health and well-being measures, such as the Sickness Impact Profile and the Duke Health Profile (Ware et al., 2005). The SF-36 has not been used previously with the PATCS. 


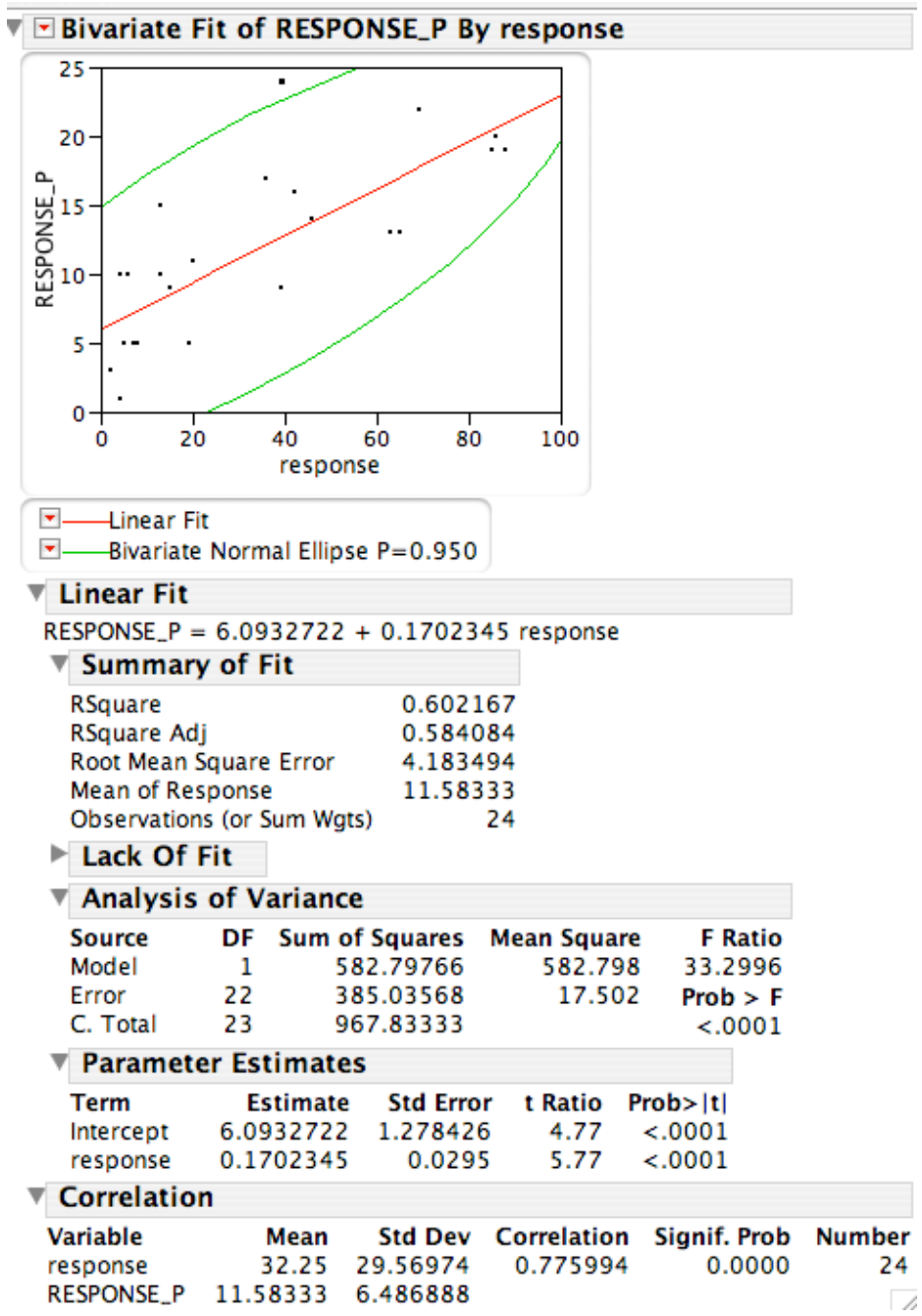

Figure 5. Correlation of BSI (X-axis) and PATCS (Y-axis) scores from a 2005 pilot study of the MCT intervention with HIV positive patients $(n=8)$.

Both the PATCS and the SF-36 were embedded into the eCampus module, with release criteria set within the course to match the research design. That is, when students entered the course, they opened to a Getting Started section which offered them the research information (Appendix L) and the choice to take part or not. The release of the learning material in the module was conditional upon their choice at that point. Those who chose not to take part in the research were sent directly into the 
learning module. When they completed the learning module, they did not receive the research questionnaires, but were directed to the module assessment. For those who chose to take part in the research, the pre-test assessment opened as soon as they submitted their choice. They were then asked to enter demographic material (Appendix M) and follow instructions to create an ID code that was repeated each time they entered the testing or evaluation. The ID code was not connected with their name in the recording or storage of information from the assessments and evaluations but was used to track comparative information by participant.

Submission of the pre-tests then sent them into the course material. They were informed that they could elect to drop out of the research at any time, and if they wished to drop out at any point during the assessments, they could do so by clicking "Submit." Incomplete data would automatically be dropped from the study.

Both the SF-36 and the PATCS rely on participants' honest self-report regarding their perceptions of their own health and their state of mind, and both use a five-point likert scale, so that participants would not find them confusing taken contiguously.

The SF-36 is a 36-item test developed in the early 1990s. At the suggestion of the publisher, this research used Version 2, the most current version, for which scoring information and validation information are available (Ware, Kosinski, \& Dewey, 2000). The publishers provided normative data for the general U.S. population $(\mathrm{n}=2,474)$, as well as break-downs of normative data by gender and by age groups. The norms of primary interest for this study are those for Males and Females ages 18-24 $(\mathrm{n}=173)$ and ages 25-34 $(\mathrm{n}=474)(\mathrm{pp} .10: 14-10: 16)$. Normative 
data are provided for the global score on the SF-36 as well as for each of the 8 subscales. The subscales refer to:

1. Physical Functioning (PF) (10 items)

2. Role Physical (RP) (4 items)

3. Bodily Pain (BP) (2 items)

4. General Health Perceptions (GH) (5 items)

5. Vitality (VT) (4 items)

6. Social Functioning (SF) (2 items)

7. Role Emotional (RE) (3 items)

8. Mental Health (MH) (5 items).

In addition, there is one unclassified item called "Reported Health Transition.”

The SF-36 has been found suitable for repeated measures testing. Its authors (Ware et al., 2005) provided tables of sample sizes needed to obtain results for a "non-experimental two-group study with repeated SF-36 measure," indicating the need for an approximately 20\% larger group for a non-experimental design than for an experimental design. The sample sizes are broken down by sub-scale and by the number of points difference that can be detected (pp. 7:12-7:13). Given a sample size between 50 and 100, the SF-36 used in this study can reliably detect 10-point differences between the study sample and the norm on all sub-scales; it would require a sample size close to 400 to detect 5-point differences on all sub-scales, although the General Health Scale (sample size 132) and the Mental Health scale (sample size 
104) could be relied upon to detect 5-point differences in this study with the anticipated participant sample sizes.

The Mental Health scale is described as the "flagship" measure of mental health in the SF-36 scoring material (p. 9:11). The "undesirable outcomes" it measures are:

- Dissatisfaction with Life

- Depressive Symptoms

- Diagnosis of Depression

- Suicidal Ideation

- Mental Health Care (inpatient or outpatient).

These SF-36 Mental Health indices are useful measures for this project because they cover a range of issues that are often typical of individuals who are experiencing difficulties in adjustment to situations in life, such as responding to demands and performing competitively in a challenging professional course of study. They are also symptoms that are linked to chronic stress in the literature (Sapolsky, 2004b). An improvement in these symptoms would indicate an increased state of well-being and diminished experience of stress.

The PATCS was chosen for this study because it was designed by long-time MCT practitioner Dr. William Pettit to address habits of thinking that are typical of chronic stress and that are intended to be alleviated by the MCT interventions.

The PATCS asks participants to rate the degree to which they experience themselves caught up in the following types of thinking:

1. Worry (thinking about what-if's to the point of finding it hard to act in the face of uncertainty); 
2. Guilt (thinking about remorse over past behavior);

3. Resentment (thinking about being hurt by what others have done);

4. Upset (thinking about things that aren't the way you wanted them or expected them to be);

5. Unresolved Grief (thinking about losses with which you have not come to peace);

6. Fear (thinking about danger or harm);

7. Driven-ness (thinking about having to work hard to live up to an idea of what you feel you need to be);

8. Analysis (analyzing things to the point of confusion - going over and over the same thoughts in your mind).

In addition, the PATCS asks participants to rank the degree to which they experience thoughts about external challenges and internal stress.

The PATCS is currently in validation in a study for which Dr. Pettit and the author are co-investigators. Anonymous data from this research will be included in that study, for which IRB approval has already been obtained.

\section{Materials}

Supplementary materials that could be downloaded or accessed on-line from the Ex-Stress Yourself module include videotapes, audio lectures, papers, and books. The materials are all linked through the Extra Resources icon in the Ex-Stress module. The learning module elements could be printed directly from the course for review, as well. 
The topic headings and a list of related materials for the seminar are outlined in Appendix N.

\section{Data Maintenance}

Completed SF-36 and PATCS instrument data were stored on discs in the locked research files at the West Virginia Initiative for Innate Health, accessible only to the researcher and her assistant, who reviewed the original data entry in Excel spreadsheets. Data were downloaded directly into Excel from both treatment and control groups, the former via the Assessment Tool in eCampus, the latter via SimpleForms through WVU Web Administration. The researcher transferred the data to SPSS for evaluation. Once the data were entered into SPSS, the researcher reviewed each entry, to assure accuracy. Computerized data was accessible only by password of the authorized parties.

Focus group discussions were to be preserved electronically. The original transcriptions and all research notes would be kept in locked files. Anonymity of participants would be preserved in the dissemination of findings.

\section{Procedure}

Once the study plan was approved, an expedited IRB proposal was submitted for the program evaluations for the on-line module and the seminar. Once IRB approval was received, the study was set up in Nursing 110. The on-line module appeared on the eCampus web-site for Nursing 110 in the Fall 2007 semester. Data 
were collected and input as it was generated within the module and from the control group. The data collection period closed at the end of the fall semester.

The treatment for this study was a principle-based psychoeducational on-line course module called Ex-Stress Yourself, designed to eliminate stress and nurture strength, resiliency, and confidence. The module was developed specifically for Nursing students based on the facilitator's more than 20 years of experience presenting Mind-Consciousness-Thought seminars and on the feedback generated from a pilot study conducted in 2006 with Engineering students. For example, all of the students interviewed for the pilot study reported having difficulties with stress in the preceding year, but most of the students in the pilot study ultimately arrived at individually appropriate common sense ways to pull themselves out of stress. Yet for all of them, getting over stress was a struggle, and, when they did feel better, it appeared to them to be a serendipitous event. These reports led the researcher (Sedgeman, 2006) to conclude:

All the students I interviewed had very wise and healthy perspectives on stress and resiliency and demonstrated their own innate health and wisdom again and again. They just didn't have the framework of understanding from which to realize it and build on it. ... These students are living at the effect of their negative thinking because they do not recognize that they truly are the engineers of their own experience, not the products of inexplicably bad engineering! (pp. 15 16)

The research flow chart for this module is shown in Figure 6. 
$T$
00
0
0
0
0
0
0
0
0
0
0
0
00
0

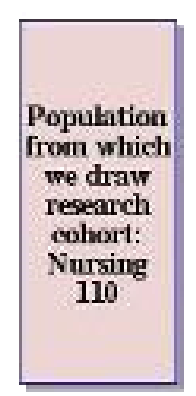

$$
\begin{aligned}
& \text { Population } \\
& \text { from which } \\
& \text { we draw } \\
& \text { control } \\
& \text { groupc pre- } \\
& \text { mursing } \\
& \text { stndents on } \\
& \text { Morgantown }
\end{aligned}
$$

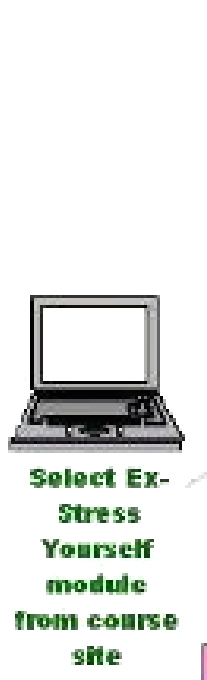

sife

pre-tes?

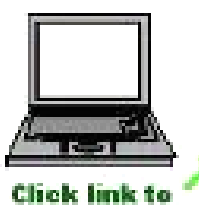

Assessmeints

when

prompted by

e-mail
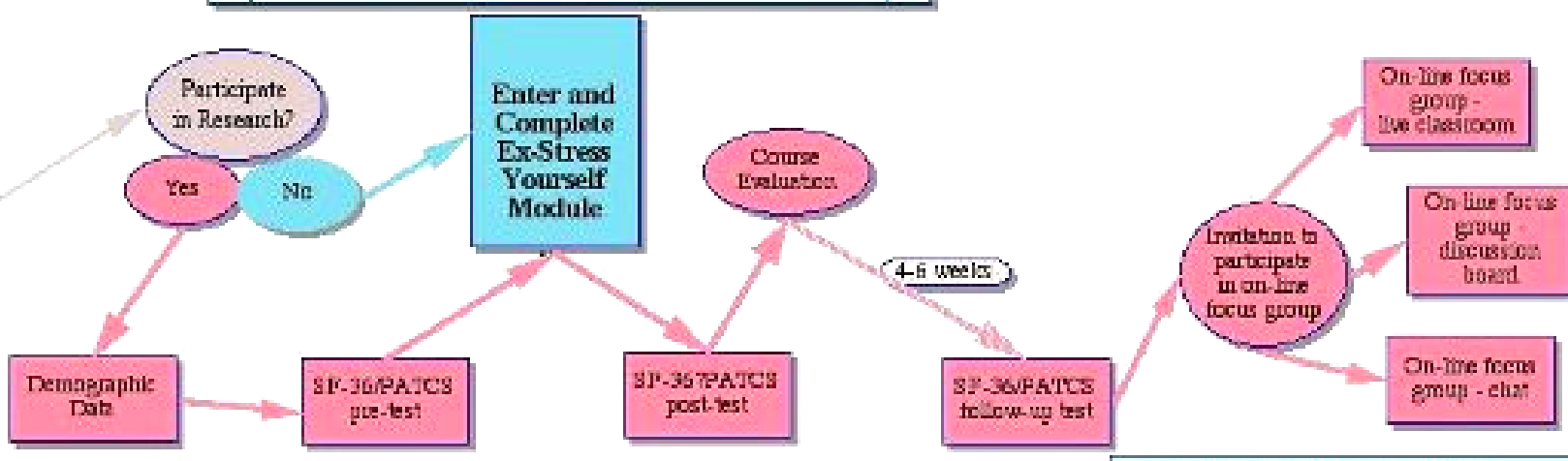

si-36reatcs

\section{Research Plan}

Effect of Health Realization/Innate

Health On-Iine Module on stress and

Well-Being in Freshman Nursing

students

Judith A. Sedgeman, M.A

Data to be collected

\section{Quantrtative}

1. Demosaplitic tuformantion

8F-36n RTCS pre-kest:sentre

SF-36nim $\alpha$ TLS pas:-test reault

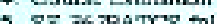

6. Trese speut in $\&$ mimber of vatt to matul: Qualrtative

Qualitative

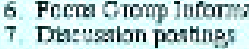


The On-Line MCT Module was called 'Ex-Stress Yourself' because it points participants to their own internal resilience and ability to bounce back from upsetting thinking/experiences. It was designed specifically to include case examples and questions relevant to nursing and to nursing students. The module poses questions that help participants to consider how things look different to them in different states of mind. Participants then follow brief case examples, followed by learning points and questions for reflection. Participants completing the module were directed to the post-tests and the evaluation form when they submitted the last learning assignment.

When the evaluation form opened, students were once more informed that their reports and module assessments would be evaluated anonymously in the qualitative arm of the study if they signed up to participate in research, and that their responses would be kept anonymous. They would be given an electronic link to the sign-up calendar if they indicated they wished to participate in focus groups.

The pre- and post-test data and module evaluations were downloaded from eCampus by the researcher. In addition, data provided in standard eCampus tracking reports that document the number of visits and time spent each visit in the parts of the module were downloaded. These data were of interest, since it is worthwhile to learn how long students take to complete the module, if they revisit certain sections, how much time they spend on various learning activities. But these data were not intended to be part of the analysis since all students have different learning styles, and the variables that might lead students to spend more or less time in a module are irrelevant to the potential impact of the learning. These data have implications primarily for pedagogical and course-design evaluations. 
The foundation of the Module, as all MCT interventions, was an understanding of the Principles of Mind, Consciousness, and Thought and the insideout nature of life. The objective of the module was for participants to realize that they think, and how thinking works to create our moment-to-moment reality, with its shifting moods and perceptions of events. It focused on presenting the inside-out paradigm in a simple, direct way with examples relevant to students and to the professional life of health practitioners.

The lecture given to students in Nursing 110 the week the module opened was not about the Principles, but set the stage for the students to understand the significance of the module by presenting the history of stress research and the current literature linking stress to physical, as well as psychological and spiritual, well-being. Because it was offered to the class in advance of them entering the module, with opportunity for questions and answers, the lecture did not address the implications of the inside-out paradigm and innate health. The research plan to test the on-line module as an educational experience precluded lecturing about the MCT approach specifically. Doing so could have affected student responses on the pre-tests and changed the nature of the study.

A question this study was intended to begin to answer is whether a brief, selfdirected module focused primarily on the Principles embedded within an existing course is a sufficiently effective way to transmit the Mind-Consciousness-Thought intervention so that it does impact well-being and performance.

The logic model for the study is shown in Figure 7 on the following page. 


\section{Procedure}

Mind-Consciousness-Thought module is incorporated in Syllabus for Nursing 110 and posted as a link in the Nursing 110 eCampus site.

Students in Nursing 110 receive lecture.

Nursing 110 students are given access to enter module and choose yes or no to research.

Pre-tests are administered on-line to control group via a link provided in a Mix e-mail.

Nursing 110 students complete final assignment and submit to discussion board.

Post-tests are administered on-line to control group via a link provided in a Mix e-mail.

All participants are immediately directed to post-tests of SF-36 and PATCS when they submit the final discussion posting.

All participants and control group receive instructions about accessing 6-week follow-up assessments via e-mail. Students who complete all assessments receive 15 bonus points from Nursing.

Participants receive invitation to participate in Live Classroom or Chat Room focus group(s).

Focus groups held on-line as scheduled.

Figure 7. Logic model for Ex-Stress Yourself.

\section{Timing}

August, 2007

As scheduled by instructor, early in September, 2007

No takes them directly to the learning material; yes takes them to assessments.

Coordinated with Nursing 110 schedule

According to syllabus instructions

Coordinated with Nursing 110 schedule

Mid September, 2007

Six weeks after completing the first follow-up, completed by mid-November, 2007

Immediately after completing 6week SF-36 and PATCS followup

Late November, 2007 
Analysis

There were two separate analyses planned. The first, the program evaluation, required only straightforward compilation of data, entered by ID code. Students' responses to the on-line module evaluation would be recorded and compared.

A distribution would be created showing the means and standard deviations of responses to evaluations for the treatment group. In addition, qualitative data would be analyzed for trends or insights and the response data will be triangulated with the quantitative material.

The repeated measure SF-36 Health Survey was to be analyzed using MANOVA applied to the SF-36 subscales. Across the eight subscales of the SF-36, an initial Multivariate Analysis of Variance (MANOVA) would be computed. This initial MANOVA would protect against "experiment-wise error rate" and allow subsequent tests of the individual scales as dependent measures without inflating Type I error. Accordingly, the independent variable in this MANOVA would be the testing occasion (pre, post-, and six-week follow-up). The dependent variables would be the eight subscales of the SF-36.

If this MANOVA were to yield a significant $F$ ratio, the eight individual ANOVAs would be tested at the $p<0.05$ level of significance, using the same independent variable. The dependent variables in these eight ANOVAs would be the eight subscales of the SF-36. Additional ANOVAs would be computed for the global SF-36 scores for General Health and Mental Health, the two indices for which results are most meaningful in this study. The Mental Health index of the SF-36 would be correlated with changes in the PATCS scores. 
The PATCS does not have a validated and normed scoring mechanism at this point, so PATCS results were simply recorded and noted. PATCS results were to be correlated with the SF-36 Mental Health scores as part of the ongoing validation of the PATCS, which is part of a different research project.

Qualitative information from participant comments and from the focus groups would be analyzed and reported. The purpose of the qualitative analysis was to discover what difference, if any, the MCT intervention made to students and to discover what other means of help/support they found important during the semester, as well as to explore how they think the intervention could be improved.

A chart showing the research questions, variables, measures to be used, and methods of analysis is shown as Table 4. 
Table 4

Research Questions, Variables, and Analysis

\section{Research Question}

1. Does the MCT intervention change the general level of wellbeing of participants as measured by the SF-36 administered pre- and post- the intervention?

\section{Variables}

MANOVA

IV = test occurrences (pre-, post-, and 6-wk follow-up)

DV = SF-36

subscales and global scores

ANOVA

IV = test occurrences

DV = SF-36

subscales and global scores

2. Do changes in wellbeing as measured by the SF-36 Mental Health Scale following the seminar correlate with changes in the PATCS?

3. What is revealed about lurking variables from the Focus Group interviews and evaluation comments that may account for data and evaluations?

\section{Method of Gathering Data}

SF-36 scores, prepost- and follow-up downloaded from eCampus and obtained via e-mail return.

\section{Method of Analysis}

MANOVA and ANOVA
IV = Change in SF-36 Mental Health scale scores pre-, post-, and 6-wk follow-up; DV $=$ Change in PATCS scores over same times.
SF-36 scores at pre-, post- and 6-wk post; PATCS scores at same intervals downloaded from eCampus and obtained via e-mail return.

\section{Student responses;} evaluation comments; focus group discussions.
Focus Group and individual discussions with students who took the seminar; review of evaluations.
Review interviews and evaluations and other data; triangulate data
Correlation 


\section{Chapter Four \\ Evaluation}

That which we must learn to do, we learn by doing.

Aristotle

Nicomachean Ethics II

\section{Procedure}

Institutional Review Board approval for the study (H-20283) was received on July 26, 2007.

The study began with the introductory one-hour lecture (Appendix H) offered to Nursing 110 on October 3, 2007. This lecture explained the relevance of understanding the nature and implications of stress to health and well-being, and focused on the importance to health professionals of recognizing how to maintain their own common sense and peace of mind, regardless of circumstances.

Additionally, it included a PowerPoint series to walk students through the mechanics of the Ex-Stress Yourself module and show them how to make the choice to participate in the research. In accordance with the research plan, the lecture did not address Mind-Consciousness-Thought in depth, but created a context for realizing the significance of one's state of mind in professional and personal life, explained the operation of the module, and requested their participation in the research.

Ex-Stress Yourself, embedded in Nursing 110 as a self-contained SCORM (Sharable Content Object Reference Material) unit ${ }^{4}$ (Appendix N), opened to students

\footnotetext{
${ }^{4}$ This means that the unit is transferable between learning modules. That is, it can be moved, as an intact, self-contained module, between courses and learning management systems that are SCORMcompliant. This provides the capacity to use this unit in different courses and different contexts, as well as to sustain its integrity as distinct and unique within the course. It is like a "course within a course."
} 
on the day on the day of the lecture. It remained open through the rest of the fall semester. The pre-test questionnaire embedded in it was set so that it opened immediately upon students clicking "yes" after reading the research information (Appendix L), and the module evaluation and post-test opened as the last clickable windows in the learning module. Because of the nature of eCampus, knowledgeable students could also access the pre-test directly from the Assessment tool in the course, without entering the module. Students were asked not to do that because of the requirements for disclosure before participation in research.

Also, on the day of the Nursing 110 lecture, the first pre-test e-mail was sent through the student e-mail system to WVU Freshmen identified as pre-Nursing. Students who wished to participate clicked a link in the e-mail (Appendix O), which took them to a SimpleForm questionnaire that they could complete and submit online. The SimpleForm questionnaire (Appendix P) remained open for three days, which was the amount of time estimated for most Nursing 110 students to have accessed the module and taken the pre-test. Ten days after the pre-test opened, which was the day the Nursing 110 students had been assigned to complete the stress unit, the post-test link was e-mailed to the control group (Appendix O). The post-tests were open to control group participants for three days.

On November 15, 2007, the Nursing 110 students were sent an e-mail by their instructor informing them how to take the six-week post-test and reminding them to do so if they had agreed to participate in the research. The instructor also announced 
it in class on November 17, 2007, emphasizing the importance of follow-up repeated measures to a researcher and reminding them to click the link in her e-mail to take the study. The post-post test for Nursing 110 was also a SimpleForm, not an assessment in the course, since it was expected that compliance would be better if students could click it open directly from the reminder, rather than having to re-enter the module to take it. The link to the post-post-test was e-mailed to the control group population at the same time. For both the treatment and control groups, the post-post-tests were timed to remain open for five days.

The Nursing 110 students, the treatment group, were informed by e-mail of the availability of focus group discussions of Ex-Stress Yourself at the same time. They were asked to e-mail the researcher directly to be included in an on-line focus group.

Although adequate numbers of responses to support the research plan were received for the study from each administration of the research instruments, analysis of the data revealed inadequate numbers that matched the study criteria, from test to test. The study design required that respondents be matched by ID code, and also that all respondents be at least 18 years of age when the research began, and that questionnaires be completed in full. When responses were matched for those criteria, the actual number of responses that could be included in the study was very small. No one filled out the module evaluation. No one in the treatment group volunteered to participate in the Focus Groups, the qualitative arm of the study. The researcher later learned that the students had been expected to participate in class discussion groups of Ex-Stress Yourself at the time the unit was being studied. Students apparently did 
not recognize that the Focus Groups with the researcher were different from the class discussion groups in which they had already participated. Also, there were no additional points offered for participation in Focus Groups. The researcher did not attend the discussions groups within the course and was not aware of them until after they had taken place.

The total response rates and the response rates for matches on the research inclusion criteria are shown in Table 5. When the data were analyzed, most of the respondents were dropped from the study because of no ID match, incomplete questionnaires submitted with too few questions answered for analysis, or respondents not meeting the age requirement.

Nursing 110 students were awarded 5 bonus points by the instructor each time they completed one test instrument. The researcher sent 25 mall gift cards to students in the control group who matched by ID code and submitted the three study questionnaires before realizing that 12 of them either were not 18 years old at the time the study began or had not fully completed one or more of their questionnaires and had to be dropped from the analysis.

Table 5

Responses and matched responses to the pre- and post-questionnaires

\begin{tabular}{|c|c|c|}
\hline Test Instrument & Nursing 110 - Treatment & WVU Freshmen - Control \\
\hline Pre & 110 & 95 \\
\hline Post & 87 & 94 \\
\hline Post-post & 50 (19 matched) & 53 (13 matched) \\
\hline Invitation to Focus Group & 0 & $\mathrm{n} / \mathrm{a}$ \\
\hline
\end{tabular}


Table 6 shows the original procedure approved for this research, with departures from procedure noted in bold italic, and actual dates of events included. There were three course instructors, and the researcher had to make adjustments to suit their needs and the timing of other course components. The instructors decided to award the 15 bonus points for participation in the study, five at a time, each time a student completed the survey because of the operation of the internal course grade book. The exact six-week follow-up, the post-post test, fell during Thanksgiving week because of the instructors' decision that the stress unit worked most naturally within their syllabus the first week in October, rather than earlier, in mid-September, as originally planned. The instructors preferred that follow-up questionnaires be completed before students left for Thanksgiving and asked that the follow-up be scheduled starting November 17, one week earlier than the actual six-week time period. 
Table 6

Planned and actual procedures

\section{Procedure}

Mind-Consciousness-Thought module is incorporated in Syllabus for Nursing 110 and posted as a link in the Nursing 110 eCampus site.

Students in Nursing 110 receive lecture.

Nursing 110 students are given access to enter module and choose yes or no to research.

Pre-tests are administered on-line to control group via a link provided to their instructor.

Nursing 110 students complete final assignment and submit to discussion board. Actual: Students are asked by the instructor to participate in inclass Discussion Groups on the module rather than posting.

Post-tests are administered on-line to control group via a link provided to their instructor.

All participants are immediately directed to post-tests of SF-36 and PATCS when they submit the final discussion posting.

All participants and control group receive instructions about accessing 6week follow-up assessments via e-mail. Students who complete all assessments receive 1 hour community service credit from Nursing. Actual: 15 bonus points for course

Participants receive invitation to participate in Live Classroom or Chat Room focus group(s).

Focus groups held on-line as scheduled.

\section{Timing}

August, 2007

As scheduled by instructor, early in September, 2007

Actual: October 3, 2007

No takes them directly to the learning material; yes takes them to assessments.

Actual: October 3, 2007

Coordinated with Nursing 110

schedule

Actual: October 3-6, 2007

According to syllabus instructions Actual: October 10, 2007

Coordinated with Nursing 110 schedule

Actual: October 10-13, 2007

Mid September, 2007

Actual: October 10-13, 2007

Six weeks after completing the first follow-up, completed by mid-

November, 2007

Actual: November 15, 2007

Immediately after completing 6-week SF-36 and PATCS follow-up. Actual: By invitation issued verbally and by e-mail by the course instructor.

Late November, 2007

Actual: No response; none scheduled.

Despite some departures from the original plan, the procedure was generally

followed. The instructors later reported that they were satisfied with the students' inclass discussions of the stress unit. They reported that the class performed satisfactorily on the questions from the unit they had incorporated in the mid-term 
exam. They were surprised and puzzled by how few students successfully completed the research. When the research plan was created, the instructors expressed confidence that the majority of students in the class would participate in the research because they felt that students would welcome help with stress, and because research is strongly emphasized in the nursing program at WVU as an important contribution to the health care field.

\section{Sorting the Data}

When an initial data analysis was performed to match subjects after the preand first post-tests, the researcher recognized that some ID codes that did not match were very close. For example, one digit or letter would be off in a six-digit code, or the first five digits would match but there would be no sixth digit in one of the codes. Because names of the respondents were in the initial information set (to provide for mailing the gift certificates to control group participants and for the grade book so points could be awarded in Nursing 110), the researcher applied to the IRB for permission to match responses by names and make code corrections if exact name matches were found, before discarding names from the research data being kept for analysis. When that permission was granted, on October 16, 2007, the matches were conducted, and an initial 12 subjects were added to the treatment group and 7 subjects were added to the control group from name matches. Nonetheless, when the data were further analyzed, after the post-post-test, for birth date and completion of questionnaires, a number of responses had to be discarded and the final number of study participants remained small, 19 in the treatment and 13 in the control groups. 
Realizing how few Nursing 110 student responses were available for the treatment group study, and that none of the students had filled out the module evaluations or volunteered for the focus group discussions, the researcher asked for permission to speak with the whole Nursing 110 class and was granted a half-hour on November 28, 2007. By this time, as finals were approaching, the instructors felt pressure to get through the remaining class material and said that was all the time they could spare.

The researcher asked four questions (Appendix Q) and was only able to take a rough hand-count of responses to some of them. Attendance at the class appeared to be about $2 / 3$ of the original attendance observed on the first meeting with the class in October. The instructor accounted for the attendance by the fact that students tend to drop out of Nursing 110 if they discover early-on that nursing may not be for them, and by the fact that it was late in the semester.

To the question: "Did you find the Ex-Stress Yourself module personally helpful?" about half of the students present tentatively raised their hand to indicate yes. It appears that social desirability may have been a factor in that response since they all knew the researcher was the creator of the module. Five students raised their hand to indicate no. The remainder did not respond.

To the question of whether the layout and placement of the tests within the module made it harder to complete them, 10 raised their hand to indicate yes. Most of the others raised their hands to indicate no.

To the question of why participants dropped out of the research, one person raised his hand to "lost interest in it," no one raised a hand to "too hard to do," no one 
raised a hand to "objected to the questions," three people raised their hands to "wasn't sure how to submit questionnaires," and two people raised their hands to "other." Most offered no response to this question.

The remaining time was used for soliciting answers to "What could I have done to make this a better experience for you?" The researcher asked only for verbal comments from students who were willing to speak out, since there was not sufficient time to collect written comments, which might have provided more information.

One student who said he had dropped out of the research said there was "too much reading" and there were "too many questions." One student said she had not taken the post-test because "when I looked at it, the questions were exactly the same as the pre-test. I had already just taken it, so I didn't understand why I had to take it again." Several other students indicated their agreement with her about that.

One student said that being part of the research "involved a lot of work we weren't required to do to pass the course, so why do it?" That, too, brought forth assenting remarks from several other students. Another said "the last five points weren't worth the effort."

At the time of the class visit the researcher brought paper forms of the postpost-test, pre-addressed so they could be folded and returned via campus mail to the researcher, and asked any students who had taken the pre- and post-tests and would be willing to take the post-post test on paper to pick up one of the paper forms, complete it, and return it through campus mail. None was returned to the researcher. 


\section{Review of Usage Information}

To explore the actual student engagement with the Ex-Stress module and try to understand the results more clearly, the researcher visited the course Tracking Tool in Nursing 110. A review of that information casts extreme doubt on the usefulness of any of the treatment group data. From a class of 150, fewer than 10 visits were recorded to most of the critical learning elements of the module (Table 7). Threequarters of the visits averaged about 40 seconds on each element of the module that was visited. It must be said that it would be impossible to know if there were a treatment effect from this research because there really was no treatment. Most of the class never even entered the actual intervention. Looking at the number of visits per module element is generally more meaningful than looking at time statistics, since students can open a page and leave the computer up and running while distracted with something else, so the time count is not a reliable indicator. Also, students can use time printing material from a course, and there is no way to track whether they ever read what they printed. But in this case, the combination of very few visits for very brief times for every segment of the module except the post-test is informative.

The learning module introduction, "How can this module help you," which was visited only 14 times, advised students to take their time, and stop to reflect on each element of the module. But course statistics show that the few students who entered the module worked quickly through the sections of Ex-Stress Yourself, and it seems that fewer than 5 actually visited almost every element in the learning module (Table 7). This suggests that an on-line module incorporated in a class for freshman 
students early in the semester is not an effective way to transmit meaningful personal information to them.

It is tempting, looking at Table 7, to conclude that 1-4 students went through the entire module, but it must be remembered that these statistics only count the number of times the pages were opened; they do not distinguish whether the same person opened a page several times, or several individuals visited a page. So it is actually conceivable that only one student completed the module and visited several pages three or four times. The important conclusion is that the number of visits per page of the module make it stunningly clear that almost all the approximately 100 students who participated in the pre- and post-tests did not enter the module at all between tests. The highest number of visits per page was 122, to "Ex-Stress Yourself," which is the opening page of Getting Started, a personal, narrated greeting from the instructor, and the first mention of the kind of reflective learning experience the module represents. The average time per visit for that page is 20 seconds; the narration is a little more than 2 minutes long.

A confusing statistic is the small number (25) counted in this table as entering the pre-test, although there were 110 responses to the pre-test recorded (Table 5). The reason for this is that a larger number of students entered the pre-tests through the Assessment tool in the course, even though they had been advised not to do that, rather than through the link internal to the module. Those visits were counted separately in the course Tracking tool as "Assessment" visits. This indicates that the majority of students took the pre-test without reading the research instructions in the SCORM module, which means that the majority of students who took the pre-test 
never read the letter informing them of their rights as a participant. That letter is item 5, "Research info", which received only 4 visits. Thus, even students who did participate in the research did not do so as informed subjects.

Another statistic that would indicate none of the visitors took the module to heart is the average times per visit for items 13 and 21, which are both cartoon animations that, when played all the way through, last more than 5 minutes. The average time per visit for the 9 visits to item 13 was 1 minute, 45 seconds, and the average time per visit for the 4 visits to item 21 was 57 seconds.

The pattern of visits to the module suggests that the demand of the intervention might have appeared daunting to students who looked at the left-hand menu of pages and did not enter the introductory material or browse the module sufficiently to learn that the module contained video and audio materials, animations, and case stories, to make it an enjoyable and personalized learning experience. It suggests the need to introduce the module differently, and to arrive at a better balance between incentive and demand. 
Table 7

Report of Visits and Average Time Per Visit: Ex-Stress Module Components

\begin{tabular}{|c|c|c|}
\hline Ex-Stress Yourself Module Pages & $\begin{array}{l}\text { Number } \\
\text { of visits }\end{array}$ & $\begin{array}{l}\text { Average time/visit } \\
\text { (hours:minutes: } \\
\text { seconds) }\end{array}$ \\
\hline 1 Ex Stress Yourself & 122 & $0: 00: 20$ \\
\hline 2 How to find my office & 2 & $0: 00: 03$ \\
\hline 3 Things you need to know & 3 & $0: 00: 13$ \\
\hline 4 How to approach the module & 5 & $0: 00: 18$ \\
\hline 5 Research info & 4 & 0:00:07 \\
\hline 6 Survey:Ex-Stress_Pre-Test_inclusive & 25 & $0: 01: 10$ \\
\hline 7 How can this module help you & 14 & $0: 00: 22$ \\
\hline 8 Student Case Study-Julie & 11 & $0: 00: 29$ \\
\hline 9 What is in this module? & 10 & $0: 00: 27$ \\
\hline 10 Some Common Questions & 10 & $0: 02: 16$ \\
\hline 11 Things people face & 11 & $0: 00: 21$ \\
\hline 12 Student Case Study - Carl & 8 & $0: 00: 28$ \\
\hline 13 Outside-In versus Inside-Out (animation) & 9 & $0: 01: 45$ \\
\hline 14 Principles & 8 & $0: 01: 23$ \\
\hline 15 Principles in action & 5 & $0: 00: 55$ \\
\hline 16 Case Study - Sam & 7 & $0: 00: 38$ \\
\hline 17 Innate Health & 6 & $0: 00: 44$ \\
\hline 18 State of Mind & 6 & $0: 00: 38$ \\
\hline 19 Case Study - Susan & 4 & $0: 01: 06$ \\
\hline 20 State of Mind Chart & 4 & $0: 00: 44$ \\
\hline 21 Recognizing Secure and Insecure Thinking & 4 & $0: 00: 57$ \\
\hline 22 Knowing how we create stress & 3 & $0: 01: 06$ \\
\hline 23 Using your feelings as a guide & 3 & $0: 00: 38$ \\
\hline 24 Case Study - Missy & 2 & $0: 00: 34$ \\
\hline 25 Why... a rollercoaster? & 3 & $0: 00: 14$ \\
\hline 26 What if I'm out of control? & 4 & $0: 00: 32$ \\
\hline 27 Am I OK if I'm sad? & 4 & $0: 00: 52$ \\
\hline 28 Why is it easier sometimes? & 6 & $0: 00: 16$ \\
\hline 29 Case Study - Pat & 4 & $0: 00: 30$ \\
\hline 30 If upsetting things are happening? & 4 & $0: 00: 37$ \\
\hline 31 Just can't pull myself together ... & 6 & $0: 00: 57$ \\
\hline 32 Leaving thinking alone & 6 & $0: 00: 19$ \\
\hline 33 Not take low mood thought to heart & 4 & $0: 00: 27$ \\
\hline 34 Trust wisdom & 4 & $0: 00: 23$ \\
\hline 35 Something to Remember & 8 & 0:00:09 \\
\hline 36 One Thought & 7 & $0: 00: 23$ \\
\hline 37 Rely on Innate Health (narration) & 6 & $0: 01: 10$ \\
\hline 38 About the stress post test & 51 & $0: 00: 53$ \\
\hline Survey:Ex-Stress Post-Test_inclusive & 74 & 0:03:04 \\
\hline 39 Principles Lecture (35-minute video) & 22 & $0: 04: 25$ \\
\hline 40 Happiness (paper) & 2 & $0: 02: 18$ \\
\hline 41 How To Study (podcast) & 4 & $0: 00: 37$ \\
\hline 42 Innate Health Crossword & 2 & $0: 00: 56$ \\
\hline 43 Less Stress, More Joy (paper) & 1 & $0: 34: 23$ \\
\hline 44 Principles Paper & 1 & $0: 00: 10$ \\
\hline 45 Spiritual Power is Not Willpower (paper) & 0 & $0: 00: 00$ \\
\hline 46 Recommended books and articles & 1 & $0: 00: 02$ \\
\hline 47 Other Web Sites (links) & 1 & 0:00:01 \\
\hline 48 Ex-Stress Yourself Chat Room & 1 & 0:00:04 \\
\hline
\end{tabular}

Items are arranged in the order intended for them to be viewed. The section "Getting Started", which students were told they must enter and complete first, before proceeding to the main learning module, is highlighted at the beginning. Extra Resources, which students were told contained additional material which might be of interest to them if they found the unit helpful, is highlighted at the end. 
Table 8 shows the minimum, maximum, and mean time per visit for the individual frames that could have been opened in the module (Appendix N). It should be noted that the mean time statistic is skewed by the fact that one of the total 48 visits to the module was to the pamphlet Less Stress, More Joy, provided as a link, for 34 minutes. The person accountable for that visit e-mailed the researcher and expressed thanks for the Ex-Stress module, saying she had found that particular part of it especially helpful and had downloaded it to keep and share. If that one lengthy visit, the only outlier, is removed from the analysis, the average time per visit (Table 9) is 47 seconds. As mentioned, some of the pages in the module were flash animations or links to video or other presentations, which, if viewed completely, would have taken anywhere from 2.5 minutes for the brief narrated pages to 35 minutes for the longest, a video lecture on the Principles. Once the outlier is removed, the maximum time spent on any visit, including completing the pre- and post-test questionnaires, is 4 minutes, 25 seconds.

\section{Table 8}

Average mean times per visit including outlier

\begin{tabular}{lrrrl}
\hline & Number & Minimum & Maximum & Mean \\
$\begin{array}{l}\text { Average Time per } \\
\text { Visit }\end{array}$ & 48 & $0: 00: 01$ & $0: 34: 23$ & $0: 01: 29$
\end{tabular}

Table 9

Average mean times per visit with outlier removed

\begin{tabular}{lrrrl}
\hline & Number & Minimum & Maximum & Mean \\
Average Time per & 47 & $0: 00: 01$ & $0: 04: 25$ & $0: 00: 47$ \\
Visit & & &
\end{tabular}




\section{Data Analysis}

The primary research instrument for this study was the SF-36, which is a comprehensive well-being test widely used in the U.S. and abroad. A major factor in selecting the SF-36 was the publisher's willingness for the instrument to be set up in an on-line research process (permission that could not be obtained from publishers of other instruments under consideration). Another important factor was the information provided in the SF-36 manual supporting the instrument's validity for repeated measures testing (Ware et al., 2000). A third important factor was that sections could be broken out from the SF-36 for analysis that were particularly relevant to this study: Questions 9 b, c, d, f, and h, representing "Mental Health" along with Questions 9 a, e, g and i, representing "Vitality." These question sets, representing the psychological well-being of participants, can be grouped and scored separately for analysis (Ware et al., 2005). These are also the question sets that were of interest in terms of correlating the responses to the SF-36 with the other instrument, the PATCS, which was to be studied, since it is designed to evaluate mental/emotional health.

The determination to focus only on the Question 9 subsections of the SF-36 was made because the remaining questions of the health survey include physical health and well-being. It was anticipated that, since the study group was composed of college freshmen, there would be a significant negative skew to these responses as few, if any, of them would likely be experiencing "difficulty climbing stairs" or "carrying groceries."

A power analysis (Appendix R) conducted with the computer program GPower in advance of the study indicated that, to achieve a p-value $<.05$ with a $95 \%$ 
Confidence Interval for the tests planned for this study and an effect size of .5, the sample sizes shown in Table 10 would be required:

Table 10

Sample sizes needed for tests, from power analysis

Test

MANOVA, repeated measures, between factors MANOVA - global effects

One-tailed t-test between two dependent means

\section{Sample Size}

54

42

45

The matched sample sizes actually produced in this study fall far short of those required for the statistical methods planned. In addition, MANOVA and ANOVA assume a normal distribution of data. The distribution of the data in the samples achieved for this study are skewed, not normal. (Table 11).

Table 11

Distribution of responses, Mental Health sub-section of the SF-36

\begin{tabular}{|c|c|c|c|c|}
\hline $\begin{array}{l}\text { control(0) } \\
\text { trt (1) }\end{array}$ & & $\begin{array}{c}\text { Pre (SF-36, } \\
\text { Q 9) }\end{array}$ & $\begin{array}{l}\text { Post (SF- } \\
36, \text { Q 9) }\end{array}$ & $\begin{array}{c}\text { PostPost } \\
\text { (SF-36, Q } \\
9 \text { ) }\end{array}$ \\
\hline $\mathrm{N}$ & & 13 & 13 & 13 \\
\hline \multicolumn{5}{|l|}{$\begin{array}{l}0 \\
\text { Control }\end{array}$} \\
\hline \multirow[t]{5}{*}{ Group } & Mean & 3.12 & 3.74 & 3.67 \\
\hline & Std. Deviation & .344 & .644 & .535 \\
\hline & Variance & .118 & .414 & .286 \\
\hline & Skewness & -1.062 & -2.062 & -.360 \\
\hline & Std. Error of Skewness & .616 & .616 & .616 \\
\hline 1 & $\mathrm{~N}$ & 19 & 19 & 19 \\
\hline \multicolumn{5}{|l|}{ Treatment } \\
\hline \multirow[t]{5}{*}{ Group } & Mean & 3.61 & 3.64 & 3.61 \\
\hline & Std. Deviation & .456 & .492 & .558 \\
\hline & Variance & .208 & .242 & .312 \\
\hline & Skewness & -.132 & -.422 & -.973 \\
\hline & Std. Error of Skewness & .524 & .524 & .524 \\
\hline
\end{tabular}

The range of responses is $1-5$, with 5 representing the most positive response. 
For a normal distribution, the skew would be 0 . In this case, the results are negatively skewed, meaning that response frequencies are clustered to the right of the distribution, in the higher range of scores.

The analytical methods anticipated in the research plan for this study could not be used with a sample size far too small to achieve the desired power, and a skewed distribution. The researcher must conclude that the original plan failed and the data set obtained is not useful for MANOVA and ANOVA testing either between factors (answers to each question) or between groups.

One can look at the means charts (Table 12) and see, without analysis, that the treatment and control groups are not far apart, and that the pre- post- and post-post scores do not differ appreciably.

Table 12

Means on PATCS and SF-36 (Question 9) for treatment and control groups

\begin{tabular}{llll}
\hline Group & Pre & Post & Post-Post \\
PATCS Control & 3.80 & 3.90 & 3.90 \\
PATCS Treatment & 3.40 & 3.70 & 3.70 \\
SF Control & 3.40 & 3.70 & 3.60 \\
SF Treatment & 3.60 & 3.60 & 3.60
\end{tabular}

Research question 1, "Does the Mind-Consciousness-Thought intervention change the general level of well-being of participants as measured by the SF-36 administered pre- and post the intervention?" could not be answered by the statistical methods contemplated in the research design. The application of less powerful non- 
parametric methods, such as the Mann-Whitney $\mathrm{U}$, which is recommended for small sample sizes, was considered and revealed the statistics shown in Table 13.

Table 13

Non-parametric tests for significance

\begin{tabular}{|c|c|c|c|}
\hline Test & $\begin{array}{l}\text { Pre (SF-36- } \\
\text { Q9) }\end{array}$ & $\begin{array}{l}\text { Post (SF- } \\
\text { 36-Q9) }\end{array}$ & $\begin{array}{l}\text { PostPost (SF- } \\
\text { 36-Q9) }\end{array}$ \\
\hline Mann-Whitney U & 42.000 & 101.000 & 119.500 \\
\hline Wilcoxon W & 133.000 & 291.000 & 309.500 \\
\hline Z & -3.146 & -.868 & -.154 \\
\hline Asymp. Sig. (2-tailed) & .002 & .385 & .877 \\
\hline $\begin{array}{l}\text { Exact Sig. [2*(1-tailed } \\
\text { Sig.)] }\end{array}$ & $.001(\mathrm{a})$ & $.404(a)$ & $.880(a)$ \\
\hline
\end{tabular}

a Not corrected for ties.

The tests are non-significant for the post- and post-post tests, which would be indicative of the response of the treatment group as compared to the control group following the intervention. Thus, and not surprisingly, even non-parametric methods applied to these samples do not reveal significance in responses to research question one.

Looking at the skewness of the samples, however, it is clear that the population that (a) completed the three questionnaires, (b) followed the instructions for creating an ID code, and (c) met the age criterion for inclusion, fell generally into the category of good mental health, low stress, and high vitality, both in the control group and in the treatment group. The treatment group never elected to enter the intervention, so there was no treatment effect to measure. The responses the treatment group gave in the follow-up meeting suggested that the bonus points offered by the instructors were insufficient motivation to complete the research component of the 
Ex-Stress Yourself module, and that those who self-selected out of the research simply found the process arduous or not in their own interest.

The data might lead to the conclusion that the students in the treatment group who were stressed did not benefit from the unit and did not find a sufficient level of well-being to go ahead with the study. The tracking data do not support that conclusion, since so few students even entered the unit. Yet the responses of the Nursing 110 class to the question of whether they found the unit personally helpful, and the feedback from instructors about both the quality of the student discussion groups and the success of the class with mid-term questions related to the module, create ambiguity about any conclusion. Ultimately, because the course data from the unit (Table 7) How that very few of the students could have visited the learning material in the course, any conclusion about the treatment group is impossible. The fact that the control group members and the treatment groups members who managed to complete the study were very close to the same level of mental health, and that about the same number of treatment group members as control group members submitted questionnaires at each step of the way confirm that factors other than the intervention itself influenced participation in the research.

\section{Correlation of PATCS with SF-36}

The second research question to be considered was whether changes in wellbeing as measured by the SF-36 correlated with changes in the Pettit Attachment to Thought Content Scale (PATCS). The small matched sample size, coupled with the insignificant changes, make this correlation analysis meaningless. In addition, the 
PATCS category "Upset" was inadvertently dropped from one of the treatment group tests, so the PATCS analysis does not include all of the questions on the test. The term "Upset" could not be included in the final analysis.

It can be noted that there were minimal changes in the PATCS means between pre- post- and post-post tests and that the subjects fell into the category of generally mentally healthy (scores higher than 3) on the PATCS likert scale as well as on the SF-36 scale.

The comparison is visually obvious in Figures 8 and 9, which show how little change there was between the three tests with either group.
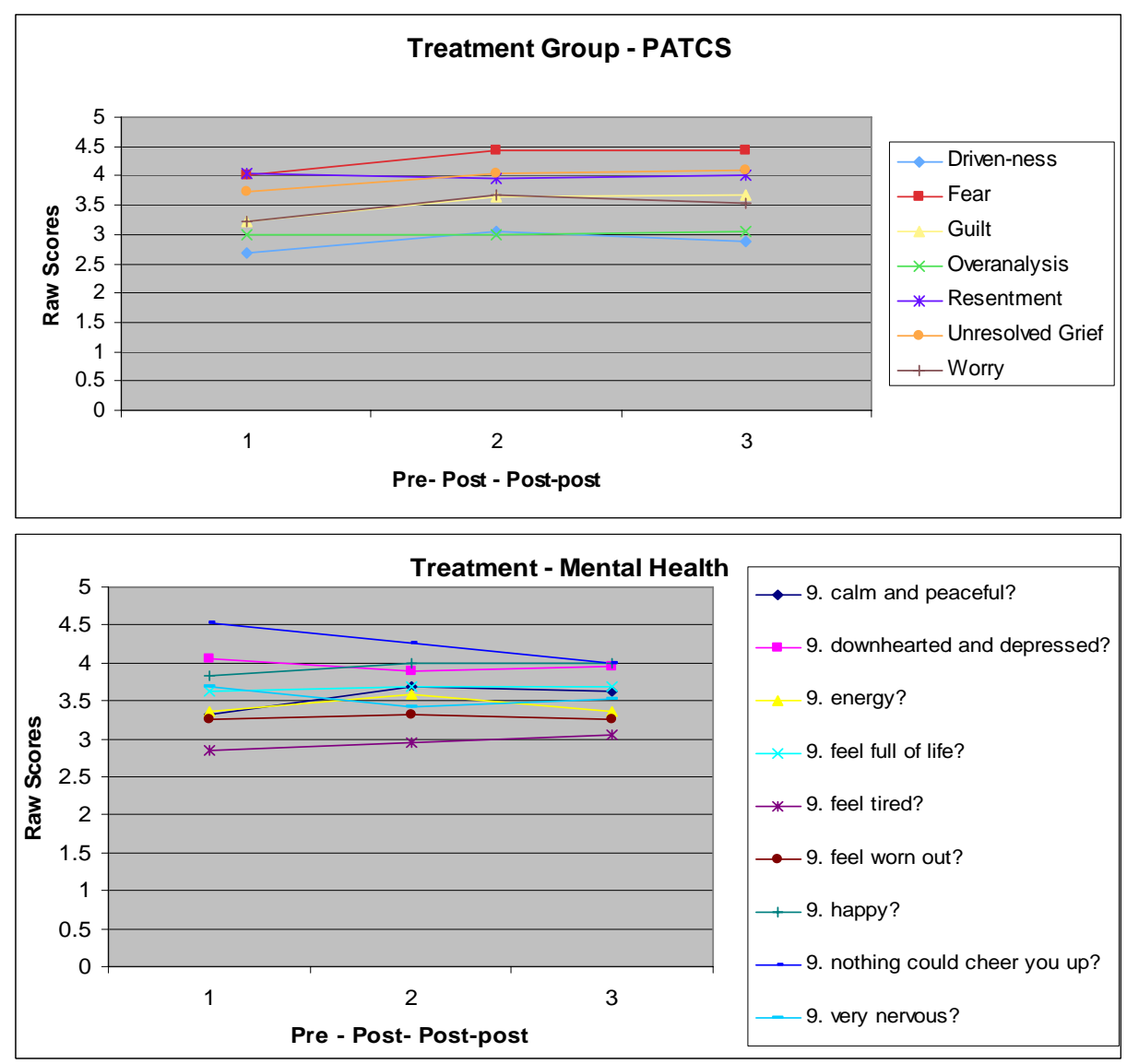

Figure 8. PATCS and SF-36 Mental Health Scale Treatment Group Means 

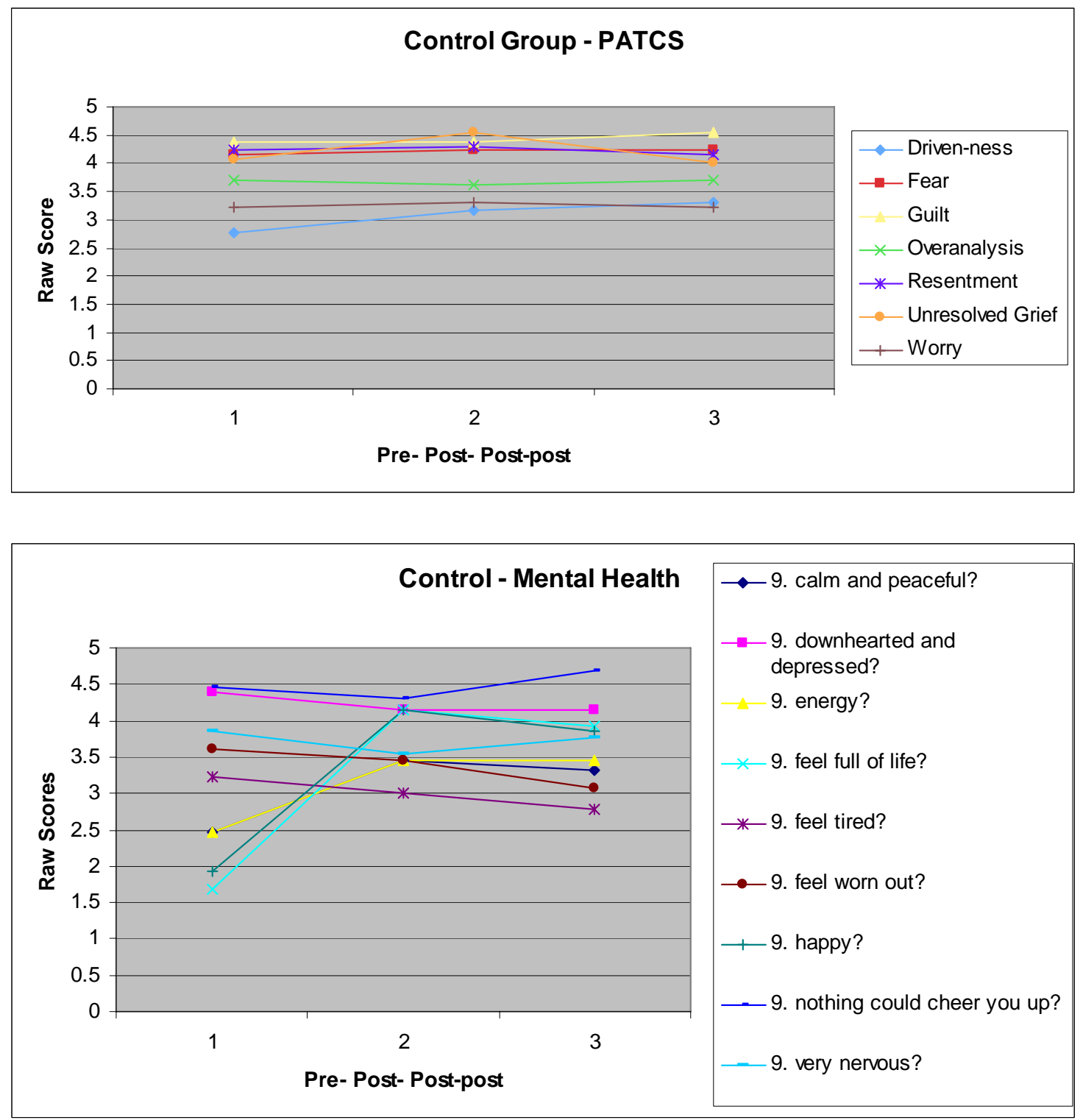

Figure 9. Control group Means, PATCS and SF-36 Mental Health scale. The relatively low scores on "feel full of life," "have lots of energy" and "feel happy" on the pre-test seem to be an anomaly. Although they cannot be explained, the pre-tests were administered to the control group of students during the days immediately following the WVU football team's crushing loss to the University of South Florida.

The research hypothesis was that changes in the PATCS would correlate with changes in the SF-36. Using the Pearson correlation (Table 14), significance was not 
achieved. There was no correlation at $r=.04$ between the six PATCS and SF-36Question 9 means, representing the pre-, post- and post-post tests for both groups.

Table 14

Correlation of PATCS and SF-36

\begin{tabular}{rlrr}
\hline \multirow{2}{*}{ PATCS } & Pearson & PATCS & \multicolumn{2}{c}{ SF36 } \\
& Correlation & 1 & .036 \\
SF36 & $\mathrm{N}$ & 6 & 6 \\
& Pearson & & \\
& Correlation & .036 & 1 \\
& $\mathrm{~N}$ & 6 & 6
\end{tabular}

\section{Lurking Variables}

Since no one from the treatment group signed up to participate in focus groups following the post-post tests, the only sources of information regarding lurking variables were the brief meeting with the class as a whole and the conversations with instructors about their observations. Variables that affected participation in the research identified though these informal methods were:

- Length of research instrument

- Insufficient motivation/reward

- $\quad$ Timing of the post-post tests (close to vacation and heavy school pressures) An additional and absolutely the most critical lurking variable is the level of interest/involvement of the treatment group in the actual intervention, which course statistics suggest was less than minimal, since $63 \%$ of the total time spent accounted for within the learning module was the average 3 minutes 109 students spent taking the embedded post-test. The unit was designed for students to spend 1 to 3 hours, 
total, in the learning material, depending on how many of the links they selected to follow. Course data suggest that students took the pre- and post-tests without paying attention to the module content. This cannot be taken as a judgment about the module, however, since the usage statistics for other on-line content of Nursing 110 were similar in the Fall 2007 semester. It appears that the Nursing 110 students did not generally put a lot of time into on-line course assignments.

\section{Conclusions}

Only two conclusions can be drawn from analysis of the data from this study. First, freshman pre-nursing students at WVU in Fall, 2007 who were willing and able to complete pre-, post-, and post-post tests according to the instructions in both the treatment and control groups were at the outset, and remained, in generally good mental health. Second, those in the treatment group were not inclined to undertake this on-line assignment. 


\section{Chapter Five \\ Discussion \\ Truth comes out of error more readily than out of confusion. \\ Francis Bacon \\ Novum Organum (1620)}

In order for this project to succeed, two critical conditions needed to be met: (1) the level of well-being indicated by the pre-tests would be low enough to leave room for significant change, and (2) the same participants who started the research process would stay with it and be identifiable through the post-tests and post-post tests. One critical assumption needed to be met: The treatment group would actually receive the treatment as intended.

In retrospect, nothing in the preparation for the research was done to assure that those conditions would be met or that the research assumption would be achieved. In this instance, the assumption that the intervention would be received was not totally within the control of the researcher because the treatment was presented in a self-directed on-line module embedded in a survey course. Indeed, inherent in both the timing of the research and the presentation of the intervention and the test instruments were elements that actually, in retrospect, set the project up for failure. This chapter explores what went wrong, what can be learned, and how research into Mind-Consciousness-Thought on-line experiences can be approached more successfully in the future. 


\section{Preliminary Planning}

Planning for a dissertation project with freshman students to lower their levels of stress actually began in Fall, 2005, with discussions in the College of Engineering. A qualitative study (Sedgeman, 2006) was completed in April, 2006, after in-depth, hour-long interviews with 8 freshman Engineering students who volunteered that they were experiencing stress and depression. The interviews took place shortly after the students had been notified of their Spring semester mid-term grades. At that point, their future in the Engineering program was at stake, and they were feeling tremendous pressure to succeed. The students indicated a strong desire for help with controlling chronic stress and a real interest in some sort of directed self-study that they could access.

The qualitative pilot study in Engineering predicted the likely value of an online stress elimination module and an interest in it. The College of Engineering had an ideal platform for the delivery of such a module, in a web-site for students called Intensive Counselor that contains a variety of self-help modules to assist students with life, study, and career-planning issues. These modules are assigned in some of the freshman courses, and the researcher was assured that one of the courses would direct students into the Ex-Stress Yourself module to provide a consistent treatment group.

In Fall, 2006, the Ex-Stress Yourself Module created for Engineering students was inserted into the Intensive Counselor series. The plan was that one class of Engineering students would be exposed to an introduction to it with the researcher and then would respond to various requests for discussion postings within the module 
to assure they had actually completed the module. Pre- and post- testing would include psychological tests as well as a review of the first-semester grades for a control group and the treatment group. That plan, however, fell through when the College was unable to recruit a class to serve as the treatment group, and there was no way to track the participation of students who entered the module by choice in Intensive Counselor once a key member of the staff, who had been working closely with the researcher, resigned. The module remains part of Intensive Counselor, but research was not completed.

In Spring, 2007, the research plan was modified after discussion with members of the faculty of the School of Nursing. The Nursing faculty members were interested in the research because they perceived stress to be an important topic for continued study in nursing. The faculty agreed to the development of the module as the new stress component for Nursing 110 after the researcher presented a lecture on Stress, Well-being and Innate Health (Appendix I) to the Spring, 2006, class of Nursing 110. Both faculty and students liked the approach. A completely new on-line Ex-Stress Yourself module, specifically targeted to nursing students, was subsequently created with the help of course developers in the Instructional Technology Resource Center (ITRC).

The Ex-Stress Yourself module was reviewed in late July, 2007, and approved by nursing faculty for inclusion in Nursing 110. It was implemented in August, 2007. Nursing faculty and the researcher believed it would meet an important student need, based on the information about stress in the literature and observations of student stress reported by the faculty. The research was pursued on the presumption, 
grounded in the review of Nursing literature, that Nursing students are as likely to perceive themselves to be as stressed as Engineering students. There was no research that supported the idea that Nursing students would prefer self-directed help with stress, a preference that had emerged in the pilot study with Engineering students.

The research plan was agreed to by the instructors for Nursing 110 in early August, 2007, without much discussion, and the module was originally scheduled for introduction in the first week in September. The instructors reorganized their syllabus right before classes started in mid-August, and the schedule was changed to move the Ex-Stress Yourself project forward one month, from early September to early October.

\section{Preliminary Mistakes}

The pilot project in Engineering establishing the need to address stress was conducted in the Spring semester, at a time when freshman students have confronted the realities of college and experienced the differences between the academic and social demands of college life and the life they had before. So the data that supported the need for the intervention were based on the experience of students in a far different state of mind than entering freshmen in the early fall, who are naïve to what lies ahead and have not yet gone through paper-writing and exams and all of the challenges of college life.

No pilot data were pursued for the actual Nursing student population to be studied, and the assumption that these students just entering a professional survey course would be experiencing similar levels of stress to students who were well into 
their first year of an intense professional course of study proved to be wrong on two counts. The majority of pre-nursing students pre-tested in the early fall did not exhibit high levels of stress. And Nursing 110, an introductory course, was not as academically demanding as courses students would take once they selected the Nursing major.

The literature consulted about stress in nursing students primarily evaluated stress in students already committed to nursing studies, not freshmen pre-nursing students taking an introductory nursing course. Relying on this literature proved misleading because the students in Nursing 110 were taking a broad overview of nursing as a profession, with no actual experience of the academic rigor of the required courses for the major. Nursing 110 is the course that sorts out serious nursing students from those dabbling in the idea of nursing, so it does not reflect the same stress profile, or level of interest in stress as a factor in human health, as might be reflected in students deeper into the Nursing curriculum.

The reorganization of the syllabus, which placed the Ex-Stress Yourself module in a context the instructors felt worked well with the flow of the course, seemed inconsequential at the time. But it pushed the administration of the test questionnaires forward so that the final questionnaires were delivered right before Thanksgiving break at a time when students are both busy and distracted. And it pushed the timing for follow-up focus groups to right before final exams at a time when students are highly unlikely to undertake anything extraneous to their required studies. 


\section{Implementation of the Module}

When the project was first conceived with Nursing faculty, the initial plan was to place Ex-Stress Yourself as a self-contained module onto the Nursing web-site and open it to nursing students and faculty at all levels, promoting it through flyers and appearances in classes. That initial plan, which was similar to the Engineering plan that offered access through a special web-page, proved technically impossible because of the nature of the module and the nature of the Nursing web-site, although the WVU Instructional Technology staff did think it through with the researcher and attempt to arrive at a methodology for it.

It is not possible to put a free-standing SCORM module developed in eCampus onto a web-site that is open to the public. The Engineering web-site, Intensive Counselor, is a closed site, restricted to students enrolled in the College of Engineering at WVU. The Nursing web-site is a public site, open to anyone who accesses the School of Nursing through the WVU web-site. The School of Nursing does not have a general closed site, comparable to the Engineering site, on which a SCORM module could be placed for access only by students and faculty. Course modules must be incorporated only into restricted sites for enrolled students.

Nonetheless, vestiges of the assumptions informing that initial plan for individualized self-selection into the module remained in the plan that was ultimately devised, primary among them the belief that Nursing 110 students would choose to participate because (1) they really need help with stress and (2) they value research and understand the need to follow through with a commitment to it. 
The research was undertaken without pilot data regarding the stress profile of Nursing 110 students or direct understanding of their interest in information about stress. The nursing faculty liked the idea because they needed a new stress module for that course; the researcher liked the idea because there are 150 students enrolled in Nursing 110, a large captive treatment population. There was no consideration that almost all of those 150 students are incoming freshmen, who are not comparable demographically or emotionally to students who are further along in their course of study as true nursing majors. This differentiates Nursing 110 students from the pilot group in Engineering, who had been admitted to the College of Engineering already fully committed to the study of Engineering, and who were well into their second semester when interviewed.

Although the nursing faculty at the WVU School of Nursing expresses dedication to research and promotes student participation in research as an important contribution to the field of nursing, the Nursing 110 class is the first academic exposure to Nursing that students have. As freshmen, they have little idea what is involved in research, and they cannot fairly be expected to recognize or appreciate the time and effort that goes into setting up a research project, or the significance of the decision to participate in one. When the module was introduced to the students at the introductory lecture, they focused on it as an "assignment" for class because, indeed, it was. Although they would get bonus points for participating in the research, the points were not important to them that early in the semester. When the researcher presented the research information to the class, they did not ask many questions about 
it. The only questions asked had to do with whether the module would be covered on their exams. In retrospect, this should have been a red flag.

For the convenience of students, the module was set up with the post-test research questionnaires built into the e-Campus "Assessment" tool, which is the same place that students find their exams. So, while the first research questionnaire, the pre-test, opened up automatically once the student submitted a "yes" answer to participation in the research (Appendix L), the post-test was clicked open as an Assessment. Intuitively, that could have been an impediment to students who generally do not like tests and probably are disinclined to take an optional test. Until they entered the questionnaire, they would not necessarily know that it was not a "test" as such, but simply a repeat of the pre-test research questionnaire.

For students who worked through the module in a brief period of time, which the few who actually entered the learning materials did (Table 7), the post-test also might have seemed pointless. Given the comment of one of the students that it was "the same test she had already just taken," so she did not see any point taking it again, it appears that some of the drop-out of the treatment group between pre- and post-test might be attributable to the proximity of pre- and post-tests, especially for students who spent no time at all in the module, which was intended to take 1-3 hours. This issue might be addressed by randomizing the questions, except for the fact that the SF-36 restrictions do not allow for changing the order of the questions, and, in fact, specifically prohibit it (Ware et al., 2005). Since the SF-36 is well-established for repeated measures testing, this issue did not occur to the researcher at all in advance. However, it may not happen often in the use of the SF-36 that the post-test occurs 
within minutes or hours of the pre-test, as could have happened with the Ex-Stress Yourself module. Additionally, since most of the students had not entered the module and experienced the learning before accessing the post-test, it would be less obvious to them that the purpose of a post-test would be to see whether answers to any of the questions on the pre-test seemed different to them in light of what they had learned.

The module was set up with an assignment for an on-line Discussion Board posting near the end, which was meant to contribute to the qualitative data for the study. Once the class entered the module, that assignment was altered. The course was built around in-class discussion groups of materials studied in the library or online ahead of class rather than on-line postings. Unbeknownst to the researcher, discussions of the module in small groups in class were substituted for posting to the discussion board. Later, this proved problematic because, not only was participation in research focus groups after all the pre- and post-tests timed to occur right before exam week, but also students felt they had already discussed the module in groups once, and saw no reason to discuss it again. Given how little time so few students had spent in the module, as it turned out, they may also have been embarrassed to enter focus groups. Also, there were no further bonus points associated with participation in focus groups; the bonus points were all attached to the completion of the questionnaires.

\section{Control Group}

Concurrent with the students in the treatment group taking the assessments, a control group of nearly 200 freshmen students was sent an e-mail, written by the 
researcher but distributed from the WVU Web-Services office, seeking participation in the sequence of questionnaires. The questionnaires were set up, with help from WVU Administrative Services, as a SimpleForm, an on-line test instrument format developed at WVU for WVU students and faculty. The SimpleForm allows for the kinds of questions on the SF-36 and the PATCS, and the set-up of the questions appeared user-friendly and readable.

The researcher provided the demographic questions to be added at the top of the form, including the six-digit ID code information, using a standard series of identifiers that has been used successfully with several other research projects. Those identifiers were:

- The first letter of your Mother's maiden name

- The second letter of your Mother's maiden name

- The last digit in your social security number

- The day of the month you were born (using a 0 before single digits, as in "06")

- The last digit of the year you were born (for example, if that were 1989, you would supply the number 9).

This code has posed no problem in previous research settings, all of which have been with adults in treatment groups, not with participants in control groups. In retrospect, this code might have been easier for freshmen college students if it asked for the first letter of their Mother's first name. It is possible that some students do not know the term "maiden name" or might not know their mother's maiden name, even so. In an attempt to assure absolute anonymity with obscure digits for a code, this request might have instead created a task too complex for the participants. 
In addition, the SimpleForm (Appendix P) did not supply one box for each item in the code, but rather one big box into which the students had to place the code sequentially. Because so many students either did not create consistent codes, or completely misinterpreted the code request, it seems likely that the way the code was set up and presented was a serious detriment to the study because so many codes were incomplete, contained too few or too many digits, or did not seem in any way related to the instructions.

The demographic information was placed at the beginning of the form because that is the convention followed in previous research of MCT. But, once the data were analyzed, it was discovered that 37 of the 94 post-test students got part-way through the demographics and submitted the form, suggesting they lost interest. Twelve post-test control students skipped the demographics and submitted answers to the questions, which then had to be discarded from the study because they did not match to an ID code or a birth date. There was a strong rate of return on the pre- and post-tests from the control group population, but the majority of the ID codes did not match and many of the questionnaires were incomplete, suggesting the possibility that if the survey had been simpler and quicker, the response rate might have worked out as planned. A large number of control group students entered the surveys; a much smaller number completed the surveys successfully before submitting them.

It is impossible to submit a SimpleForm accidentally, because if the user clicks "Submit" while some questions are incomplete, the form provides a redletter response indicating the incomplete questions and asking "Are you sure you 
want to Submit?" Therefore it must be concluded that the students who submitted incomplete forms deliberately chose to do so. The research instructions told them, as required by the IRB, that they could end their participation at any time, including while taking the tests, by clicking "Submit," as incomplete forms would be dropped automatically from the study. Of the 242 total pre-, post- and postpost tests submitted, only 13 , about $5 \%$, matched on ID and completion criteria.

The Control Group participants were voluntarily responding to an e-mail request, and had no idea why they were answering the questions on the form. Their only incentive was the promise of a modest mall gift certificate to those who completed all three phases of the study. It seems, in retrospect, imperative that the questionnaires should have been as easy and brief as possible to hold their interest. The reward was clearly sufficient to entice a large number of control group respondents to enter the study, but not sufficient to entice a large number of them to work their way through it once they saw what was entailed.

Future studies should use a brief questionnaire that is simple and self-evident to complete. Demographic information would be better placed at the end, and, if ID codes are used as identifiers, individual boxes should be provided for each digit. ID code variables should be intuitive and require no thought to decipher.

\section{Value of the Module}

The module was created with the idea that students would move in and out of it, following the logic of the module sequence, over the course of the week it was being studied. It was expected that they would spend time watching the video 
links and animations, and listening to the narrated segments. It was expected they would understand and follow the instructions that suggested the primary purpose of the module was for their own personal benefit, to realize how their thinking and state of mind works, and how to maintain their own happiness and peace of mind through changing life situations.

This format has been effective in other on-line presentations, but previous successes were with populations who self-selected into the on-line presentations. They wanted to know more about the Principles and were already aware of the idea of the health of the helper and already hopeful that it would benefit them or contribute to their work with others.

In the case of Nursing 110, the students were assigned to the MindConsciousness-Thought module, which represented less than $1 / 10$ of the content material in an entire survey course, in the same way they were assigned to all other course material. As the pre-tests showed, they were not experiencing stress early in October in their first semester. Since stress was not affecting them, the module title may have had limited appeal to them. The few students who did choose to enter the module appear to have browsed it casually, without immersing themselves in it or looking to gain from it through their own reflection on it, as the instructions advised them to do. More students read the instructions than entered the module, according to the tracking report, so they may have concluded that they did not want or need that kind of learning experience.

Nursing 110 students apparently self-selected into the research based on whether it was worth it to them to fill out a questionnaire for 5 extra points. 
Looking at the course tracking statistics, it is very clear that the majority of students who chose to participate filled out the forms pre- and post- module without spending time in the module. The average time spent filling out the posttest questionnaire was 3 minutes, compared to the average time of 44 seconds spent on individual segments of the learning module. Getting points for filling out the forms would offset points they might lose on the test, since they had been told in advance there would be mid-term questions from the module. Since the researcher was not present for the discussion groups held about the module in class, it is not clear on what basis the instructors felt the discussions "went well." In addition, without knowledge of the researcher, the Nursing 110 instructors posted a stress PowerPoint in the course, which was the presentation given as a pilot lecture in April, 2007 (Appendix I) to test whether the instructors and the students in the Spring, 2007 section of Nursing 110 were satisfied with MindConsciousness-Thought content for a stress module. There were 160 visits to that PowerPoint in the treatment group shortly before the midterm, with an average time of one minute- 45 seconds per visit. The instructors may have offered that PowerPoint as a mid-term review. Less than two minutes would not have provided a meaningful experience of the material in the PowerPoint, and the PowerPoint without the lecture that had accompanied it would not even make much sense.

One of the most telling statistics from the course data is that there were 122 visits to the opening page of the module, with an average of 20 seconds spent on the opening page. The opening page was a 2-1/2-minute narrated greeting from 
the instructor, if students clicked open the narration, welcoming students to the module and setting the tone for their involvement with the material. There were 51 visits to the page "About the stress post-test," with an average 53 seconds spent on that page, and there were 74 visits to the post-test from the module. As shown in Table 5, 87 students submitted the post-test, which would suggest that some students did not even look for it in the module, but directly accessed it though the Assessment Tool in the course. Removing those visits, and looking only at module content pages, Table 15 shows that the average number of visits to any one content page was about 6 . (That means any one of the 43 content pages was accessed an average of only six times by any of the 150 students in the course during the research period, from October 3 to November 17, 2007; it does not reveal whether any one student accessed it more than once.) The most frequently visited content page was the Principles Lecture, a video link from Extra Resources, which was visited 22 times, with average visit time of 4.24 minutes. The video lecture is 35 minutes long.

Table 15

Average visits and time per visit of course content pages only (not including links

$\begin{array}{llrrr} & \text { N } & \text { Minimum } & \text { Maximum } & \text { Mean } \\ \text { Average Time/Visit } & 43 & 0: 00: 01 & 0: 04: 25 & 0: 00: 44 \\ \text { Visits } & 43 & 1 & 22 & 5.6\end{array}$

Since there are no qualitative data of any value, and since no one filled out the Course Evaluation, it is speculative to try to imagine what students thought about the module. The very brief time spent on it, and the very small number of visits to 
content pages, suggest they were neither touched by the idea of it nor particularly interested in it.

For future research, it would make sense to pilot test the module on a small group of students already identified as experiencing stress, or as interested in human stress and resiliency, and wanting help to alleviate stress in themselves and others. The guiding questions the researcher had in mind when the module was created for Nursing 110 arose from questions that students have asked or sought help with over the past 10 years that the researcher has mentored students at WVU. They have primarily been professional students in graduate programs in the Health Sciences; the material has not been tested on freshmen college students. Results of this study would suggest, at the very least, that if such a module is offered to freshmen, it should be offered in their second semester, when it is more likely they may feel a need to attend to their levels of stress. But it may be that an MCT module called Ex-Stress Yourself is most appropriate for students who have selected and entered their major, and who are more likely to have a desire, both personally and professionally, to understand stress and well-being in themselves and others, and to address it constructively.

An MCT on-line module for fall semester freshmen which is intended to prevent stress across their lifetimes, and to explain how they can enjoy and navigate all of life, regardless of circumstances, might more appropriately be focused and named in a way that students do not have to consider themselves as already experiencing stress in order to benefit from it. For example, the Morgantown High School program using the metaphor of a rollercoaster ride and 
offering to help students understand themselves better and feel more in control of their emotional ups and downs appealed to students because it addressed an immediate concern for that age group.

The Ex-Stress Yourself module, nevertheless, received about as much attention from students in Nursing 110 as other on-line elements of the course, which is designed as an overview, survey course. It did not stand out to them or draw them, despite efforts to present it as a unique and enjoyable learning experience. Nor was it differentially rejected.

There is no reason to remove the module from Nursing 110 as an instructional element if there is a possibility that it might help even one student. But this research demonstrates that evaluating the module as a vehicle for personal change while presenting it to students as a unit in a survey course is a poor strategy. It appears that students found neither reason nor motivation to enter the module with the idea that it was a unique, direct appeal to their innate wisdom and common sense that could provide lasting value to them. They appear to have made decisions about how they would approach it based on the credit given for filling out questionnaires.

While a few students did spend time with various parts of the module, for the most part, individual content pages were hardly visited at all (Table 7). If such a module is set up within a course in future research, rewards for participation should be tied to engagement in the intervention as much as to answering the questionnaires. It would be important that the researcher and instructors have a clear agreement about not posting extraneous materials with the module, and a 
firm commitment to the qualitative components of the research, especially the requests for posting responses to a discussion board. If students had to post a written response before the class discussions, it is more likely they would have felt a need to enter the intervention and pay more attention to the ideas presented.

In the 2006 experience with Engineering, before the research project abruptly ended, 11 student Discussion Board postings were received by the researcher. They reflected a connection to the learning, and some reported actual changes in the students' perspectives from reflection on the power of their own Innate Health. A few of the postings recounted personal experiences the students had handled with surprising grace after realizing that their state of mind mattered in how they responded to life situations, and realizing they had it within their power to calm down before they acted. Although these responses had to be discarded because the students' names were inadvertently left on the postings when they were sent to the researcher without ID codes, they did color the researcher's expectations about the likely outcome in the Nursing class because they were aligned with the kind of response to which Mind-Consciousness-Thought practitioners are accustomed.

\section{Future Research}

It is disappointing that this project, which involved hundreds of hours of preparation and considerable support and help from WVU Instructional Technology staff, the Instructional Technology Research Center (ITRC), colleagues in Innate Health, and nursing faculty, produced no treatment-control comparison data. It did, 
however, produce valuable information and an opportunity to learn from mistakes to develop future research in Mind-Consciousness-Thought.

The Principles of Mind, Consciousness and Thought are always presented as experiential, not intellectual, learning (Sedgeman, 1996). Although they represent a logical explanation for how the mind works, the recognition of this logic is an internal experience, an "Aha!" that arises out of reflection in a quiet state of mind. The starting point of any psychoeducational presentation of the Principles that describe Innate Health is to awaken hope and create a safe and quiet environment in which participants can relax and reflect.

Many aspects of on-line education support such a presentation of the Principles. People enter on-line courses on their own time, when they are comfortable and prepared to sit down for a while and experience the course. They can watch or listen to presentations more than once, to get the full experience of them. If the course is well-designed, with a lot of audio and video material that brings the instructor's enthusiasm and feeling to life, students can pick up the warmth and hopefulness of the approach. If they take time to reflect on the questions raised and post comments or discussions about them, they can learn from each other and each other's experiences.

The researcher offers a Continuing Education on-line course through WVU Extended Learning, The Natural Remedy for Stress and Burnout, which has elicited extremely personal postings and positive comments from participants, many of whom used expressions like "savor" and "see something new each time," and "came to the realization," and "saw, when I reflected, that ..." Although no formal research has been conducted on that course, anecdotal evidence supports the premise that the 
Principles can be presented successfully on-line. In a dynamic on-line environment that incorporates a variety of materials, including video and audio presentations that allow for a connection with the feeling and hopefulness of the facilitators, it appears that adult participants do respond.

It is important, however, to demonstrate this with strong research. No institution will invest in the development of an on-line program in a unique mental well-being approach without evidence to support its likely success.

This study with Nursing 110 suggests that, if Mind-Consciousness-Thought material is presented as a unit incorporated within a traditional course that is based on rote-learning of information, it may not succeed, even if every effort is made to distinguish it. The Ex-stress Yourself module was set up as a SCORM, with its own welcome page and many dynamic features, so it would be clearly distinguished from the rest of the material in the Nursing 110 course as a unique and special unit, not just a routine assignment. It included "personal" elements such as a spoken greeting from the instructor, case studies and stories of previous students who had benefited from understanding the Principles, video lectures to transmit the feeling as well as the ideas, pictures and illustrations to go with the written material, FLASH animations that were lighthearted but to the point to engage students, a crossword game and a matching exercise to help students think for themselves about the ideas presented, background music behind some of the final narrations to enhance the tone and feeling of the module, links to Sydney Banks' web-site where students can hear and watch Mr. Banks speak of his own discoveries and the hope they offer. None of this mattered, however, to most of the students in Nursing 110 because they never saw or 
experienced the unique elements of the module. They treated the module as they did other assigned reading material on line, mostly by ignoring it, or at best, skimming it.

Some may argue that this strongly suggests the on-line environment cannot transmit the feeling or the experience of the Principles. But the responses to The Natural Remedy... coupled with the fact that many people have responded to audioand videotapes offered over the years by practitioners who base their work on the Principles, suggest otherwise. Instead, it appears that the experience of this research indicates that Mind-Consciousness-Thought as an on-line offering should be presented either as a course unto itself (as with the three-credit-hour graduate courses taught by the researcher) or as an on-line element that can be selected from an array of learning opportunities by students, but is not a part of a course syllabus. The idea of creating on-line experiences in Mind-Consciousness-Thought as SCORM modules may ultimately work well, once the problem of presenting those modules outside of eCampus courses is resolved.

One idea that has been discussed at WVU is presenting the Ex-Stress Yourself module as one of a series of offerings that can be recommended or selected by faculty for students, or selected by students themselves from a web-site where they would go to find help for themselves, much as the Intensive Counselor offerings are set up in the College of Engineering. If this can be accomplished technically, the MindConsciousness-Thought module should be researched in that context.

In addition, lessons learned from this research could be applied to establishing a formal research project with The Natural Remedy..., which is already scheduled with ITRC for a complete revamping in 2008, since it was first put on-line in 2005 
and is ready to be updated and improved. As it is being revamped, an IRB proposal could be submitted for pre- and post- research to be built into it as an option for participants. The difficulty of planning such research is that participants in that course are not demographically homogeneous and do not enter and leave the course simultaneously; they represent many different ages, professions, and levels of previous exposure to the Principles. They enter the course at various times during each semester it is offered, and complete it at their own speed, which has been as brief as a few days for some, and as long as several months for others. It would be impossible to match them with a control group in an experimental study. But pre- and post-tests would offer useful information about their response to the on-line material, and some of them might agree to be followed and to continue to take post-tests over time.

Further Nursing Research

It is up to the Nursing 110 faculty whether to keep the Ex-Stress Yourself module in their course. Perhaps if the research design were changed so that Ex-Stress Yourself was a "blended" presentation, including lecture and on-line study, so that the researcher was not limited by the research design from talking in depth about the Mind-Consciousness-Thought approach during the introductory lecture, more students would enter the module with an understanding of what it could offer them, and consequently benefit from it. Also, it would be helpful if the researcher guided the in-class discussion groups of the module. Modest changes in the research 
description within the module and an amended IRB would make this shift easily achievable by the Fall, 2008 semester.

One next step for research with the Nursing program would be to find a way to introduce the module on the Nursing web-site, as originally conceived, so that faculty or students could access it as a personal choice. At present, this would require creating a new module on a different learning management system or a separate web-site, not in eCampus. As the technology options change and evolve, however, this is an increasingly likely option, possibly available within the next year or two. In addition, if the module were created outside of the WVU eCampus environment, it could become more widely available to the public.

Another idea would be to introduce the module as it is to students in a course for juniors or seniors who are Nursing majors. Since the SCORM module is easily transferable between eCampus courses, and since, at present, every accredited course at WVU has an eCampus location automatically open to students registered for that course, this would be easy to accomplish. Nursing faculty who teach junior-level courses to Nursing majors have offered to review the module for inclusion at that level of course work, and to consider it for the Fall, 2008, semester.

When a new research plan is established, the research questionnaire should be one of the available brief Quality of Life Surveys (Zimmerman, Ruggero, Chelminski, Young, Posternak, Friedman et al., 2006) combined with the PATCS, rather than the SF-36. Although the SF-36 is a well-validated instrument that is used on-line by its originator, Dr. John Ware, and has been normed with many populations, it has proven to be too complex for this research. This project has demonstrated that 
student respondents do not become sufficiently engaged in the SF-36 to complete the instrument on-line.

\section{Other Educational Research Implications}

Although this project was directed specifically towards research of an on-line learning module as a means of addressing stress in college freshmen, information that emerged from it raises important, and different, questions for future educational research. Data from the freshman students in both the treatment and control groups for this study over the months of the study, showed that freshmen students in their fall semester enjoy satisfactory mental well-being. They come to college relatively stressfree and high-spirited, which is the ideal state of mind in which to live and learn. Yet the literature, in both Nursing and Engineering, reviewed for this project, plus the researcher's own experience working with students over the years, suggests that once students have become fully immersed in college, their mental well-being often deteriorates. There is a considerable body of evidence that stress, insecurity, the lack of stable mental well-being, are issues for students on college campuses, even sometimes issues that lead to tragedy.

What happens in the minds of students between their entry into higher education and their full involvement in it? Would students who were taught MCT and exposed to a deeper understanding of how their own minds work, and how they can regain their bearings in the face of pressure, have a different college experience from others? Would they be better learners, more "present" in their classes and more able 
to concentrate and enjoy new learning without fear? Would they be more resilient in the face of personal, social, and academic pressures?

These questions are important. Mental health treatment for college students is primarily after-the-fact. Many mental health services are available for students who are having trouble and are either referred to, or willing to, seek help. But there is little offered to students to help them understand how they can prevent stress and mental distress. Would an effective stress prevention strategy forestall problems?

\section{Longitudinal study proposal}

The data and background literature from this study suggest two things:

1. Entering freshmen are not particularly concerned about stress and are not experiencing it as a problem.

2. Stress is a significant impediment to learning and enjoyment later in the college and graduate years.

This suggests a longitudinal study which would entail creating a stress profile of all entering freshmen, then drawing random samples of the general freshman population into a control group, which would proceed through the curriculum as usual, and a treatment group, which would receive an intensive MCT prevention program early in their freshman year, and self-directed access to further MCT education throughout their college years. The treatment group and the control group would then be profiled with the same psychological tests every semester through the entire four years of college, and additional factors, such as drop-out rates, GPA, 
discipline or academic referrals (information generally tracked by the university anyway) would be tracked for each group.

It is very difficult to "measure" prevention, but this study design would allow for reasonable evaluation of whether the state of mind of the treatment group affected their success in college. If there were significant differences between the treatment group and the control group, it would set the stage for much larger studies of student populations, to determine whether MCT education and students' understanding of the importance of their own state of mind to the success of their life would have a significant impact on the quality of their educational experience and the culture of campus life generally.

It is vital to continue to explore and evaluate the methodology of delivery of MCT education to young people, particularly since so many young people now are highly reliant on internet and on-line experiences to manage their lives and find the information they need. But it is equally vital to address the impact of mental distress among students on the quality of their educational experience, their ability to respond to life situations, and their prospect of living a stress-free, constructive and wise life as citizens, parents, and the leaders of the future

\section{Conclusion}

There is much to learn from projects that do not work out as anticipated. So in this experiment, which appears to have "failed" as a statistical exercise, there is an opportunity to transcend circumstances and take a fresh look to see what can be learned. In this case, the researcher's intent is to take a fresh look not only at the 
organization and presentation of Mind-Consciousness-Thought materials on line, but the context in which they are offered and the means by which students are invited to participate in them.

The inside-out paradigm that fundamentally distinguishes MCT therapy and prevention from the prevailing models for eliciting mental well-being applies as well to MCT education. Learning from the inside-out, insight-based learning, is a completely different experience from simply reading and retaining facts and ideas.

Generally, the type of learning that is necessary for people to grasp the difference between seeing things for themselves and absorbing information can be unsettling for those acclimated only to rote learning. It requires them to examine something in a state of reflection, as opposed to active memorization or analysis. It does not offer techniques or methods, inviting students to find their own way. Often the notion of inside-out learning can be unsettling for teachers as well, because it requires them to draw out insights from the assembled group through the discovery process so that people see for themselves. The compulsion to "give the answer" rather than simply facilitating dialogue and trusting that dialogue to bring out the answers is strong in highly trained teachers, which may be why the Nursing 110 instructors tried to "help" by posting the researcher's previous PowerPoints for the students. And the desire for their instructors to give them the answer is ingrained in students, which may be why so few students decided to go ahead with the module after exposure to the first element of Getting Started which suggested that they look for their own insights, rather than trying to remember the detailed content of the module. 
Working with the Principles of Mind, Consciousness and Thought in a traditional academic setting is fascinating and challenging. It requires those who constantly present the Principles to uncover the kinds of distinctions that help both teachers and students to find a useful roadmap for this journey. One clear distinction is that transmitting ideas in this paradigm requires a partnership between presenter/presentation and learner. Such a partnership implies an understanding on each side that the learning only arises from reflection and a quiet state of mind. When we talk about the Principles as a "subject," we are talking about the memory of the last thing we heard or read about the Principles. That is always a metaphor for the true point. Recognizing that we have the ability to create new thoughts and bring them to mind is the true point. As soon as we write something down, we have described the shadow of the Principles, a metaphor for the Principles, the memory of the experience of the Principles in action. Thus we cannot "teach" the Principles by any traditional means. What we are looking for in the learning is a realization of the dynamic process, the energetic flow that makes all of our thinking come to life and allows everything we say or describe to change and evolve as new ideas come to mind.

The Principles are not an "it," an object; they are the formless universal logic by which we form experience and thus see our lives unfold. Only dialogue and reflection can elicit an internal discovery of the Principles in action, the realization of the flow of thought in the creation of moment-to-moment experience. The on-line experience created for the Ex-Stress Yourself module presented several explanations, in easy lay terms, of the nature of the learning in that module and why it was both 
natural to people, and different from their expectations. But so few students accessed that information that the distinction was never available to the Nursing 110 class.

Figure 10 is a screen shot of just one of the early pages that addressed the learning strategy of this module to students. This page appeared in the Getting Started section, the initial frames students were asked to visit before they entered the Learning Module. It was visited three times, with an average time per visit of 13 seconds.

< Your location: Home Page > Ex Stress Yourself > Ex-Stress Yourself Getting Started > Things you need to know

\section{Things you need to know}

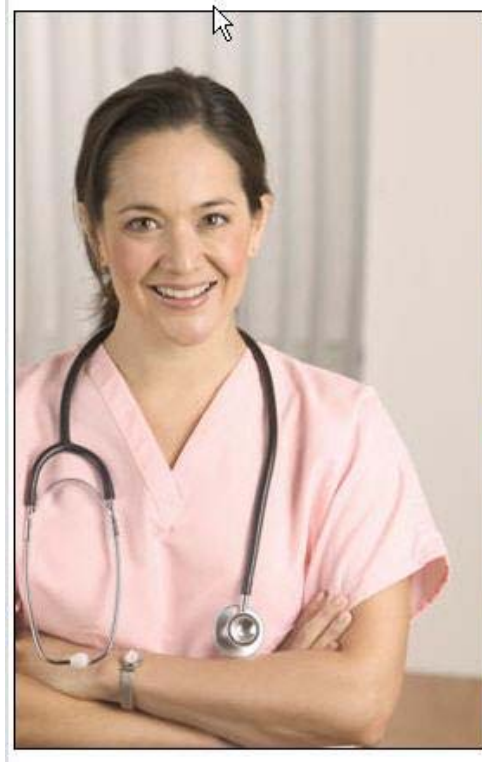

This module is intended to help you see for yourself how to live the rest of your life with much less stress and more joy, regardless of circumstances.

Reflecting on the ideas and seeing what comes to mind for you is more important than trying to focus on the details of the content. Just relax as you read. You can safely assume that what will be helpful to you will "register" with you.

You'll find the module gives you some of the same information in different ways. That should help you to see it more clearly and more deeply as you go through the module.

It's likely you'll continually have insights as you proceed; your insights are your true learning experience. Remember, insights are just helpful ideas that come to mind that had never occurred to you before. For example, I had the insight, when I first started to understand how to live with less stress, that I was needlessly keeping myself awake at night going over and over things I had to do. I realized I didn't need to be using my thinking that way. It seemed like a small thing, but it made a big difference to me when I "saw" it for myself so clearly that I changed.

Try to enter the course at times when you aren't distracted by a lot of activity or noise, and when you are at ease and able to take it slowly. Stop to reflect, page by page.

Don't think too hard or try to remember; just stop to see what the ideas expressed might mean to you.

Figure 10. Instructions about the learning experience from "Getting Started" in $E X$ Stress Yourself.

The module followed an internal logic that provided case examples or illustrations as ideas were presented, and invited participants to reflect and see things for themselves. The researcher took for granted that students who were assigned to this module would enter it as planned, and go through it sequentially, taking the 
inside-out learning premise and the logic of the module to heart. Because the module represented one week of coursework, the researcher expected that students would spend a minimum of one hour, and as much as three or more hours, in the module. Since the course tracking information makes it clear that students did not do that, it is not possible to draw conclusions from an evaluation of this module as to the efficacy of presenting the Principles on-line. But this module, although especially created with nursing students in mind so that examples and illustrations were selected to appeal to them and feel relevant to them, was configured similarly to the Natural Remedy course in terms of its internal logic. That course has consistently received the expected response from participants who share insights in discussion postings and often contact the instructor directly to express their feelings about the course.

Future research must clearly separate the issues of delivery and efficacy and address them independently. That is, it must be acknowledged that this material falls into the category of personal learning intended to awaken insights and wisdom about oneself and other people. Although there is substantive content, the understanding and application of that content depends upon the insights of the learner and the awakening of the learner's own creativity and common sense about what to do with what they are learning and seeing for themselves. It depends upon an in-the-moment access to one's own wisdom, not the application of others' wisdom. This is described in The Missing Link by Sydney Banks:

There is an enormous difference between finding your own inner wisdom and adopting someone else's beliefs. If you take on someone else's belief to replace a belief 
or your own, you may experience a temporary placebo

effect, but you have not found a lasting answer.

However, if you replace an old belief with a realization

from your own inner wisdom, the effect and results are

superior and permanent. (pp. 92-93)

In order for the uniqueness of this approach to seeing new material to be tested, it should next be offered in a standalone setting where the learning approach is made clear and is not mixed or confused with other learning strategies. In the Nursing 110 course, the only way students could have seen this uniqueness would be by entering and experiencing the module as it was intended. But because the module was inserted into a familiar course structure, most did not appear to have investigated it with open minds, but treated it as just one more content-based assignment.

It is important, in future research, that the delivery of the module be rigorously controlled to set up the conditions that will assure that participants enter the materials open to a new and different way of approaching the experience of learning. The Nursing 110 research demonstrates that subjects cannot be counted on to approach material with curiosity without stronger incentives, and more careful preparation. It may be too great of a departure from customary learning strategies, even with preparation, but this has yet to be evaluated.

If it can be shown that participants entered and completed MCT on-line learning experiences in the spirit intended, then the efficacy of on-line course delivery can be evaluated by assessing changes in the students' levels of well-being and stress. 
The promise of on-line delivery of the Principles to a global audience is too great not to be carefully evaluated. This project represents a small step in the direction of developing well-considered research projects in the future. Although many mistakes were made and many assumptions were proved wrong in this experience, nothing in it suggests that it is not worthwhile to continue to pursue research into MCT work to prevent and alleviate stress and distress in students.

In the words of Sydney Banks, from The Missing Link:

"There is no way to guarantee a trouble-free life. Life is like any other contact sport. You may encounter hardships of one sort of another. Wise people find happiness not in the absence of such hardships, but in their ability to understand them when they occur. ( $p$. 124.). 


\section{References}

Admi, H. (1997a). Nursing students' stress during the initial clinical experience. The Journal of Nursing Education, 36(7), 323-327.

Admi, H. (1997b). Stress intervention: A model of stress inoculation training. Journal of Psychosocial Nursing and Mental Health Services, 35(8), 37-41.

Antoni, M. H. (2003). Stress management effects on psychological, endocrinological, and immune functioning in men with HIV infection: Empirical support for a psychoneuroimmunological model. Stress, 6(3), 173-188.

Ashby, F. G., Isen, A. M., \& Turken, A. U. (1999). A neuropsychological theory of positive affect and its influence on cognition. Psychological Review, 106(3), 529-550.

Bachman, M. L. (1998). Anxiety, critical thinking and age as performance predictors of Community College Nursing Students. Unpublished doctoral dissertation, Colorado State University.

Backer, B. A. (1989). Utilization of assessment as an intervention in nursing student stress: An exploratory project. Unpublished doctoral dissertation, City University of New York.

Bailey, J. (1999). The speed trap. San Francisco: HarperSanFrancisco.

Banerjee, K., Howard, M., Mansheim, K., \& Beattie, M. (2007). Comparison of Health Realization and 12-Step Treatment in women's residential substance abuse treatment programs. American Journal of Drug \& Alcohol Abuse, 33(2), 207-215.

Banks, S. (1989a). In quest of the pearl. Tampa, FL: Duval-Bibb Publishing Co.

Banks, S. (1989b). Second chance. Tampa, FL: Duval-Bibb Publishing Co.

Banks, S. (1998). The missing link. Renton, WA: Lone Pine Publishing.

Banks, S. (2001). The enlightened gardner. Renton, WA: Lone Pine Publishing.

Banks, S. (2004). Dear Liza. Edmonton, AB Canada: Lone Pine Publishing.

Benard, B., \& Marshall, K. (1997a). Fostering resiliency in communities, an insideout process. Minneapolis: University of Minnesota Center for Drug-Free Schools and Communities.

Benard, B., \& Marshall, K. (1997b). A framework for practice: Tapping innate resilience. Research/Practice, 9-15.

Benson, H. (1982). The relaxation response: History, physiological basis and clinical usefulness. Acta medica Scandinavica Supplementum 660, 231-237.

Benson, H. (1997). The relaxation response: Therapeutic effect. Science, 278(5344), 1694-1695.

Benson, H. (2002). The Relaxation Response: a bridge between mind and body. Paper presented at the Science and Mind-Body Medicine, Cambridge, MA.

Benson, H., Beary, J. F., \& Carol, M. P. (1974). The relaxation response. Psychiatry, 37(1), 37-46.

Benson, H., \& Goodale, I. L. (1981). The relaxation response: Your inborn capacity to counteract the harmful effects of stress. Journal of The Florida Medical Association, 68(4), 265-267. 
Benson, H., Greenwood, M. M., \& Klemchuk, H. (1975). The relaxation response: Psychophysiologic aspects and clinical applications. International Journal of Psychiatry and Medicine, 6(1-2), 87-98.

Benson, H., Klemchuk, H. P., \& Graham, J. R. (1974). The usefulness of the relaxation response in the therapy of headache. Headache, 14(1), 49-52.

Benson, H., Kotch, J. B., \& Crassweller, K. D. (1977). The relaxation response: A bridge between psychiatry and medicine. Medical Clinics of North America, 61(4), 929-938.

Benson, H., Lehmann, J. W., Malhotra, M. S., Goldman, R. F., Hopkins, J., \& Epstein, M. D. (1982). Body temperature changes during the practice of $g$ Tum-mo yoga. Nature, 295(5846), 234-236.

Blackerby, R. F. (1998). Application of chaos theory to psychological models. Austin, Texas: Performance Strategies Publications.

Bohm, D. (1999). Thought as a system. New York: Routledge.

Bond, C. A. (2007). Leadership training, leadership style and organization effectiveness. Unpublished doctoral dissertation, Boston University School of Education.

Borg, M. (1997). The Impact of training in the Health Realization/Community Empowerment Model on affective states of psychological distress and wellbeing. Unpublished doctoral dissertation, California School of Professional Psychology, Los Angeles, CA.

Bowman, M. (1997). Individual differences in posttraumatic response: Problems with the adversity-distress connection. Mahwah, NJ: Lawrence Erlbaum Associates, Publishers.

Cannon, W. (1939). The wisdom of the body (2nd ed.). NY: Norton Pubs.

Carlson, R., \& Bailey, J. (1997). Slowing down to the speed of life. San Francisco: HarperSanFrancisco.

Carr, K. P. (1989). Perceived stressors and symptoms of stress of students in generic baccalaureate nursing programs. Unpublished doctoral dissertation, Vanderbilt University.

Charney, D. S. (2004). Psychobiological mechanisms of resilience and vulnerability: Implications for successful adaptation to extreme stress. American Journal of Psychiatry, 161(2), 195-216.

Cook, P. H. (1997). Coping resources for stress and assertiveness training for nurses. Unpublished doctoral dissertation, The Ohio State University.

Cox, D. D. (1995). The impact or stress, coping, constructive thinking and hardiness on health and academic performance of female registered nurse students pursuing a baccalaureate degree in nursing. Unpublished doctoral dissertation, University of Pittsburgh.

Csikszentmihalyi, M. (1990). Flow: The psychology of optimal experience. New York: Harper Collins.

Davis-LaGrow, P. A. (1993). Effects of selected stress modifiers on text anxiety in baccalaureate nursing students. Unpublished doctoral dissertation, Texas Women's University. 
Derogatis, L. R., \& Melisaratos, N. (1983). The Brief Symptom Inventory: An introductory report. Psychological Medicine, 13(3), 595-605.

Derogatis, L. R., \& Spencer, P. M. (1982). Administration and Procedures: BSI Manual - I. Johns Hopkins University: Johns Hopkins University School of Medicine.

Duquette, A., Kerouac, S., Sandhu, B. K., Saulnier, P., \& Lachance, L. (1997). [Validation of a model of psychosocial determinants of occupational health of geriatric nurses]. Santé Mentale au Québec, 22(2), 257-278.

Elliott, M. (2002). The clinical environment: a source of stress for undergraduate nurses. The Australian Journal of Advanced Nursing : a Quarterly Publication of the Royal Australian Nursing Federation, 20(1), 34-38.

Esch, T., Fricchione, G. L., \& Stefano, G. B. (2003). The therapeutic use of the relaxation response in stress-related diseases. Medical Science Monitor, 9(2), RA23-34.

Esch, T., Stefano, G. B., Fricchione, G. L., \& Benson, H. (2002a). The role of stress in neurodegenerative diseases and mental disorders. Neuroendocrinology Letters, 23(3), 199-208.

Esch, T., Stefano, G. B., Fricchione, G. L., \& Benson, H. (2002b). Stress-related diseases -- a potential role for nitric oxide. Medical Science Monitor, 8(6), RA103-118.

Fergus, S., \& Zimmerman, M. A. (2005). Adolescent resilience: A framework for understanding healthy development in the face of risk. Annual Review of Public Health, 26(1), 399-419.

Flood, A. (1999). Perfect misfortune: Hope, healing and happiness. Bend, OR: The Psychology of Mind/Health Realization Center.

Frederickson, B. L. (2001). The role of positive emotions in positive psychology. American Psychologist, 56(3), 218-226.

Frederickson, B. L. (2003). The value of positive emotions. American Scientist, 91, 330-335.

Fricchione, G. L., Mendoza, A., \& Stefano, G. B. (1994). Morphine and its psychiatric implications. Advances in Neuroimmunology, 4(2), 117-131.

Gigliotti, E. (2001). Development of the Perceived Multiple Role Stress Scale (PMRS). Journal of Nursing Measures, 9(2), 163-180.

Goetzel, R. Z., Anderson, D. R., Whitmer, R. W., Ozminkowski, R. J., Dunn, R. L., \& Wasserman, J. (1998). The relationship between modifiable health risks and health care expenditures: An analysis of the multi-employer HERO health risk and cost database. The Health Enhancement Research Organization (HERO) Research Committee. Journal of Occupational and Environmental Medicine, 40(10), 843-854.

Greenwood, M. M., \& Benson, H. (1977). The efficacy of progressive relaxation in systematic desensitization and a proposal for an alternative competitive response--the relaxation response. Behavioral Research Therapy, 15(4), 337343.

Gunn, R. W., \& Gullickson, B. R. (2005). On the high wire: How to survive being promoted. Westport, CT: Praeger Publishers. 
Hawking, S. (1996). The illustrated a brief history of time. New York: Bantam Books.

Henderson, N. (2003). Hard-wired to bounce back. The Prevention Researcher, 10(1), 5-7.

Hesselberg, B. J. (2000). Perceived stress, role strain and role involvement, predictors of academic achievement in associate degree female nursing students. Unpublished doctoral dissertation, University of South Florida.

Hight, L. J. (1996). A comparative study of anxiety levels in traditional and nontraditional undergraduate nursing students in Tennessee. Unpublished doctoral dissertation, The University of Memphis, Memphis.

Hosoda, Y. (2006). Development and testing of a Clinical Learning Environment Diagnostic Inventory for baccalaureate nursing students. Journal of Advanced Nursing, 56(5), 480-490.

Howard, M., \& Mansheim, K. (2005). Myths \& realities: Questions and answers about Health Realization. Santa Clara County Department of Alcohol and Drug Services, Health Realization Services Division.

Huerta, C. G. (1990). The relationship between life change events and academic achievement in registered nursing education students. Unpublished doctoral dissertation, Texas A\&M University.

Jennette, M. R. (1995). A phenomenological study of the lived experience of nursing students enrolled in an associate degree nursing program. Unpublished doctoral dissertation, West Virginia University.

Johnson-Holloway, P. (2001). Exploring the nature of the phenomenon of stress as it relates to nursing students. Unpublished doctoral dissertation, University of Idaho.

Jones, M. C., \& Johnston, D. W. (1997). Distress, stress and coping in first-year student nurses. Journal of Advanced Nursing, 26(3), 475-482.

Jones, M. C., \& Johnston, D. W. (2000). Reducing distress in first level and student nurses: A review of the applied stress management literature. Journal of Advanced Nursing, 32(1), 66-74.

Kabat-Zinn, J. (1990). Full catastrophe living. New York: Dell Publishing.

Karlamangla, A. S., Singer, B. H., McEwen, B. S., Rowe, J. W., \& Seeman, T. E. (2002). Allostatic load as a predictor of functional decline. MacArthur studies of successful aging. Joural of Clinical Epidemiology, 55(7), 696-710.

Karn, M. (1998). Adolescents and the myth of peer pressure: Mavis Karn \& Associates.

Kausen, R. C. (2003). We've got to start meeting like this! Trinity Center, CA: Life Education, Inc.

Keatley, V. M. (1998). Critical incident stress in generic baccalaureate nursing students. Unpublished Dissertation, Widener University School of Nursing.

Kelley, T. M. (2004). Positive psychology and adolescent mental health: False Promise or True Breakthrough? Adolescence, 39(154), 257-277.

Kelley, T. M., \& Stack, S. A. (2000). Thought recognition, locus of control, and adolescent well-being. Adolescence, 35(139), 531-550. 
Kennedy, S. (2000). Applications: Health Realization in the community [videotape]. Canada: Lone Pine Media.

Kiecolt-Glaser, J. K., \& Glaser, R. (1992). Psychoneuroimmunology: Can psychological interventions modulate immunity? Journal of Consulting Clinical Psychology, 60(4), 569-575.

Kiecolt-Glaser, J. K., McGuire, L., Robles, T. F., \& Glaser, R. (2002). Psychoneuroimmunology and psychosomatic medicine: Back to the future. Psychosomatic Medicine, 64(1), 15-28.

Kuhn, T. (1962). The structure of scientific revolutions (2nd ed.). Chicago: University of Chicago Press.

Kuhrik, M. (1996). A comparison of humor using the Situational Humor Response Questionnaire and the Coping Humor Scale by nontraditional and traditional students in midwestern schools of nursing. Unpublished doctoral dissertation, Southern Illinois University, Carbondale, Ill.

Lamb, K. A. (1998). Baccalaureate nursing students' perception of empathy and stress in their interactions with clinical instructors: Testing a theory of optimal student system stability according to the Neuman Systems Model. Unpublished doctoral dissertation, The University of Tennessee.

Lewis, R. (2003). Brief theories. In D. Capuzzi \& D. R. Gross (Eds.), Counseling and psychotherapy: Theories and interventions (3rd ed.). Upper Saddle River, NJ: Merrill Prentice Hall.

Lomuti, G. G. (1995). The relationshp between effective coping strategies and conceptual systems development among baccalaureate nursing students (Nursing Education). Unpublished doctoral dissertation, Seton Hall University.

Lutgendorf, S. K., \& Costanzo, E. S. (2003). Psychoneuroimmunology and health psychology: An integrative model. Brain Behavior and Immunity, 17(4), 225232.

Marker, J. K. R. (2001). Perceptions and practices of nurse educators in recognizing and addressing student nurse stress. Unpublished doctoral dissertation, Ball State University.

Marshall, K. (1998). Reculturing systems with resilience: Health Realization. Paper presented at the Promoting Positive and Healthy behaviors in children: 14th Annual Rosalyn Carter Symposium on Mental Health Policy, Atlanta, GA.

Marshall, K. (2004). Resilience research and practice. In H. C. Waxman, Y.Padron, J.P. Gray, (Eds.), Educational resiliency: Student, teacher and school perspectives (pp. 63-84). Greenwich, CT: Information Age Publishing.

Masten, A. S. (2001). Ordinary magic: Resilience processes in development. American Psychologist, 56(3), 227-238.

Maville, J. A., Kranz, P. L., \& Tucker, B. A. (2004). Perceived stress reported by nurse practitioner students. Journal of the American Academy of Nurse Practitioners, 16(6), 257-262.

McEwen, B. S. (2000). Allostasis and allostatic load: Implications for neuropsychopharmacology. Neuropsychopharmacology, 22(2), 108-124. 
McEwen, B. S. (2002). Sex, stress and the hippocampus: Allostasis, allostatic load and the aging process. Neurobiological Aging, 23(5), 921-939.

Mills, R. C. (1991). A new understanding of self: The role of affect, state of mind, self understanding and intrinsic motivation. The Journal of Experimental Education, 60(1), 67-71.

Mills, R. C. (1995). Realizing mental health. New York: Sulzburger \& Graham Publishing, Ltd.

Mills, R. C. (2003, August 1, 2006). Status of research-based programs. from http://store.mentalhealth.org/schoolviolence/part2chp2.asp

Mills, R. C. (2005, April 12, 2005). Empowering communities: Prevention from the inside out. Paper presented at the Creating a Dialogue Between Science and Spirituality, Morgantown, WV.

Mills, R. C., Bradford, V., \& Garcia, M. (1989). An innovative approach to motivating high-risk youth. University of Miami School of Continuing Education: Metro Dade Dept. of Youth and Family Development.

Mills, R. C., Dunham, R., \& Albert, G. (1998). Working with high-risk youth in prevention and early intervention programs: Toward a comprehensive wellness model. Adolescence, 23(91), 643-660.

Mills, R. C., \& Mills, C. (2003). Review of literature: Current and archival materials on "Health Realization" and the evolving psychological paradigm founded on the principles of mind, consciousness and thought. Saratoga, CA: Health Realization Institute, Inc.

Mills, R. C., \& Spittle, E. (2001). The wisdom within. Renton, WA: Lone Pine Publishing.

Morgan, D. A. (2001). The impact of stress on integration and attrition of nursing education in Texas. Unpublished doctoral dissertation, Baylor University.

Niess, J. H., Monnikes, H., Dignass, A. U., Klapp, B. F., \& Arck, P. C. (2002). Review on the influence of stress on immune mediators, neuropeptides and hormones with relevance for inflammatory bowel disease. Digestion, 65(3), 131-140.

Nikou, V. R. (1998). The relationships among hardiness, stress, and healthpromoting behaviors in undergraduate nursing students. Unpublished doctoral dissertation, New York University.

Nilya, Y., Crocker, J., \& Bartmess, E. N. (2004). From vulnerability to resilience: Learning orientations buffer contingent self-esteem from failure.

Psychological Science, 15(12), 801-805.

Patton, M. Q. (1997). Utilization-focused evaluation: The new century text (3rd ed.). Thousand Oaks, CA: Sage.

Pert, C. (1997). Molecules of emotion. New York: Scribner.

Pettit, S. (1987). Coming home. Fair Oaks, CA: Sunrise Press.

Pettit, W. F. (2007, November). Are there principles at the source of experience? Paper presented at the Grand Rounds, Cardiology Section, Department of Medicine, West Virginia University School of Medicine.

Pransky, G. (1998). Renaissance of psychology. New York: Sulzburger \& Graham. 
Pransky, G., Mills, R. C., Sedgeman, J., \& Blevens, K. (1995). An emerging paradigm for brief treatment and prevention. Innovations in Clinical Practice: A Sourcebook, 15, 401-420.

Pransky, J. (1998). Modello: A story of hope for the inner city and beyond. Cabot VT: NEHRI Publications.

Pransky, J. (1999). The experience of participants after Health Realization training: A one-year follow-up phenomenological study. Unpublished Doctoral Dissertation, The Union Institute, Cabot, VT.

Pransky, J. (2001). Parenting from the heart (3rd ed.). Cabot, VT: NEHRI Publications.

Pransky, J. (2003). Prevention from the inside out. Bloomington, IN: 1st Books.

Pransky, J., \& Carpenos, L. (2000). Healthy thinking/feeling/doing from the insideout. Brandon, VT: Safer Society Press.

Pressman, S. D., \& Cohen, S. (2005). Does positive affect influence health? Psychology Bulletin, 131(6), 925-971.

Rahe, R. H., \& Arthur, R. J. (1978). Life change and illness studies: past history and future directions. Journal of Human Stress, 4(1), 3-15.

Rahe, R. H., Biersner, R. J., Ryman, D. H., \& Arthur, R. J. (1972). Psychosocial predictors of illness behavior and failure in stressful training. Journal of Health and Social Behavior, 13(4), 393-397.

Rahe, R. H., Mahan, J. L., Jr., \& Arthur, R. J. (1970). Prediction of near-future health change from subjects' preceding life changes. Jounal of Psychosomatic Research, 14(4), 401-406.

Rahe, R. H., Veach, T. L., Tolles, R. L., \& Murakami, K. (2000). The stress and coping inventory: an educational and research instrument. Stress Medicine, $16,199-208$.

Ray, O. (2004). How the Mind Hurts and Heals the Body. American Psychologist, 59(1), 29-40.

Reynolds, K. R. (1996). Self-concept as a predictor of psychosocial stress in male and female nurses. Unpublished doctoral dissertation, United States International University.

Richardson, G. E., \& Waite, P. J. (2002). Mental health promotion through resilience and resiliency education. International Journal of Emergency Mental Health, $4(1), 65-75$.

Roy, A. F. (2007). An examination of the principle-based leadership trainings and business consultations of a group private practice. Unpublishd doctoral dissertation, Massachusetts School of Professional Psychology.

Rusin, C. A. (1990). "You have to tough it out": Experiences of registered nurses while obtaining the baccalaureate degree in nursing through an external degree program. Unpublished doctoral dissertation, Syracuse University.

Salovey, P., Rothman, A. J., Detweiler, J. B., \& Steward, W. T. (2000). Emotional states and physical health. American Psychologist, 55(1), 1101-1121.

SAMHSA. (2003). Status of Research Based Programs: A general approach applied in different settings. Washington, D.C.: Substance Abuse and Mental Health Services Administration (SAMHSA). 
Sapolsky, R. M. (2004a). Organismal stress and telomeric aging: An unexpected connection. Proceedings of the National Academy of Science U S A, 101(50), $17323-17324$.

Sapolsky, R. M. (2004b). Why zebras don't get ulcers. New York: Henry Holt \& Co., LLC.

Sapolsky, R. M., Krey, L. C., \& McEwen, B. S. (1986). The neuroendocrinology of stress and aging: The glucocorticoid cascade hypothesis. Endocrinolgy Review, 7(3), 284-301.

Sedgeman, J. (1996, June). Conceptualization: The route to relevance and depth. Paper presented at the Psychology of Mind Annual Conference, San Jose, CA.

Sedgeman, J. (1997, April, 1997). Teaching the principles: The beauty of simplicity. Paper presented at the 15th Annual Psychology of Mind Conference, Turtle Bay, Oahu, Hawaii.

Sedgeman, J. (2005). Health Realization/Innate Health: Can a quiet mind and a positive feeling state be accessible over the lifespan without stress-relief techniques? Medical Science Monitor, 11(12), 47-52.

Sedgeman, J. (2006). Freeze, Flight or Fight: Engineering students' perceptions of stress: West Virginia University.

Sedgeman, J., \& Sarwari, A. (2006). The effect of a Health Realization/Innate Health psychoeducational seminar on stress and anxiety in HIV-positive patients. Medical Science Monitor, 12(10), CR397-399.

Seligman, M. E., \& Csikszentmihalyi, M. (2000). Positive psychology. An introduction. American Psychologist, 55(1), 5-14.

Selye, H. (1950). Stress and the general adaptation syndrome. British Medical Journal, 4667, 1383-1392.

Sharif, F., \& Armitage, P. (2004). The effect of psychological and educational counselling in reducing anxiety in nursing students. The Journal of Psychiatric Mental Health Nursing, 11(4), 386-392.

Sheu, S., Lin, H. S., \& Hwang, S. L. (2002). Perceived stress and physio-psychosocial status of nursing students during their initial period of clinical practice: the effect of coping behaviors. International Journal of Nursing Studies, 39(2), 165-175.

Shipton, S. P. (2002). The process of seeking stress-care: Coping as experienced by senior baccalaureate nursing students in response to appraised clinical stress. The Journal of Nursing Education, 41(6), 243-256.

Shuford, R., Gaughen, J., \& Kiaka. (2000). Client outcome data. Honolulu, HI: State of Hawaii Department of Health and Education.

Spittle, E. (2005). Wisdom for life. Edmonton, AB Canada: Lone Pine Publishing.

Stefano, G. B., Benson, H., Fricchione, G. L., \& Esch, T. (2005). The stress response: Always good and when it is bad. New York: Medical Science International Co.

Stefano, G. B., Cadet, P., Fimiani, C., \& Magazine, H. I. (2001). Morphine stimulates iNOS expression via a rebound from inhibition in human macrophages: Nitric oxide involvement. International Journal of Immunopathology

Pharmacology, 14(3), 129-138. 
Stefano, G. B., Fricchione, G. L., Slingsby, B. T., \& Benson, H. (2001). The placebo effect and relaxation response: Neural processes and their coupling to constitutive nitric oxide. Brain Research Reviews, 35(1), 1-19.

Stefano, G. B., Murga, J., Benson, H., Zhu, W., Bilfinger, T. V., \& Magazine, H. I. (2001). Nitric oxide inhibits norepinephrine stimulated contraction of human internal thoracic artery and rat aorta. Pharmacology Research, 43(2), 199-203.

Stewart, D. (1993). Creating the teachable moment. Bradenton, FL: HSI.

Suarez, R., Mills, R. C., \& Stewart, D. (1987). Sanity,insanity and common sense. New York: Fawcett-Columbine.

Taylor, S. E., Kemeny, M. E., Reed, G. M., Bower, J. E., \& Grunewald, T. L. (2000). Psychological resources, positive illusions and health. American Psychologist, 55(1), 99-109.

Tebes, J. K., Irish, J. T., Puglisi, V., \& Perkins, D. V. (2004). Cognitive transformation as a marker of resilience. Substance Use and Misuse, 39(5), 769-788.

Thurn, K. E. (1993). A cross sectional study of depressive symptoms in student nurses (Beck Depression Inventory). Unpublished doctoral dissertation, Adler School of Professional Psychology.

Timmins, F., \& Kaliszer, M. (2002). Aspects of nurse education programmes that frequently cause stress to nursing students -- fact-finding sample survey. Nurse Education Today, 22(3), 203-211.

Tugad, M. M., Frederickson, B. L., \& Barrett, L. F. (2004). Psychological resilience and positive emotional granularity: Examining the benefits of positive emotions on coping and health. Journal of Personality, 72(6), 1161-1190.

Tully, A. (2004). Stress, sources of stress and ways of coping among psychiatric nursing students. Journal of Psychiatric Mental Health Nursing, 11(1), 43-47.

VanItallie, T. B. (2002). Stress: A risk factor for serious illness. Metabolism: Clinical and Experimental, 51(6 Suppl 1), 40-45.

Waite, P. J., \& Richardson, G. E. (2004). Determining the efficacy of resiliency training in the work site. Journal of Allied Health, 33(3), 178-183.

Walton, R. L. (2002). A comparison of perceived stress levels and coping styles of junior and senior students in nursing and social work programs. Unpublished doctoral dissertation, Marshall University, Huntington, WV.

Ware, J. E. J., Kosinski, M., \& Dewey, J. E. (2000). How to score Version 2 of the SF-36 Health Survey. Lincoln, RI: QualityMetric Incorporated.

Ware, J. E. J., Kosinski, M., \& Gandek, B. (2005). SF-36 Health Survey: Manual and interpretation guide. Lincoln, RI: QualMetric Inc.

Wartel, S. G. (2003). A strengths-based practice model: Psychology of Mind and Health Realization. Families in Society, 84(2), 185-191.

Woodiel, D. K. (1997). Evaluating the mental health of mental healthcare providers (stress/coping). Unpublished doctoral dissertation, University of Arkansas.

Ybarra, M. L., \& Eaton, W. W. (2005). Internet-based mental health interventions. Mental Health Services Research, 7(2), 75-87.

Yonge, O., Myrick, F., \& Haase, M. (2002). Student nurse stress in the preceptorship experience. Nurse Educator, 27(2), 84-88. 
Zimmerman, M., Ruggero, C. J., Chelminski, I., Young, D., Posternak, M. A., Friedman, M., et al. (2006). Developing brief scales for use in clinical practice: The reliability and validity of single-item self-report measures of depression symptom severity, psychosocial impairment due to depression, and quality of life. Journal of Clinical Psychiatry, 67(10), 1536-1541. 
Appendix A

Substance Abuse and Mental Health Services Administration Review

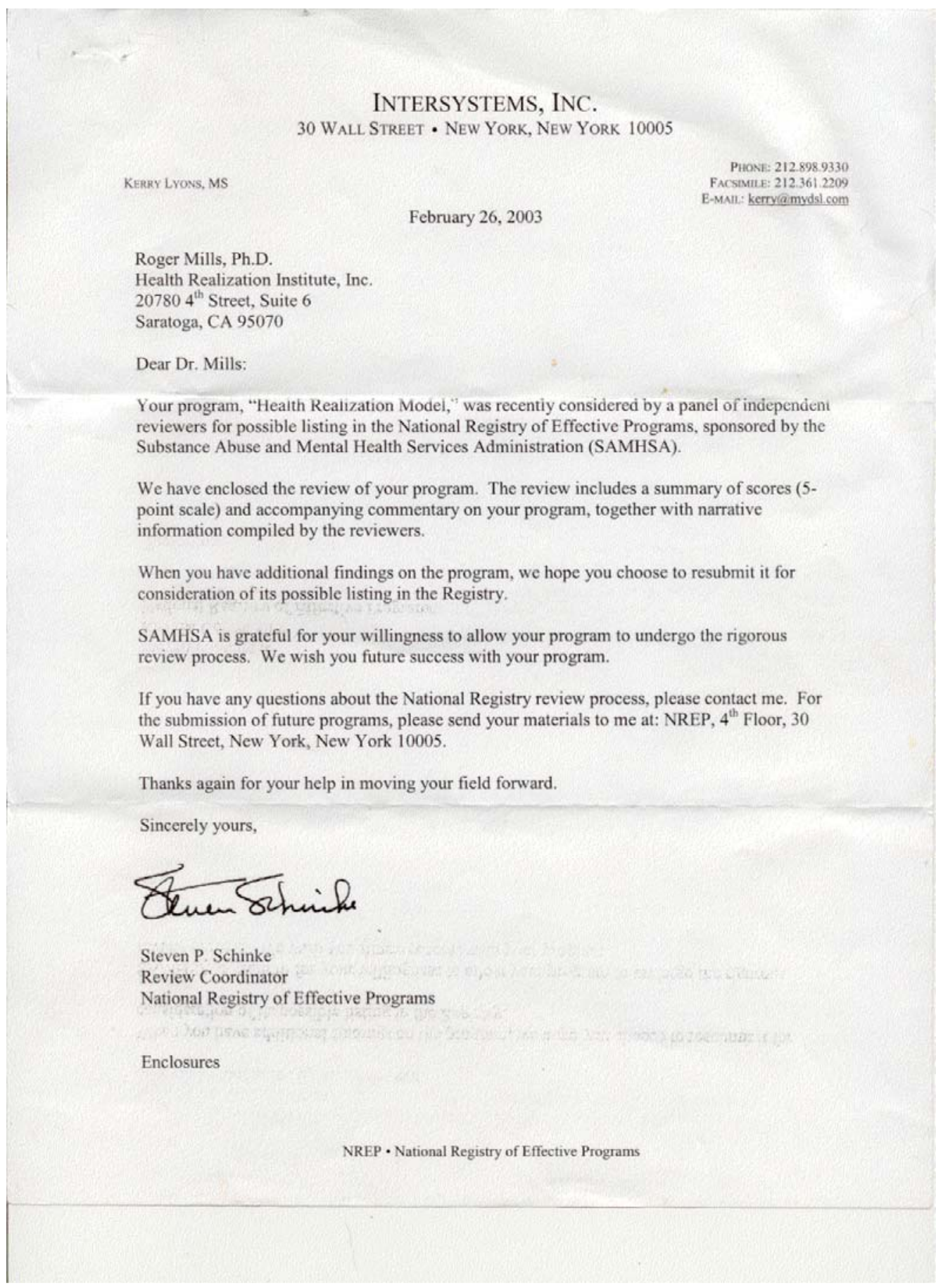




\section{Score Summary}

\section{Program Title: Health Realization Model}

Roger Mills, Ph.D.

Health Realization Institute, Inc.

$207804^{\text {th }}$ Street, Ste. 6

Saratoga, CA 95070

(408) 868-9876

\begin{tabular}{|c|c|c|}
\hline NREPP CRITERIA & SCORE & COMMENTS \\
\hline Theory & 5.00 & $\begin{array}{l}\text { The information provided on theory was full and } \\
\text { insightful. The principles of this humanistic } \\
\text { psychological model are fully explained and its } \\
\text { assumptions are contrasted with other well known } \\
\text { psychological theories. }\end{array}$ \\
\hline Fidelity of Interventions & 1.50 & $\begin{array}{l}\text { Although there were several different studies } \\
\text { presented, there is little information given indicating } \\
\text { the measures researchers took to closely follow the } \\
\text { research design. }\end{array}$ \\
\hline Process Evaluation Quality & 2.00 & $\begin{array}{l}\text { There is little information presented regarding the } \\
\text { actual delivery of various programs that utilize the } \\
\text { Health Realization Model. }\end{array}$ \\
\hline Design and Sample & 2.00 & $\begin{array}{l}\text { Although the sample size overall is adequate, the } \\
\text { individual interventions have small sample sizes. } \\
\text { Furthermore, the overwhelming majority of the } \\
\text { interventions that have been carried out using the } \\
\text { Health Realization Model have not included a control } \\
\text { group. }\end{array}$ \\
\hline Attrition & 1.00 & Data on attrition were not provided. \\
\hline Outcome Measures & 2.00 & $\begin{array}{l}\text { There are concerns about the validity and reliability } \\
\text { of the measures used in the Health Realization } \\
\text { interventions because most of the measures were } \\
\text { locally developed. Some of the interventions did use } \\
\text { standardized measures. }\end{array}$ \\
\hline Missing Data & 3.50 & No information was given on missing data. \\
\hline Outcome Data Collection & 3.50 & Standard data collection measures were used. \\
\hline Analysis & 2.00 & $\begin{array}{l}\text { The analyses used were basic and important factors } \\
\text { were not considered. }\end{array}$ \\
\hline Other poss. threats to validity & 2.50 & $\begin{array}{l}\text { Because most of the interventions have no control } \\
\text { group, and longitudinal data are not presented, there } \\
\text { is a high threat to validity. Control groups would } \\
\text { show impact. It is difficult to determine if the positive } \\
\text { findings should be attributed to the model. }\end{array}$ \\
\hline Replications & 4.50 & $\begin{array}{l}\text { There are several interventions using the Health } \\
\text { Realization Model reported. }\end{array}$ \\
\hline Dissemination Capability & 5.00 & $\begin{array}{l}\text { Since there is a Health Realization Institute, it is } \\
\text { assumed that adequate materials, technical }\end{array}$ \\
\hline
\end{tabular}


School Violence Prevention: Status of the Research and Research-Based Programs - A General Approach Page 1 of 3

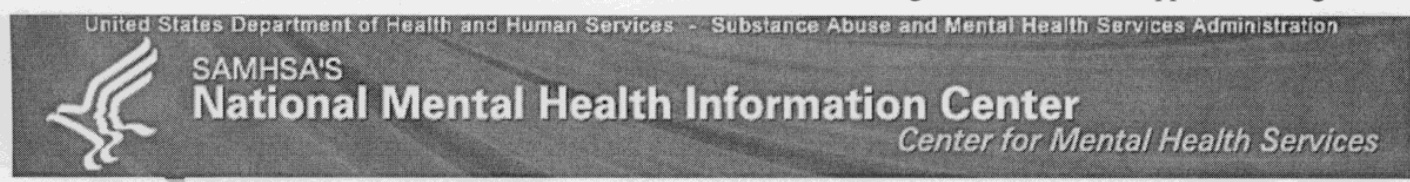

Home

Programs

Mental Health Topics

Newsroom

Publications

Resources

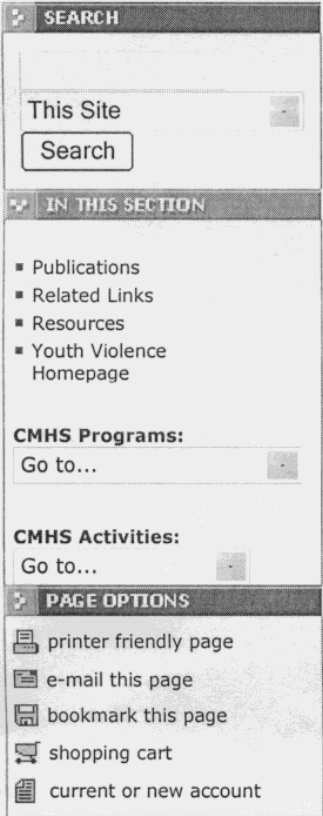

\section{Part II:}

Status of Research-Based Programs

\section{A General Approach Applied in Different Settings}

\section{Health Realization/Psychology of Mind}

\section{Dr. Roger Mills and Associates, Long Beach, California}

Health Realization programs, which have been widely applied in clinical, educational, and community settings, are based on the resiliency or strengthsbased paradigm known as Psychology of Mind (POM). Community psychologist Dr. Roger Mills and his colleagues began developing POM some 20 years ago in response to their recognition that existing paradigms were inadequate to address the multitude of personal and societal problems of their clients and the world they lived in.

POM proceeds from three assumptions about the basic nature of human psychological functioning:

- Thought is the source of human experience.

- Regardless of their current state of mental functioning, all people have the same innate capacity for healthy psychological functioning.

- There are two modes of thought, one related to memory and the other to healthy, common-sense, wiser intelligence (Mills, 1995; Pransky et al., 1997).

POM differs from cognitive therapy in that the latter proceeds from the premise that problems result from irrational beliefs, and that it is the content of thoughts that is at fault. POM, in contrast, focuses on the process of thought-that is, how we think. It is the quality of our thinking, not the content, that determines our stability. By coming to understand the process of our thinking, we can achieve an adaptive distancing from problems and can find healthy, hopeful, common sense approaches to dealing with those problems. Pransky et al. (1997) provide the comparison of cognitive and POM approaches shown in Table 5.

Table 5. Comparison of Cognitive Therapy and Psychology of Mind

\begin{tabular}{||l||l|l|}
\hline $\begin{array}{l}\text { Point of } \\
\text { Comparison }\end{array}$ & \multicolumn{1}{|c|}{ Cognitive } & \multicolumn{1}{c|}{ POM } \\
\hline \hline Source of problems & $\begin{array}{l}\text { Irrational beliefs and } \\
\text { unrecognized assumptions }\end{array}$ & $\begin{array}{l}\text { Failure to see, in the } \\
\text { moment, what thought is } \\
\text { and what it does }\end{array}$ \\
\hline \hline Specific focus on & Focus on what we think & Focus on that we think and \\
\hline
\end{tabular}

http://www.mentalhealth.samhsa.gov/schoolviolence/part2chp2.asp

$8 / 1 / 2006$ 
School Violence Prevention: Status of the Research and Research-Based Programs - A General Approach Page 2 of 3

\begin{tabular}{||l||l||l|}
\hline thought & & how we think \\
\hline \hline Assessment & $\begin{array}{l}\text { To identify dysfunctional } \\
\text { beliefs and assumptions }\end{array}$ & $\begin{array}{l}\text { To discover client's present } \\
\text { understanding of and use of } \\
\text { thought as a function }\end{array}$ \\
\hline \hline $\begin{array}{l}\text { Objective of } \\
\text { therapy }\end{array}$ & To renovate client's schema & $\begin{array}{l}\text { To teach client to recognize } \\
\text { the role of thought, moment } \\
\text { to moment }\end{array}$ \\
\hline \hline Therapy process & $\begin{array}{l}\text { Strategies and techniques to } \\
\text { address thought content }\end{array}$ & $\begin{array}{l}\text { Education to teach an } \\
\text { understanding of relevant } \\
\text { generic human psychological } \\
\text { functioning }\end{array}$ \\
\hline $\begin{array}{l}\text { View of moods and } \\
\text { the past }\end{array}$ & $\begin{array}{l}\text { Thinking is influenced by } \\
\text { moods and the past }\end{array}$ & $\begin{array}{l}\text { Moods and memory are } \\
\text { themselves thoughts }\end{array}$ \\
\hline \hline View of reality & Thought interprets reality & Thought creates reality \\
\hline
\end{tabular}

Source: Pransky, G.S., Mills, R.C., Sedgeman, J.A., \& Blevens, K. (1997). An emerging paradigm for brief treatment and prevention. In Vandecreek, L., Knapp, S., \& Jackson, T.L., Eds., Innovations in Clinical Practice: A Source Book, Vol. 15. Professional Resource Press: Sarasota, FL.

Mills and his colleagues call POM an educational process, and they provide training in a specific skill. However, they do so via the community psychology model of enlisting the interest and support of concerned and influential people in the community and by providing a facilitating environment staffed by exceedingly well-trained and supervised "teachers." Benard (1994b) notes that the Health Realization helper "sees all people as 'doing the best they can, given how things appear to them,' listens with compassion and without blame, and welcomes clients' active participation and ownership, being merely a guide and a coach in their quest to access their innate wisdom" (p. 2). She further notes that, while a number of traits of resilience are fostered throughout this process, the emergence of a strong sense of self-efficacy, social competence, problem-solving abilities, autonomy, and a sense of a bright future among previously "disempowered" people are especially noteworthy.

The Health Realization model has been applied in a variety of settings-with psychiatric inpatients and outpatients, in drug and alcohol rehabilitation programs, in schools, and in prisons. But perhaps nowhere are the data so compelling as in Mills's work in communities, especially in "hopeless" housing projects in urban areas such as Miami, the South Bronx, Minneapolis, and Oakland. After three years, results of the Health Realization project, which served 150 families and 650 youth in the Modello and Homestead Gardens Housing Projects in Miami, were as shown in Table 6.

Table 6. Results of the Health Realization Project in the Modello and Homestead Gardens Housing Projects

$\begin{array}{lll}\text { Risk Factors } & \text { Before } & \text { After } \\ \text { Households selling or using drugs } & 65 \% & 20 \% \\ \text { Overall crime rate } & \text { Endemic } & 70-80 \% \text { decrease } \\ \text { Teen pregnancy } & 50+\% & 10 \% \\ \text { School dropout rates } & 60 \% & 10 \%\end{array}$


School Violence Prevention: Status of the Research and Research-Based Programs - A General Approach Page 3 of 3

$\begin{array}{lll}\text { Child abuse and neglect } & \text { Endemic } & 70 \%+\text { decrease } \\ \text { Households on public assistance } & 85 \% & 35 \% \\ \text { School absenteeism/truancy } & 65 \% & \text { Negligible } \\ \text { Parent unemployment rate } & 85 \% & 35 \%\end{array}$

Source: Mills, R. (1997a). Psychology of Mind-Health Realization: Summary of clinical, prevention, and community empowerment applications documented outcomes. Unpublished paper.

Mills, R. (1997b). Comprehensive Health Realization community empowerment projects: List of completed and current projects. Unpublished paper.

Similarly, for Coliseum Gardens, a 200-unit public housing project that had the highest rates of homicide and drug-related arrests in the city of Oakland, California, Mills reports the following results for the Health Realization program:

- Homicides dropped by $100 \%$ (none reported in years 2 ).

- Violent crime was reduced by $45 \%$.

- Drug possession/sales decreased by $16 \%$.

- Assault with firearms was reduced by $38 \%$.

- Youth attendance and involvement in Boys and Girls Clubs increased by $110 \%$.

- Gang warfare and ethnic clashes between Cambodian and African American youth ceased.

- 62 families have members gainfully employed.

- $80 \%$ of residents participated in regular meetings with housing management and community police.

- 45 residents regularly participated in weekly empowerment classes (Mills, 1997a, 1997b).

While these and other data are impressive, Mills notes the need for a more rigorous evaluation process for the various Health Realization programs.

Table of Contents | Previous | Next 
Appendix B

Data from National Pilot Study in Instrument Validation Project

\section{Instrument Administration}

- Pre data from 477 participants of Foundations I class taught during 2000.

- Post data matched with 247 participants.

-6-month follow-up data matched with 59 participants.

- Data shows significant trends from baseline through 6-month follow-up.

\section{Data Analysis}

- Conducted a Principle Component Factor Analysis on pre data.

-5 factors explained over $47 \%$ of the variance for the first set of items (first 2 factors explained over $32 \%$ of the variance).

-2 factors explained over $42 \%$ of the variance for the second set of items.

\section{Factors for First Set of Items (4=Always,}

3Often, 2Sometimes, $1=$ Never)

- Factor 1: "Things people think are limitations to success."

*3 I worry.

*6. I get nervous when I have to make choices.

*29 I get stressed out.

*3Q My life takes effort.

*31. It's hard for me to get over feeling bad.

- Factor 2: "Things that people think are limitations to clarity."

*7 I work hard to avoid mistakes.

*15. I've got a lot on my mind.

*26. I feel the way I do because of stuff that happens around me. 
*37 Rude behavior annoys me.

$$
{ }^{*} \mathrm{p}<005 \text { pre-post, } \quad \text { pre- } 6 \mathrm{moF} / \mathrm{U} \mathrm{P} \cdot \mathrm{p}-\mathrm{p}
$$

\section{Understanding of Experience Scale (Part I: Q1- 37) \\ "The degree to which people find life difficult." \\ (4=Always, $3=$ Often, $2=$ Sometimes, $1=$ Never)}

Factor 1: Things people think are linitations to success.

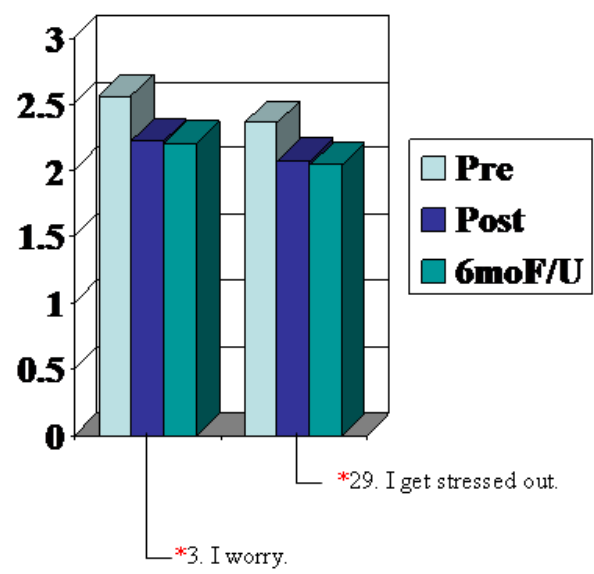

] ]

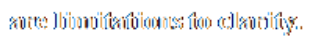

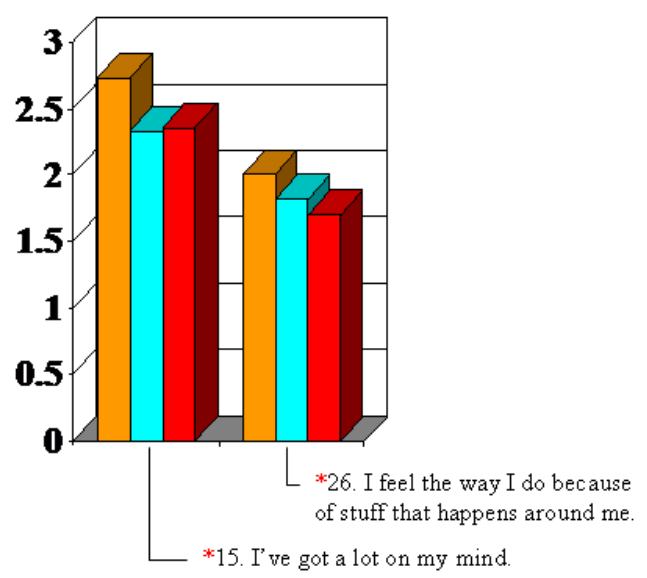

\section{Data Analysis}

- Conducted a Principle Component Factor Analysis on pre data.

-5 factors explained over $47 \%$ of the variance for the first set of items (first 2 factors explained over $32 \%$ of the variance)

-2 factors explained over $42 \%$ of the variance for the second set of items.

\section{Factors for Second Set of Items}

(4 Strongly Agree, 3 Agree, 2= Disagree, 1 Strongly

Disagree) 
Factor 1: "People's understanding of their own states of mind."

— * 1. When I'm in a bad mood, I feel I have to do something to get over it.

— $* 2$. When I cant figure something out, I get frustrated.

— $* 17$. When I fail at something, I start to doubt myself.

$* 18$. When I have a lot to do, I get really tense.

Factor 2: People's understanding of their own resiliency."

— *6. When I'm unhappy, I know it won't last.

— *9 When I'm down, I don't take my thinking seriously.

—*12. When I'm upset, I calm down before acting.

— *15. When someone hurts me, I know I'll get over it.

${ }^{*} \mathrm{p}<005$ pre-post, ${ }^{*} \mathrm{p}<0.05$ pre-post pre- $6 \mathrm{mo} \mathrm{F} / \mathrm{U}$

\section{Understanding of Experience Scale (Part II: Q1- 19)}

"Concerning people's state of mind."

(4=Strongly Agree, 3=Agree, 2=Disagree, 1=Strongly Disagree)

Factor 1: People's understanding

of their own strtes of mind.

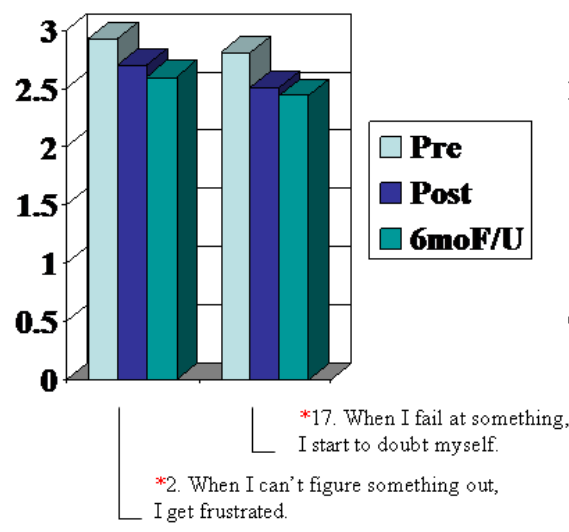

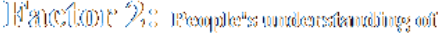

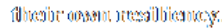

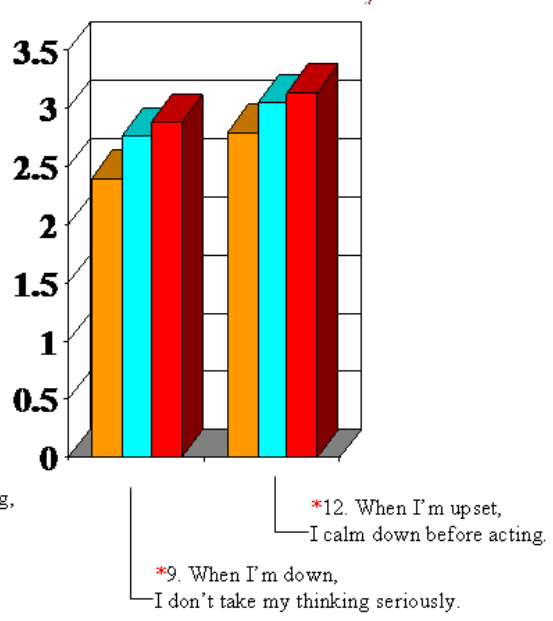


Appendix C

Grand Rounds PowerPoint Presentation

\section{Understanding the Effect of Innate Health in our Professional and Personal Lives}

James M. Shumway, Ph.D.

Judith Sedgeman, M.A.

Dept. of Internal Medicine

25 January, 2002 


\section{Review of Cognitive Psychology}

- Premise: cognitive processes exert powerful effects on emotions and behaviors. (What we think strongly affects how we feel and what we do.)

- Cognitive Intervention premise: many psychological disorders stem from faulty or distorted thought. (Change the thoughts and the disorders can be alleviated.)

\section{Types of Cognitive Therapy}

- Rational-Emotive Therapy (Overcoming irrational beliefs. $)^{1}$

- Beck's Cognitive Behavior Therapy for Depression (Overcoming self-defeating modes of thought.) ${ }^{2}$

- Constructivist Cognitive Therapy (Overcoming dysfunctional thought patterns acquired early in life and the strong emotions associated with these thoughts. $)^{3}$ 


\section{Cognitive Restructuring}

- Premise: "much of psychotherapy ... is based on the assumption that reorganizing and restructuring a patient's verbal statements about himself and his world will result in a corresponding reorganization of the patient's behavior with respect to that world."1

- Therapies:

- Cognitive Behavior Modification ${ }^{2}$

- Reframing (or called Relabeling) ${ }^{3}$

- Stress Inoculation ${ }^{4}$ (developing palliative coping strategies)

\section{Mind-Body relaxation techniques}

- Premise: People can practice techniques that help them manage their thinking to quiet their minds and relax their bodies to provide the stress-releasing benefits of temporary rest and repose.

- Example: Herbert Benson, M.D., President and Founder of the Mind/Body Medical Institute at Harvard has studied "the relaxation response" and "healing" effects for nearly 30 years among people who meditate or practice relaxation methods. 


\section{Self-efficacy and Resiliency}

- Premise: Numerous cognitive-behavioral approaches build coping skills and emphasize self-esteem through focusing on people's positive thinking and behaviors and teaching people to concentrate on their strengths and learn more resilient behaviors by imitating observed resilient behaviors in others.

\section{Learned Optimism and Emotional Intelligence}

- Seligman suggests that people can learn to choose optimistic thinking over pessimistic thinking by learning a set of cognitive skills in a cognitivebehavioral model that emphasizes teaching people to notice and then change their thoughts. ${ }^{1}$

- Goleman separates intellect from emotion and suggests that people learn to identify their emotions, and then learn what to do with various emotions. He suggests two different kinds of "intelligence," emotional and rational, both of which must be developed in harmony. ${ }^{2}$ 


\title{
Common assumptions of current stress/distress interventions:
}

1. Problems are external to people and must be taken seriously and addressed.

2. Thoughts people have are fixed and substantive and the content of nonconstructive thoughts must also be taken seriously and addressed.

\section{Paradigm for most models}

\author{
External Factors $\Rightarrow$ What we \\ think and feel
}

Outside-in 


\section{Intervention plan for most models}

We will use methods that fix external factors and reframe the contents of your thinking in order for you to feel better.

Outside-in 


\section{Intervention Assumptions for the Innate Health models}

1. "Problems" are the internal experience of thoughts of doubt, uncertainty or difficulty over time.

2. It is innate to people to experience a dynamic, responsive flow of thoughts.

3. When people recognize the nature of thought as an innate power, the content of their thinking is less fixed, and they see how to change and adapt with resilience.

\section{Paradigm of innate health model}

Understanding

how thoughts and $\Rightarrow$

feelings are created
Experiencing

factors

Inside -out 


\section{Intervention plans for innate health models}

We work together to learn how thinking works so you can realize how your perceived reality changes as your thinking changes and see how to gain insights to address your life circumstances .

\section{Research vision for SBIIH $(2000-2010)$}

\section{-Evaluate behavioral effects (Education and} Prevention)

-Evaluate therapeutic effects

- Evaluate biochemical and physiological effects 


\section{Research vision for SBIIH}

\section{EDUCATION \& PREVENTION}

- Develop and validate instrument to measure internal experience of health and behavioral outcomes of that experience

- Evaluate SBIIH educational model that is designed to reduce and prevent stress

- Evaluate behavioral outcomes over time 


\section{The Continuum of Research into Human Understanding}

- Descriptive Phase

- Descriptive research defines the phenomenon or concept you wish to measure and develops agreed upon terminology for talking about the concept.

- Reflective Phase

- As with thinking, research also requires reflective activity. In research terms, reflection suggests the generation of ideas and hypotheses.

- Analytical Phase

- This is what most of us think research "really is". At this point observations are collected of the ways in which various groups respond to different levels of the phenomenon.

- Evaluative Phase

- Evaluation involves judgment and placing value on a phenomenon, often comparing one understanding with other conceptualizations. It entails a thorough understanding of criteria, standards, generalizability of findings, and the value society assigns to things.

\section{Instrument Development Cycle}

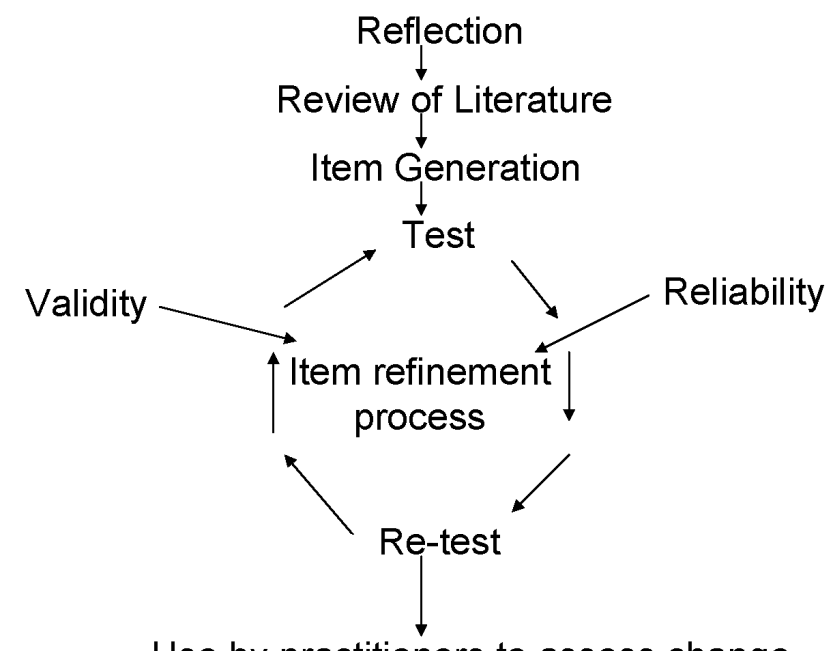

Use by practitioners to assess change due to understanding of the principles.

Establish norms and refine for various populations. 


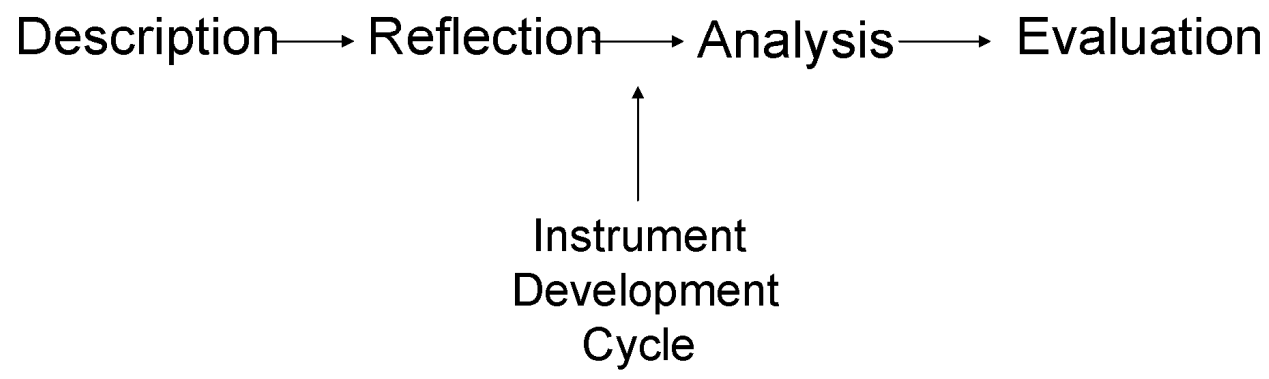

\section{Instrument Administration}

- Pre data from 477 participants of Foundations I class taught during 2000.

- Post data matched with 247 participants.

- 6-month follow-up data matched with 59 participants.

- Data shows significant trends from baseline through 6-month follow-up. 


\section{Data Analysis}

\section{- Conducted a Factor Analysis on pre data.}

- Principle Component Analysis using Varimax Rotation with Kaiser Normalization

- 5 factors explained over $47 \%$ of the variance for the first set of items (first 2 factors explained over $32 \%$ of the variance).

- 2 factors explained over $42 \%$ of the variance for the second set of items.

\section{Factors for UES-Part I}

(4=Always, 3=Often, 2=Sometimes, 1=Never)

- Factor 1: "Things people think are limitations to success."

*3. I worry.

${ }^{*} 6$. I get nervous when I have to make choices.

*29. I get stressed out.

*30. My life takes effort.

*31. It's hard for me to get over feeling bad.

- Factor 2: "Things that people think are limitations to clarity."

${ }^{*} 7$. I work hard to avoid mistakes.

*15. I've got a lot on my mind.

*26. I feel the way I do because of stuff that happens around me.

*37. Rude behavior annoys me. 


\section{Factors for UES-Part II}

(4=Strongly Agree, 3=Agree, 2=Disagree, 1=Strongly Disagree)

- Factor 1: "People's understanding of their own states of mind."

- *1. When I'm in a bad mood, I feel I have to do something to get over it.

- ${ }^{\star}$ 2. When I can't figure something out, I get frustrated.

- ${ }^{* 17 . ~ W h e n ~ I ~ f a i l ~ a t ~ s o m e t h i n g, ~ I ~ s t a r t ~ t o ~ d o u b t ~ m y s e l f . ~}$

- *18. When I have a lot to do, I get really tense.

- Factor 2: People's understanding of their own resiliency."

- *6. When I'm unhappy, I know it won't last.

- ${ }^{*} 9$. When l'm down, I don't take my thinking seriously.

- ${ }^{*} 12$. When I'm upset, I calm down before acting.

- ${ }^{\star} 15$. When someone hurts me, I know l'll get over it.

\section{Statistical Analysis}

- Pairwise t-tests were performed for comparison of pretest data with posttest data because samples were not independent.

- For comparison of pre-post-6moF/U data a one-way repeated measures ANOVA was performed.

- Pairwise post-hoc comparison of contrast tests were performed when differences were found in pre-post$6 \mathrm{moF} / \mathrm{U}$ data. 


\section{Understanding of Experience Scale (Part I: Q1-37) \\ "The degree to which people find life difficult." \\ 4=Always, 3=Often, 2=Sometimes, 1=Never}

Factor 1: Things people think are limitations to success.

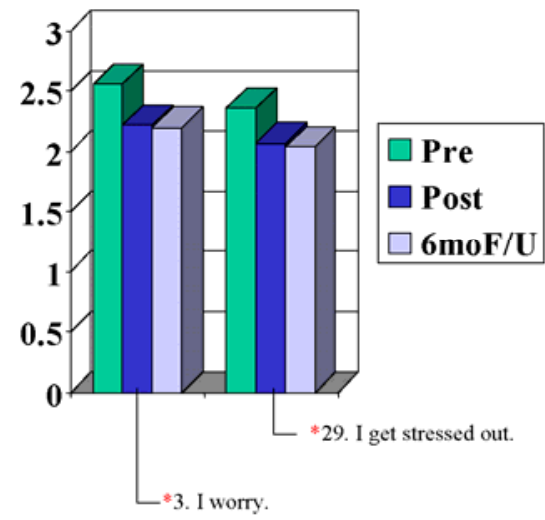

Factor 2: Things that people think are limitations to clarity.

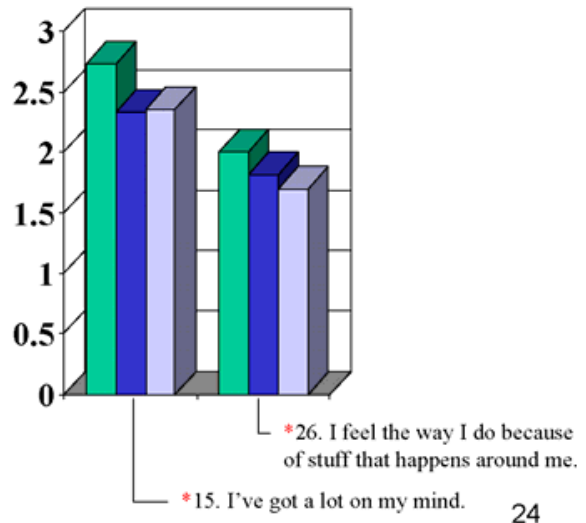

\section{Understanding of Experience Scale (Part II: Q1-19)}

"Concerning people's state of mind." 4=Strongly Agree, 3=Agree, 2=Disagree, 1=Strongly Disagree

Factor 1: People's understanding of their own states of mind.

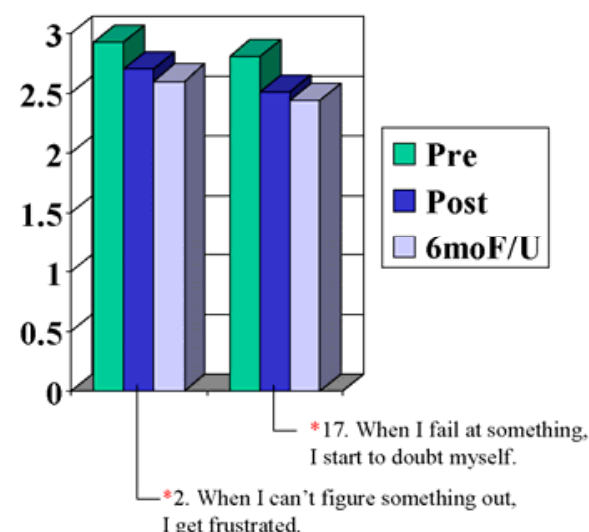

Factor 2: People's understanding of their own resiliency.

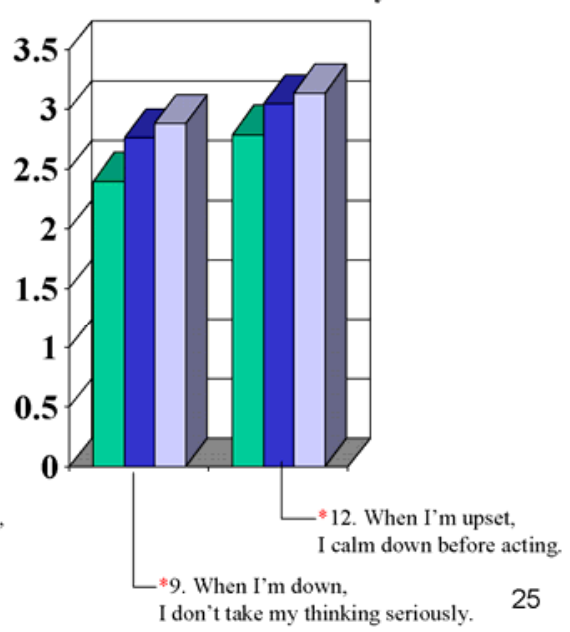




\section{Limitations}

- No comparison groups, therefore cannot control for history (other changes) over time.

- Were unable to match more surveys based on ID code since completion was voluntary.

- Follow-up completion has not been as strong as prepost completion.

- What if only those who showed "positive" changes choose to supply ID codes?

\section{Next Steps}

- Decrease the number and refine the items based on factor analysis. Analyze and combine with alternative scales.

- Create meaningful subscales based on factor analysis.

- Analyze the data according to demographic categories.

- Compare instrument to re-administration and standardized measures to assess reliability and validity.

- Implement designs that test for placebo effects using controls.

- Work with other institutions and organizations wishing to use the instrument. 


\section{Research initiative}

- Hypothesis we are studying:

- Will a simple educational program that provides an explanation and experience of the understanding of thought as a power that generates an constantly changing experience of reality, delivered in a safe seminar-type group setting, result in people learning how to lower their own levels of stress and distress over time? 
Appendix D

SF-36 Health Survey

\section{Your Health and Well-Being}

This survey asks for your views about your health. This information will help keep track of how you feel and how well you are able to do your usual activities. Thank you for completing this survey!

For each of the following questions, please mark an $\triangle$ in the one box that best describes your answer.

1. In general, would you say your health is:

\begin{tabular}{|lclll|}
\hline Excellent & Very good & Good & Fair & Poor \\
$\square_{1}$ & $\square_{2}$ & $\square_{3}$ & $\square_{4}$ & $\nabla$ \\
\hline
\end{tabular}

2. Compared to one year ago, how would you rate your health in general now?

$\begin{array}{|ccccc|}\begin{array}{c}\text { Much better } \\ \text { now than one } \\ \text { year ago }\end{array} & \begin{array}{c}\text { Somewhat } \\ \text { better now } \\ \text { than one year } \\ \text { ago }\end{array} & \begin{array}{c}\text { About the } \\ \text { same as one } \\ \text { year ago }\end{array} & \begin{array}{c}\text { Somewhat } \\ \text { worse now } \\ \text { than one year } \\ \text { ago }\end{array} & \begin{array}{c}\text { Much worse } \\ \text { now than one } \\ \text { year ago }\end{array} \\ \square_{1} & \square_{2} & \square_{3} & \square_{4} & \square\end{array}$




\section{The following questions are about activities you might do during a typical day. Does your health now limit you in these activities? If so, how much?}

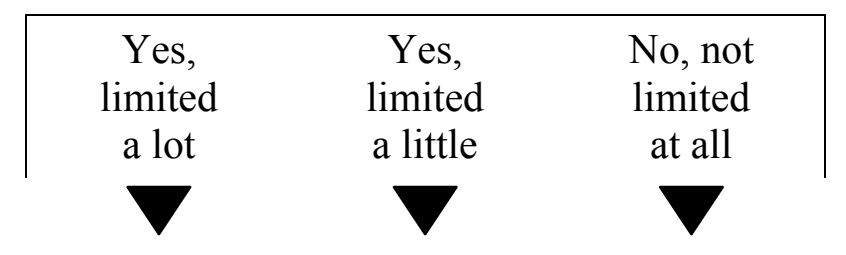

a Vigorous activities, such as running, lifting heavy objects, participating in strenuous sports

b Moderate activities, such as moving a table, pushing a vacuum cleaner, bowling, or playing golf

c Lifting or carrying groceries

${ }_{d}$ Climbing several flights of stairs.

e Climbing one flight of stairs.

f Bending, kneeling, or stooping.

g Walking more than a mile

h Walking several hundred yards

i Walking one hundred yards

j Bathing or dressing yourself. 


\section{During the past 4 weeks, how much of the time have you had any of the following problems with your work or other regular daily activities as a result of your physical health?}

All of Most of Some of A little
the time the time the time
of the
time time

a Cut down on the amount of time you spent on work or other activities

b Accomplished less than you would like.

c Were limited in the kind of work or other activities

d Had difficulty performing the work or other activities (for example, it took extra effort)

5. During the past 4 weeks, how much of the time have you had any of the following problems with your work or other regular daily activities as a result of any emotional problems (such as feeling depressed or anxious)?

a Cut down on the amount of time you spent $\begin{array}{cccc}\begin{array}{c}\text { All of } \\ \text { the time }\end{array} \text { Most of } \begin{array}{l}\text { Some of } \\ \text { the lime the time } \\ \text { of the } \\ \text { time }\end{array} & \begin{array}{l}\text { None of } \\ \text { the time }\end{array}\end{array}$ on work or other activities.

b Accomplished less than you would like 
c Did work or other activities less carefully than usual

6. During the past 4 weeks, to what extent has your physical health or emotional problems interfered with your normal social activities with family, friends, neighbors, or groups?

\begin{tabular}{|lcccc|}
\hline Not at all & Slightly & Moderately & Quite a bit & Extremely \\
$\square_{1}$ & $\square_{2}$ & $\square_{3}$ & $\square_{4}$ & $\square_{5}$
\end{tabular}

7. How much bodily pain have you had during the past 4 weeks?

\begin{tabular}{|cccccc|}
\hline None & Very mild & Mild & Moderate & Severe & Very Severe \\
$\square_{1}$ & $\square_{2}$ & $\square_{3}$ & $\square_{4}$ & $\square_{5}$ & $\square_{6}$
\end{tabular}

8. During the past 4 weeks, how much did pain interfere with your normal work (including both work outside the home and housework)?

\begin{tabular}{|lcccc|}
\hline Not at all & A little bit & Moderately & Quite a bit & Extremely \\
$\square_{1}$ & $\square_{2}$ & $\square_{3}$ & $\square_{4}$ & $\square_{5}$
\end{tabular}


9. These questions are about how you feel and how things have been with you during the past 4 weeks. For each question, please give the one answer that comes closest to the way you have been feeling. How much of the time during the past 4 weeks...

\begin{tabular}{|c|c|c|c|}
\hline $\begin{array}{l}\text { All of } \\
\text { the time }\end{array}$ & $\begin{array}{l}\text { Most of } \\
\text { the time }\end{array}$ & $\begin{array}{l}\text { Some of } \\
\text { the time }\end{array}$ & $\begin{array}{l}\text { A little } \\
\text { of the } \\
\text { time }\end{array}$ \\
\hline
\end{tabular}

a Did you feel full of life?

b Have you been very nervous?

c Have you felt so down in the dumps that nothing could cheer you up?

d Have you felt calm and peaceful?

. Did you have a lot of energy?

f Have you felt downhearted and depressed?

g Did you feel worn out?

h Have you been happy?

i Did you feel tired?.

10. During the past 4 weeks, how much of the time has your physical health or emotional problems interfered with your social activities (like visiting friends, relatives, etc.)?

$\begin{array}{|ccccc|}\begin{array}{c}\text { All of the } \\ \text { time }\end{array} & \begin{array}{c}\text { Most of the } \\ \text { time }\end{array} & \begin{array}{c}\text { Some of the } \\ \text { time }\end{array} & \begin{array}{c}\text { A little of the } \\ \text { time }\end{array} & \begin{array}{c}\text { None of the } \\ \text { time }\end{array} \\ \square_{1} & \square_{2} & \square_{3} & \square_{4} & \square\end{array}$




\section{How TRUE or FALSE is each of the following statements for you?}

a I seem to get sick a little easier

\begin{tabular}{|ccccc|}
\hline $\begin{array}{c}\text { Definitely } \\
\text { true }\end{array}$ & $\begin{array}{c}\text { Mostly } \\
\text { true }\end{array}$ & $\begin{array}{c}\text { Don't } \\
\text { know }\end{array}$ & $\begin{array}{c}\text { Mostly } \\
\text { false }\end{array}$ & $\begin{array}{c}\text { Definitely } \\
\text { false }\end{array}$ \\
\hline & $\nabla$ & $\nabla$ & $\nabla$ & $\nabla$
\end{tabular}
than other people.
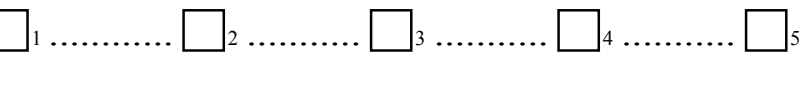

b I am as healthy as anybody I know ........ $\square_{1} \ldots \ldots \ldots \ldots . \square_{2} \ldots \ldots \ldots . . \square_{3} \ldots \ldots \ldots \ldots \square_{4} \ldots \ldots \ldots \ldots . \square_{5}$

. I expect my health to get worse<smiles>[18OH]</smiles><smiles>[GeH3]</smiles><smiles>C1CCC1</smiles><smiles>[GeH2]C1[CH][CH][CH]1</smiles>

d My health is excellent.<smiles>C1=CCC1</smiles> 
Appendix E

SBI-64 Questionnaire

Today's Date

Unique ID\#

(last four digits of your SS\#)

Page $1 / 3$

\section{SBI Questionnaire}

You will be asked to respond to this questionnaire both before and after completing the seminar/activity. For that reason, we ask you to write the last four digits of your Social Security number in the space provided on each page of the questionnaire. Recording this number will preserve your anonymity while allowing us to match your initial and subsequent responses. Please respond to each of the following statements in terms of what you generally think. Use the scale below to mark the square for your response. Please be sure to respond to each statement. There are no right and wrong answers.

\section{Agree Tend to Tend to Agree Disagree}

\begin{tabular}{|lllll|}
\hline 1. It's hard for me to forgive. & $\square$ & $\square$ & $\square$ & $\square$ \\
\hline 2. I am grateful. & $\square$ & $\square$ & $\square$ & $\square$ \\
\hline 3. When I'm upset, I calm down before acting. & $\square$ & $\square$ & $\square$ & $\square$ \\
\hline 4. My life is difficult. & $\square$ & $\square$ & $\square$ & $\square$ \\
\hline 5. I take time for myself. & $\square$ & $\square$ & $\square$ & $\square$ \\
\hline 6. I experience unconditional love. & $\square$ & $\square$ & $\square$ & $\square$ \\
\hline 7. I am easily upset. & $\square$ & $\square$ & $\square$ & $\square$ \\
\hline 8. Life is stressful. & $\square$ & $\square$ & $\square$ & $\square$ \\
\hline 9. I enjoy learning. & $\square$ & $\square$ & $\square$ & $\square$ \\
\hline 10. When l'm feeling blue, I don't take it & $\square$ & $\square$ & $\square$ & $\square$ \\
seriously. & & & & $\square$ \\
\hline 11. I feel impatient. & $\square$ & $\square$ & $\square$ & $\square$ \\
\hline 12. People do the best they can. & $\square$ & $\square$ & $\square$ & $\square$ \\
\hline 13. I trust my own wisdom. & $\square$ & $\square$ & $\square$ & $\square$ \\
\hline 14. I struggle to avoid mistakes. & $\square$ & $\square$ & $\square$ & $\square$ \\
\hline
\end{tabular}




\begin{tabular}{|c|c|c|c|c|}
\hline 15. I enjoy helping others. & $\square$ & $\square$ & $\square$ & $\square$ \\
\hline $\begin{array}{l}\text { 16. When someone hurts me, I know l'll get } \\
\text { over it. }\end{array}$ & $\square$ & $\square$ & $\square$ & $\square$ \\
\hline 17. My ideas are better than others'. & $\square$ & $\square$ & $\square$ & $\square$ \\
\hline 18. My life is boring. & $\square$ & $\square$ & $\square$ & $\square$ \\
\hline 19. I know I will be okay. & $\square$ & $\square$ & $\square$ & $\square$ \\
\hline 20.1 believe that people can change. & $\square$ & $\square$ & $\square$ & $\square$ \\
\hline $\begin{array}{l}21 . \text { I feel the way I do because of stuff that } \\
\text { happens around me }\end{array}$ & $\square$ & $\square$ & $\square$ & $\square$ \\
\hline 22. Anything is possible. & $\square$ & $\square$ & $\square$ & $\square$ \\
\hline 23. I get nervous when I have to make choices. & $\square$ & $\square$ & $\square$ & $\square$ \\
\hline 24. I can't escape my past. & $\square$ & $\square$ & $\square$ & $\square$ \\
\hline $\begin{array}{l}\text { 25. When I can't figure something out, I get } \\
\text { frustrated. }\end{array}$ & $\square$ & $\square$ & $\square$ & $\square$ \\
\hline Part II & Agree & $\begin{array}{l}\text { Tend to } \\
\text { Agree }\end{array}$ & $\begin{array}{l}\text { Tend to } \\
\text { Disagree }\end{array}$ & Disagree \\
\hline 26. Some people are beyond help. & $\square$ & $\square$ & $\square$ & $\square$ \\
\hline 27. Rude behavior affects me. & $\square$ & $\square$ & $\square$ & $\square$ \\
\hline 28. Making decisions is hard work. & $\square$ & $\square$ & $\square$ & $\square$ \\
\hline 29. People need to be told what to do. & $\square$ & $\square$ & $\square$ & $\square$ \\
\hline 30.1 can adjust to new things. & $\square$ & $\square$ & $\square$ & $\square$ \\
\hline 31. I see humor in life. & $\square$ & $\square$ & $\square$ & $\square$ \\
\hline 32.I don't stay frustrated. & $\square$ & $\square$ & $\square$ & $\square$ \\
\hline 33. When I'm unhappy, I believe it won't last. & $\square$ & $\square$ & $\square$ & $\square$ \\
\hline 34. People take advantage of me. & $\square$ & $\square$ & $\square$ & $\square$ \\
\hline 35. I worry. & $\square$ & $\square$ & $\square$ & $\square$ \\
\hline 36. I'm not creative. & $\square$ & $\square$ & $\square$ & $\square$ \\
\hline 37. I'm doing the best I can. & $\square$ & $\square$ & $\square$ & $\square$ \\
\hline 38. Change is easy for me. & $\square$ & $\square$ & $\square$ & $\square$ \\
\hline 39. I feel out of control. & $\square$ & $\square$ & $\square$ & $\square$ \\
\hline 40.I respect other's opinions. & $\square$ & $\square$ & $\square$ & $\square$ \\
\hline
\end{tabular}




$\left.\begin{array}{|lllll|}\hline \text { 41. When I have a lot to do, I get really tense. } & \square & \square & \square & \square \\ \hline \text { 42.I don't like to get embarrassed. } & \square & \square & \square & \square \\ \hline \text { 43. I'm curious. } & \square & \square & \square & \square \\ \hline \text { 44.I have difficulty getting over things. } & \square & \square & \square & \square \\ \hline \text { 45.I feel resentful. } & \square & \square & \square & \square \\ \hline \begin{array}{l}\text { 46. When I feel stressed, I bounce back } \\ \text { quickly. }\end{array} & \square & \square & \square & \square \\ \hline \text { 47.I worry about my life. } & \square & \square & \square & \square \\ \hline \text { 48. I've got a lot on my mind. } & \square & \square & \square & \square \\ \hline \text { 49.I listen to others. } & \square & \square & \square & \square \\ \hline \text { 50.I avoid upsetting situations. } & \square & \square & \square & \square \\ \hline \text { 51. When I'm in a bad mood, I feel I have to } \\ \text { do something to get over it. }\end{array}\right)$

Please provide the following demographic information:

(1) Gender:

Female Male 
(2) Date of Birth:

1

(3) Ethnic Group:

Native American or Alaskan Native

African American

Asian or Pacific Islander

Hispanic

Caucasian (non-Hispanic)

(4) Highest level of education you have completed:

_ Grade School

High School

Trade School

_ College

_ Graduate Degree

(5) How many hours have you spent learning about these ideas? hrs.

THANK YOU FOR COMPLETING THE SBI QUESTIONNAIRE 
Appendix F

Interim Report to Morgantown High School Principal

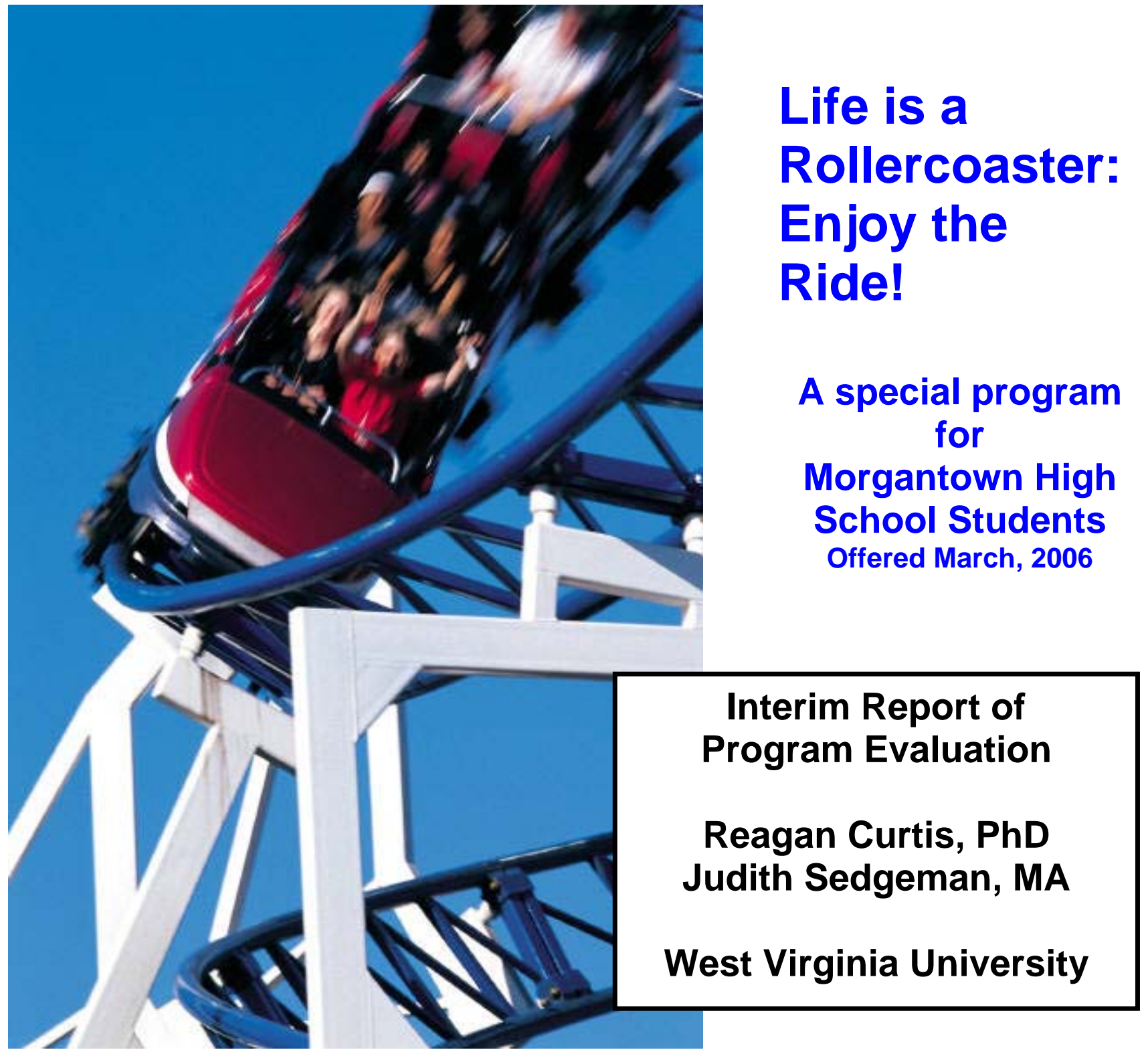




\title{
LOGIC MODEL FOR PROGRAM ASSESSMENT
}

\author{
"LIFE IS A ROLLERCOASTER: ENJOY THE RIDE!"
}

Especially developed for students at

Morgantown High School

by

Judith A. Sedgeman

West Virginia Initiative for Innate Health

\begin{tabular}{|ll|}
\hline $\begin{array}{l}\text { Objectives } \\
\text { - Students will understand how and why } \\
\text { people experience a "rollercoaster ride" } \\
\text { of emotions; }\end{array}$ & $\begin{array}{l}\text { Outcomes } \\
\text { - Students are able to self-correct and } \\
\text { require less attention/intervention. }\end{array}$ \\
$\begin{array}{l}\text { - Students will understand how the } \\
\text { human mind works naturally to bring } \\
\text { us back into balance; }\end{array}$ & $\begin{array}{l}\text { - Students display fewer emotional } \\
\text { reactions or outbursts. }\end{array}$ \\
- $\begin{array}{l}\text { Students will understand how and why } \\
\text { people can override that natural } \\
\text { resiliency; }\end{array}$ & $\begin{array}{l}\text { Students display fewer hostile, negative } \\
\text { or dangerous behaviors. }\end{array}$ \\
- $\begin{array}{l}\text { Students will learn how they can } \\
\text { reconnect to their own common sense } \\
\text { and wisdom when they need it most. }\end{array}$ & $\begin{array}{l}\text { The "tone" or "climate" of student life } \\
\text { is less stressful and more positive and } \\
\text { constructive. }\end{array}$ \\
\hline
\end{tabular}

\begin{tabular}{|l|}
\hline Data is \\
collected from \\
administration \\
reflecting \\
attendance, \\
discipline, etc. \\
in the weeks \\
preceding and \\
following the \\
program. \\
\hline
\end{tabular}
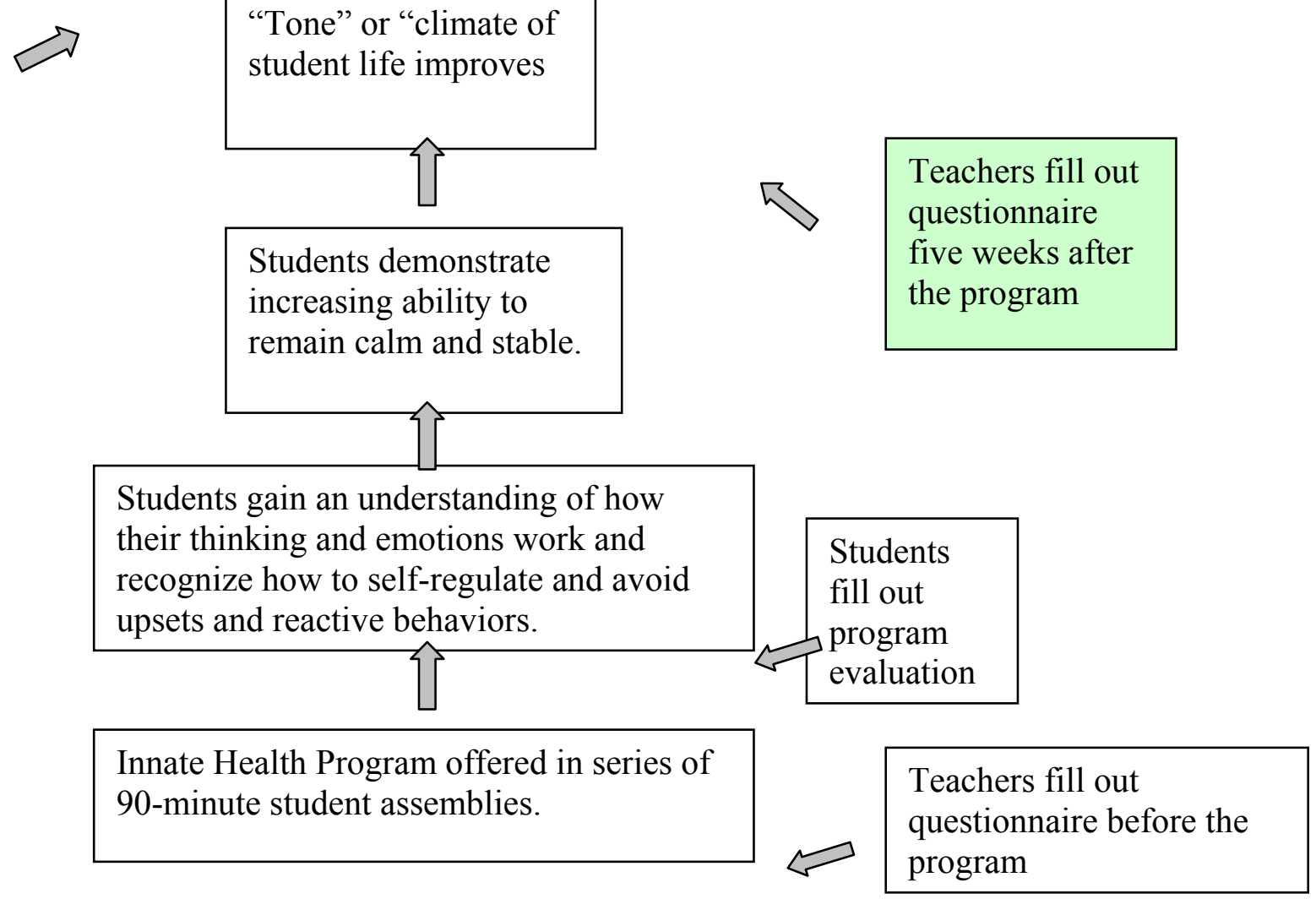


\section{Average Responses to the Questionnaire $(\mathbf{n}=\mathbf{8 0 6})$}

\section{Student Questionnaire Morgantown High School Innate Health Program Evaluation}

Please rate the program you just attended. Check the box that applies to each statement.

1. The program held my attention and made sense to me.

\begin{tabular}{ccccc} 
not at all & a little bit & pretty much & very much & completely \\
\hline & 2.5 & $\square$
\end{tabular}

2. The examples and stories helped me to get the point.

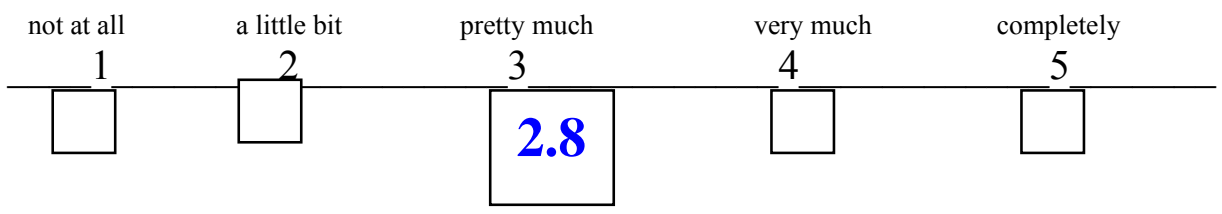

3. The presenter showed respect for students.

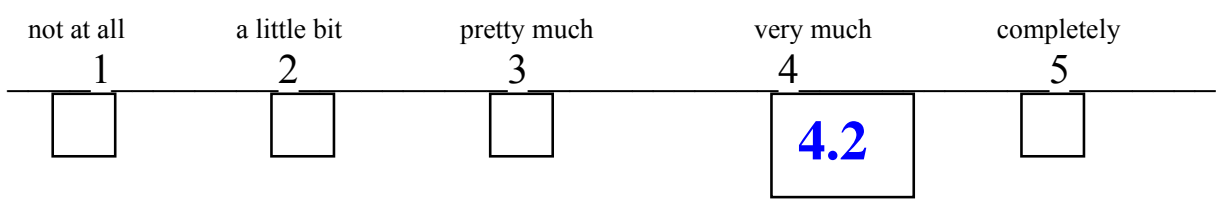

4. This program helped me understand why people get upset and how people calm down.

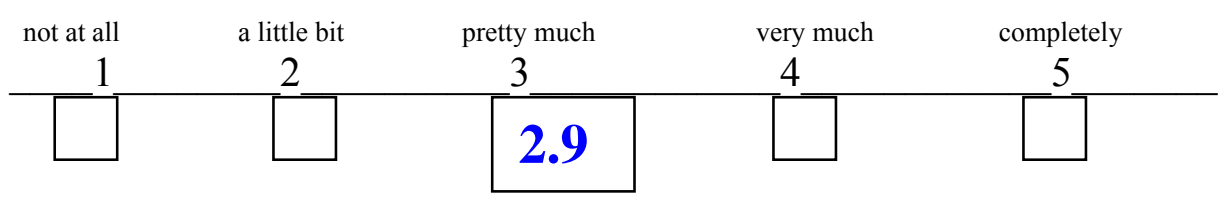

5. I think programs on this topic should be presented to students every year.

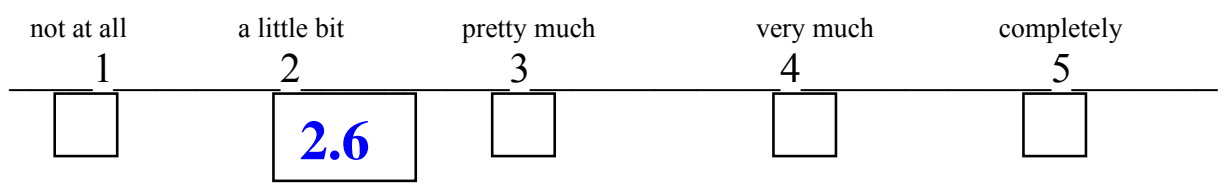

6. Please add any other comments you would like to make about the program: 


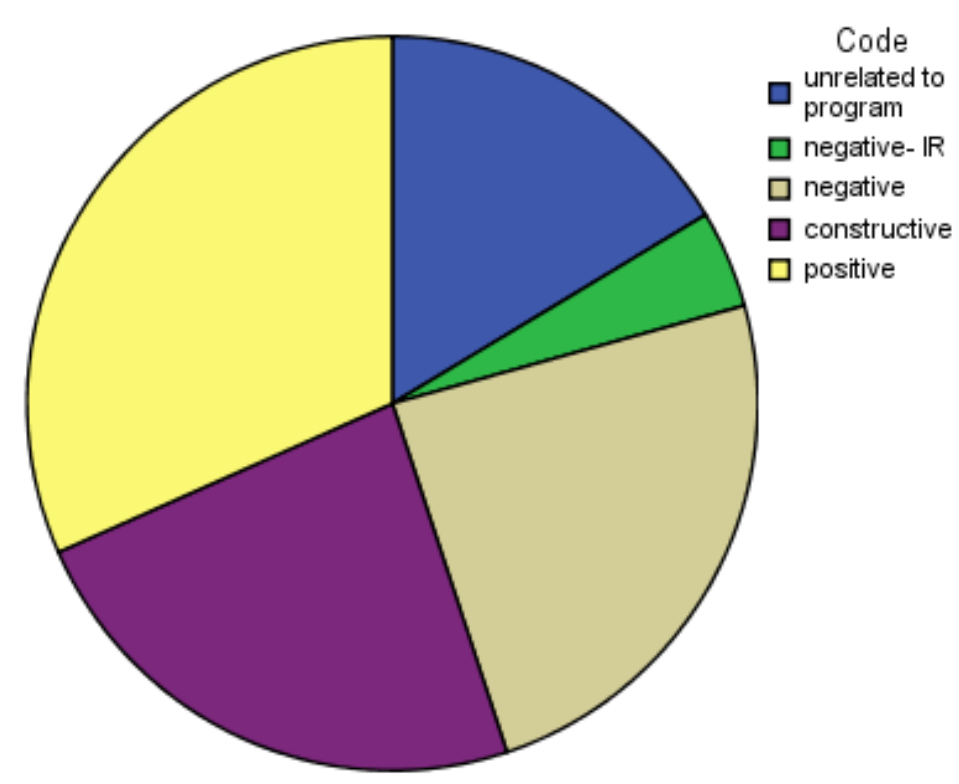

\section{Student Responses to Programs (806 respondents)}

\section{Sample comments for each category:}

\section{Unrelated to program:}

- "Nice sweater."

- "Save the whales!"

\section{Negative IR:}

- "Seeing as this was my study period, I was looking forward to studying and therefore didn't pay as much attention as I could have."

- "I missed make up."

\section{Negative:}

- "It made me go to sleep."

- "I have no idea what the point of this presentation was."

\section{Constructive:}

- "Maybe not as drawn out, or more colorful \& eye catching to hold attention."

- "This was helpful, it would be better in small groups."

\section{Positive:}

- "The presenter was very knowledgeable, understanding and was flexible towards students."

- "Very good, helped me to understand how to overcome my own problems. Very nice, respectful presenter. 


\section{Average of responses from the questionnaires $(n=46)$}

\section{Teacher Questionnaire Morgantown High School Innate Health Program Evaluation}

1. About how many times in the past 5 weeks have you observed students fighting or engaged in conduct that you consider hostile or dangerous?

\section{5}

2. About how many times in the past 5-weeks have you observed students in emotional reactions?

\section{2}

3. On a scale of 1 to 5,1 being never stressed at all and 5 being stressed most of the time, how would you rate the stress level among your students?

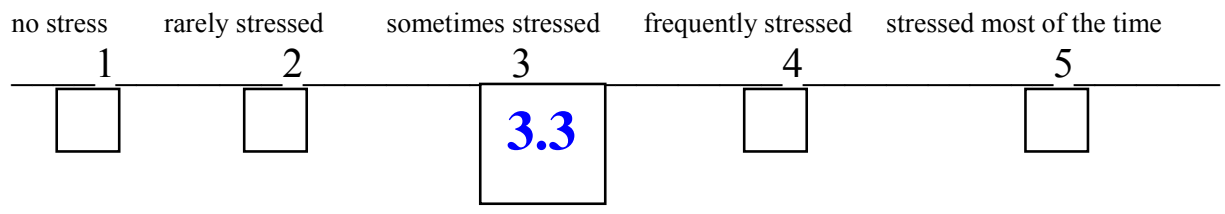

4. On the same scale, how would you rate your stress level when you are dealing with upset students?

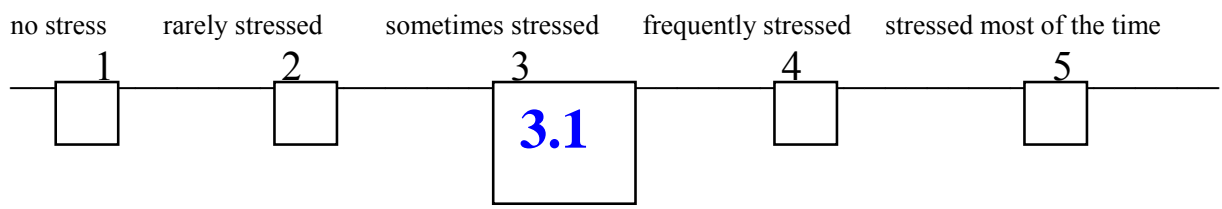

5. On a scale of 1 to 5, 1 being never and 5 being most of the time, how often do you observe that students have the ability to calm down and regulate their own behavior?

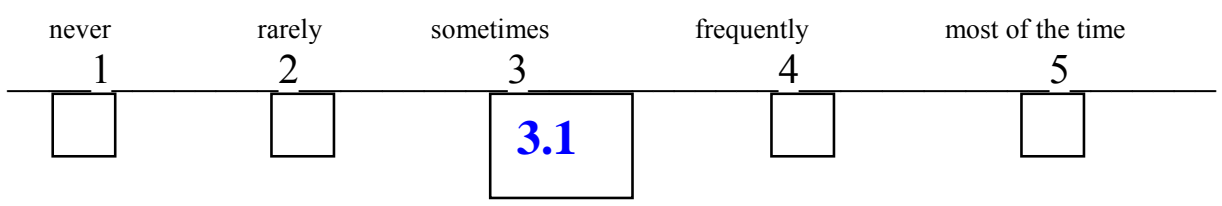

6. Are there any other observations you would like to make about stress levels or student behaviors at MHS? 


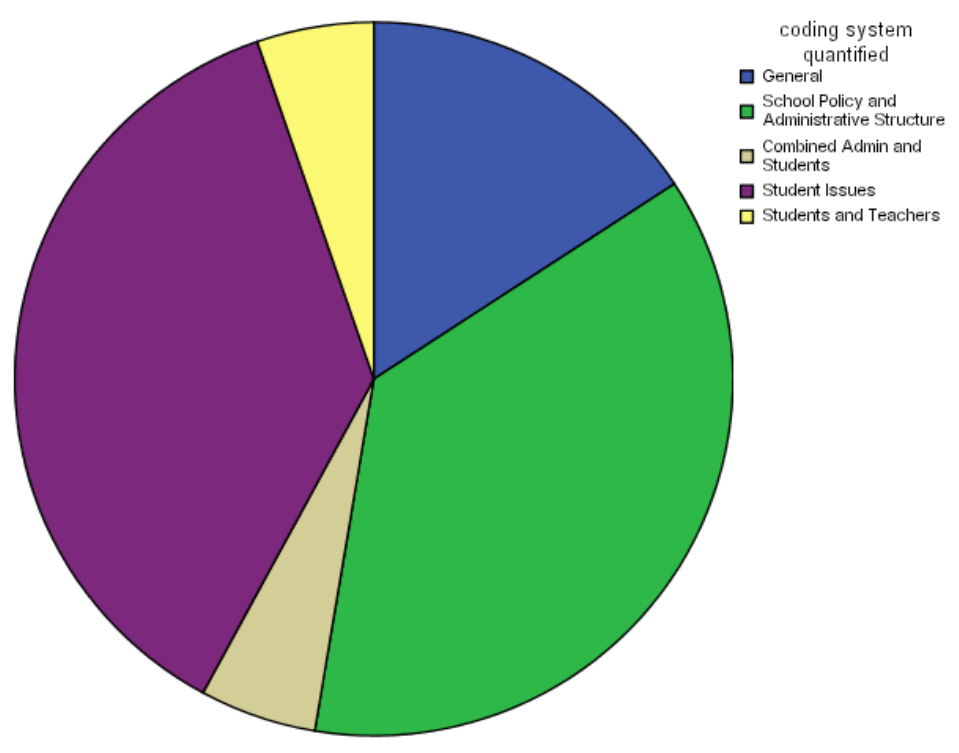

\section{Teacher Pre- program Surveys (46 responses)}

Sample comments for each category:

\section{General:}

- "Many students are stressed."

- "Overall, I have found that the stress level of both the students and faculty has dropped since we went on the modified block schedule."

\section{School Policy and Administrative Structure:}

- "Teacher stress heightened by many deadlines due at one time rather than spread out throughout the semester."

- "Being consistent. Behaviors that disrupt classes must have consequences."

\section{Combined Admin and Students:}

- "Some schedules are more prone to stress than others or maybe [some students] just know how to handle it better. Students would be better if they knew how to not put themselves in stressful situations."

\section{Student Issues:}

- "I, being a new teacher, am surprised at fighting among females in the school."

- "Students (some) at MHS bring on their own stress because they don't take responsibility for completing assignments on time. They always have an excuse. They do not understand the concept of accountability."

\section{Students and Teachers:}

- 'Students do not get a lot of opportunity to calm their thinking because adults' reactions are harsh and judgmental. Students just seem to feel judged and unloved." 


\section{What we've learned so far....}

- Students would gain more from the program in smaller groups that allowed for more active learning.

- Students would prefer more technology - color, action, music that relates more to their learning style for non-academic information about life.

- Some students are interested in seeing this information in greater depth in health classes or psychology classes.

- Students and some teachers suggested that the Innate Health model be offered to peer educators and then delivered to students by peers over time.

- Students who are resentful about being mandated to attend a program they did not select or anticipate tend to tune out (although none created a discipline problem in any of the sessions).

- A separate program for teachers might be helpful. 


\section{Appendix G}

Pettit Attachment to Thought Content Scale

\section{PETTIT ATTACHMENT TO THOUGHT CONTENT SCALE (PATCS)}

Thought is a constant process. The content of our thought process is either allowed to pass freely across the "screen of our mind," or is given varying degrees of attention - that is, "dwelled on" or "fought" in an attempt to change or eliminate it. Some people find it easier to allow some kinds of thoughts to pass more freely than others. This scale is an attempt to assess the degree to which you tend to give attention to different kinds of thoughts to the point where it interferes with your peace of mind or feelings of well-being. A 0 means you do not dwell on the thoughts at all; a 1 means you dwell on them a little bit; a 2 means you dwell on them moderately; a 3 means you dwell on them quite a bit; and a 4 means you dwell on them to an extreme.

\begin{tabular}{|c|c|c|c|c|c|}
\hline KIND OF THINKING & \multicolumn{5}{|c|}{ DEGREE IT IS ON YOUR MIND } \\
\hline & \multicolumn{5}{|c|}{ Not at all A little bit Moderately Quite a bit Extremely } \\
\hline Worry: Attention to thoughts of "what-It's." & 0 & 1 & 2 & 3 & 4 \\
\hline $\begin{array}{l}\text { Guilt: Attention to thoughts of self- } \\
\text { judgment over past mistakes. }\end{array}$ & 0 & 1 & 2 & 3 & 4 \\
\hline $\begin{array}{l}\text { Resentment: Attention to thoughts of hurt } \\
\text { over what others have done. }\end{array}$ & 0 & 1 & 2 & 3 & 4 \\
\hline $\begin{array}{l}\text { Upset: Attention to thoughts of things not } \\
\text { meeting your expectations or desires. }\end{array}$ & 0 & 1 & 2 & 3 & 4 \\
\hline $\begin{array}{l}\text { Unresolved Grief: Attention to thoughts } \\
\text { about losses with which you have not come } \\
\text { to peace. }\end{array}$ & 0 & 1 & 2 & 3 & 4 \\
\hline $\begin{array}{l}\text { Fear: Attention to thoughts about potential } \\
\text { danger or harm. }\end{array}$ & 0 & 1 & 2 & 3 & 4 \\
\hline $\begin{array}{l}\text { Driven-ness: Attention to thoughts of } \\
\text { having to live up to self-imposed } \\
\text { expectations. }\end{array}$ & 0 & 1 & 2 & 3 & 4 \\
\hline $\begin{array}{l}\text { Over-analysis: Attention to going over the } \\
\text { same thoughts again and again in search of } \\
\text { a solution. }\end{array}$ & 0 & 1 & 2 & 3 & 4 \\
\hline
\end{tabular}




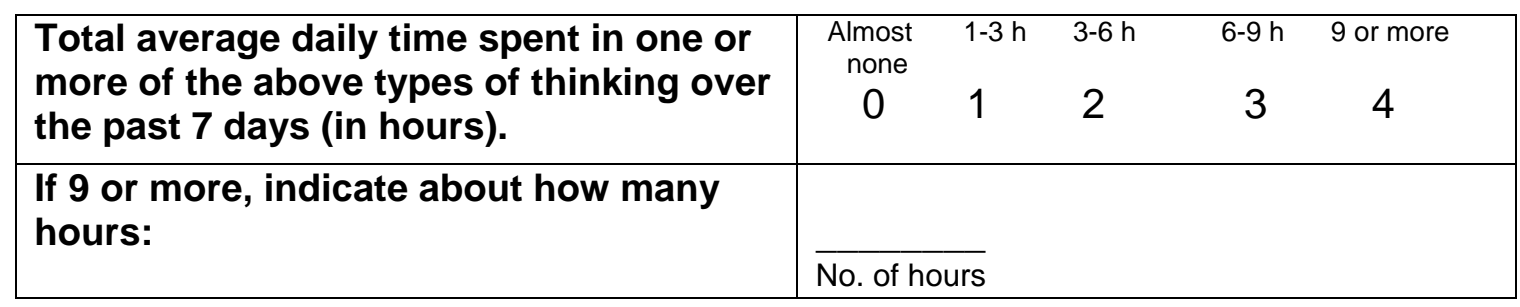

(c) 2007 William F. Pettit, M.D. The West Virginia Initiative for Innate Health. All rights reserved. 
Appendix $\mathrm{H}$

Nursing 110 Lecture, Fall 2007

\title{
Understanding stress, \\ Recognizing Resiliency
}

\author{
Judith A. Sedgeman, M A
}

West Virginia Initiative fc + Innate Health

Nursing 110

October 3, 2007

\section{The healthy human being}

- Peace of MIND

- Balance of BODY

- Vitality of SPIRIT
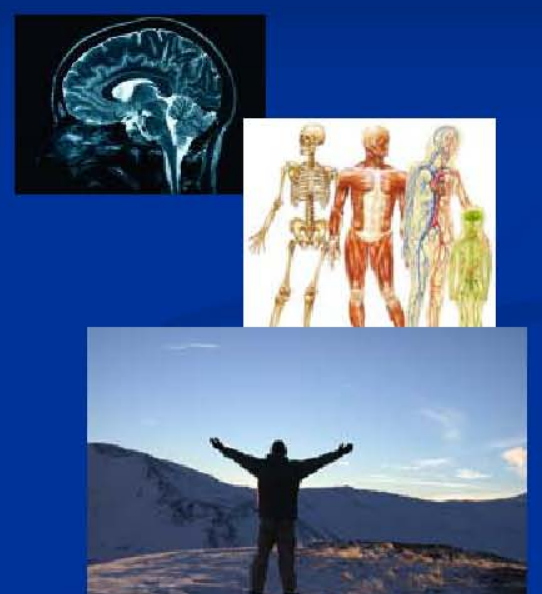


\section{Is there "a norm" for stress?}

- Where do you think the curve peaks?

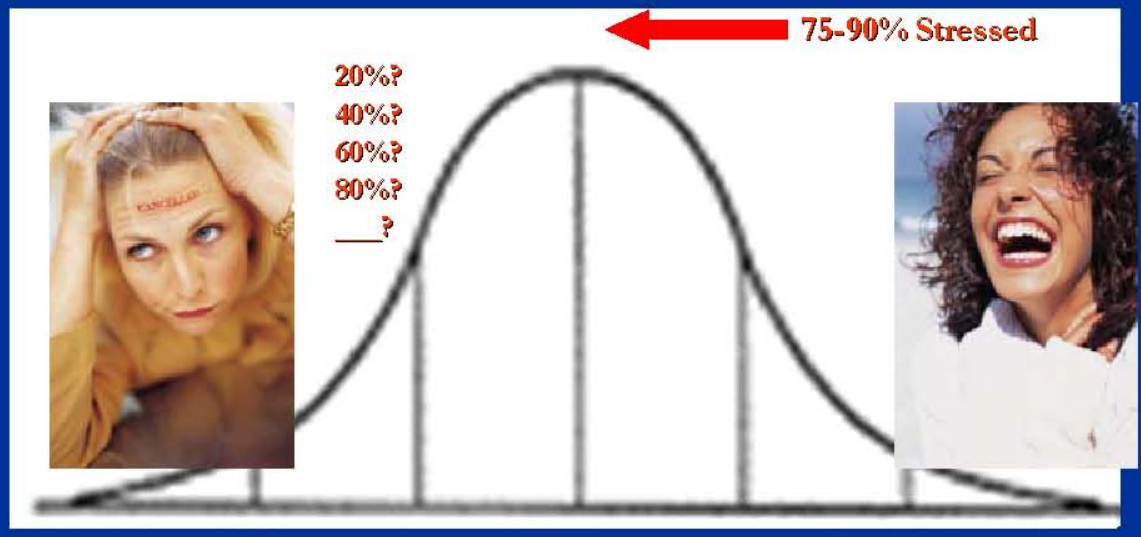

\section{Is there really a norm?}

- When doing science ... be very careful and very certain before pronouncing something to be the norm - because at that instant, you have made it supremelv disr _un to ever again look obje tively at an exception to that supposed norm."

Robert Sapolsky Wby Zebras Dont Get Ulcers, p. 185 
There is strong scientific agreement about what chronic stress does to us.

But we're still exploring where it comes from and how to overcome it.

\section{Stress is a national health} emergency

*1 = DEPRESSION

(70\% greater adjusted annual health care expenditures)

\#2 = STRESS

( $46 \%$ greater adjusted annual health care expenditures) 


\section{Walter Cannon First Described It}

- Cannon defined the "fight or flight" response of the

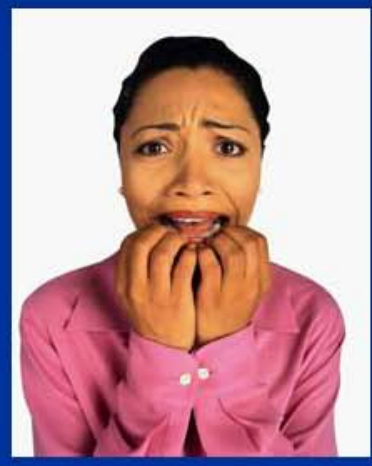
Sympathetic Nervous System to threats $\left(1920^{\prime} \mathrm{s}-30^{\prime} \mathrm{s}\right)$ :

- Heart rate and blood pressure increase

- Perspiration increases

- Hearing and vision become more acute

- Hands and feet get cold, because blood is directed away from the extremities to the large muscles to prepare for fighting or fleeing.

\section{Hans Selye Put It on The Map}

- Selye's stress research (1930's-50's) involved:

- Exposing rats to extreme climates unprotected

- Holding rats' feet in a bucket of cold water;

- Performing surgery on rats without anesthesia;

- Severing rats' spinal cords

- Forcing rats to perform excessive

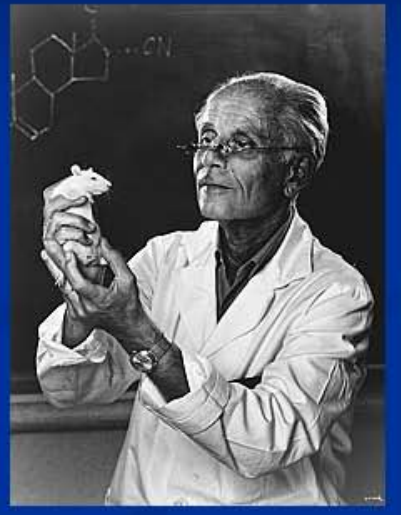
exercise 


\section{Selye's Assumption}

- Selye assumed that stress is inevitably created or generated by external factors or pressures.

- This assumption was made because

- Selye generalized human stress from animal studies;

- Selye compared human stress with stress as it was understood in engineering $-\mathrm{a}$ force exerted against an object over time.

\section{How Selye Described Stages in Response to Stress}

- Alam Reaction

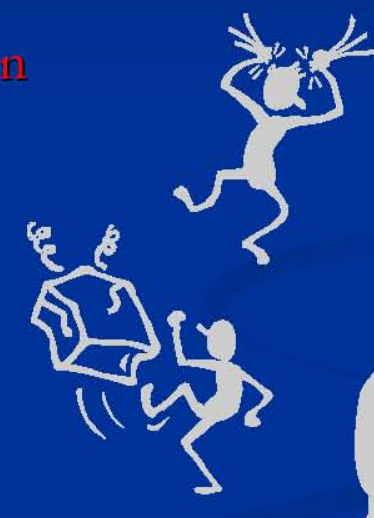

Exhaustion

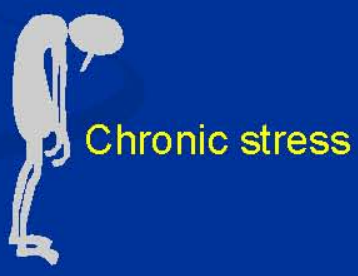




\section{Selye's assumption prevailed}

- This assumption has remained fundamental for decades, as researchers looked at stress and stressors.

- If we do not question our assumptions, we cannot change our results.

\section{Subsequent research defined} "stressors"

- Measurements of the impact of presumed stressful life events on large groups of people.

- Assumptions drawn from the medien.

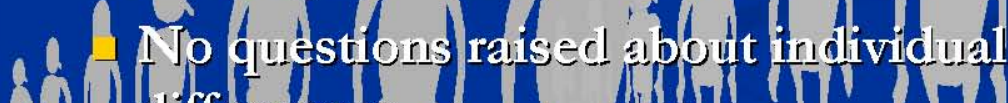

ond 


\section{Mind-Body Research} is defining outcomes
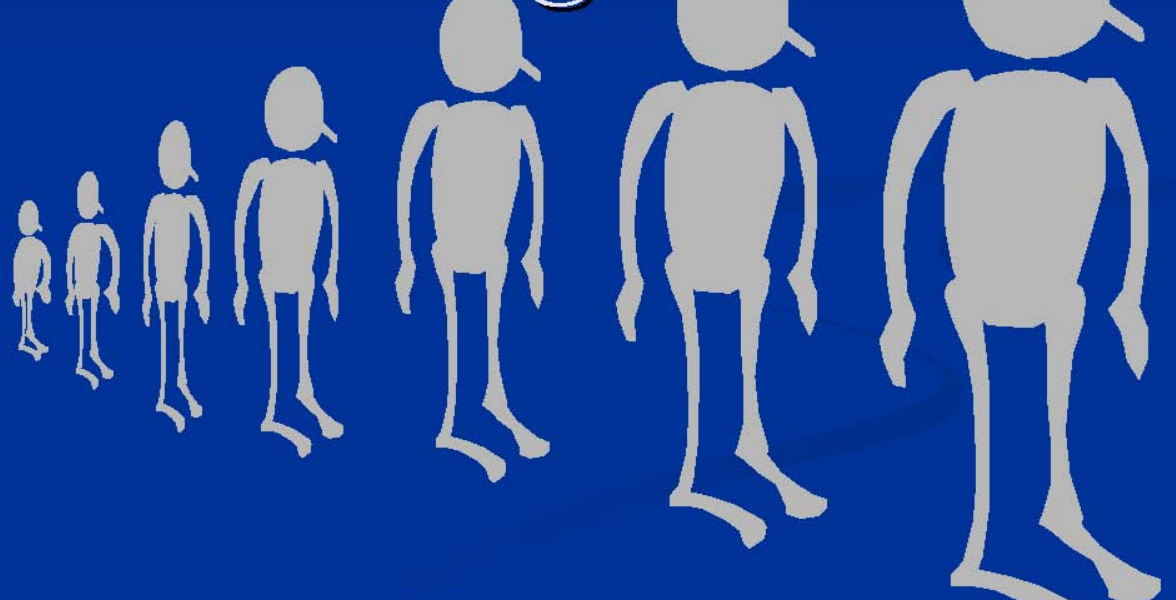

\section{Chronic Stress}

"provides a hormonal milieu conducive to the development of..."

- Visceral Obesity

- Insulin Resistance/Dyslipidemia Syndrome

- Hypertension

- Atherosclerosis

- Osteoporosis

- Immune Dysfunction

- Depression

- Irritable Colon

- Peptic Ulcer

- Substance abuse

Vanltallie, T.B. (2002). Stress: A risk factor for serious illness. Metabolism: Clinical and Experimental 51(6 Suppl 1):40 45. 


\section{Mind-Body Connection}
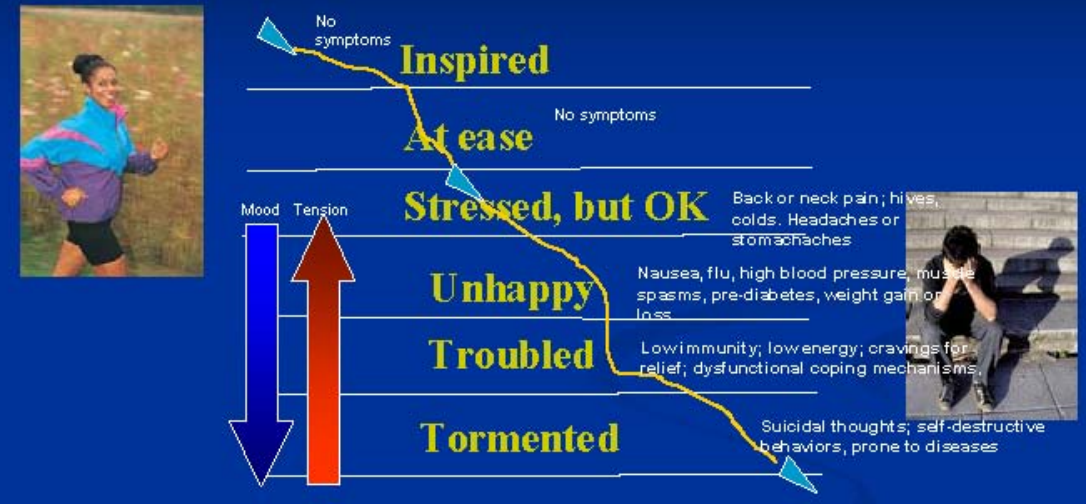

(The physical manifestation of chronic stress is related to genetic vulnerability and emirommental factors.)

\section{Chronic Stress A different definition:}

The weight of

negative thinking

taken seriously

over time

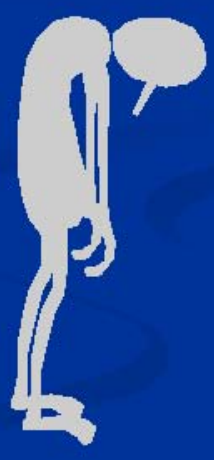




\section{"Hormonal Milieu"}

It starts with negative thinking Mood Tension taken seriously over time, leading to chronic stress.

When our mood goes down and our tension goes up, our body chemistry responds.

We then become more vulnerable to illnesses to which we are prone.

Research has shown that quieting our thinking can reverse the process rapidly.

\section{Prevailing Assumption}

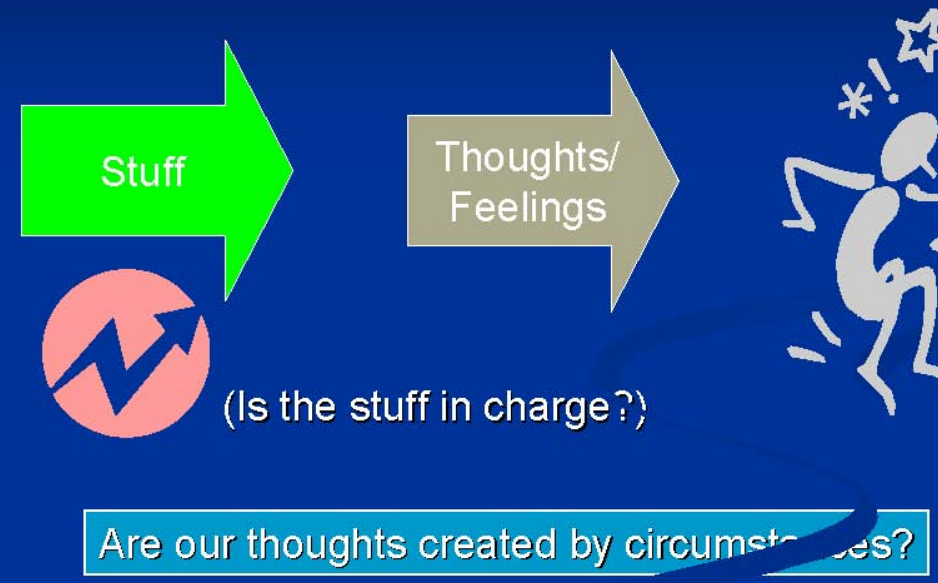




\section{Outside-in or Inside-Out?}

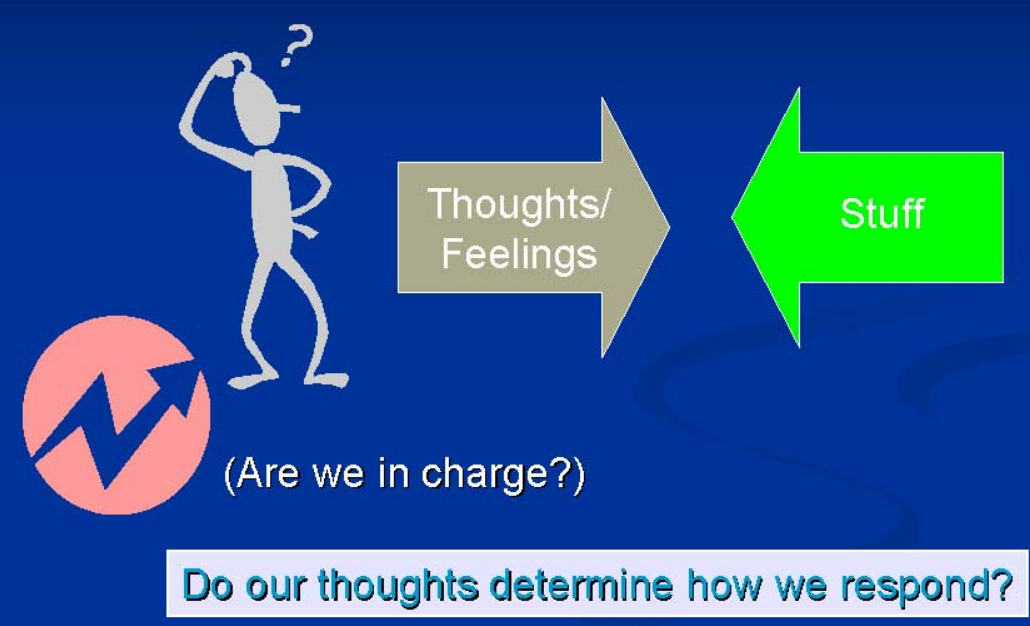

\section{Ex-Stress Yourself}

How to take advantage of this on-line module created especially for Nursing 110 students (and help someone finish her doctoral degree at the same time) 

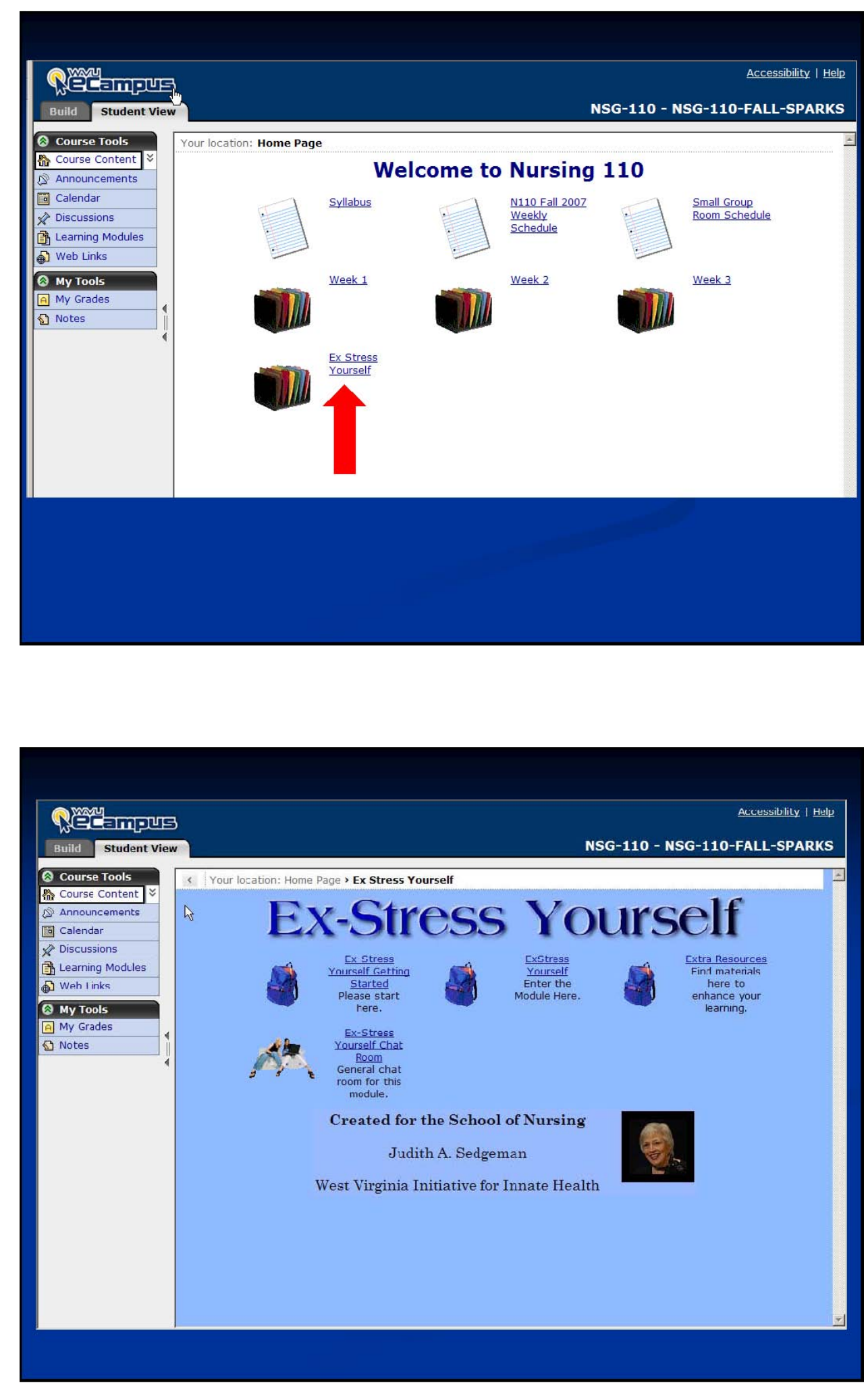

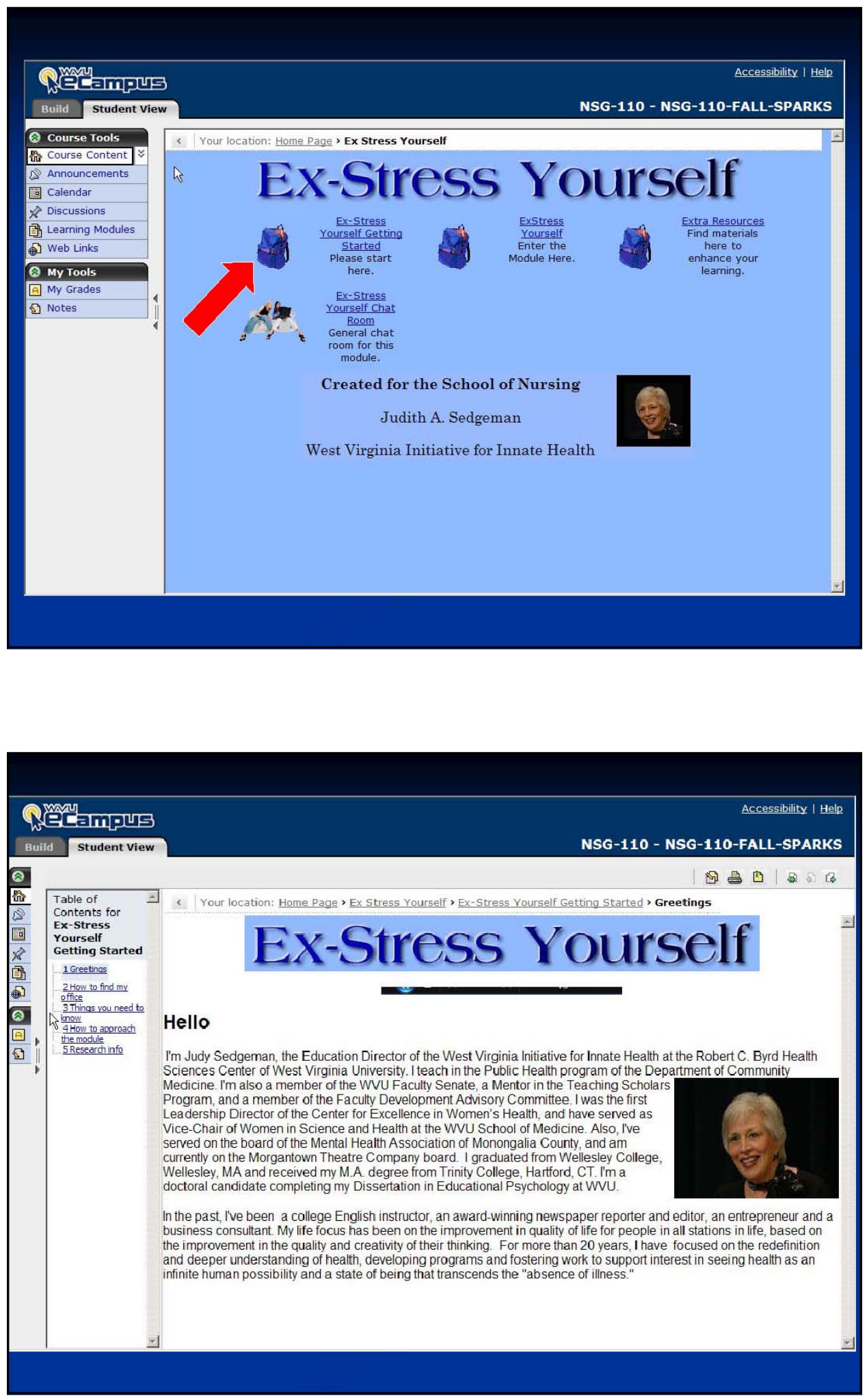

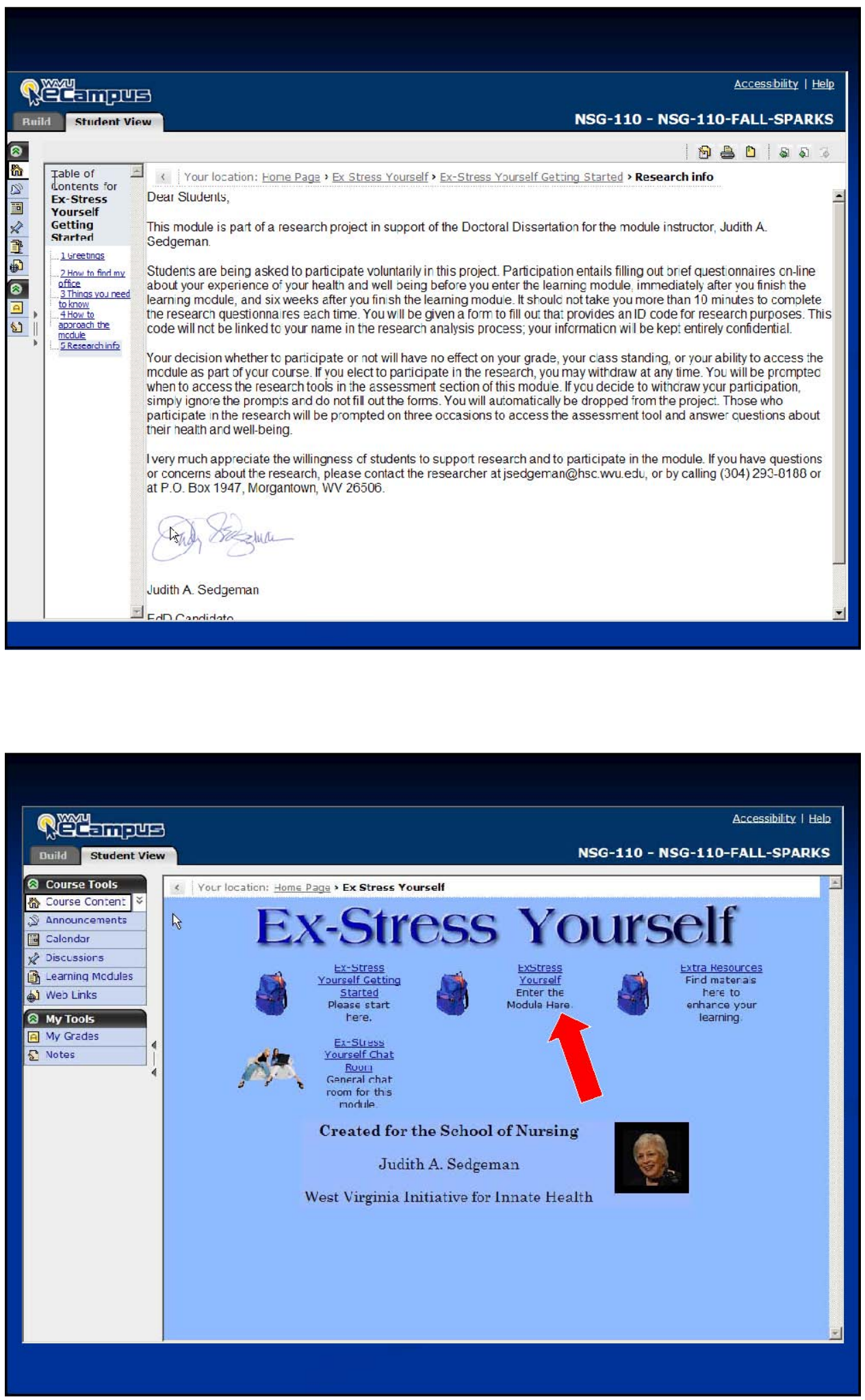

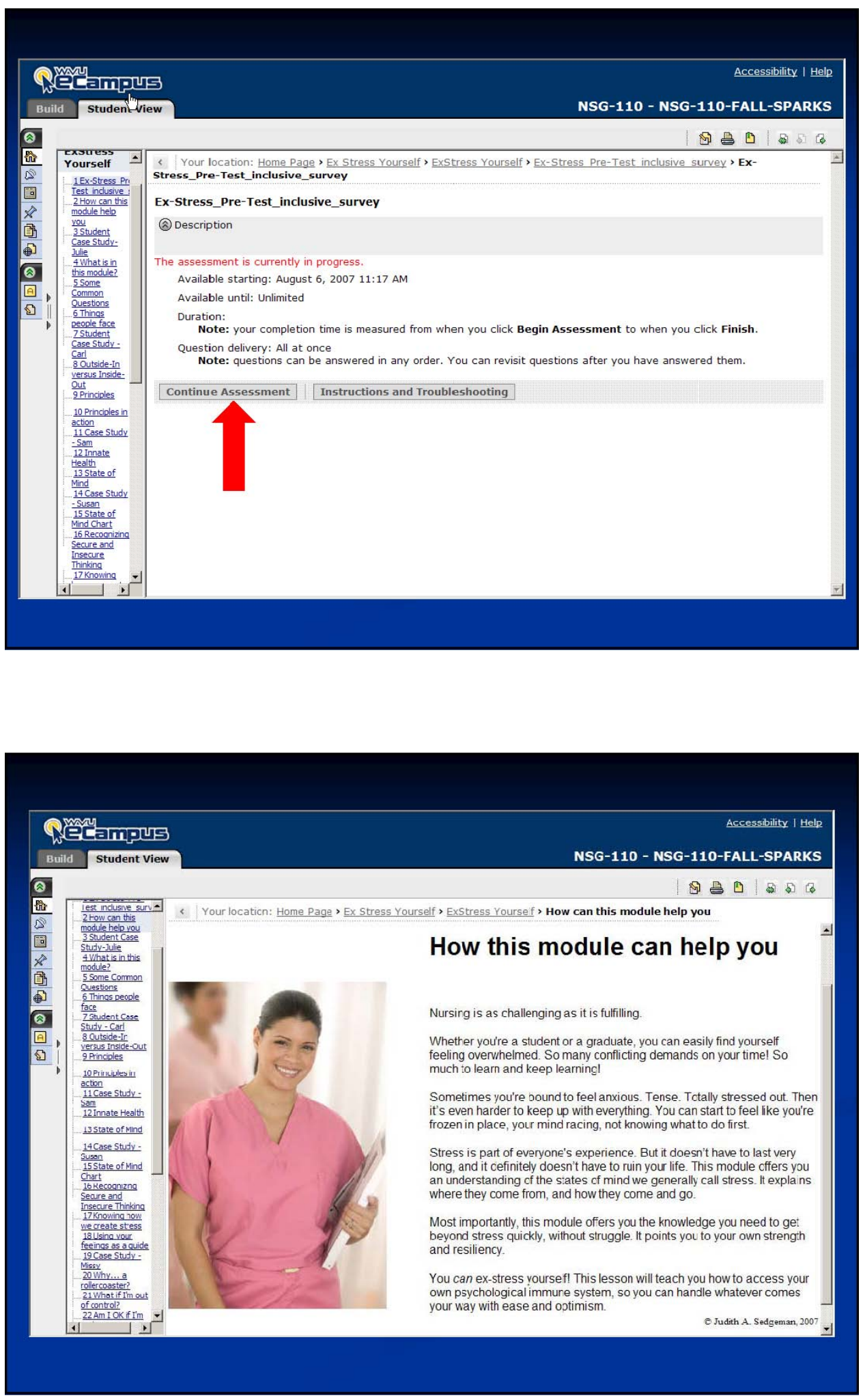

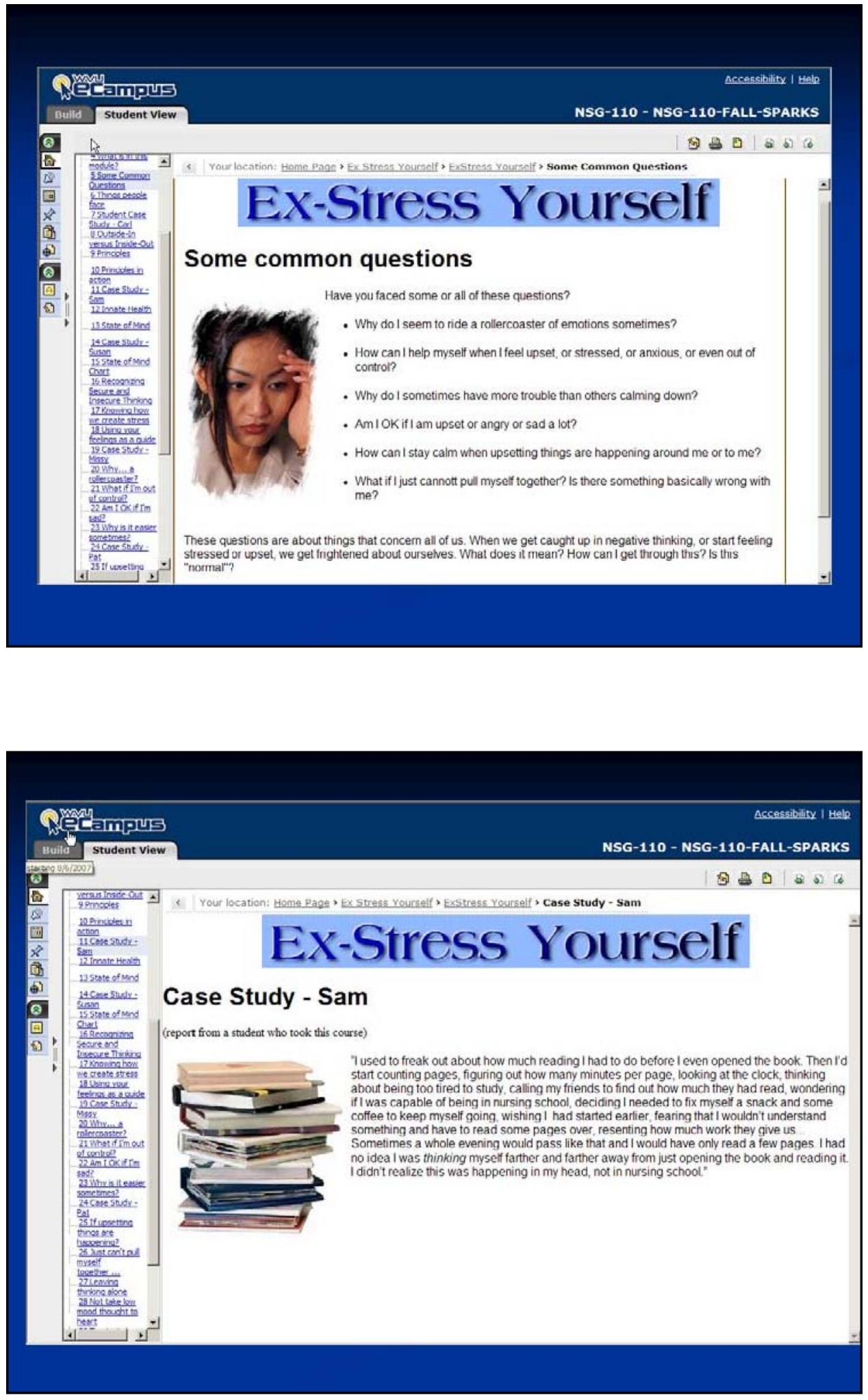

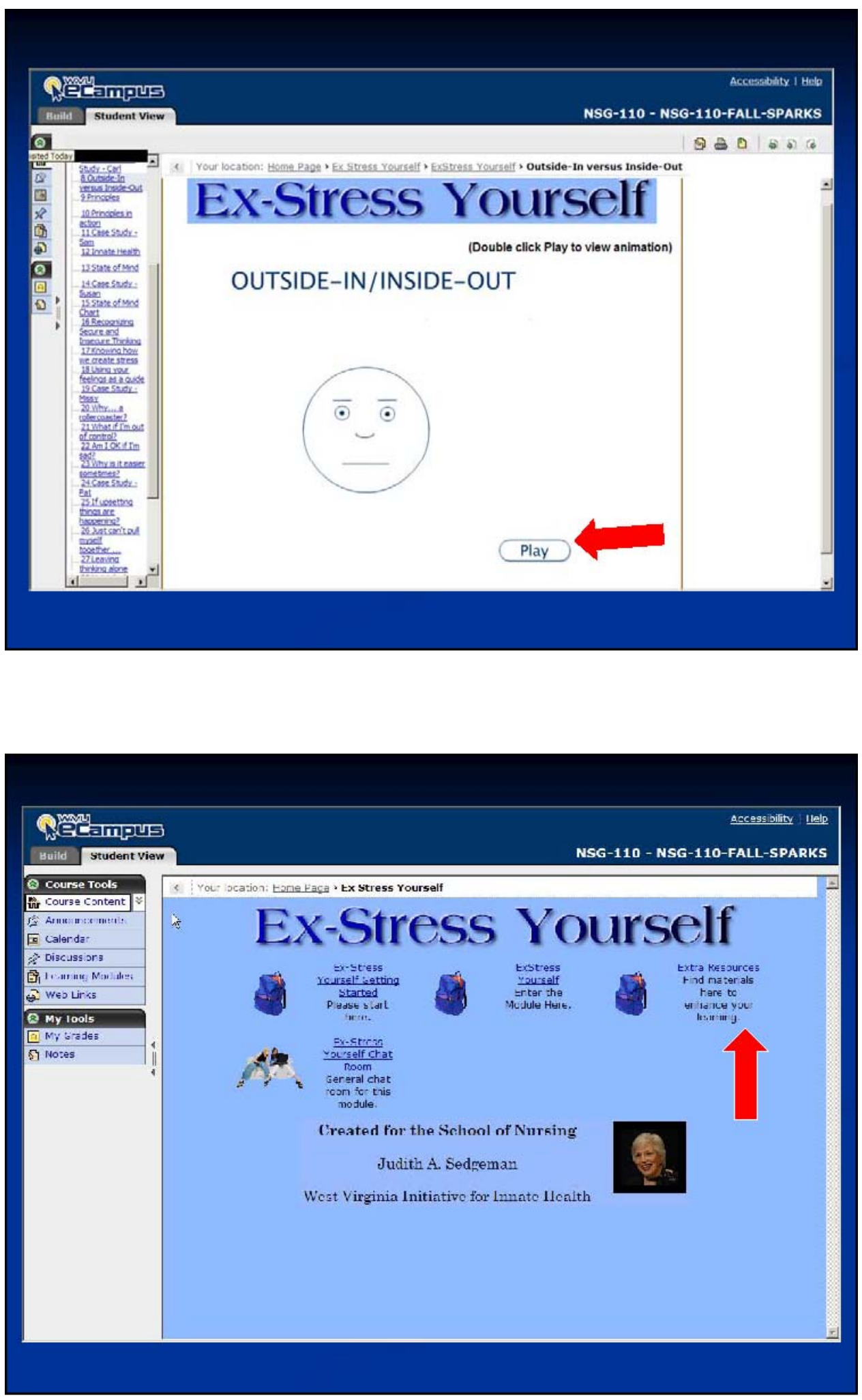

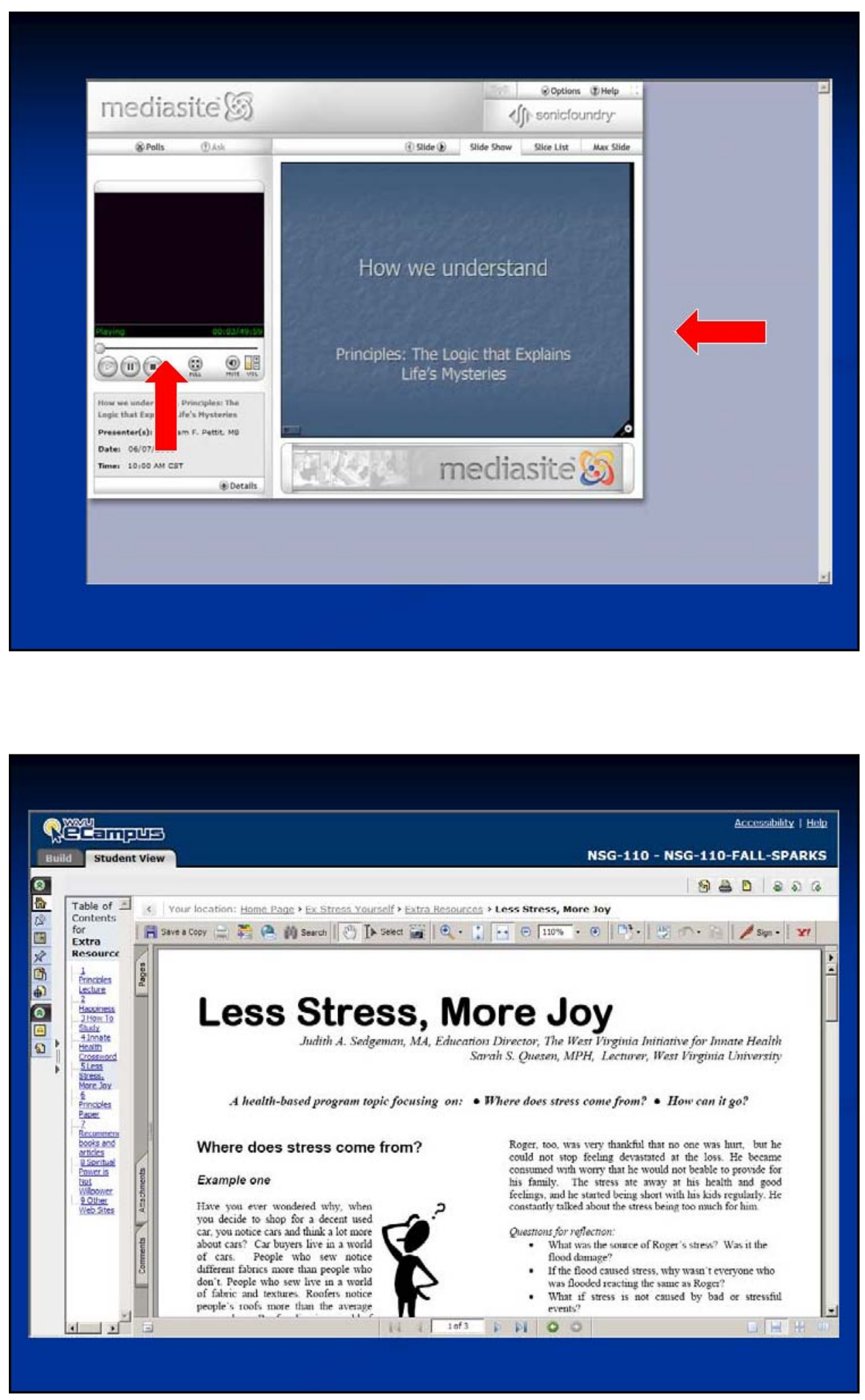

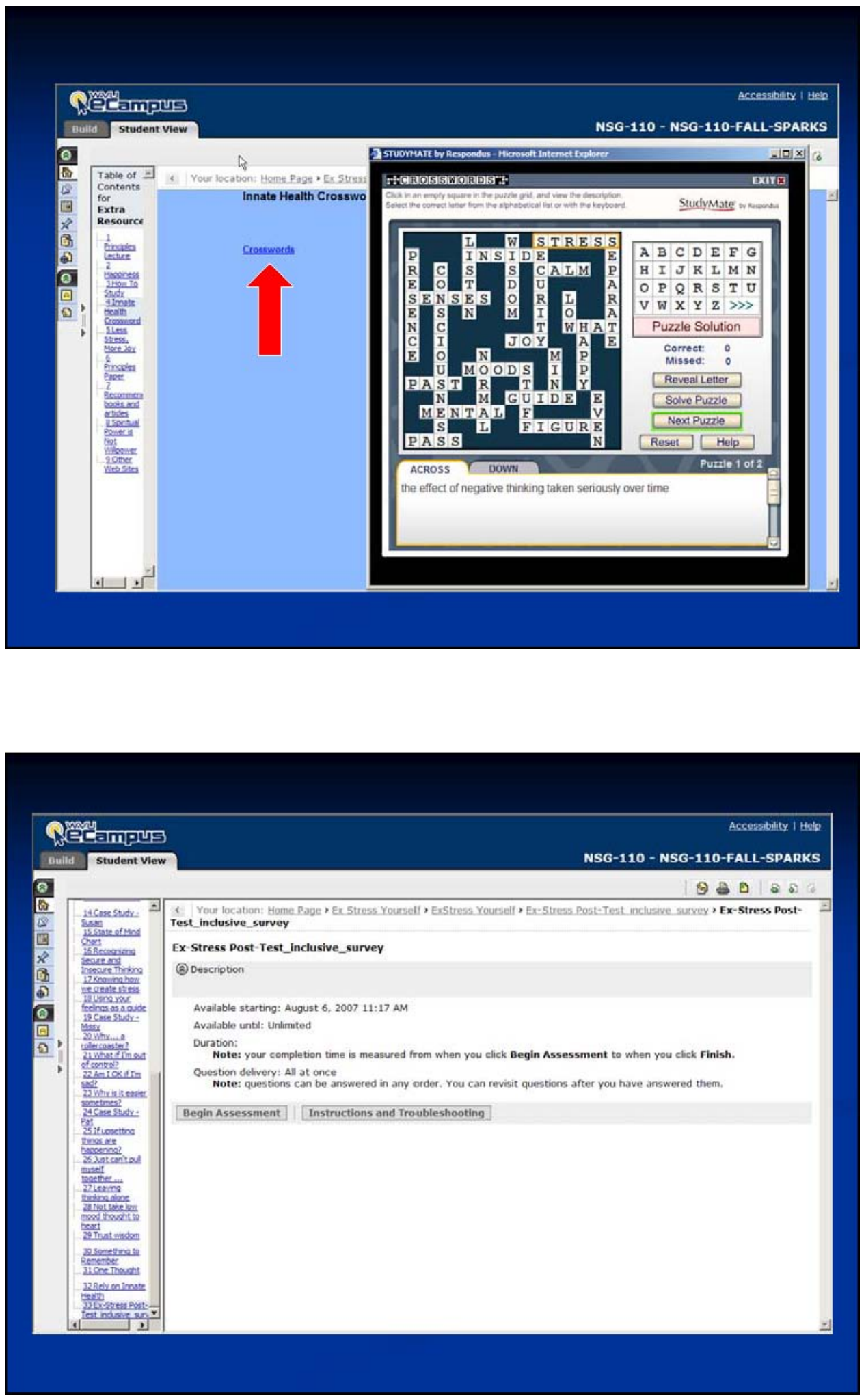


\section{6-week follow-up}

- You'll get an e-mail asking you to take the last assessment (also within your Nursing 110 course on-line).

- You'll get one hour of community service credit.

- You'll be invited to participate (totally optional) in a discussion group on-line.

$$
\square \text { and }
$$

- You will have access to this module for your own reference throughout the course.

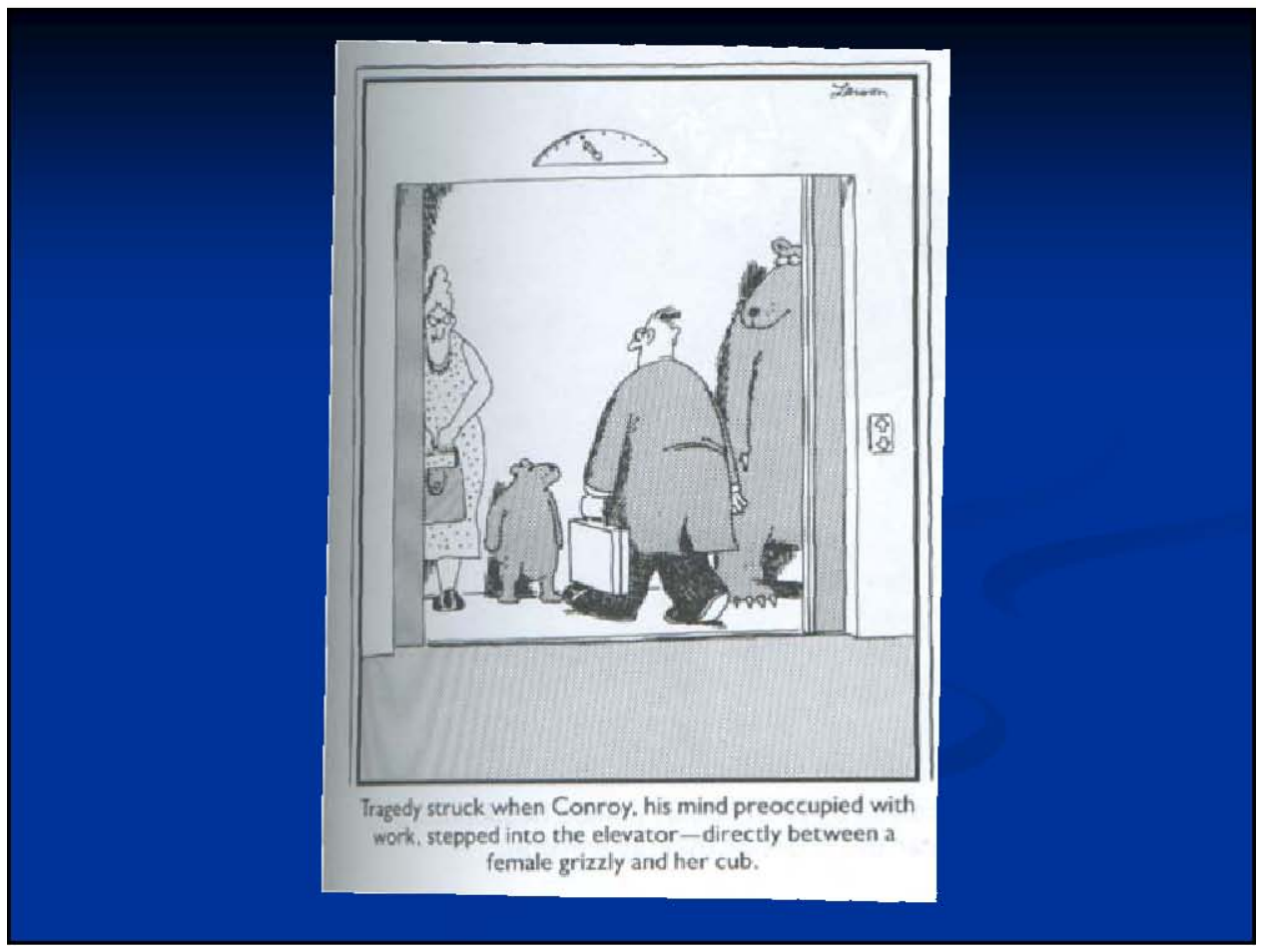




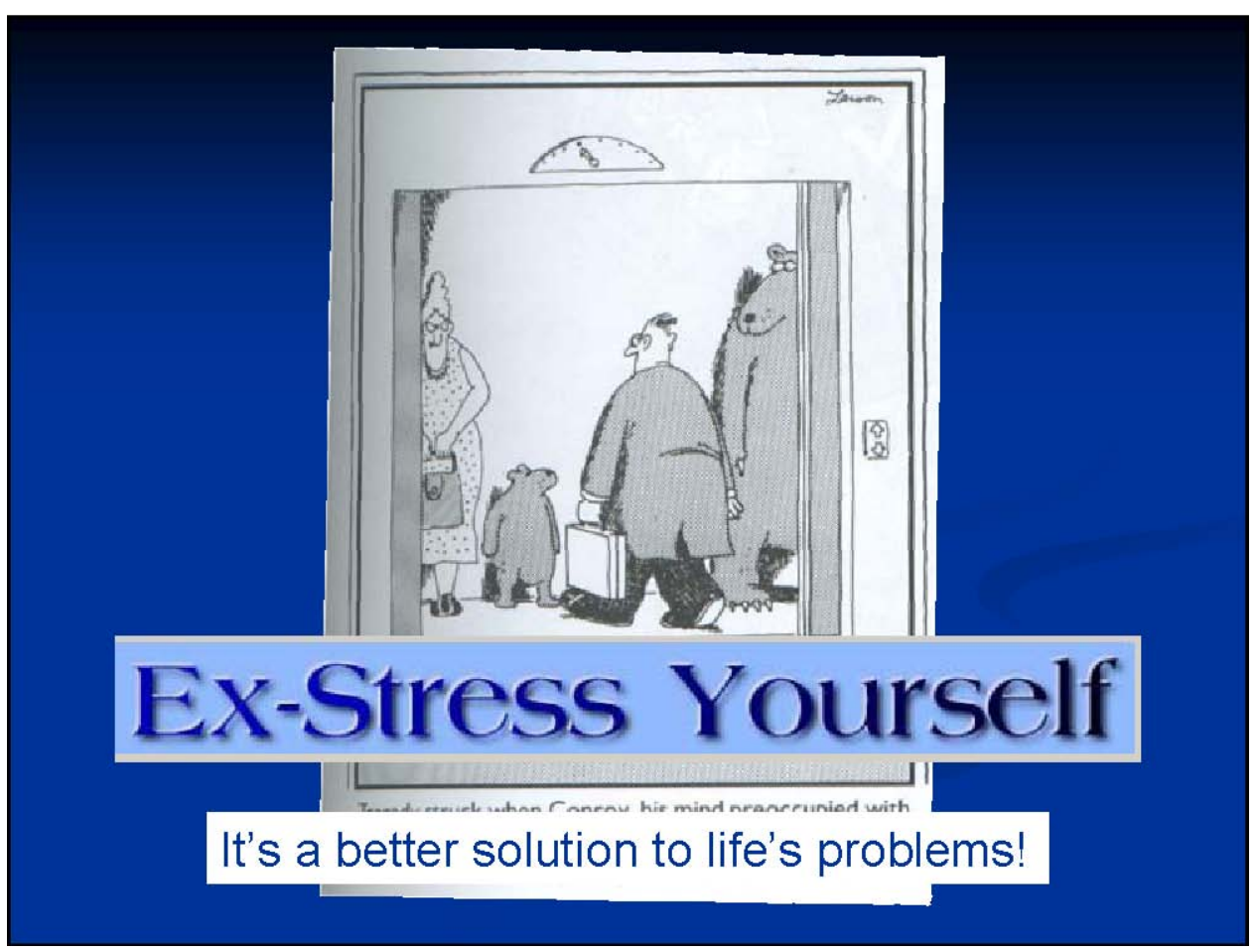


Appendix I

Trial Lecture for Nursing 110 - Spring 2007

\title{
Less Stress, More Enjoyment: State of Mind Matters
}

\author{
Judith A. Sedgeman, M.A. \\ Education Director
}

The West Virginia Initiative for Innate Health

\section{Three Objectives}

1. Participants will be able to:

Appreciate the value

of a positive feeling state

and a quiet mind 


\section{Three Objectives}

2. Participants will be able to:

See the principles

at the source

of human experience

\section{Three Objectives}

3. Participants will be able to:

Realize that

a positive feeling state

offers access to wisdom 


\section{Innate Health}

u Inborn

- Intuitive

- Non-contingent

\section{Stress}

The weight of negative thinking

taken seriously

over time 


\title{
Enjoyment
}

\author{
A quiet mind \\ and a positive feeling state \\ in the present moment
}

\section{Principles}

- Universal

- Discoverable

- Always operating 


\section{Examples of Principles}

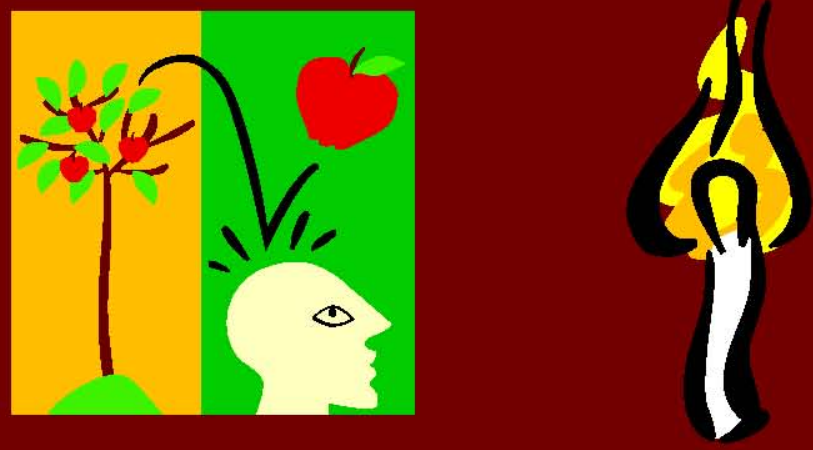

\section{Mind}

The intelligent

energy of

all things 


\section{Thought}

The ability

to create

ideas

\section{Consciousness}

The experience

of thoughts

as our reality 


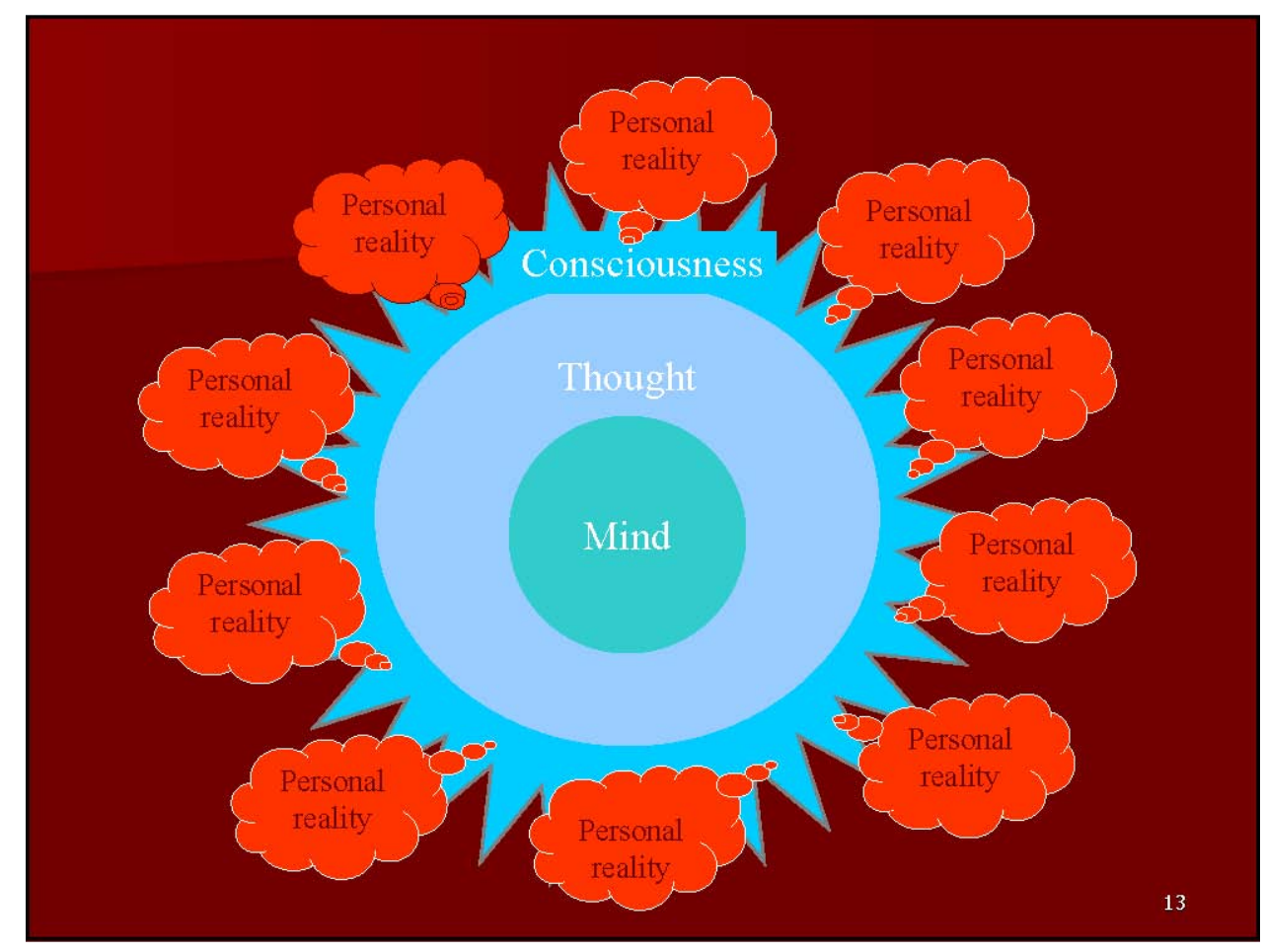

\section{State of Mind}

The feeling state

produced by

the quality of our thinking

in the moment 


\section{Mood+Tension $=$ State of Mind}

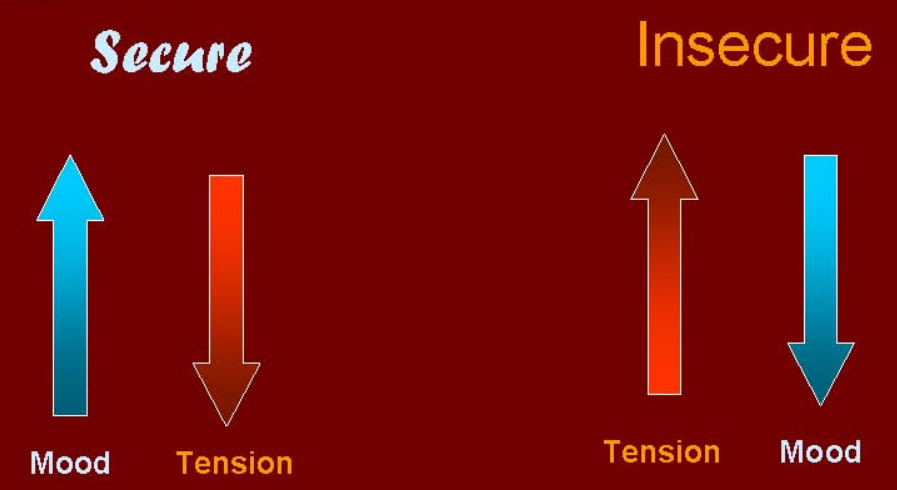

\section{We know how we feel}

joy Gosirede

Gappy. Euthereinstis

Sepsose

Qabru, Bonpidess

Stress, Impatience

Frustration, Blaming

Insecure

Despair, Depression 


\section{State of Mind is a Signal}

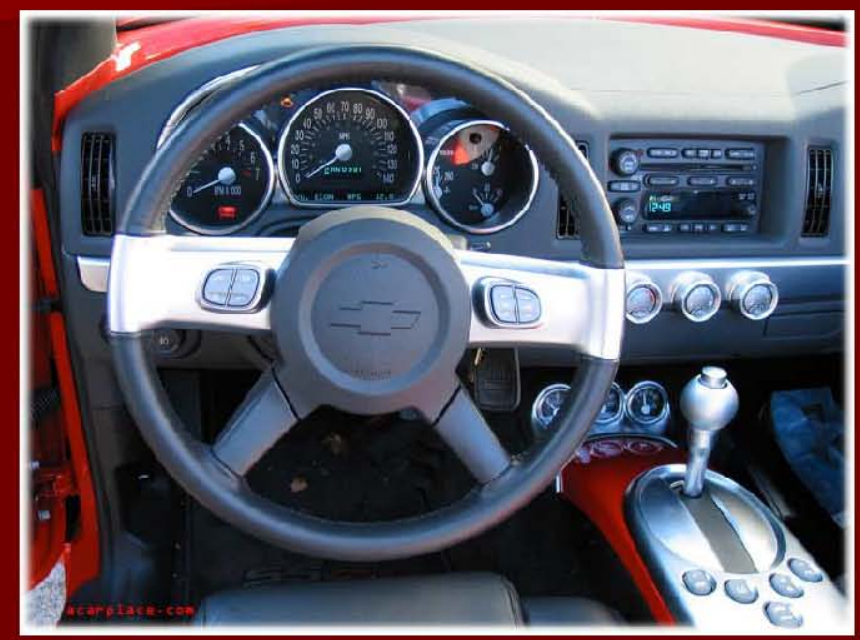

\section{State of Mind Matters}

\begin{tabular}{|c|c|}
\hline $\begin{array}{l}\text { Secure } \\
\text { upree and cecar unind } \\
\text { in a positre peating) }\end{array}$ & $\begin{array}{l}\text { Connected } \\
\text { Caning } \\
\text { Prodnetive } \\
\text { good wice } \\
\text { Satisfied }\end{array}$ \\
\hline $\begin{array}{l}\text { Insecure } \\
\text { (racing mind in a } \\
\text { negative feeling) }\end{array}$ & $\begin{array}{l}\text { Distracted } \\
\text { Self-absorbed } \\
\text { Second-guessing } \\
\text { Distrust } \\
\text { Unhappiness }\end{array}$ \\
\hline
\end{tabular}




\section{Innate Health}

Our psychological immune system

\section{Less Stress, More Enjoyment?}

- Allow thinking to pass.

- We are always one thought away from a different state of mind.

- Our thoughts naturally return to balance if we do not interfere. 


\section{Wisdom}

- Mind quiets.

- Attachment to insecure thought content disappears.

- Gratitude, love and hope re-emerge.

- Insight and common sense return.

- We have good judgment and make good choices.

- We feel awake, alive and present.

- Our body's healing potential revives.

\section{Wisdom}

We scarcely notice it because it is natural.

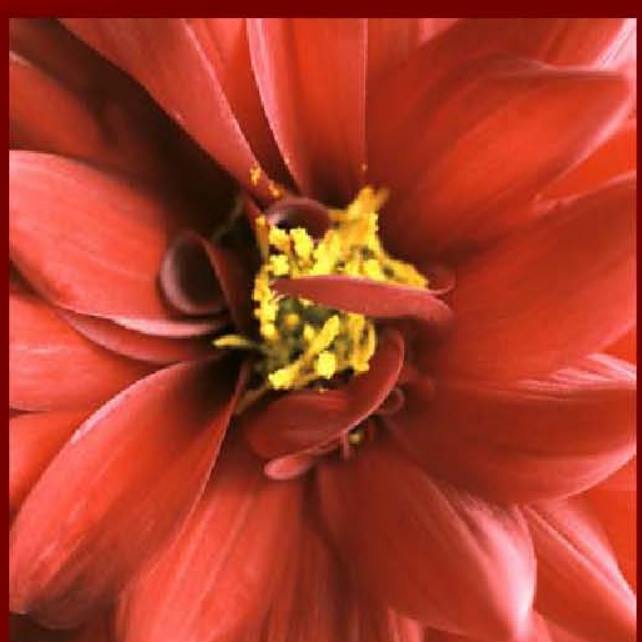




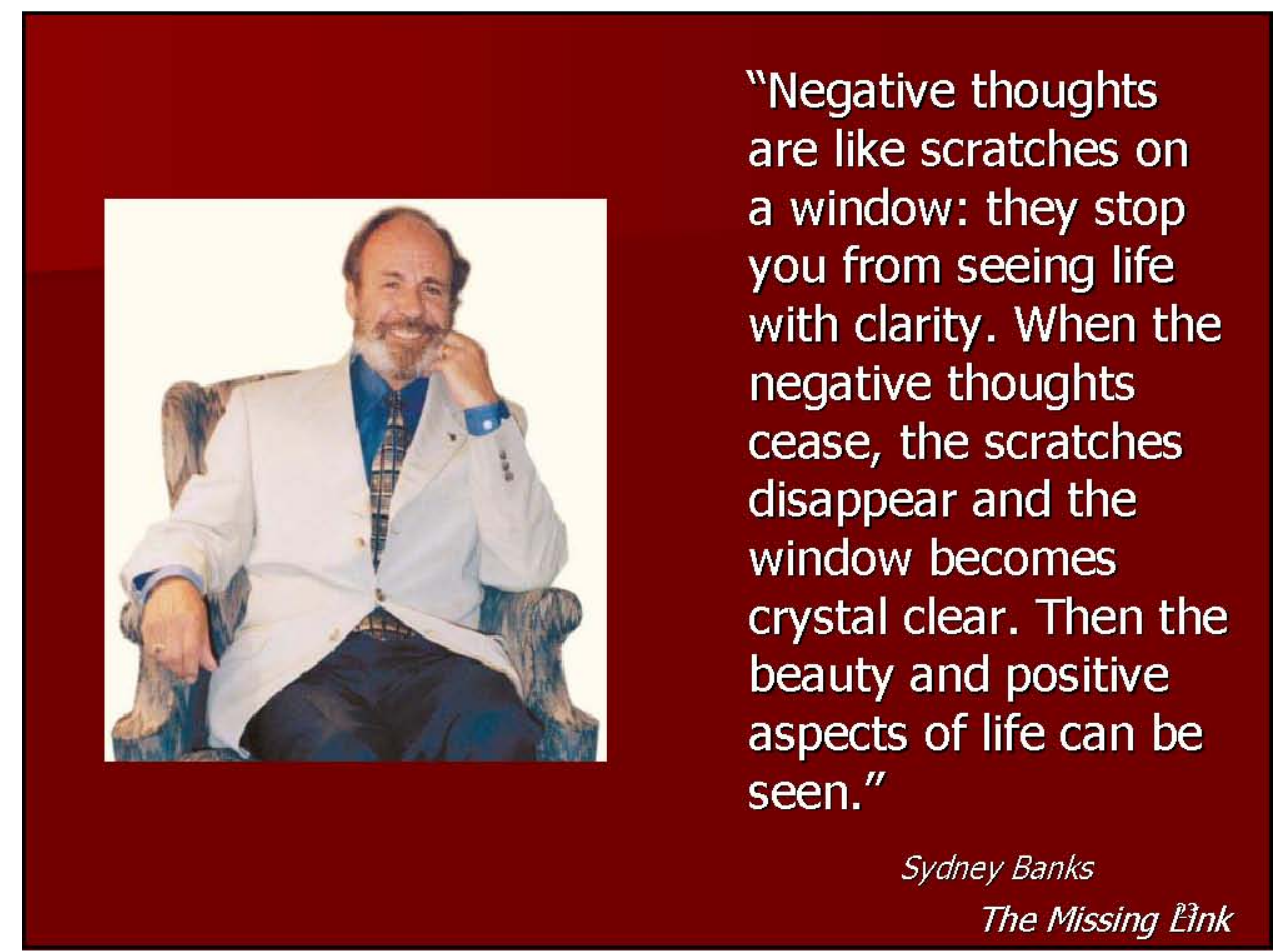

\section{For more information}

- To contact the instructor:

- jsedgeman@hsc.wvu.edu

- To locate reading materials/resources

- www.wvilh.org

- For more about the principles

- www.sydneybanks.org 


\section{Appendix $\mathrm{J}$ \\ Evaluation - Ex-Stress Module \\ Evaluation \\ Ex-Stress Yourself Module}

Please rate the Ex-Stress Yourself learning module you just completed. Check the box that applies to each statement.

1. It makes sense to me that my thinking creates my experience.

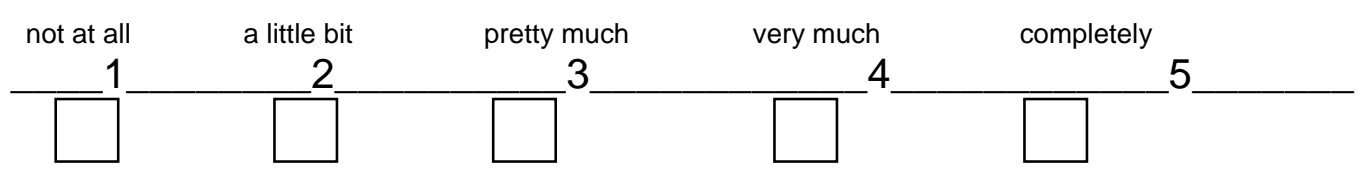

2. I can see why external events do not determine my experience of life.

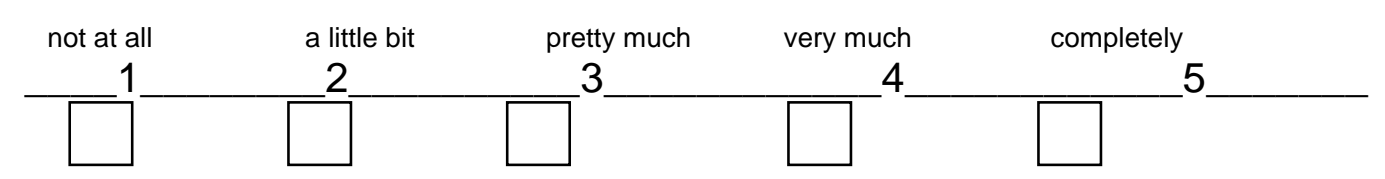

3. I recognize the relationship between how I use my ability to think and how stressed I feel, moment-to-moment.

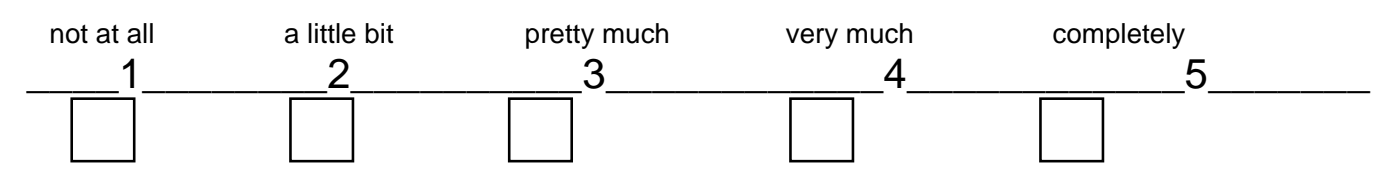

4. This module helped me understand why people get upset.

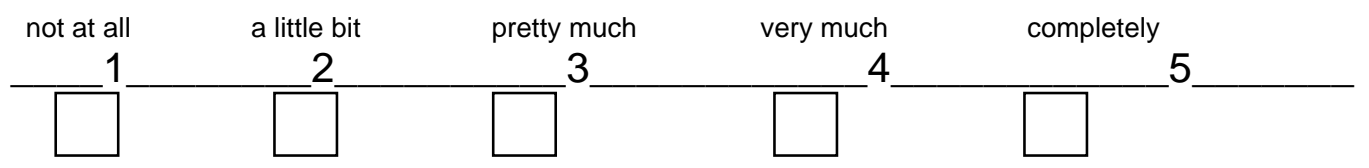

5. This module helped me to understand how people calm down.

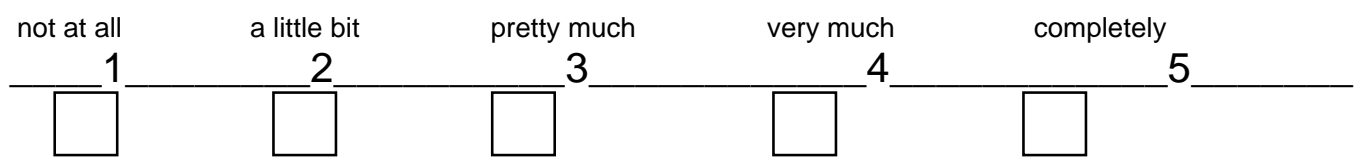


6. I feel more hopeful that I can recognize my own state of mind when I'm getting upset and quickly calm down.

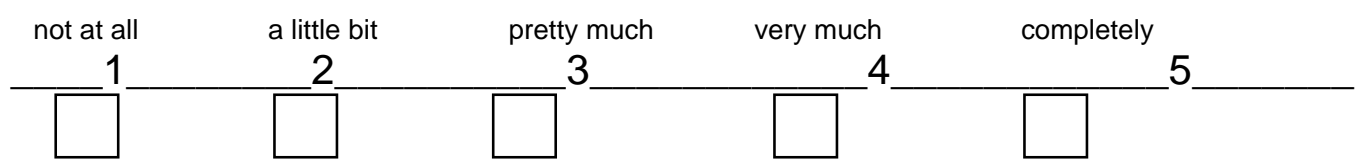

7. This module helped me to realize that my stress levels affect my ability to learn and study and achieve my goals.

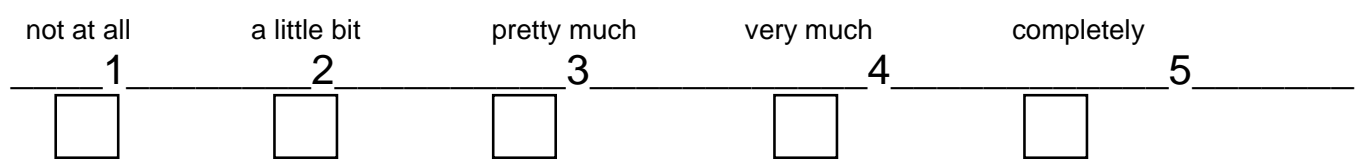

8. This module helped me to recognize that I can take better care of my own mental well-being through understanding how thinking works.

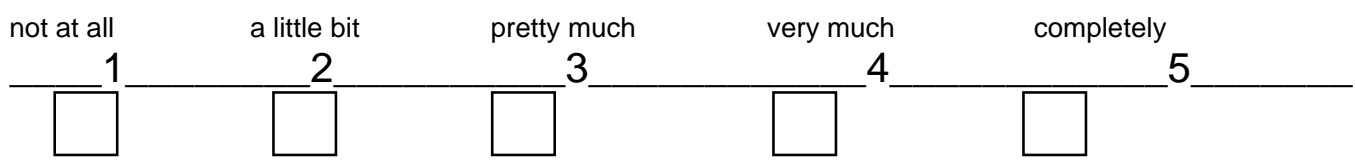

9. I feel more confident that I can reduce or eliminate the stress in my life and become more productive and effective.

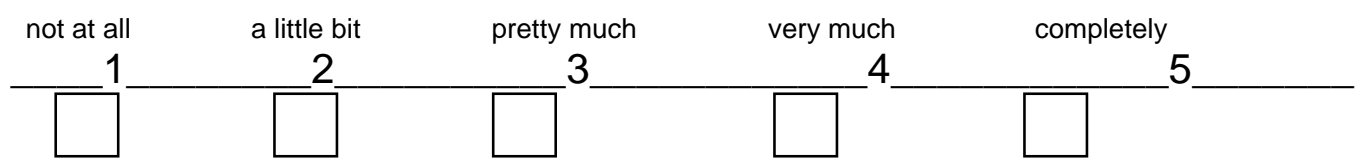

10. Please add any other comments you would like to make about the module: 


\title{
Appendix K \\ Permission to Use SF-36 On-line
}

\author{
From: $\quad$ "Dana Kopec" < d dkopec@qualitymetric.com> \\ To: $\quad<$ jsedgeman@hsc.wvu.edu> \\ Date: $\quad$ 2/5/2007 3:04 PM \\ Subject: $\quad$ QualityMetric \#29897 \\ Attachments: $\quad$ CD-ROM Info - 3QM_HSbro.pdf; SoftwareLevels - r.doc; Demo Instructions (10) \\ .doc
}

Dear Judith,

Thank you for your interest in using the SF Health Surveys.

Please find below a quote to license SF health survey. Dr. Ware, the developer of the SF-36 would strongly recommend version 2 over version 1 when using the SF12 or SF36 due to the substantial improvements that are noted below:

1 Improvements in instructions and questionnaire items to shorten and simplify the wording and to make them more familiar and less ambiguous;

2 An improved layout for questions and answers in the self-administered form that make them easier to read and complete and the reduced missing responses;

3 Greater comparability with translations and cultural adaptations widely used in the US and in other developed countries;

$4 \quad$ Five-level response choices in place of dichotomous response choices for four items in the two role functioning scales; and

$5 \quad$ Five-level response categories in place of six-level to simplify items in the mental health and vitality scales

\section{Updated Norms}

7. The ability to score the 8 subscale scores and 2 summary scores.

The SF-12(r) only scores the 2 summary scores

Our license agreements are on an annual basis and for a single study. This quote is for the study "I am getting and EdD degree and want to use the SF-36 for my Dissertation Research. The research involves an on-line course module I developed called "Ex-Stress yourself." I would use the SF-36 for pre- and post-testing.." If you have not already received funding approval, please submit this email as a quote for the annual license fee, required documentation purchase and the use of our Scoring Software to the Educational Psychology for approval before requesting a formal license agreement be emailed to you.

This license will allow you unlimited administrations for the study 
specified above.

HOW DO I REQUEST A FORMAL LICENSE AGREEMENT?

Please reply to this e-mail to confirm you would like QualityMetric

Incorporated to invoice the license agreement and which scoring package.

Note: Please provide the shipping and billing address needed on your invoice and license agreement.

Kind Regards,

Dana Kopec

Sales Administrative Assistant

QualityMetric Inc.

640 George Washington Hwy

Suite 201

Lincoln, RI 02865

Fax (401) 334-8770

Toll Free 1-800-572-9394

dkopac@qualitymetric.com <mailto:dkopac@qualitymetric.com>

The information contained in this e-mail is confidential and privileged. Any unauthorized disclosure, copying, distribution or taking of any action based on the contents of this material is strictly prohibited. If you have received this e-mail in error please notify the sender and delete this email immediately. 
Appendix L

Research Letter from Getting Started

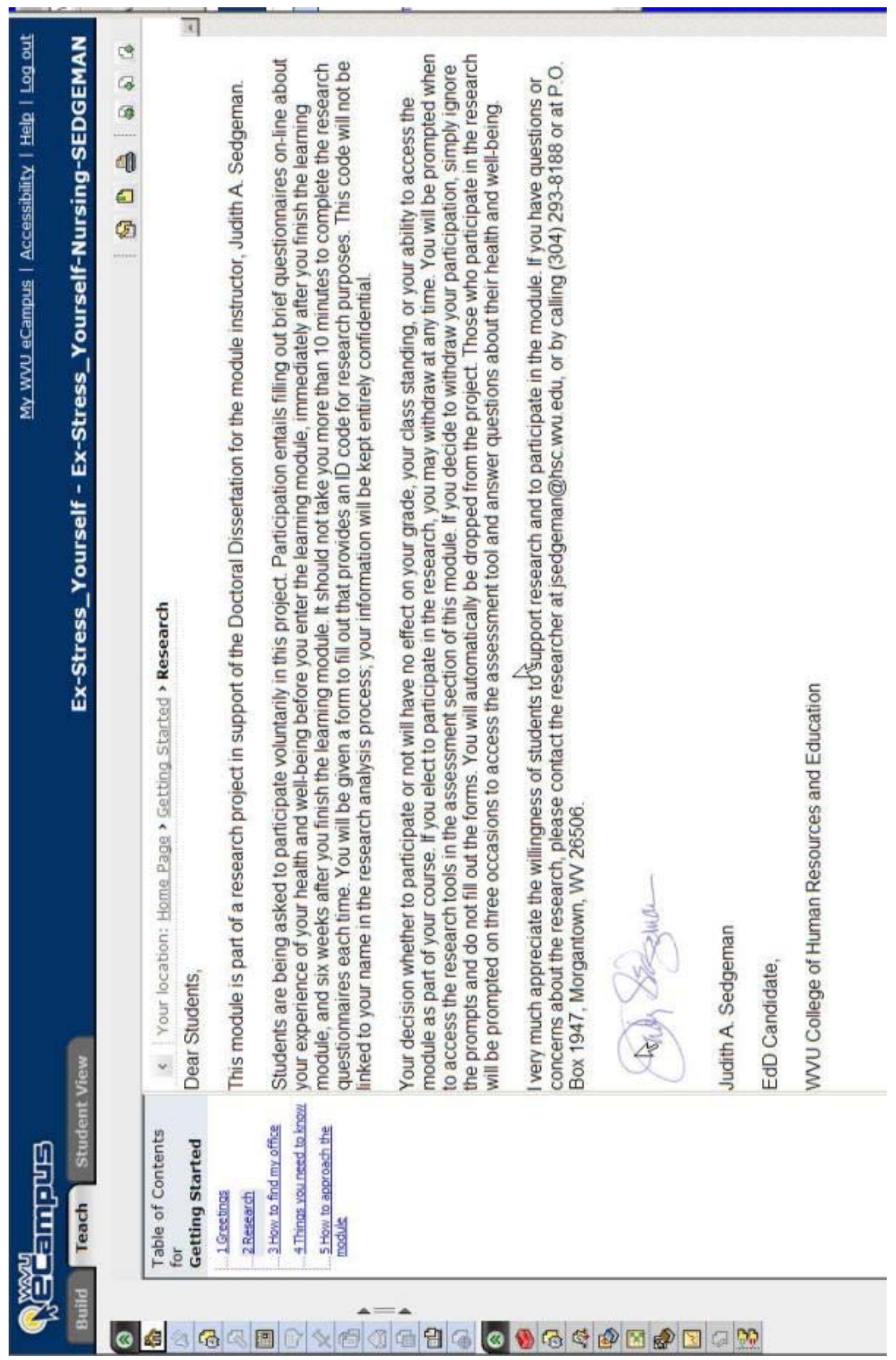




\section{Appendix M \\ Demographic Information}

\section{Instructions: Create a six-digit code in the boxes provided using: (in order)}

1. The first letter of your mother's maiden name. .

.......

2. The second letter of your mother's maiden name

3. The last number of your social security number

4. The day of the month you were born (use a " 0 " before single digits).

5. The last number of the year you were born. .... .......

For any information you do not know, please insert a zero.

You will be asked to provide the above information each time you take the tests. This will preserve your anonymity in the research process while allowing the researcher to make individual pre- post- comparisons matched by subject.

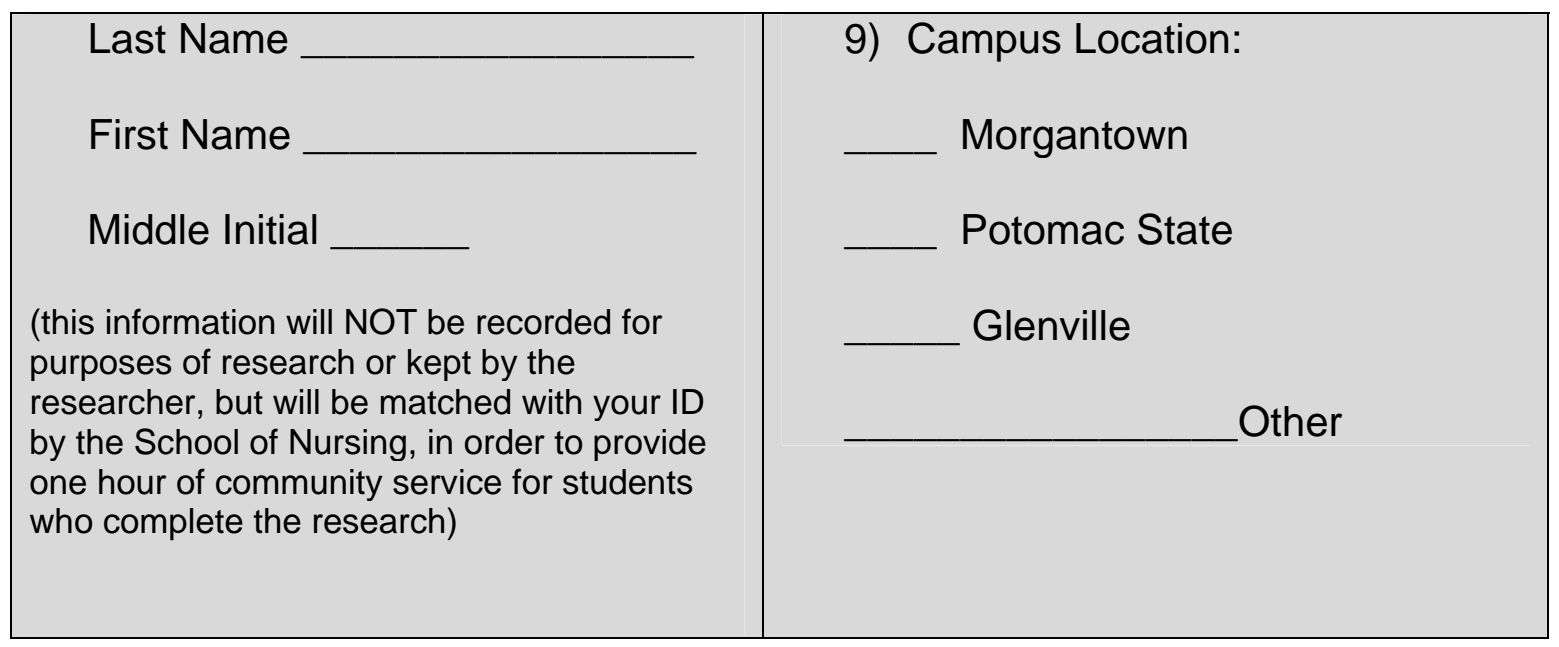



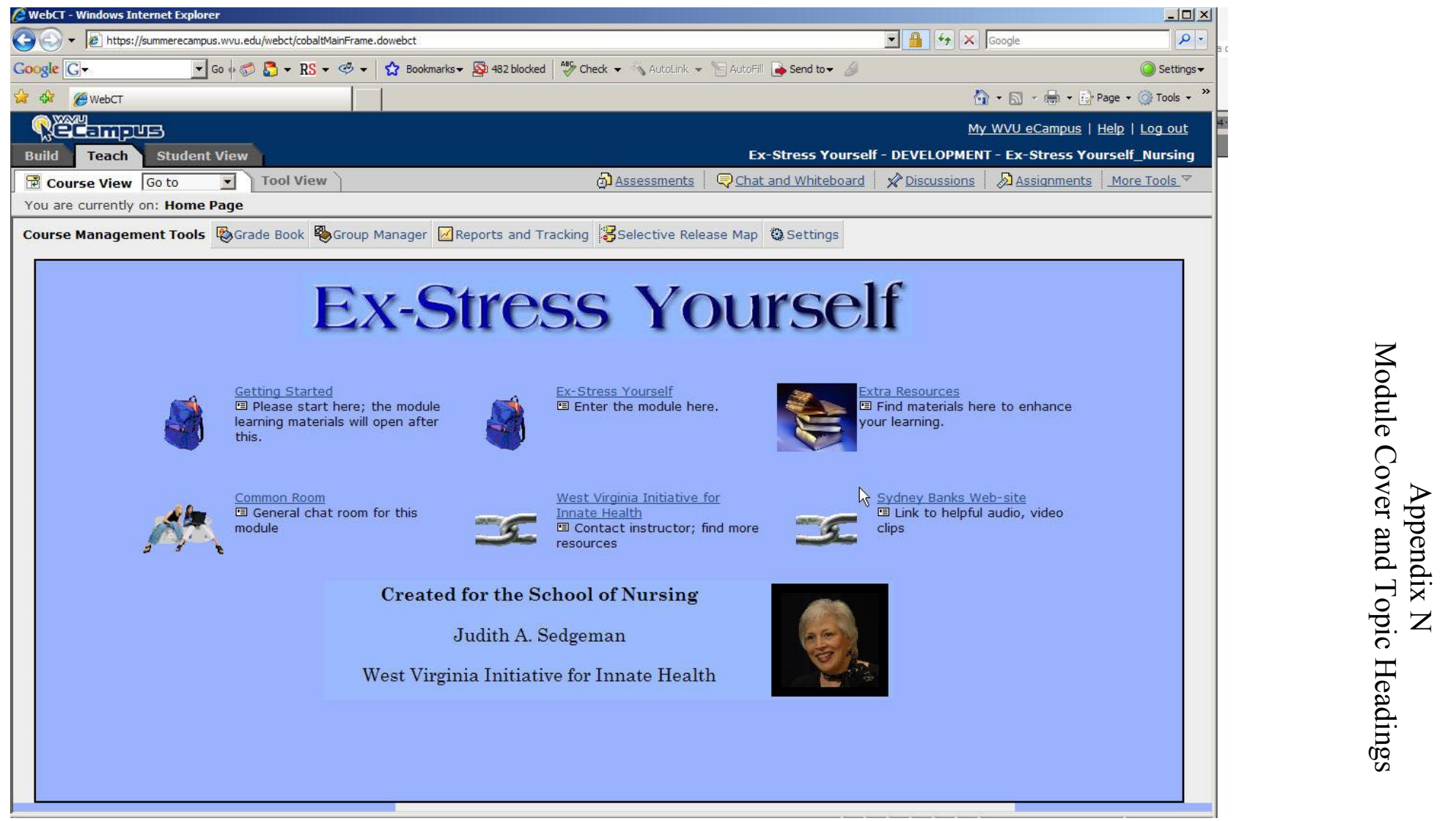


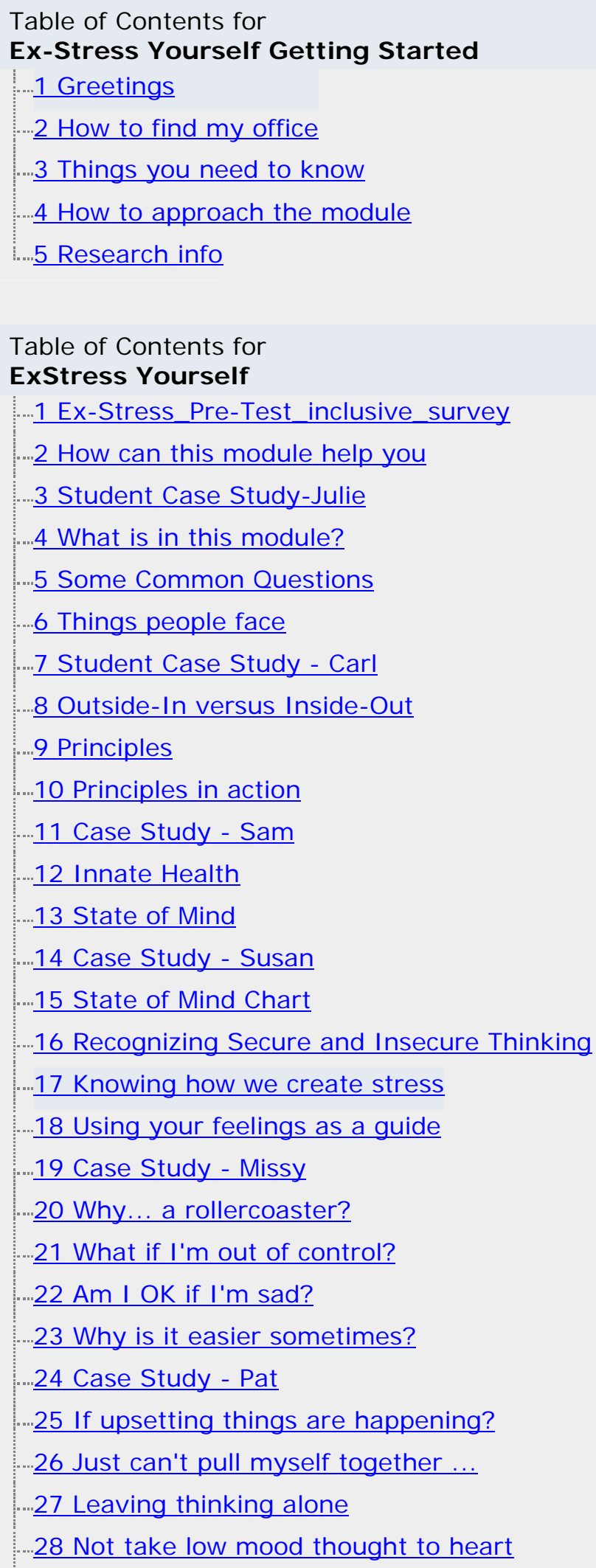


29 Trust wisdom

30 Something to Remember

31 One Thought

32 Rely on Innate Health

....33 Ex-Stress Post-Test_inclusive_survey

Table of Contents for

Extra Resources

1 Principles Lecture

...2 Happiness

3 How To Study

4 Innate Health Crossword

5 Less Stress, More Joy

6 Principles Paper

7 Recommended books and articles

8 Spiritual Power is Not Willpower

9 Other Web Sites 
Appendix O

E-Mails to Control Group

For Pre Test:

Dear Students,

This questionnaire is part of a research project in support of the Doctoral Dissertation for Judith A. Sedgeman.

Students are being asked to participate voluntarily in this project. Participation entails filling out brief questionnaires on-line about your experience of your health and well-being on three separate occasions when prompted to do so by e-mail. It should not take you more than 10-15 minutes to complete the research questionnaires each time. Each time you will be asked to start by filling out a form that provides an ID code for research purposes. This code will not be linked to your name in the research analysis process; your personal information will be kept entirely confidential.

Your decision whether to participate or not will have no effect on your grades or your class standing, If you elect to participate in the research, you may withdraw at any time. If you decide to withdraw your participation, simply ignore the prompts and do not fill out the forms. You will automatically be dropped from the project. Those who complete the research will receive a \$15 Morgantown Mall gift certificate.

I very much appreciate the willingness of students to support research and to participate in the module. If you have questions or concerns about the research, please contact the researcher at jsedgeman@hsc.wvu.edu, or by calling (304) 293-8188 or at P.O. Box 1947, Morgantown, WV 26506.

Again, thank you. Please fill out the form as soon as possible, as it is timesensitive. Here is the link to the questionnaire:

http://simpleforms.scripts.wvu.edu/sf/Dissertationsurvey1/

\section{For Post-Test}

Dear Students,

This questionnaire is the second part of a research project in support of the Doctoral Dissertation for Judith A. Sedgeman. If you filled out the first questionnaire sent about 10 days ago, I hope you will follow up and fill out this one and the final one in about six weeks, in order to receive your Mall gift certificate. Thank you in advance. 
Participation is voluntarily. Participation entails filling out brief questionnaires online about your experience of your health and well-being when prompted to do so by e-mail. Each time you will be asked to start by filling out a form that provides an ID code for research purposes. This code will not be linked to your name in the research analysis process; your personal information will be kept entirely confidential.

Your decision whether to participate or not will have no effect on your grades or your class standing, If you elect to participate in the research, you may withdraw at any time. If you decide to withdraw your participation, simply ignore the prompts and do not fill out the forms. You will automatically be dropped from the project. Those who complete the research will receive a \$10 Morgantown Mall gift certificate. Gift certificates will be mailed after the third questionnaire is completed, some time in early November, 2007.

I very much appreciate the willingness of students to support research and to participate in the module. If you have questions or concerns about the research, please contact the researcher at jsedgeman@hsc.wvu.edu, or by calling (304) 293-8188 or at P.O. Box 1947, Morgantown, WV 26506.

Again, thank you. Please fill out the form as soon as possible, as it is timesensitive. Here is the link to the questionnaire:

http://simpleforms.scripts.wvu.edu/sf/Dissertationsurvey2/

For Post-post test:

Dear Students,

This questionnaire is the third and final part of a research project in support of the Doctoral Dissertation for Judith A. Sedgeman. If you filled out the second questionnaire sent about 6 weeks ago, I hope you will follow up and fill out this one, in order to receive your Mall gift certificate. Thank you in advance.

Participation is voluntarily. Participation entails filling out brief questionnaires online about your experience of your health and well-being when prompted to do so by e-mail.You will be asked to start by filling out a form that provides an ID code for research purposes. This code will not be linked to your name in the research analysis process; your personal information will be kept entirely confidential.

Your decision whether to participate or not will have no effect on your grades or your class standing, If you elect to participate in the research, you may withdraw at any time. If you decide to withdraw your participation, simply ignore the 
prompts and do not fill out the forms. You will automatically be dropped from the project. Those who complete the research will receive a \$15 Morgantown Mall gift certificate. Gift certificates will be mailed after the third questionnaire is completed, some time in early November, 2007.

I very much appreciate the willingness of students to support research and to participate in the module. If you have questions or concerns about the research, please contact the researcher at jsedgeman@hsc.wvu.edu, or by calling (304) 293-8188 or at P.O. Box 1947, Morgantown, WV 26506.

Again, thank you. Please fill out the form as soon as possible, as it is timesensitive. Here is the link to the questionnaire:

http://simpleforms.scripts.wvu.edu/sf/Dissertationsurvey3/ 
Appendix P

Control GroupSimpleForm

\title{
Well-Being Questionnaire - Fall 2007
}

\author{
Dear Students, \\ This questionnaire is part of a research project in support of the Doctoral Dissertation in Educational \\ Psychology for Judith A. Sedgeman, M.A.
}

Students are being asked to participate voluntarily in this project. Participation entails filling out brief questionnaires on-line about your experience of your health and well-being on three separate occasions during the fall, 2007 semester when prompted to do so by e-mail. It should take you no more than 10-15 minutes to complete the research questionnaires each time. Each time you will be asked to start by filling out a form that provides an ID code for research purposes. This code will not be linked to your name in the research analysis process; your personal information will be kept entirely confidential.

Your decision whether to participate or not will have no effect on your grades or your class standing, If you elect to participate in the research, you may withdraw at any time. If you decide to withdraw your participation, simply ignore the prompts and do not fill out the forms. You will automatically be dropped from the project. Those who complete the research will receive a \$10 Morgantown Mall gift certificate.

I very much appreciate the willingness of students to support research and to participate in the questionnaires. If you have questions or concerns about the research, please contact the researcher at jsedgeman@hsc.wvu.edu, or by calling (304) 293-8188 or at P.O. Box 1947, Morgantown, WV 26506.

UNIQUE PARTICIPANT ID:

Please follow instructions to create a unique ID to be used for research to preserve your anonymity, and answer the demographic questions below.

Create a six-digit code in the box using (in order):

1. The first letter of your mother's maiden name.

2. The second letter of your mother's maiden name.

3. The last digit in your social security number.

4. The day of the month you were born (use a "0" before single digits, as in " 06 " if you were born on the sixth of the month).

5. The last digit in the year you were born (for example, 1989 -- you would supply number 9).

required

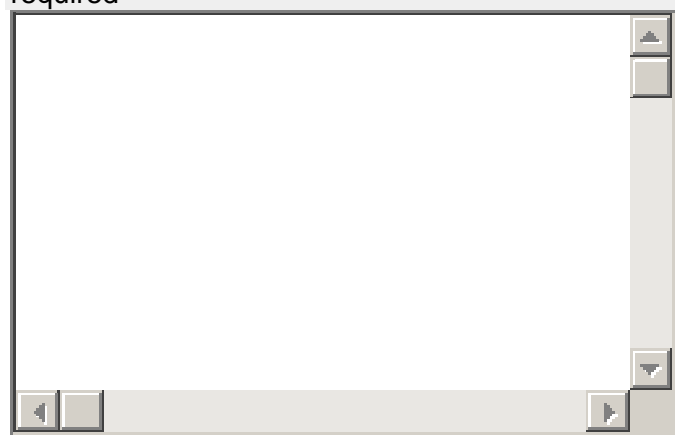

What is your campus location?

What is your campus location?

Morgantown 


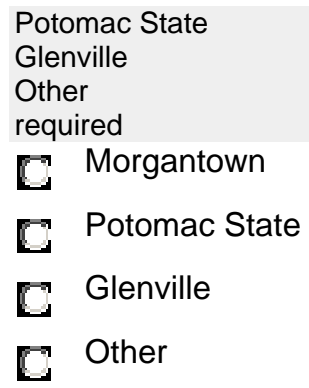

What is your date of birth? (ex., MM/DD/YYYY) required

Example: MM/DD/YYYY

What is your marital status?

required

----

What is your Gender?

required

\begin{tabular}{|l|l|}
\hline$-\cdots$ \\
\hline
\end{tabular}

Have you $\mathrm{p}$ [reviously been exposed to programs based on Health Realization/Innate Health?

Have you p[reviously been exposed to programs based on Health Realization/Innate Health?

required

C yes

C. no

What is your Ethnic group?

required

- -

Are you a member of the Nursing 110 class in the Fall 2007 term?

Are you a member of the Nursing 110 class in the Fall 2007 term?

required

C. yes

no

Please supply your name and a mailing address. Your name will NOT be associated with your unique ID in the research process or in files maintained by the researcher. It is needed only to provide you with the reward for completing the research.

required 


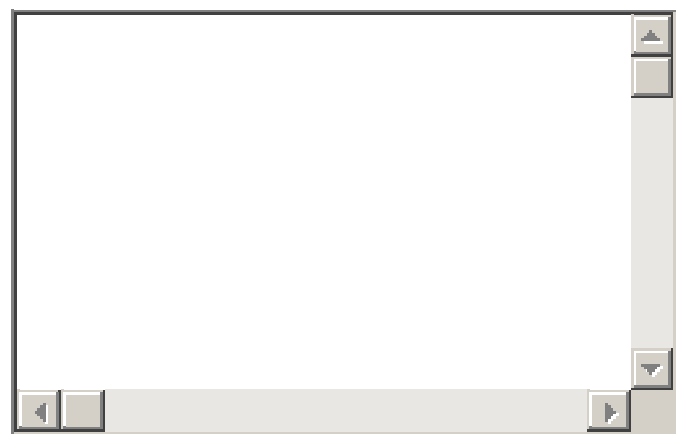

This survey asks for your views about your health. This information will help keep track of how you feel and how well you are able to do your usual activities. Thank you for completing this survey!

For each of the following questions, please select the radio button that best describes your answer.

1. In general, would you say your health is:

1. In general, would you say your health is:
required
C Excellent
C Very good
C Good
C Fair
C Poor

2. Compared to one year ago, how would you rate your health in general now?

2. Compared to one year ago, how would you rate your health in general now?
required
C Much better now than one year ago
Somewhat better now than one year ago
C About the same as one year ago
Somewhat worse now than one year ago
C Much worse now than one year ago

3. The following questions are about activities you might do during a typical day. Does your health now limit you in these activities? If so, how much?

Yes, limited a lot

Yes, limited a little

No, not limited at all

Vigorous activities such as running, lifting heavy objects, participating in strenuous sports

Vigorous activities such as running, lifting heavy objects, participating in strenuous sports

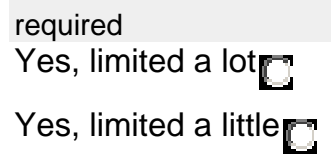


No, not limited at all $\mathbf{C}$

Moderate activities, such as moving a table, pushing a vacuum cleaner, bowling, or playing golf

Moderate activities, such as moving a table, pushing a vacuum cleaner, bowling, or playing golf

required

Yes, limited a lot

Yes, limited a little

No, not limited at all

Lifting or carrying groceries

Lifting or carrying groceries

required

Yes, limited a lot $\mathrm{C}$

Yes, limited a little $\mathbf{C}$

No, not limited at all $\mathrm{C}$

Climbing several flights of stairs

Climbing several flights of stairs

required

Yes, limited a lot

Yes, limited a little

No, not limited at all

Climbing one flight of stairs

Climbing one flight of stairs

required

Yes, limited a lot $\mathbb{C}$

Yes, limited a little

No, not limited at all

Bending, kneeling, or stooping

Bending, kneeling, or stooping

required

Yes, limited a lot

Yes, limited a little

No, not limited at all

Walking more than a mile

Walking more than a mile

required

Yes, limited a lot

Yes, limited a little 


\author{
No, not limited at all $\mathbf{C}$ \\ Walking several hundred yards \\ Walking several hundred yards \\ required \\ Yes, limited a lot \\ Yes, limited a little \\ No, not limited at all \\ Walking one hundred yards \\ Walking one hundred yards \\ required \\ Yes, limited a lot \\ Yes, limited a little \\ No, not limited at all \\ Bathing or dressing yourself \\ Bathing or dressing yourself \\ required \\ Yes, limited a lot $\mathbf{C}$ \\ Yes, limited a little $\mathbf{C}$ \\ No, not limited at all
}

4. During the past 4 weeks, how much of the time have you had any of the following problems with your work or other regular daily activites as a result of your physical health?

All of the time

Most of the time

Some of the time

A little of the time

None of the time

Cut down on the amount of time you spent on work or other activities

Cut down on the amount of time you spent on work or other activities

required

All of the time

Most of the timer

Some of the time

A little of the time $\mathrm{C}$

None of the time

Accomplished less than you would like

Accomplished less than you would like

required

All of the time 
Most of the time

Some of the time $\mathrm{C}$

A little of the time $\square$

None of the time $\mathrm{C}$

Were limited in the kind of work or other activities

Were limited in the kind of work or other activities

required

All of the time

Most of the time

Some of the time

A little of the time

None of the time

Had difficulty performing the work or other activities (for example, it took extra effort)

Had difficulty performing the work or other activities (for example, it took extra effort)

required

All of the time

Most of the time

Some of the time

A little of the time

None of the time

5. During the past 4 weeks, how much of the time have you had any of the following problems with your work or other regular daily activities as a result of any emotional problems (such as feeling depressed or anxious)?

\section{All of the time \\ Most of the time \\ Some of the time \\ A little of the time \\ None of the time}

Cut down on the amount of time you spent on work or other activities

Cut down on the amount of time you spent on work or other activities

required

All of the time

Most of the time

Some of the time

A little of the time

None of the time

Accomplished less than you would like 


\section{Accomplished less than you would like}

required

All of the time $\mathrm{C}$

Most of the time

Some of the time $\mathrm{C}$

A little of the time $\bar{C}$

None of the time

Did work or other activities less carefully than usual

Did work or other activities less carefully than usual

required

All of the time

Most of the time $\mathrm{C}$

Some of the time

A little of the time

None of the time

6. During the past 4 weeks, to what extent has your physical health or emotional problems interfered with your normal social activities with family, friends, neighbors, or groups?

6. During the past 4 weeks, to what extent has your physical health or emotional problems interfered with your normal social activities with family, friends, neighbors, or groups?

required

C Not at all

C Slightly

C Moderately

C Quite a bit

C Extremely

7. How much bodily pain have you had during the past 4 weeks?

7. How much bodily pain have you had during the past 4 weeks?

required

C None

C. Very mild

C Mild

C. Moderate

C. Severe

C Very Severe

8. During the past 4 weeks, how much did pain interfere with your normal work (including both work outside the home and housework)? 
8. During the past 4 weeks, how much did pain interfere with your normal work (including both work outside the home and housework)?
required
C Not at all
A little bit
C Moderately
C Quite a bit
C Extremely

9. These questions are about how you feel and how things have been with you during the past 4 weeks. For each question, please give the one answer that comes closest to the way you have been feeling. How much of the time during the past 4 weeks...

All of the time

Most of the time

Some of the time

A little of the time

Did you feel full of life?

None of the time

Did you feel full of life?

required
All of the time
Most of the time
Some of the time
A little of the time

Have you been very nervous?

Have you been very nervous?

required

All of the time $\mathrm{C}$

Most of the time

Some of the time $\mathrm{C}$

A little of the time

None of the time

Have you felt so down in the dumps that nothing could cheer you up?

Have you felt so down in the dumps that nothing could cheer you up?

required

All of the time $\mathrm{C}$

Most of the time

Some of the time $\mathrm{C}$ 
A little of the time
None of the time

Have you felt calm and peaceful?

Have you felt calm and peaceful?

required
All of the time
Most of the time of the time
A little of the time
None of the time
Did you have a lot
required
All of the time
Most of the time
Some of the time
A little of the time
None of the time

Have you felt downhearted and depressed?

Have you felt downhearted and depressed?

required

All of the time

Most of the time $\mathrm{C}$

Some of the time

A little of the time $\mathrm{C}$

None of the time

Did you feel worn out?

Did you feel worn out?

required

All of the time

Most of the time $\mathrm{C}$

Some of the time $\mathrm{C}$

A little of the time $\mathrm{C}$

None of the time

Have you been happy?

Have you been happy?

required 
All of the time $\mathrm{C}$

Most of the time [

Some of the time $\mathrm{C}$

A little of the time $\mathrm{C}$

None of the time

Did you feel tired?

Did you feel tired?

required

All of the time

Most of the time

Some of the time

A little of the time

None of the time

10. During the past 4 weeks, how much of the time has your physical health or emotional problems interfered with your social activities (like visiting friends, relatives, etc.)?

10. During the past 4 weeks, how much of the time has your physical health or emotional problems interfered with your social activities (like visiting friends, relatives, etc.)?
required
a All of the time
C Most of the time
C Some of the time
C A little of the time
C None of the time

11. How TRUE or FALSE is each of the following statements for you?

$$
\begin{aligned}
& \text { Definitely true } \\
& \text { Mostly true } \\
& \text { Don't know } \\
& \text { Mostly false } \\
& \text { Definitely false }
\end{aligned}
$$

I seem to get sick a little easier than other people

I seem to get sick a little easier than other people
required
Definitely true
Mostly true
Don't know
Mostly false $\mathrm{C}$
Definitely false 
I am as healthy as anybody I know

I am as healthy as anybody I know

required
Definitely true
Mostly true
Don't know
Mostly false
Definitely false

I expect my health to get worse

I expect my health to get worse

required

Definitely true $\mathbf{C}$

Mostly true

Don't know

Mostly false

Definitely false $\mathrm{C}$

My health is excellent

My health is excellent

required

Definitely true $\mathbf{C}$

Mostly true $\mathrm{C}$

Don't know

Mostly false

Definitely false $\mathrm{C}$

Pettit Attachment to Thought Content Scale (PATCS) (@2007)

Thought is a constant process. The content of our thought process is either allowed to pass freely across the "screen of our mind," or is given varying degrees of attention - that is, "dwelled on" or "fought" in an attempt to change or eliminate it. Some people find it easier to allow some kinds of thoughts to pass more freely than others. This scale is an attempt to assess the degree to which you tend to give attention to different kinds of thoughts to the point where it interferes with your peace of mind or feelings of well-being. A 0 means you do not dwell on the thoughts at all; a 1 means you dwell on them a little bit; a 2 means you dwell on them moderately; a 3 means you dwell on them quite a bit; and a 4 means you dwell on them to an extreme.

not at all

a little bit

moderately

quite a bit

Worry

extremely 


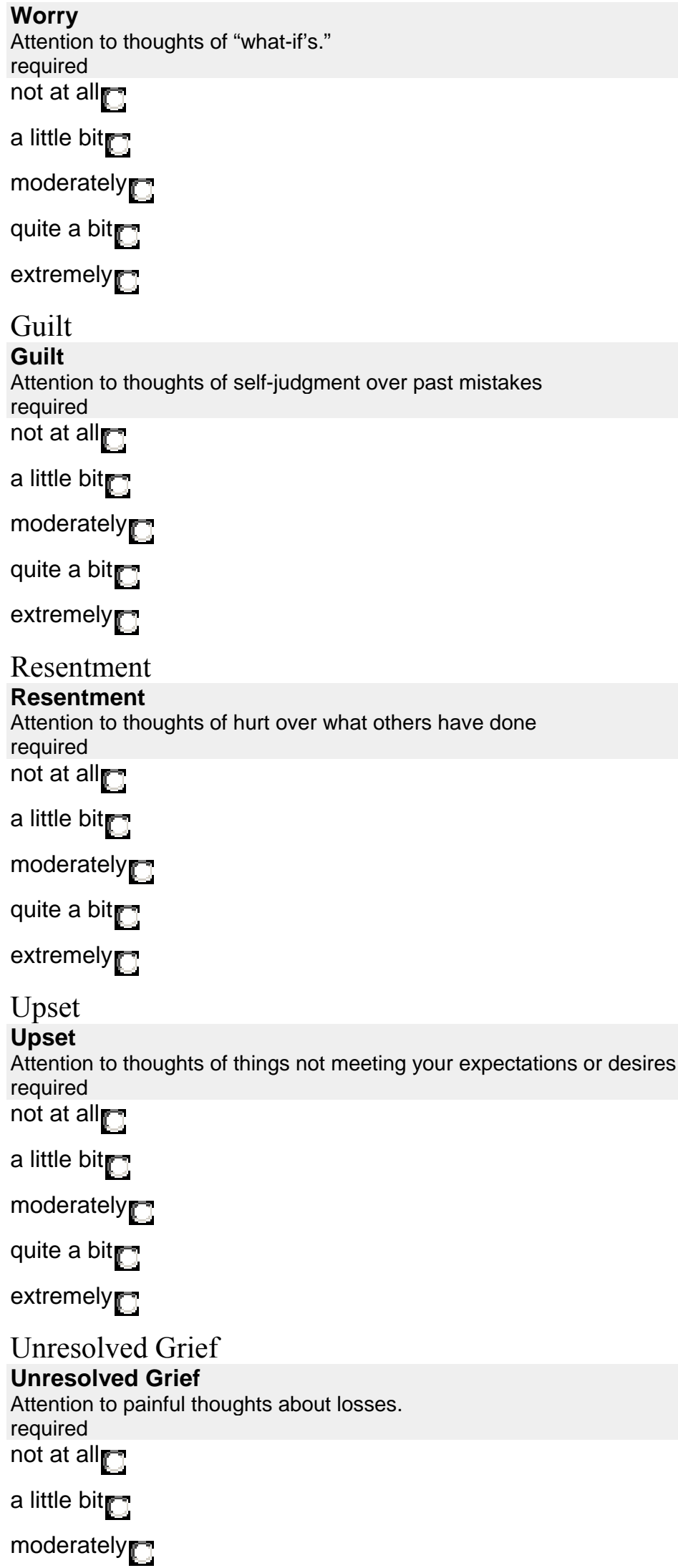




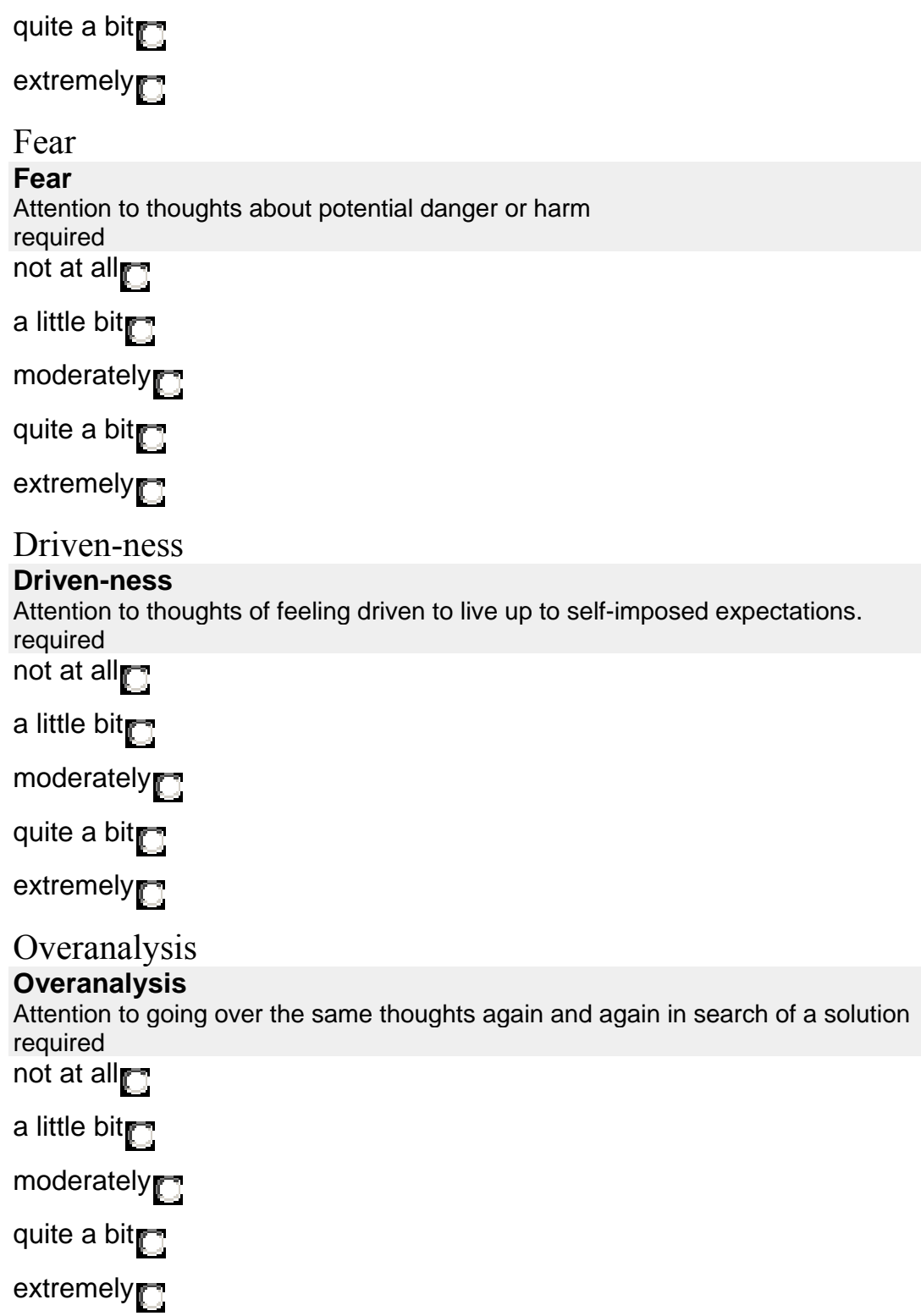

Total average daily time

Total average daily time

Time you spent in one or more of the above types of thinking each day over the past 7 days (in hours) required

Almost 0

$$
\begin{aligned}
& { }^{1-3} \mathbf{C} \\
& { }^{3-5} \mathbf{C} \\
& { }^{5-7} \mathbf{C}
\end{aligned}
$$


More than $7 \mathrm{C}$

If you answered more than 7 in the pevious question...

indicate about how many hours you spent

Submit This Form

This web application is maintained by Web Services

Technical questions and/or comments: web services@mail.wvu.edu 
Appendix Q

Four Questions - Nursing 110 class - November, 2007

1. Did you find the Ex-Stress Yourself module personally helpful? (show of hands)

Approx. $1 / 3$

$\underline{5}$

Yes

No

2. Did the layout and placement of the pre- and post-tests make it harder for you to complete them?

$\begin{array}{ll}10 & \text { Yes } \\ \text { Most } & \text { No }\end{array}$

3. If you started out thinking you would participate in th research and then dropped out, was it because:

Lost interest in it
Too hard to do
Objected to the questions
Wasn't sure how to submit responses

3. What could I have done to make this a better experience for you?

Brief discussion in Chapter 4 
Appendix R

Power Analyses

\begin{tabular}{|c|c|c|}
\hline Analysis: & A priori: Compute required & le size \\
\hline \multirow[t]{4}{*}{ Input: } & Tail(s) & $=$ One \\
\hline & Effect size $d z$ & $=0.5$ \\
\hline & $\alpha$ err prob & $=0.05$ \\
\hline & Power ( $1-\beta$ err prob) & $=0.95$ \\
\hline \multirow[t]{5}{*}{ Output: } & Noncentrality parameter $\delta$ & $=3.354102$ \\
\hline & Critical t & $=1.680230$ \\
\hline & Df & $=44$ \\
\hline & Total sample size & $=45$ \\
\hline & Actual power & $=0.951240$ \\
\hline
\end{tabular}

F tests - MANOVA: Repeated measures, between factors

\begin{tabular}{|c|c|c|}
\hline \multirow[t]{6}{*}{ Input: } & Effect size $f$ & $=0.25$ \\
\hline & $\alpha$ err prob & 0.05 \\
\hline & Power ( $1-\beta$ err prob) & 0.95 \\
\hline & Number of groups & $=$ \\
\hline & Repetitions & $=$ \\
\hline & Corr among rep measures & $=$ \\
\hline \multirow[t]{6}{*}{ Output: } & Noncentrality parameter $\lambda$ & $=13.500000$ \\
\hline & Critical F & $=4.026631$ \\
\hline & Numerator df & $=1.000000$ \\
\hline & Denominator df & $=52.000000$ \\
\hline & Total sample size & $=54$ \\
\hline & Actual power & $=0.950077$ \\
\hline
\end{tabular}

F tests - MANOVA: Global effects

\begin{tabular}{|c|c|c|}
\hline \multirow[t]{5}{*}{ Input: } & Effect size $f^{2}(V)$ & $=0.25$ \\
\hline & $\alpha$ err prob & $=0.05$ \\
\hline & Power ( $1-\beta$ err prob) & 0.95 \\
\hline & Number of groups & $=$ \\
\hline & Response variables & $=2$ \\
\hline \multirow[t]{6}{*}{ Output: } & Noncentrality parameter $\lambda$ & $=21.000000$ \\
\hline & Critical F & $=2.488886$ \\
\hline & Numerator df & $=4.000000$ \\
\hline & Denominator df & $=78.000000$ \\
\hline & Total sample size & $=42$ \\
\hline & Actual power & $=0.961916$ \\
\hline
\end{tabular}




\section{Biography \\ Judith A. Sedgeman}

Judith A. Sedgeman, EdD, is the Education Director of the West Virginia Initiative for Innate Health at the Robert C. Byrd Health Sciences Center of West Virginia University. An Assistant Professor, she teaches in the Public Health program of the Department of Community Medicine at West Virginia University Medical School. She is on the Advisory Board of the Faculty Development Committee at WVU Health Sciences Center, and is also a mentor in the Teaching Scholars Program, for which she has developed an on-line leadership seminar. She serves as an executive coach, seminar leader and program facilitator for professionals and organizations outside of the University and is an internationally recognized speaker, seminar leader, teacher and author in the emerging principle-based field of Mind-Consciousness-Thought. Her program, Creating Leadership from Within, has been offered at numerous health organizations in the U.S. and abroad. A graduate of Wellesley College, Wellesley, MA, she received her M.A. degree from Trinity College, Hartford, CT. She will receive her doctoral degree in Educational Psychology from WVU in May, 2008. She has been a college instructor, an award-winning newspaper reporter and editor, an entrepreneur and a business consultant. For the past 20 years, her work has been entirely based on the Principles of Mind, Consciousness and Thought that awaken the health and resiliency in people.

jsedgeman@hsc.wvu.edu

jsedgeman@mac.com 